\title{
Critical Determinants for Mobile Commerce Adoption in Vietnamese Small and Medium-Sized Enterprises
}

A thesis submitted in fulfilment of the requirements for the degree of Doctor of Philosophy

\section{Chau Ngoc Tuan}

BSc (Maths \& Informatics - Danang University of Education, Vietnam)

BA (Business Administration - Danang University of Economics, Vietnam)

MSc (Information Technology - Sheffield Hallam University, UK)

School of Accounting, Information Systems \& Supply Chain

College of Business and Law

RMIT University

October 2020 


\section{Declaration}

I certify that except where due acknowledgement has been made; the work is that of the author alone. The work has not been submitted previously, in whole or in part, to qualify for any other academic award. The content of the thesis is the result of work which has been carried out since the official commencement of the approved research program. Any editorial work, paid or unpaid, carried out by a third party is acknowledged. Ethics procedures and guidelines have been followed.

\section{Chau Ngoc Tuan}

20 October 2020 


\section{Acknowledgement}

First and foremost, I would like to take this opportunity to express my deepest gratitude to my principal supervisor, Professor Hepu Deng, for his continuous support throughout my $\mathrm{PhD}$ journey. I am very grateful to him for his patience, encouragement, motivation, wisdom, and knowledge, which made the completion of this research possible. His constructive feedback and criticism helped me to improve my research skills and establish myself as a researcher. I am also extremely grateful to my second supervisor, Associate Professor Richard Tay whose vast knowledge and experience in research direction provided me with valuable feedback for improving the quality of this research. My sincere thankfulness also goes to Dr. Konrad Peszynski, for providing me with great support and encouragement to overcome difficulties in the first year of my $\mathrm{PhD}$ journey. I will never forget his inspiring directions and advice.

I would like to dedicate this thesis to my beloved country, Vietnam, and RMIT University. I could not accomplish my PhD program without the financial support provided by the Vietnamese Government and RMIT University. I would also like to extend my thanks to the board of directors and managers at the University of Economics - The University of Danang, Vietnam, for their encouragement and support throughout the last four years of my $\mathrm{PhD}$ journey.

I would like to thank all HDR coordinators and administrators at the School of Accounting, Information Systems \& Supply Chain, College of Business and Law for their advice and support during my candidature. Thanks to all my friends and colleagues 
in both Vietnam and Australia for their sharing in both academic and personal life, which makes my $\mathrm{PhD}$ journey more joyful.

Finally, my special gratitude goes to all my family members, especially my parents, my wife Thu Dao, and my lovely daughters Hoang My and Ha My, for standing beside me and supporting me to complete this thesis. Their support and endless love helped me to overcome the entire barrier during the journey. They have also been a great source for my motivation to do my $\mathrm{PhD}$ program. Without their caring and encouragement, my $\mathrm{PhD}$ would not have been possible. 


\section{Table of Contents}

Declaration ...................................................................................................................... i



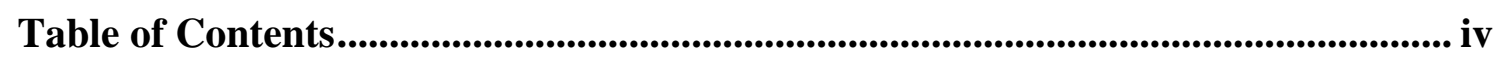

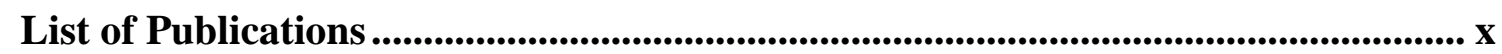

List of Abbreviations .................................................................................................. xii









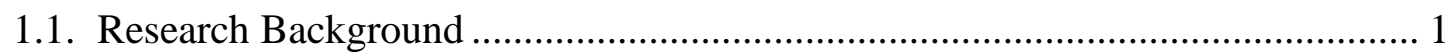

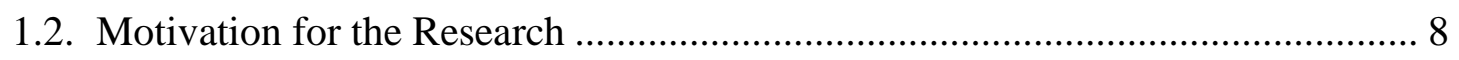

1.3. Research Objectives and Research Questions ............................................... 10

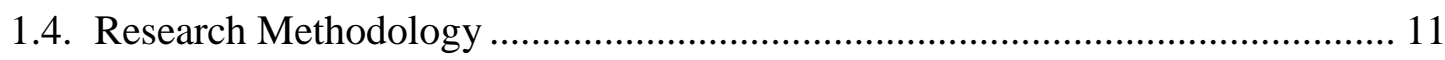

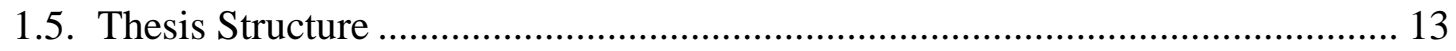

Chapter 2 Literature Review................................................................................ 17

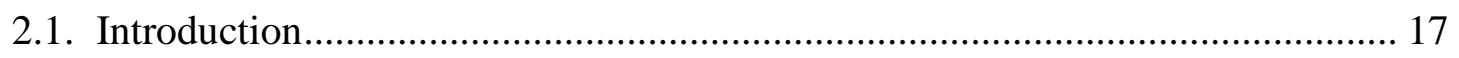

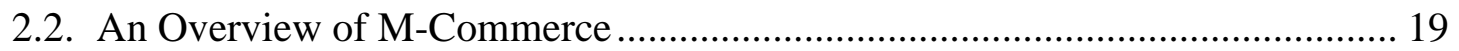

2.3. Vietnamese SMEs and their Development .................................................. 24

2.4. M-Commerce Adoption in Vietnamese SMEs ................................................. 28 
2.5. Organizational M-Commerce Adoption Studies

2.5.1. Conceptualization of Organizational M-Commerce Adoption

2.5.2. Empirical Studies on M-Commerce Adoption in Organizations 36

2.6. Concluding Remarks 53

Chapter 3 A Conceptual Framework 54

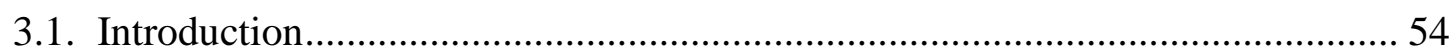



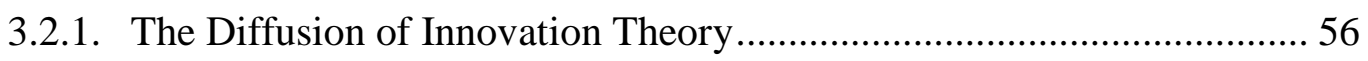

3.2.2. Technology-Organization-Environment Framework.............................59

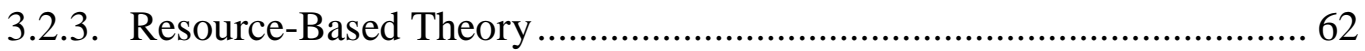



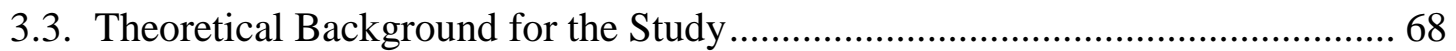

3.4. A Conceptual Framework …........................................................................ 72

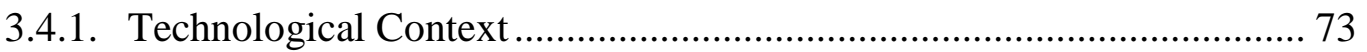

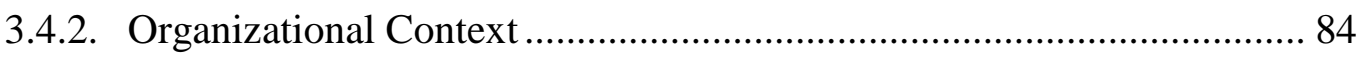

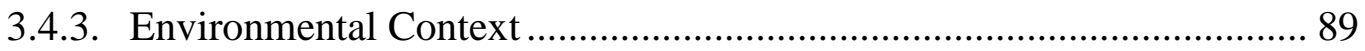

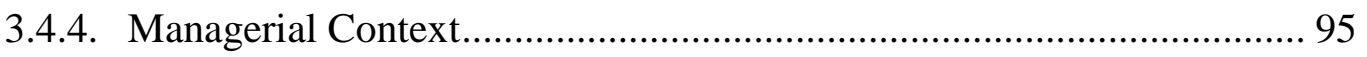

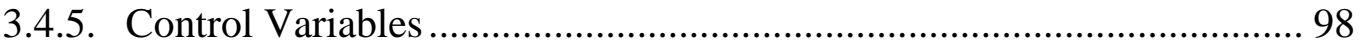



Chapter 4 Research Methodology ...................................................................... 101

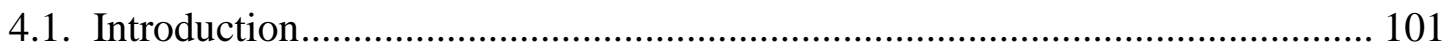




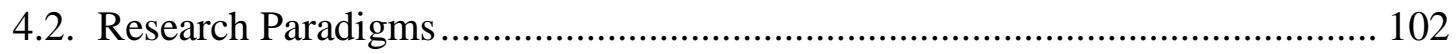

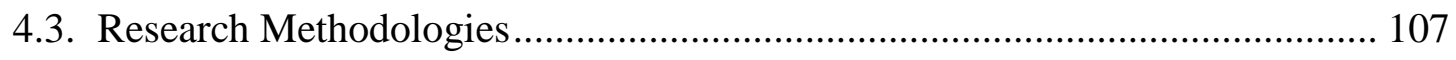

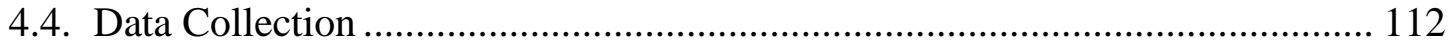

4.4.1. Survey Instrument Development ................................................ 113

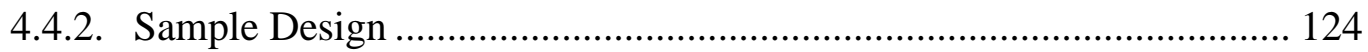

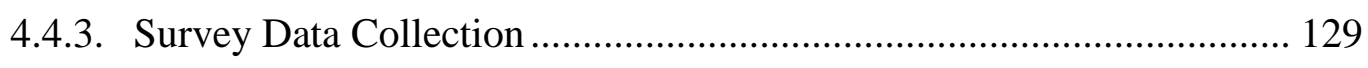

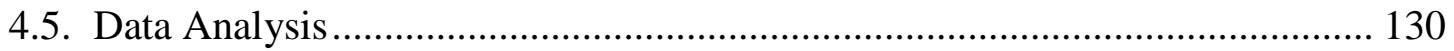

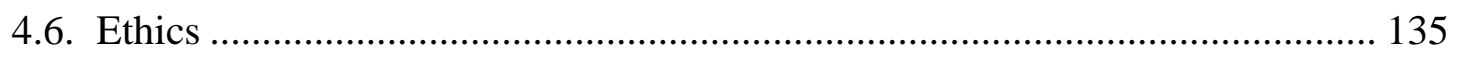



Chapter 5 Data Examination and Preparation ...................................................... 137

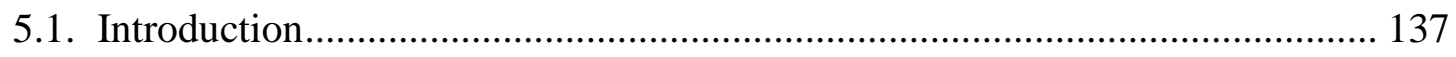

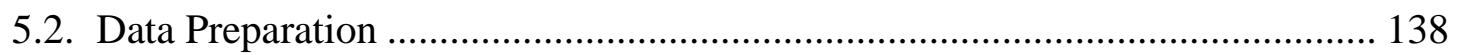

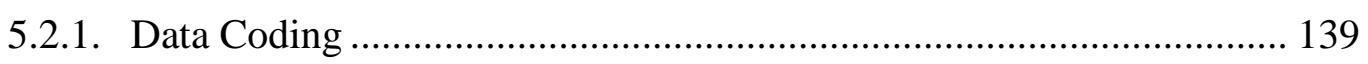

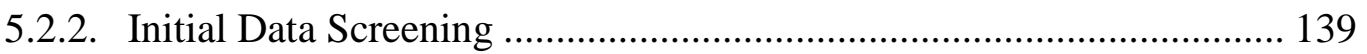

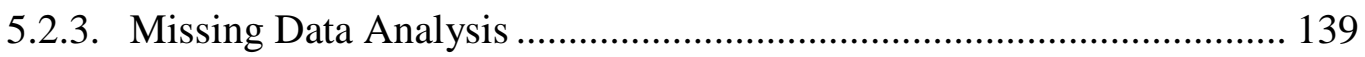



5.2.5. Multivariate Normality Testing …................................................. 145

5.2.6. Non-Response Bias Testing .......................................................... 148

5.2.7. Survey Type Bias Testing ........................................................ 151

5.2.8. Common Method Bias Testing ...................................................... 152

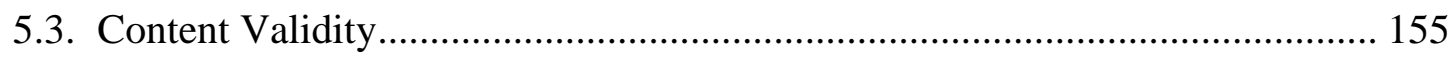

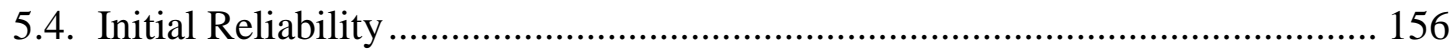




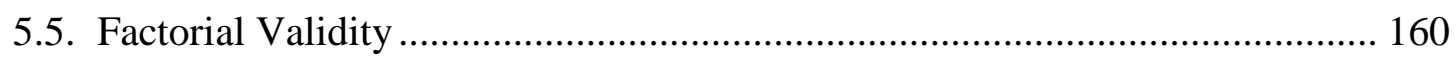

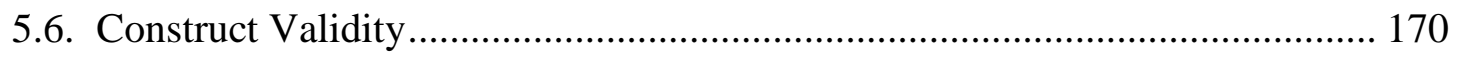

5.6.1. Goodness of Fit ................................................................................... 171

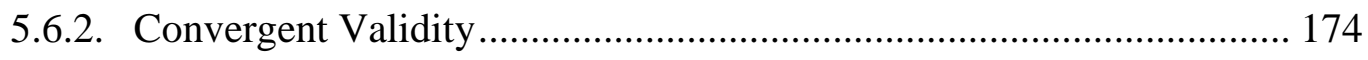

5.6.3. Discriminant Validity......................................................................... 176

5.6.4. Measurement Model for the Technological Determinants .................... 177

5.6.5. Measurement Model for the Organizational Determinants ................... 180

5.6.6. Measurement Model for the Environmental Determinants ................... 182

5.6.7. Measurement Model for the Managerial Determinants ......................... 184

5.6.8. Measurement Model for the Dependent Construct ............................... 185

5.6.9. Full Measurement Model................................................................. 187

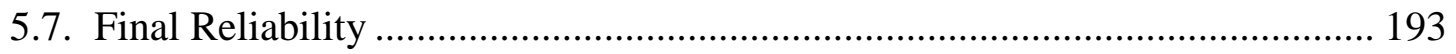

5.8. Concluding Remarks ..................................................................................... 194

Chapter 6 Emerging Patterns for the Adoption of Mobile Commerce .................. 196

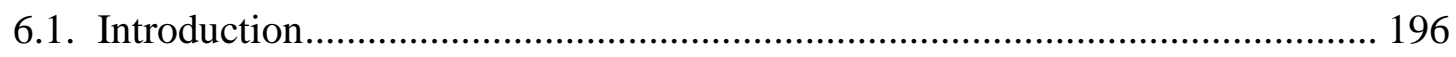

6.2. Demographic Characteristics of the Sample..................................................... 198

6.3. M-Commerce Adoption Patterns in Vietnamese SMEs .................................... 203

6.4. Research Findings and Discussion .............................................................. 215

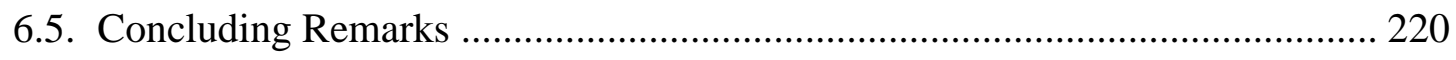

Chapter 7 Critical Determinants for the Adoption of Mobile Commerce............ 221

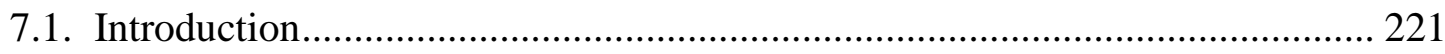


7.2. Structural Model Analysis 223

7.2.1. Structural Model 223

7.2.2. Structural Model with Control Variables 229

7.3. Hypotheses Testing 233

7.4. Artificial Neural Network Analysis 236

7.4.1. An Overview of the Artificial Neural Networks 238

7.4.2. Selection and Validation of Neural Networks 242

7.4.3. Sensitivity Analysis 245

7.5. Discussion of the Findings 248

7.5.1. Technological Determinants for M-Commerce Adoption 248

7.5.2. Organizational Determinants for M-Commerce Adoption . 251

7.5.3. Environmental Determinants for M-Commerce Adoption ... .254

7.5.4. Managerial Determinants for M-Commerce Adoption. 256

7.5.5. Ranking of the Critical Determinants for M-Commerce Adoption . 258

7.6. Concluding Remarks 259

Chapter 8 Conclusion. 262

8.1. Introduction. 262

8.2. Summary of the Research Findings 264

8.2.1. Emerging Patterns for M-Commerce Adoption. .265

8.2.2. Critical Determinants for M-Commerce Adoption 267

8.3. Research Contributions. 271

8.4. Research Implications. 273 
8.4.1. Implications for SMEs' Owners and Managers

8.4.2. Implications for Government and Policy-Makers.

8.4.3. Implications for Technology and M-Commerce Vendors

275

8.5. Research Limitations and Future Directions 276

References 278

Appendix A - Invitation Letter for Participation (English) 320

Appendix B - Survey Questionnaire (English) 321

Appendix C - Invitation Letter for Participation (Vietnamese). 329

Appendix D - Survey Questionnaire (Vietnamese) 330

Appendix E - Ethics Approval Letter 338

Appendix F - Purification Measurement

Appendix G - Comparison of Loadings 341

Appendix H - Ten-Fold Cross-Validation Results for Neural Networks. 343 


\section{List of Publications}

\section{Refereed Book Chapters}

[1] Chau, N. T. and Deng, H. (2020), 'Evaluating the Critical Determinants for Mobile Commerce Adoption in SMEs in Developing Countries: A Case Study of Vietnam', in Handbook of Research on Managing Information Systems in Developing Economies, IGI Global, Hershey, United States, pp. 114-142.

\section{Refereed Journal Papers}

[1] Chau, N. T. and Deng, H. (2018), 'Critical Determinants for Mobile Commerce Adoption in Vietnamese SMEs: A Conceptual Framework', Procedia Computer Science, vol. 138, no. 2018, pp. 433-440.

[2] Chau, N. T., Deng, H. and Tay, R. (2020), 'Critical Determinants for Mobile Commerce Adoption in Vietnamese Small and Medium-Sized Enterprises', Journal of Marketing Management, vol. 36, no. 5-6, pp. 456-487.

[3] Chau, N. T., Deng, H. and Tay, R. (2021), 'A Perception-Based Model for Mobile Commerce Adoption in Vietnamese Small and Medium-Sized Enterprises', Journal of Global Information Management, vol. 29, no. 1, pp. 44-67.

[4] Chau, N. T. and Deng, H. (2021), 'Conceptualisation for Mobile Commerce Adoption in SMEs: A Perspective of Developing Countries', International Journal of Business Information Systems (Forthcoming). 
[5] Chau, N. T., Deng, H. and Tay, R. 'SEM-Neural Networks Analysis for Exploring the Critical Determinants for Mobile Commerce Adoption in Vietnamese SMEs', Electronic Commerce Research (Under review).

\section{Refereed Conference Papers}

[1] Chau, N. T. and Deng, H. (2018), 'Critical Determinants for Mobile Commerce Adoption in Vietnamese SMEs: A Conceptual Framework', Paper presented at the $10^{\text {th }}$ International Conference on Enterprise Information Systems, Lisbon, Portugal, November 21-23.

[2] Chau, N. T. and Deng, H. (2018), 'Critical Determinants for Mobile Commerce Adoption in Vietnamese SMEs: A Preliminary Study', Proceedings of the $29^{\text {th }}$ Australasian Conference on Information Systems, Sydney, Australia, December 3-5, pp. $1-11$. 


\section{List of Abbreviations}

AGFI

AMOS

ANOVA

AVE

BTOS

B2B

B2C

CFA

CFI

CR

df

DOI

E-business

EDI

E-commerce

EFA

E-market

FVM

ERP

SFL

GDP

GOF
Adjusted goodness of fit index

Analysis of moment structures

Analysis of variance

Average variance extracted

Bartlett's test of sphericity

Business to business

Business to customer

Confirmatory factor analysis

Comparative fit index

Composite reliability

Degrees of freedom

Diffusion of innovation theory

Electronic business

Electronic data interchange

Electronic commerce

Exploratory factor analysis

Electronic market

Fit viability model

Enterprise resource planning

Standardized factor loading

Gross domestic product

Goodness of fit 
Kaiser-Meyer-Olkin

M-commerce Mobile commerce

MLP

Multilayer perceptron

RBT

Resource-based theory

RMSEA

Root mean square error of approximation

SEM

Structural equation modelling

SMEs

Small and medium-sized enterprises

SPSS

Statistical package for social science

TAM

Technology acceptance model

TOE

Technology-organization-environment

TRA

Theory of reasoned action

TPB

Theory of planned behaviour

TTF

Task technology fit

UTAUT

The unified theory of acceptance and use of technology

VCCI

Vietnam chamber of commerce and industry

VECITA

Vietnam e-commerce and information technology agency

VINASME

Vietnam association of small and medium enterprises

$\alpha$

Alpha

$\chi^{2}$

Chi-square

$\chi^{2} / \mathrm{df}$

The normed chi-square 


\section{List of Tables}

Table 2.1 Classification of Vietnamese SMEs

Table 2.2 An overview of country types investigated in the literature 37

Table 2.3 An overview of organization types investigated in the literature 37

Table 2.4 An overview of the dominant theoretical perspectives in the literature 38

Table 2.5 A summary TAM-based studies on organizational m-commerce adoption 40

Table 2.6 A summary of TOE-based studies on organizational m-commerce adoption. 42

Table 2.7 A summary of theory-specific studies on organizational m-commerce adoption 46

Table 2.8 An overview of the integrated theoretical perspectives 47

Table 2.9 A summary of TOE integrated studies on organizational m-commerce adoption 49

Table 2.10 A summary of TAM integrated studies on organizational m-commerce adoption ... 51

Table 2.11 A summary of other integrated studies on organizational m-commerce adoption.... 52

Table 3.1 Technological determinants of organizational m-commerce adoption .76

Table 3.2 A summary of the measurement items for Perceived Benefits 78

Table 3.3 A summary of the measurement items for Perceived Compatibility 80

Table 3.4 A summary of the measurement items for Perceived Security .82

Table 3.5 A summary of the measurement items for Perceived Cost

Table 3.6 Organizational determinants of organizational m-commerce adoption 85

Table 3.7 A summary of the measurement items for Employees' IT knowledge 86

Table 3.8 A summary of the measurement items for Organizational Readiness 87

Table 3.9 A summary of the measurement items for Organizational Innovativeness 88

Table 3.10 Environmental determinants of organizational m-commerce adoption 90

Table 3.11 A summary of the measurement items for Competitive Pressures. 91 
Table 3.12 A summary of the measurement items for Customer Pressures 92

Table 3.13 A summary of the measurement items for Government Support .94

Table 3.14 A summary of the measurement items for Top Management Support 96

Table 3.15 A summary of the measurement items for Managers' IT knowledge 97

Table 4.1 A summary of the three paradigms 105

Table 4.2 A comparison of different survey methods 111

Table 4.3 The description of technological determinants of m-commerce adoption in SMEs . 114 Table 4.4 The description of organizational determinants of m-commerce adoption in SMEs 114 Table 4.5 The description of environmental determinants of m-commerce adoption in SMEs 115 Table 4.6 The description of managerial determinants of m-commerce adoption in SMEs .

Table 4.7 The description of control variables of m-commerce adoption in SMEs 115

Table 4.8 Measurement items for technological constructs 117

Table 4.9 Measurement items for organizational constructs. 118

Table 4.10 Measurement items for environmental constructs 118

Table 4.11 Measurement items for managerial constructs

Table 4.12 Measurement items for dependent construct.

Table 5.1 A summary of missing data analysis 141

Table 5.2 Dependent variable based missing data analysis. 142

Table 5.3 A summary of variable-based missing data analysis 142

Table 5.4 A summary of case-based missing data analysis

Table 5.5 A summary of multivariate outlier test results 145

Table 5.6 A summary of normality assessment results 148

Table 5.7 A summary of the non-response bias test for the online survey 150

Table 5.8 A summary of the non-response bias test for the paper-based survey 151 
Table 5.9 Independent sample t-test for survey types bias

Table 5.10 Test for common method bias - Total variance explained 154

Table 5.11 Rule of thumb for Cronbach's alpha coefficients 157

Table 5.12 A summary of initial reliability analysis 159

Table 5.13 KMO and BTOS tests 162

Table 5.14 Factor analysis results for the technological dimension 165

Table 5.15 Factor analysis results for the organizational dimension 166

Table 5.16 Factor analysis results for the environmental dimension 167

Table 5.17 Factor analysis results for the managerial dimension 168

Table 5.18 Factor analysis results for the dependent construct 168

Table 5.19 Summary of the EFA output 169

Table 5.20 An overview of the GOF indices. 172

Table 5.21 A summary of widely-used fit measures and established criteria 173

Table 5.22 GOF statistics and convergent validity measures for technological dimension 179

Table 5.23 GOF statistics and convergent validity measures for organizational dimension 181

Table 5.24 GOF statistics and convergent validity measures for environmental dimension .... 183

Table 5.25 GOF statistics and convergent validity measures for managerial dimension. 185

Table 5.26 GOF statistics and convergent validity measures for adoption construct 186

Table 5.27 Goodness of fit statistics for the full measurement model . 189

Table 5.28 Convergent validity assessment results. 190

Table 5.29 Convergent validity assessment results (cont'd) 191

Table 5.30 Latent construct correlation matrix 192

Table 5.31 A summary of final reliability assessment 194

Table 6.1 The general profile of the surveyed SMEs: location and duration of the business ... 199 
Table 6.2 The general profile of the surveyed SMEs: organizational size 200

Table 6.3 The general profile of the surveyed SMEs: type of business ...... 201

Table 6.4 Characteristics of top managers of the surveyed SMEs 202

Table 6.5 General m-commerce adoption scenarios 204

Table 6.6 Summary of ANOVA results for different size groups: number of employees 207

Table 6.7 Multiple comparisons for different size groups of SMEs: number of employees..... 208

Table 6.8 Summary of ANOVA results for different size groups: total capital. 209

Table 6.9 Multiple comparisons for different size groups of SMEs: total capital (VND) ........ 210

Table 6.10 Summary of ANOVA results for different industries of surveyed SMEs 212

Table 6.11 Multiple comparisons for different industries of the surveyed SMEs

Table 6.12 Multiple comparisons for different industries of the surveyed SMEs (cont'd) ....... 214

Table 7.1 Tests for structural model validity 225

Table 7.2 The summary of the model fitness statistics for the structural model. 227

Table 7.3 An overview of the size, direction, and significance of the structural paths 229

Table 7.4 Model fitness statistics for the structural model with control variables

Table 7.5 An overview of the size, direction, and significance of the structural paths

Table 7.6 Hypotheses testing results 234

Table 7.7 RMSE values for neural networks with three different number of hidden node........ 244

Table 7.8 Sensitivity analysis: normalized importance. 247

Table 7.9 Normalized importance comparison between SEM and neural network results....... 248

Table 7.10 The ranking of the critical determinants for m-commerce adoption 258 


\section{List of Figures}

Figure 1.1 An overview of the research process

Figure 1.2 An overall structure of the thesis



Figure 2.2 The percentage of business with websites over the years ........................................ 31

Figure 2.3 The percentage of mobile accessible websites over the years .................................. 31

Figure 2.4 The percentage of mobile sales application usage over the years............................. 32

Figure 3.1 Stages in the innovation diffusion process............................................................... 57

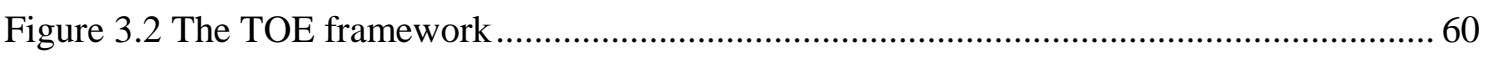

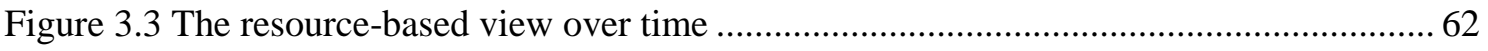

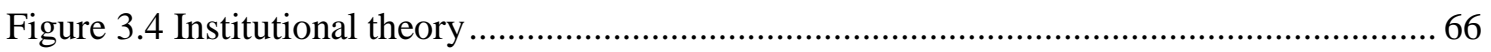

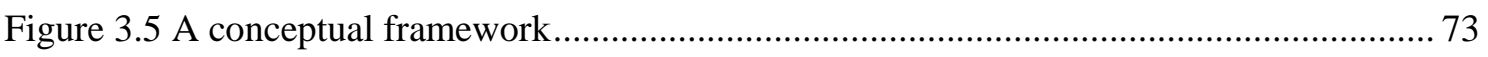

Figure 4.1 The survey instrument development process ........................................................ 113

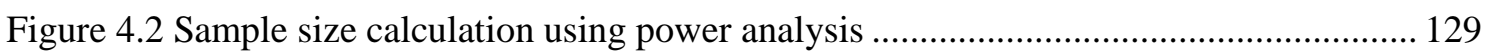



Figure 5.1 Measurement model for technological dimension ................................................. 178

Figure 5.2 Measurement model for organizational dimension............................................... 180

Figure 5.3 Measurement model for the environmental dimension......................................... 182

Figure 5.4 Measurement model for the managerial dimension ............................................. 184

Figure 5.5 Measurement model for the adoption construct..................................................... 186

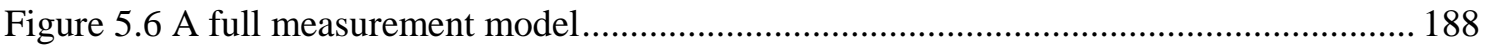

Figure 6.1 An overview of m-commerce adoption in Vietnamese SMEs...............................2205 
Figure 6.2 An overview of website functions

Figure 6.3 Distribution of m-commerce adoption by size (number of employees) 206

Figure 6.4 Distribution of m-commerce adoption by size (total registered capital) 209

Figure 6.5 Distribution of m-commerce adoption by industries 211

Figure 6.6 The conceptual typology of industries 218

Figure 7.1 A structural model 226

Figure 7.2 Structural equation model with control variables 230

Figure 7.3 A typical three-layer neural network 239

Figure 7.4 A neural network model used in this study..... 245 


\section{Abstract}

Mobile commerce (m-commerce) is about buying and selling goods and services through wireless handheld devices. It is increasingly becoming popular across the world due to the benefits it provides businesses, especially small and medium-sized enterprises (SMEs) including improving productivity, increasing customer satisfaction, and lowering operational costs. The tremendous benefits of m-commerce, however, have not been fully utilized in many developing countries. This is because the adoption of $\mathrm{m}$-commerce is a complex process with the involvement of various factors. There is limited research for understanding such adoption in SMEs. Existing research suffers from various shortcomings including (a) the lack of understanding of the emerging pattern of m-commerce adoption in SMEs and (b) the need for better understanding the critical determinants for the adoption of m-commerce in SMEs, especially SMEs in developing countries.

This study investigates the critical determinants for m-commerce adoption in Vietnamese SMEs. It aims to (a) identify the current pattern of the adoption of mcommerce and (b) explore the critical determinants for m-commerce adoption in Vietnamese SMEs. To achieve these aims, a comprehensive review of the related literature has been conducted, leading to the development of a conceptual framework for better understanding m-commerce adoption in SMEs. This framework is then tested and validated using a multi-analytical approach by combining structural equation modelling (SEM) and artificial neural networks on the data collected in Vietnam in two stages. 
In the first stage, descriptive statistics and variance analysis are used for investigating the emerging pattern of m-commerce adoption in Vietnamese SMEs with respect to (a) the overall adoption, (b) the size-based adoption, and (c) the industry-based adoption. This leads to the identification of four emerging patterns of m-commerce adoption in Vietnamese SMEs. The study shows that m-commerce adoption in Vietnamese SMEs, in general, is still quite low. It finds out that there is not much difference in the adoption of m-commerce between SMEs with different sizes. The study further reveals that there are significant differences in the adoption of m-commerce between SMEs with different capital scales and in different industries.

In the second stage, SEM is adopted for testing and validating the proposed conceptual framework for the adoption of m-commerce in Vietnamese SMEs. This leads to the identification of eight critical determinants for m-commerce adoption in Vietnamese SMEs including perceived benefits, perceived compatibility, perceived security, organizational readiness, organizational innovativeness, customer pressures, government support, and managers' IT knowledge. Such critical determinants are then used as the input for neural network analysis in evaluating their relative importance. This results in the identification of perceived security as the most critical determinant for m-commerce adoption. It is followed by customer pressures, perceived compatibility, organizational innovativeness, perceived benefits, managers' IT knowledge, government support, and organizational readiness.

This study contributes to m-commerce research from both theoretical and practical perspectives. Theoretically, this study develops an integrated framework for better 
understanding m-commerce adoption in SMEs. This expands the body of knowledge in $\mathrm{m}$-commerce adoption in developing countries. Practically, the study leads to several major findings that provide various stakeholders with insights for developing appropriate strategies and policies to enhance the diffusion of m-commerce in Vietnam. Such findings are also useful for other developing countries in their development of mcommerce in SMEs. 


\section{Chapter 1}

\section{Introduction}

\subsection{Research Background}

Mobile commerce (m-commerce) is related to transactions that involve the transfer of the ownership of goods and services with the help of mobile devices (Tiwari \& Buse 2007; Khalifa, Cheng \& Shen 2012). It is an extension of e-commerce from wired to wireless devices, and from fixed locations to anywhere and anytime transactions (Keen, Mackintosh \& Heikkonen 2001). In this study, m-commerce is simply about buying and selling of goods and services through wireless handheld devices such as cellular phones and personal digital assistants (Liao et al. 1999; Smith 2006; Zhiping 2009; Njenga, Litondo \& Omwansa 2016; Chau \& Deng 2018a, 2020).

M-commerce is becoming increasingly popular due to a variety of benefits that it can provide including improving productivity, increasing customer satisfaction, and lowering operational costs (Varshney \& Vetter 2002). It is becoming a cost-effective way for businesses to promote their products and services online (Mallat \& Tuunainen 2008; Ullah \& Khan 2012; Njenga et al. 2016; Alfahl, Houghton \& Sanzogni 2017). Mcommerce, for example, helps businesses reach customers and suppliers anywhere and anytime. It provides customers with timely services effectively (Varshney et al. 2004; Duan, Deng \& Luo 2019). The adoption of m-commerce enables businesses to directly 
sell to customers, therefore significantly reducing the business costs (Kotler \& Armstrong 2010). As a result, there is a significant increase in the revenue in $\mathrm{m}$ commerce in the global market from \$1.357 trillion in 2017 to \$1.804 trillion in 2018. The revenues are set to surpass \$2.321 trillion in 2019 (eMarketer 2018).

The popularity of m-commerce leads to its wide adoption across the world (Chau \& Deng 2020). A careful investigation of such adoption, however, reveals that there is a huge difference in the adoption of m-commerce between the developed country and the developing country (Chau \& Deng 2021). While m-commerce has had a high level of adoption in developed countries (Mbogo 2010), it has not been popularly adopted in developing countries (Chong 2013a; Nafea \& Younas 2014), except China (Liang et al. 2007; Chen 2010; Li \& Wang 2018; Sun \& Chi 2018). This difference is reflected in the total sales achieved respectively in different countries. For example, the business-tocustomer e-commerce sales (including m-commerce sales) in the United States and Australia were recorded at around \$421.1 billion and 10.6 billion respectively in 2017 . This is in direct contrast to those sales in Thailand and the Philippines only at $\$ 3$ billion and $\$ 1.2$ billion respectively. Such sales were only at $\$ 6.2$ billion in Vietnam in the same year (Vietnam eCommerce and Digital Economy Agency 2018).

The increasing popularity of m-commerce has resulted in numerous studies that have been conducted for better understanding m-commerce adoption under various circumstances (Yang 2005; Lee, Cheng \& Cheng 2007; Martin, Catalan \& Jeronimo 2012; Rahman 2013; Alrawabdeh 2014; Kalinic \& Marinkovic 2016; Cabanillas, 
Marinkovic \& Kalinic 2017; Li \& Wang 2018; Rana et al. 2019). Such studies can be generally classified into individual adoption and organizational adoption.

Individual adoption-oriented studies focus on understanding the perception and attitude of individuals on m-commerce adoption and investigating the critical determinants for the adoption with the use of various models and theories including the technology acceptance model (TAM) (Davis 1989), the theory of planned behavior (TPB) (Ajzen 1991), the diffusion of innovation theory (DOI) (Rogers 2010), the theory of reasoned action (TRA) (Fishbein \& Ajzen 1977), the unified theory of acceptance and use of technology (UTAUT) (Venkatesh et al. 2003) and the task-technology fit theory (TTF) (Goodhue \& Thompson 1995). Khalifa et al. (2012), for example, investigate the intention of individuals to adopt m-commerce through the extension of TPB. Yadav et al. (2016) explore the critical factors affecting users' intention to adopt $\mathrm{m}$-commerce in India with the integration of TAM, TRA, and TPB. Cabanillas et al. (2017) focus on the identification of the antecedent to the acceptance of m-commerce by customers in the Republic of Serbia through the extension of TAM. Verkijika (2018) investigates the factors influencing the adoption of m-commerce by customers in Cameroon with the modification of UTAUT. Tarhini et al. (2019) analyze the factors affecting mcommerce adoption by customers in developing countries with the integration of UTAUT2 and service quality. These studies have identified various critical determinants for individual $\mathrm{m}$-commerce adoption, contributing to the existing literature by expanding the body of knowledge on the information systems (IS) area, particularly in the context of individual m-commerce adoption. 
Organization-based studies concentrate on understanding the adoption of m-commerce from the perspective of organizations (Stoica, Miller \& Stotlar 2005; Alfahl, Sanzogni \& Houghton 2012; Njenga et al. 2016). Such studies can be categorized into the conceptualization of $\mathrm{m}$-commerce adoption and the implementation of empirical studies on $\mathrm{m}$-commerce adoption in organizations.

Conceptualization-based studies focus on the development of various frameworks for better understanding m-commerce adoption in organizations with the use of various models and theories including TAM, DOI, UTAUT, the technology-organizationenvironment framework (TOE) (Tornatzky \& Fleischer 1990), the resource-based theory (RBT) (Barney 1986), the fit-viability model (FVM) (Tjan 2001), the institutional theory (Scott 2004), and the relational context (Dyer \& Singh 1998) (Stoica et al. 2005; Liang et al. 2007; Zeeshan, Cheung \& Scheepers 2007; Doolin \& Ali 2008; Alfahl et al. 2012; Alrawabdeh 2014; Picoto, Belanger \& Palma-dos-Reis 2014a; Njenga et al. 2016). These studies, however, usually lack the empirical evidence for generating the finding for $\mathrm{m}$-commerce adoption in organizations.

Empirical studies investigate the critical determinants for the adoption of $\mathrm{m}$-commerce in organizations under various circumstances (Shih \& Huang 2009; Alqatan et al. 2016; Grandhi \& Wibowo 2016; Alfahl et al. 2017; Johnson et al. 2018). Shih and Huang (2009), for example, investigate the critical factors for $\mathrm{m}$-commerce adoption in organizations, leading to the identification of the critical factors in four dimensions: technology factors, organization factors, social factors, and personal factors. Grandhi and Wibowo (2016) explore the adoption of m-commerce in organizations in North 
America with the identification of various organizational factors. Alqatan et al. (2016) investigate the adoption of m-commerce in tourism small and medium-sized enterprises (SMEs) in Jordan with the focus on the trust factor and its antecedents. Alfahl et al. (2017) study m-commerce adoption in Saudi organizations with the finding of critical factors in four different dimensions: technological factors, environmental and organizational factors, and managerial and other factors. Johnson et al. (2018) investigate $\mathrm{m}$-commerce adoption in organizations with a focus on innovation characteristics. These studies, however, do not have a general agreement on the critical determinants for organizational m-commerce adoption. Furthermore, they do not differentiate SMEs from large organizations in the adoption of m-commerce.

SMEs play an important role in the global economy (Duan, Deng \& Corbitt 2012; Deng et al. 2019; Duan et al. 2019). They are one of the driving forces in economic growth, socio-economic development, and regional development (MacGregor, Bunker \& Kartiwi 2010). The performance of SMEs is closely associated with the economic development of individual countries. This demonstrates that the adoption of $\mathrm{m}$ commerce in SMEs is critical for the economic development of individual nations (AlAlawi \& Al-Ali 2015).

SMEs have unique characteristics in technology adoption (Duan et al. 2012; Deng et al. 2019). They usually lack technical expertise with poor technical infrastructure (MacGregor \& Vrazalic 2005). Often SMEs have inadequate capital and organizational planning. Furthermore, their owners and managers have a strong influence on decisionmaking for technology adoption (Lin, Huang \& Burn 2007). SMEs are usually 
dependent on their partners in pursuing competitive advantages while facing great external uncertainty (Stockdale \& Standing 2004). These characteristics lead to different behaviors of SMEs in their adoption of m-commerce (Harrigan, Ramsey \& Ibbotson 2011).

There are few studies on the adoption of $\mathrm{m}$-commerce in SMEs in developing countries (Nafea \& Younas 2014; Alfahl et al. 2017; Li \& Wang 2018). Most existing studies on organizational m-commerce adoption have been conducted in developed countries (Chang et al. 2009; Martin et al. 2012; Picoto et al. 2014a; Johnson et al. 2018; Rana et al. 2019). This makes the generalization of the research findings difficult, if not impossible, from developed countries to developing countries due to differences in social, cultural, economic, legal, and political contexts that developing countries are in (Alam, Ali \& Jani 2011).

The number of mobile phone subscribers worldwide increases rapidly, with threequarters of them from developing countries (Zhang, Li \& Deng 2017). This provides SMEs with numerous opportunities for exploring the m-commerce market in these countries. The potential of such markets is, however, very much underutilized (Rahman 2013). This is due to the insufficiency of ICT infrastructure and the availability of limited financial resources. The low computer literacy, the high cost of ICT equipment, and the lack of sufficient laws and regulations for regulating such markets have made the development of m-commerce even more difficult (Alrousan \& Jones 2016). Furthermore, the specific characteristics of developing countries limit the applicability and transferability of the successful m-commerce models used in developed countries 
(Molla \& Licker 2005a). To accelerate the development of m-commerce in developing countries, there is a need for not only establishing the physical ICT infrastructure but also better understanding the critical determinants of m-commerce adoption in SMEs with respect to the specific characteristics of developing countries.

Vietnam is a developing country with a population of 95 million (Statista 2019d). There are 54.7 million internet users and 32.3 million smartphone users (Statista 2017b, 2017a). It is ranked the thirty-third in the world and the fifth in Asia with respect to the smartphone penetration rate in the population (Statista 2019b). This shows that Vietnam has a large potential market for m-commerce. As a result, both the Vietnam Ecommerce Association and the Vietnamese Government have been actively assisting businesses, especially SMEs, in expanding, growing, and prospering their businesses through the implementation of various initiatives. Such initiatives have created a sound environment for supporting Vietnamese SMEs in their adoption of m-commerce for developing their businesses. There are, however, only about $20 \%$ of SMEs that have built websites for promoting their business. About $70 \%$ of these websites are difficult to access by mobile devices (VECITA 2017). This shows that the adoption of $\mathrm{m}$ commerce in Vietnam is still quite low. As a result, the benefits of m-commerce have not been fully utilized in SMEs. The poor adoption of m-commerce in SMEs is due to the fact that such an adoption is a complex process with various factors involved (Stoica et al. 2005). This justifies an empirical investigation of m-commerce adoption in Vietnamese SMEs for better understanding the critical determinants of such adoption. 


\subsection{Motivation for the Research}

The motivation to conduct this research arises from four main reasons. The first reason is that there is a call for investigating the adoption of $\mathrm{m}$-commerce in organizations in the context of developing countries (Rahman 2013; Alrawabdeh 2014; Alfahl et al. 2017; Gao \& Shao 2018; Chau, Deng \& Tay 2020). A review of existing studies on organizational m-commerce adoption reveals that few studies have been conducted in developing countries (Alfahl et al. 2017; Li \& Wang 2018; Chau \& Deng 2020). Prior studies also suggest that factors affecting the adoption of m-commerce in organizations in developing countries are different from those affecting such adoption in developed countries. This is due to the differences between the developed country and the developing country in social, cultural, legal, and political contexts (Alam et al. 2011). As a result, an investigation of the adoption of m-commerce with respect to the specific characteristics of developing countries can lead to better understanding of m-commerce adoption in SMEs (Chau \& Deng 2020).

The second reason is that there is lack of research in investigating m-commerce adoption in SMEs (Chau \& Deng 2018a; Li \& Wang 2018; Chau et al. 2020), despite that they are regarded as a major driving force of the economic growth of their nations (MacGregor et al. 2010). An extensive review of organizational m-commerce adoption studies shows that there are numerous studies for better understanding organizational mcommerce adoption under various circumstances (Martin \& Jimenez 2015; Alfahl et al. 2017). Most existing studies, however, focus on large enterprises, with a few studies concentrating on the adoption of m-commerce in SMEs (Chau \& Deng 2018a, 2020). 
SMEs are a distinct group of organizations with unique characteristics in technology adoption (Duan et al. 2012). These characteristics lead to different behaviors of SMEs in the adoption of m-commerce (Harrigan et al. 2011). This calls for research on better understanding m-commerce adoption with respect to the specific characteristics of SMEs.

The third reason is that Despite the enormous benefits of m-commerce in enhancing organizational competitiveness, its adoption in SMEs has remained low (Li \& Wang 2018). Current studies on m-commerce adoption in SMEs have not received much attention (Chau \& Deng 2018, 2020). Existing literature on organizational m-commerce adoption has not provided enough information on the critical determinants that SMEs need to consider for facilitating its adoption (Chau, Deng \& Tay 2020). Furthermore, the degree of importance of the critical determinants for m-commerce adoption has not been investigated. This demonstrates the need for exploring the critical determinants and their relative importance for m-commerce adoption in SMEs.

The fourth reason is that there is lack of research on exploring the critical determinants for m-commerce adoption in SMEs in Vietnam. Although several studies investigate the critical determinants for the adoption of e-commerce in Vietnamese SMEs (Huy \& Filiatrault 2006; Pham, Pham \& Nguyen 2011; Huy et al. 2012), there are no rigorous studies for investigating the adoption of $\mathrm{m}$-commerce in SMEs in Vietnam. Vietnam has a large potential m-commerce market (Chau \& Deng 2020). This is in direct contrast to the "much-slower-than expected" adoption of m-commerce in Vietnamese SMEs 
(VECITA 2017). As a result, a comprehensive investigation of the critical determinants for m-commerce adoption in SMEs in Vietnam is significant.

\subsection{Research Objectives and Research Questions}

This study addresses the issue of a lack of empirical studies on m-commerce adoption in Vietnamese SMEs. It bridges the extent research gap by developing an integrated framework for examining the m-commerce adoption in Vietnamese SMEs. For these regards, the main objective of this study is to investigate the critical determinants for the adoption of m-commerce in Vietnamese SMEs. Particularly, the study aims to (a) identify the current pattern of the adoption of m-commerce in Vietnamese SMEs and (b) explore the critical determinants for the adoption of m-commerce in Vietnamese SMEs.

To achieve these research objectives, the main research question in this study is formulated as follows:

What can be done for improving the adoption of m-commerce in Vietnamese SMEs?

To adequately answer the main research question above, two secondary research questions have been formulated as follows:

(1) What are the current patterns of the adoption of m-commerce in Vietnamese SMEs? 
(2) What are the critical determinants for m-commerce adoption in Vietnamese SMEs?

\subsection{Research Methodology}

The primary objective of this research is to identify the critical determinants for $\mathrm{m}$ commerce adoption in Vietnamese SMEs. Such an objective can be achieved through confirmatory research with the focus on testing and validating proposed hypotheses for exploring the adoption of m-commerce in Vietnamese SMEs. Based on the nature of such research, a quantitative methodology guided by the positivism paradigm is appropriate for this study. Such a quantitative methodology is used for investigating how the well-defined hypotheses are supported by the numeric data that represent the viewpoint of a whole population. This supports the evaluation of such hypotheses for answering specific research questions (Bernard \& Bernard 2013; Neuman 2013; Creswell 2017).

The adoption of a quantitative methodology for this research is due to two reasons. First, the use of a quantitative methodology helps obtain the research findings that can be generalized to a large population. It can also be used for drawing strong inferences from the data through statistical analysis (Straub, Boudreau \& Gefen 2004; Vanderstoep \& Johnson 2008; Creswell 2017). Second, the use of such a methodology facilitates the investigation of the causal relationship between specific factors through the collection and analysis of available numerical data (Creswell 2017). As a result, the findings can 
be used to make predictions for the critical determinants of m-commerce adoption in Vietnamese SMEs.

This study follows a seven-stage research process for implementing a quantitative methodology. Such a process is presented in Figure 1.1. In the first stage, research objectives and research questions are formulated to guide the whole research. In the second stage, a comprehensive review of the related literature on m-commerce adoption in organizations is conducted for better understanding the adoption of $\mathrm{m}$-commerce in organizations from different perspectives. Such an understanding leads to the third stage of the research, which focuses on the development of a conceptual framework. In this stage, several specific hypotheses are proposed for investigating the critical determinants for m-commerce adoption in SMEs in Vietnam. This supports the development of a survey instrument in the fourth stage for facilitating the data collection for the whole research. In the fifth stage, the data collection in Vietnam is conducted using the developed survey instrument. In the sixth stage, the collected data is analyzed with the employment of various data analysis techniques to address the proposed research questions. Such techniques include (a) descriptive statistics and variance analysis for investigating the emerging pattern of $\mathrm{m}$-commerce adoption in Vietnamese SMEs, (b) structural equation modelling (SEM) techniques for testing and validating the proposed conceptual framework, and (c) artificial neural networks techniques for evaluating the relative importance of the critical determinants for $\mathrm{m}$ commerce adoption in Vietnamese SMEs. Finally, in the seventh stage, the results of the data analysis are interpreted for adequately answering the proposed research questions. 


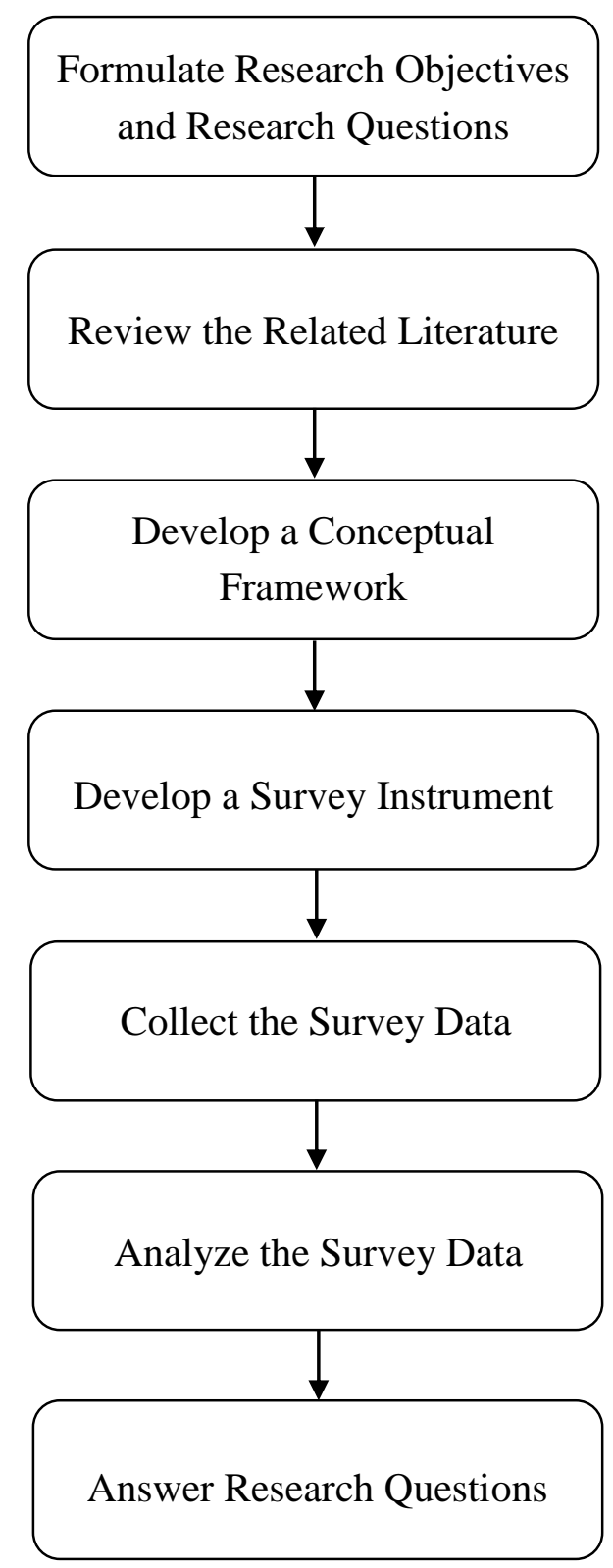

Figure 1.1 An overview of the research process

\subsection{Thesis Structure}

Figure 1.2 presents the overall structure of the thesis. Chapter 1 introduces the study with a specific focus on the research background and the motivation for the research. The chapter sets out the research objectives and the research questions and elaborates on 
the research methodology that the study adopts. It presents the structure of the thesis. This paves the way for the presentation of the whole thesis.

Chapter 2 provides a comprehensive review of the previous research related to $\mathrm{m}$ commerce and its adoption. A critical analysis of existing studies on the adoption of $\mathrm{m}$ commerce in organizations has been conducted. This leads to the identification of the concerns and limitations of these m-commerce adoption studies, therefore justifying the need for conducting this study.

Chapter 3 presents the development of a conceptual framework for investigating the critical determinants for $\mathrm{m}$-commerce adoption in Vietnamese SMEs. Such a framework grounded in the combination of the DOI theory and the TOE framework conceptualizes the critical determinants for the adoption of m-commerce in Vietnamese SMEs from four dimensions including technological dimension, organizational dimension, environmental dimension, and managerial dimension. This paves the way for developing the research instrument for testing and validating the proposed conceptual framework.

Chapter 4 discusses the research methodology available in research. This leads to the selection of an appropriate research methodology for this research. A quantitative methodology guided by the positivism paradigm is adopted in this study. This results in the adoption of a survey as the main data collection method. This chapter then presents the processes of instrument development and sample design. Finally, the chapter describes the data collection and data analysis methods. 


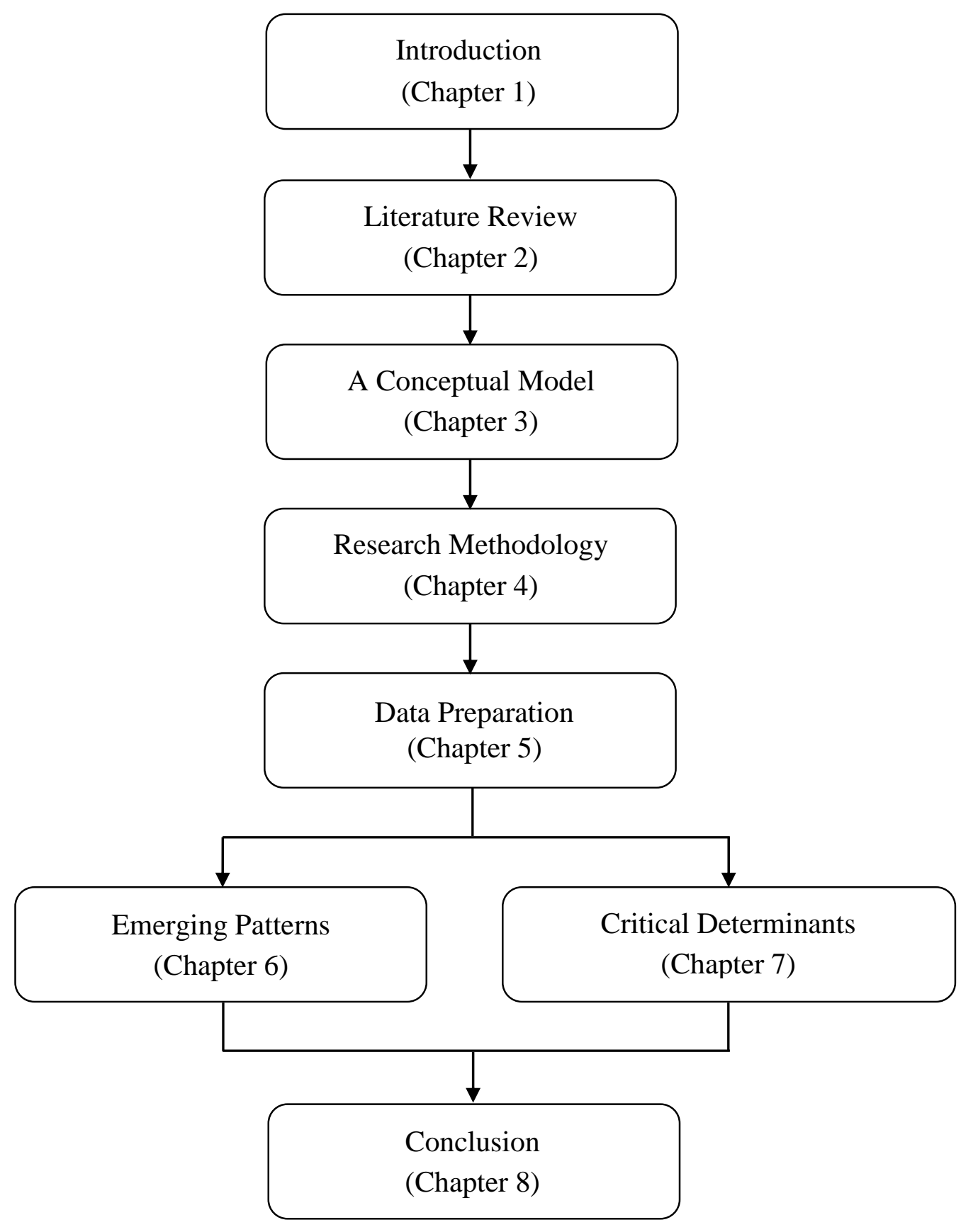

Figure 1.2 An overall structure of the thesis

Chapter 5 presents the process of data preparation for statistical analysis. Such a chapter examines the collected data with respect to missing values, outliers, and departure from normality, as well as the remedial recommendations. It also analyzes the non-respondent bias, common method bias, and the bias between paper-based and 
online surveys. The chapter finally outlines the steps followed for evaluating the reliability and validity of the measurement instrument used for this study.

Chapter 6 presents the results of the survey regarding the investigation of the emerging pattern for the adoption of m-commerce in Vietnamese SMEs. With the use of a systematic analysis of the survey results consisting of the demographic analysis, pattern analysis, and variance analysis, the emerging patterns of the adoption of $\mathrm{m}$-commerce in Vietnamese SMEs are identified. Furthermore, specific observations with respect to the use of m-commerce in Vietnamese SMEs from different perspectives have been made.

Chapter 7 presents the results of the data analysis for identifying the critical determinants for the adoption of m-commerce in Vietnamese SMEs. The proposed conceptual framework is tested and validated using SEM. A multi-analytical approach by combining the SEM technique and the neural network analysis is used to estimate the causal relationships between the critical determinants and the decision to adopt $\mathrm{m}$ commerce in Vietnamese SMEs.

Chapter 8 presents the conclusion for this study. A summary of the findings and the extent that the research questions are successfully answered are discussed. This chapter also discusses the theoretical and practical contributions of the study and their implications. The limitations of the study and the suggestions for future research are outlined. 


\section{Chapter 2}

\section{Literature Review}

\subsection{Introduction}

M-commerce is becoming increasingly popular in the world (Alfahl et al. 2017; Chau \& Deng 2018a, 2018b; Chau et al. 2020). This is exemplified by a significant increase in the revenue of $\mathrm{m}$-commerce in the global market from $\$ 1.357$ trillion in 2017 to $\$ 2.321$ trillion in 2019 (eMarketer 2018). The popularity of m-commerce is due to the potential benefits that it can provide organizations, especially SMEs, including improving productivity, increasing customer satisfaction, and lowering operational costs (Kotler \& Armstrong 2010; Duan et al. 2019; Chau et al. 2020). M-commerce is becoming a costeffective way for businesses to promote their products and services online (Mallat \& Tuunainen 2008; Ullah \& Khan 2012; Njenga et al. 2016; Alfahl et al. 2017).

SMEs are a distinct group of organizations with unique characteristics in technology adoption (Duan et al. 2012). They perform a critical role in the Vietnamese economy (Huy \& Filiatrault 2006; Huy et al. 2012; Chau et al. 2020). SMEs in Vietnam account for approximately $98 \%$ of the enterprises, contributing more than $40 \%$ of national gross domestic products (GDP). They make a contribution of $30 \%$ to the total national export value with the generation of more than 500.000 jobs annually (General Statistics Office 
of Vietnam 2019). The adoption of m-commerce offers SMEs with numerous opportunities to compete in local, regional, and global markets.

The potential of m-commerce for Vietnamese SMEs is very much underutilized. There are only about $20 \%$ of SMEs that have built websites for promoting their business. $70 \%$ of these websites are difficult to access by mobile devices (VECITA 2017). A national e-commerce survey in 2018 indicates that only $11 \%$ of Vietnamese enterprises in which $90 \%$ of them are SMEs conduct their business via e-commerce applications. There are only $13 \%$ of these enterprises that adopt m-commerce (Vietnam eCommerce and Digital Economy Agency 2018). Such a low adoption rate of m-commerce in Vietnamese SMEs is interesting in the presence of (a) the high internet and smartphone penetration rate in Vietnam for enabling m-commerce activities (Statista 2017b, 2017a) and (b) the continuous support from the Vietnam E-commerce Association and the Vietnamese Government for businesses to improve their competitiveness through the adoption of $\mathrm{m}$ commerce (Chau \& Deng 2020). As a result, better understanding the adoption of mcommerce in Vietnamese SMEs is becoming critical.

This chapter explores the research gap in the adoption of m-commerce in SMEs in Vietnam through an extensive review of the related literature for justifying the need for this study. To achieve this objective, the rest of the chapter is organized into five sections. Section 2.2 presents an overview of m-commerce. Section 2.3 describes SMEs in the Vietnamese context with a focus on their characteristics in technology adoption. Section 2.4 investigates the adoption of m-commerce in Vietnamese SMEs, followed by 
an extensive literature review on organizational m-commerce adoption in Section 2.5. Section 2.6 ends the chapter with some concluding remarks.

\subsection{An Overview of M-Commerce}

There are various definitions of m-commerce from different perspectives (Chau \& Deng 2020). Most previous studies, for example, consider m-commerce as the extension of ecommerce from wired to wireless devices and telecommunications, and from fixed locations to anywhere and any time transactions (Keen et al. 2001; Hsieh 2007). As a result, m-commerce is also known as "mobile e-commerce". From this perspective, mcommerce is described as any transaction that involves the transfer of ownership of goods and services with the help of mobile devices (Tiwari \& Buse 2007; Khalifa et al. 2012).

M-commerce can be approached from the transaction perspective. Such a perspective describes m-commerce as a business transaction with an economic value using a mobile terminal (Leung \& Antypas 2001; Terziyan 2002; Zhang, Yuan \& Archer 2002; Sadeh 2003; Clarke III 2008). In particular, m-commerce involves the delivery of trusted transactions over mobile devices for the exchange of goods and services between customers, merchants, and across organizations (Njenga et al. 2016). As a result, mcommerce is not a truncated form of e-commerce but a new and innovative way of conducting time-critical transactions between customers and organizations regardless of their locations (Carlsson \& Walden 2003). 
This study focuses on business to customer (B2C) m-commerce. It means that the study adopts a service-focused perspective in approaching m-commerce. From this perspective, m-commerce is simply about buying and selling of goods and services through wireless handheld devices such as cellular phones and personal digital assistants (Liao et al. 1999; Smith 2006; Zhiping 2009; Njenga et al. 2016). This is a broad definition of m-commerce that includes communication, transactions, and different value-added services using various kinds of mobile terminals (Paavilainen 2002).

M-commerce is an expansion of e-commerce in which electronic buying and selling on the internet are presented (Bidgoli 2002). It enables the accomplishment of commercial transactions at any time and any location through wireless connections (Harry, Vos \& Haaker 2008). M-commerce has unique characteristics regarding internet access devices, communication modes, and protocols, enabling technologies and development languages (Coursaris \& Hassanein 2002). It has some elements that make it distinctive from other forms of e-commerce. First, m-commerce provides users with accessibility. It allows users to access the mobile network at any time and from any location (Junglas \& Watson 2003). Second, it has ubiquity characteristics that allow users to access any interesting information at any location (Siau, Lim \& Shen 2003). Third, m-commerce has the convenience characteristic that provides easy accessibility to mobile networks with user-friendly wireless handheld devices, which are not dependent on time or location (Khosrow-Pour 2006). Fourth, the localization characteristics support to track the location of any mobile devices easily with the help of mobile operators or positioning technologies (Stanoevska-Slabeva 2003). Finally, the personalization 
characteristic of m-commerce provides users with different personalized services and applications according to their preferences (Andreou et al. 2002).

M-commerce improves the value-added utility in the transaction for context-specific services (Li \& Chang 2012). In particular, m-commerce can profit from location-based services. Such services provide opportunities for personalized push-marketing, leading to an increase in sales and brand presence (Li \& Chang 2012). Furthermore, mcommerce provides customers with effective services to fulfill their spontaneous decisions and needs. It can support customers to make their purchases and complete transactions while in mobility. As a result, m-commerce increases the efficiency of customers in the situation of time constraints.

M-commerce provides businesses, especially SMEs, with numerous benefits. Mcommerce, for example, helps businesses reach customers anywhere at any time. The adoption of m-commerce enables businesses to directly sell to customers, thereby significantly reducing the operating costs (Kotler \& Armstrong 2010). As a result, mcommerce has been attracting attention from businesses not only for promoting their products and services but also for enhancing their international competitiveness (Alfahl et al. 2012; Ullah \& Khan 2012; Njenga et al. 2016; Khaskheli, Jun \& Bhuiyan 2017).

M-commerce is a complex process with the involvement of various stakeholders (Chang, Li \& Liao 2012). A typical grid-based m-commerce transaction process is involved in six different stakeholders including customers, organizations (merchants), $\mathrm{m}$-commerce centres, mobile payment centres, logistics agencies, and governments 
(Chang et al. 2012). Among these stakeholders, customers are the key participant in such a process. Figure 2.1 presents an overview of a typical m-commerce process.

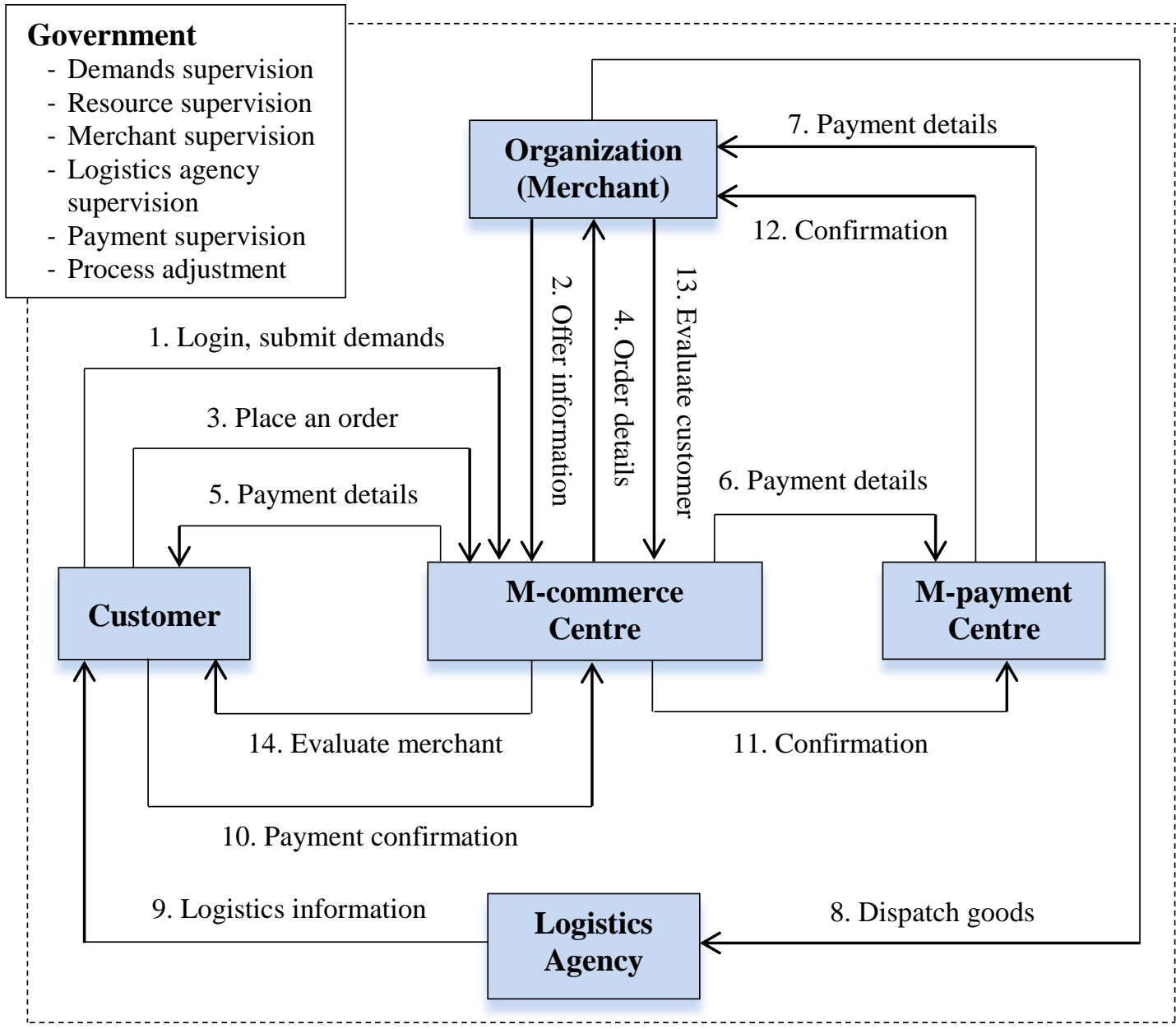

Figure 2.1 An overview of a mobile commerce process

A typical $\mathrm{B} 2 \mathrm{C}$ m-commerce process experiences in five stages including demand initiation, demand acceptance, task assignment, task execution, and feedback collection (Li \& Chang 2012). Demand initiation realizes the identity authentication of users, receives demand information, and inspects the authenticity and completeness of the information received (Li \& Chang 2012). Demand acceptance preliminarily handles the demand. In this stage, the m-commerce centre identifies the classification of demands 
and allocates resources to them (Li \& Chang 2012). In the task assignment stage, the mcommerce centre classifies the final demands of the user with merchants and content. The m-commerce centre then assigns those demand task packages to each corresponding merchant ( $\mathrm{Li} \&$ Chang 2012). In the task execution stage, all participants execute their tasks including order processing, delivering, transporting, paying, and receiving commodities (Li \& Chang 2012). Finally, in the feedback stage, customers appraise products, services, and logistics, and then provide suggestions. Merchants give an evaluation to customers' transaction behaviors (Li \& Chang 2012).

There are three main sub-processes in such an m-commerce process including authentication, payment, and logistics (Li \& Chang 2012). The success of such subprocesses contributes to the completion of the whole $\mathrm{m}$-commerce process. There are various factors affecting the success of such specific processes. The execution of the authentication process, for example, requires compatible platforms between customers and organizations. There is a need for the standardization of information and content. The payment process is concerned with the infrastructure of payment systems, as well as information security issues. The logistics process involves the participation of logistics parties. This requires the collaboration between logistics parties and organizations and the efficiency of resource utilization to provide customers with efficient and timely services. Critically, the government plays an important role in determining the success of the whole $\mathrm{m}$-commerce process with respect to the authentication, the supervision, and the provision of rules and resources. The discussion above shows that better understanding such involved factors is critical for the successful adoption of $\mathrm{m}$-commerce in organizations. 


\subsection{Vietnamese SMEs and their Development}

SMEs can be defined differently across countries and sectors with respect to the number of employees, the turnover, and the ownership structure (Poon 2002; Ayyagari, Beck \& Kunt 2007). The most commonly used measure is the level of employment due to the availability and reliability in data collection. The European Union, for example, defines an SME as a business with less than 250 employees (European Commission 2018). In the United States, an SME is referred to a business with less than 500 employees (US Small Business Administration 2018). Within Australia, an SME is referred to a business with less than 200 employees (Australia Bureau of Statistics 2018). Asia Pacific Economic Cooperation defines SMEs as businesses with less than 100 employees (Asia-Pacific Economic Cooperation 2018).

In Vietnam, the number of employees is mainly used for defining SMEs. According to the Decree 56/2009/ND-CP of 2009, an SME in Vietnam is an independent business with the average number of permanent employees not exceeding 300 (Business Insides 2011). In addition to the number of permanent employees, the total registered capital is another measure used in defining Vietnamese SMEs. Accordingly, an SME is an independent business establishment with the registered capital not exceeding VND 100 billion. Based on such two measures, SMEs are divided into three levels including very small enterprises, small enterprises, and medium enterprises. Such a classification is different for SMEs in various economic sectors. Table 2.1 presents an overview of such classifications of SMEs in Vietnam. This study is conducted in the Vietnamese context. 
As a result, the definition of SMEs based on both the number of permanent employees and the total registered capital is adopted.

Table 2.1 Classification of Vietnamese SMEs

\begin{tabular}{|c|c|c|c|c|c|c|}
\hline \multirow[b]{2}{*}{ Sectors } & \multicolumn{2}{|c|}{$\begin{array}{c}\text { Agriculture, Forestry, } \\
\text { and Fishery }\end{array}$} & \multicolumn{2}{|c|}{$\begin{array}{l}\text { Industry and } \\
\text { Construction }\end{array}$} & \multicolumn{2}{|c|}{ Trade and Service } \\
\hline & $\begin{array}{c}\text { Total } \\
\text { capital } \\
\text { (billion } \\
\text { VND) }\end{array}$ & $\begin{array}{l}\text { Number of } \\
\text { employees }\end{array}$ & $\begin{array}{c}\text { Total } \\
\text { capital } \\
\text { (billion } \\
\text { VND) }\end{array}$ & $\begin{array}{l}\text { Number of } \\
\text { employees }\end{array}$ & $\begin{array}{c}\text { Total } \\
\text { capital } \\
\text { (billion } \\
\text { VND) }\end{array}$ & $\begin{array}{l}\text { Number of } \\
\text { employees }\end{array}$ \\
\hline $\begin{array}{l}\text { Very small } \\
\text { enterprises }\end{array}$ & & 10 or fewer & & 10 or fewer & & 10 or fewer \\
\hline $\begin{array}{l}\text { Small-sized } \\
\text { enterprises }\end{array}$ & 20 or less & $\begin{array}{l}\text { Between } \\
\text { over } 10 \text { and } \\
200\end{array}$ & $\begin{array}{l}20 \text { billion } \\
\text { or less }\end{array}$ & $\begin{array}{l}\text { Between } \\
\text { over } 10 \text { and } \\
200\end{array}$ & $\begin{array}{l}10 \text { billion } \\
\text { or less }\end{array}$ & $\begin{array}{l}\text { Between } \\
\text { over } 10 \text { and } \\
50\end{array}$ \\
\hline $\begin{array}{l}\text { Medium-sized } \\
\text { enterprises }\end{array}$ & $\begin{array}{l}\text { Between } \\
\text { over } 20 \\
\text { and } 100\end{array}$ & $\begin{array}{l}\text { Between } \\
\text { over } 200 \text { and } \\
300\end{array}$ & $\begin{array}{l}\text { Between } \\
\text { over } 20 \text { and } \\
100\end{array}$ & $\begin{array}{l}\text { Between } \\
\text { over } 200 \\
\text { and } 300\end{array}$ & $\begin{array}{l}\text { Between } \\
\text { over } 10 \\
\text { and } 50\end{array}$ & $\begin{array}{l}\text { Between } \\
\text { over } 50 \text { and } \\
100\end{array}$ \\
\hline
\end{tabular}

SMEs play an important role in the economy of their nations. They make significant contributions to economic growth, employment, as well as the regional and local development (Scupola 2009; Senarathna et al. 2013). Most governments regard SMEs as a major driver of the economy and a source of employment opportunities (MacGregor et al. 2010). In the United States, for example, SMEs represent 99\% of businesses. They employ nearly half of the workforce and create two-thirds of the new jobs (Office of Advocacy 2018). In most OECD nations, SMEs account for between $96 \%$ and $99 \%$ of enterprises and contribute about $80 \%$ of the economic growth (OECD 
2017). In Australia, SMEs provide one-third of the GDP and employ about $70 \%$ of employment (Parliament of Australia 2018).

SMEs perform a critical role in the Vietnamese economy. Specifically, they represent $98 \%$ of the total number of enterprises in Vietnam. SMEs employ more than one million people and contribute more than $40 \%$ to the national GDP (General Statistics Office of Vietnam 2019). This shows that the success of SMEs is very important to the economic growth in Vietnam. In this regard, how to effectively improve the productivity of Vietnamese SMEs by adopting the latest technologies becomes critical.

The number of SMEs in the Vietnamese economy is increasing over time. There is around $8.96 \%$ increase of the active SMEs each year in Vietnam (General Statistics Office of Vietnam 2017), leading to the fierce challenge for the survival of Vietnamese SMEs in the competitive market. This is exemplified by the high exit rate of SMEs in the Vietnam economy. Specifically, there are 12.113 enterprises completing dissolution procedures in 2017, in which $91.5 \%$ of these enterprises are SMEs (General Statistics Office of Vietnam 2018b). As a result, how to actively respond to the changing economy and successfully adopt the latest technologies for promoting competitive advantages is crucial for Vietnamese SMEs.

SMEs are a distinct group of organizations with unique characteristics in the adoption of technology (Duan et al. 2012). These characteristics make them more flexible in adopting technologies. The flattened structure of SMEs, for example, enables much faster decision making (Antony, Kumar \& Madu 2005; Deros, Yusof \& Salleh 2006; 
McAdam et al. 2007). They are often seen as dynamic organizations and thus are expected to easily adapt to modern information and communication technologies (ICT) (Abdullah, Wahab \& Shamsuddin 2013; Alshamaila 2013). SMEs have the flexibility to try new approaches as their processes, structures, and systems are simpler than those of large enterprises (Taylor \& Murphy 2004). The small size of SMEs allows for an efficient and informal communication network. As a result, SMEs can react quickly to any shifts in the market. Furthermore, the lack of bureaucracy lets SMEs implement changes easily (Lippert \& Govindarajulu 2006; Boateng \& Essandoh 2014; Tarute \& Gatautis 2014). With these advantages, SMEs are more responsive to market needs than large enterprises, more adaptable to change, and more innovative to meet their customer demands (Antony et al. 2005; Edwards, Delbridge \& Munday 2005; Murphy \& Ledwith 2007).

SMEs possess unique characteristics from technological, organizational, and environmental perspectives (Duan et al. 2012). The technological characteristics of SMEs in the adoption of technologies are featured by (a) lack of technical expertise (Barry \& Milner 2002; Stockdale \& Standing 2004; MacGregor \& Vrazalic 2005) and (b) poor technical infrastructure (Cragg \& King 1992; MacGregor \& Vrazalic 2005; Lin et al. 2007). The organizational characteristics of SMEs in the adoption of technologies are reflected in (a) inadequacy of capital and organizational planning (Poon \& Swatman 1999; Levy \& Powell 2003; Lin et al. 2007) and (b) strong influences from the owner in the decision-making processes (Bunker \& MacGregor 2002; Duhan, Levy \& Powell 2001; Liang et al. 2007). The environmental characteristics of SMEs in the adoption of technologies are highlighted with (a) high dependence on business partners (Stockdale 
\& Standing 2004) and (b) greater external uncertainty (Rao, Metts \& Mora Monge 2003; Street \& Meister 2004; Carmel \& Nicholson 2005). These characteristics often pose numerous challenges for SMEs in their adoption of new technologies. Such characteristics also result in the differences between SMEs and their larger counterparts in the adoption of technologies, which has been ignored in most existing studies on organizational m-commerce adoption. As a result, such characteristics of SMEs need to be properly addressed while investigating the critical determinants for the adoption of m-commerce in SMEs.

\subsection{M-Commerce Adoption in Vietnamese SMEs}

Vietnam is a developing country with a population of approximately 95 million (Statista 2019d). There are 54.7 million internet users, and 32.3 million smartphone users represented approximately $37 \%$ of the population (Statista 2019a, 2019c). It is ranked the thirty-third in the world and the fifth in Asia with respect to the smartphone penetration rate in the population (Statista 2019b). In Vietnam, mobile devices are the most popular mean of the internet connection, accounting for $98 \%$ of all the devices used for accessing the internet. Furthermore, there are $40 \%$ of mobile internet activities that are related to searching for information on goods and services available online (Vietnam Business 2017). This shows that Vietnam has an expanding market for $\mathrm{m}$ commerce.

M-commerce is a powerful technology in cutting costs, improving efficiency, and enhancing trade links in Vietnamese SMEs (Chau \& Deng 2018a). Both the Vietnam E- 
commerce Association and the Vietnamese Government act actively in assisting SMEs with expanding, growing, and prospering their businesses through the development of a series of policies and programs for improving the economic environment. In addition to such policies and programs, the Vietnamese Government has also launched two plans for the development of e-business for the periods of 2011-2015 and 2016-2020.

The first plan for the development of e-business aims to achieve the advanced level of use of e-business in Vietnam, contributing to improving the competitiveness of enterprises in particular and the whole country in general. This helps to accelerate the process of industrialization and modernization of the country. Accordingly, there are several specific objectives that need to be achieved by 2015 by Vietnamese SMEs. Particularly, all SMEs are encouraged to conduct their B2C or business-to-business (B2B) transactions online, in which (a) 100\% of SMEs use email in their production and business activities, (b) $45 \%$ of SMEs have websites with regularly updated information on their activities and products or services, and (c) 30\% of SMEs join e-commerce websites to buy and sell their products or services (Vietnamese Government 2010).

The second plan for the development of e-business insists that e-business is one of the important infrastructures of an information society. It is the way to help Vietnamese businesses to develop their domestic market and import-export activities. It also helps Vietnamese businesses participate in the global supply chain and improves national competitiveness in the context of international integration. One of the core objectives for the period 2016-2020 is that $80 \%$ of Vietnamese businesses receive orders through e-commerce applications. There are numerous initiatives from the government to assist 
businesses in achieving such an objective such as (a) the formulation of specific laws, regulations, and policies for e-commerce, (b) the enhancement of the management and organization abilities of SMEs for e-commerce activities, (c) the establishment of infrastructure for e-commerce, (d) the development of human resources for ecommerce, and (e) the facilitation of the implementation of new technologies in ecommerce, especially mobile technologies (Vietnamese Government 2016). Such initiatives have created a sound environment for supporting Vietnamese SMEs financially and promoting the adoption of the latest technologies for developing their respective businesses.

Such continuous support from the Vietnam E-commerce Association and the Vietnamese Government further reduces the barriers for Vietnamese SMEs to adopt mcommerce for their businesses. The adoption of $\mathrm{m}$-commerce in Vietnamese businesses, especially SMEs, however, is disappointing. This is evidenced by the relatively low percentage of businesses that have their websites for demonstrating the enterprise information and promoting their products and services online. Figure 2.2 presents the percentage of enterprises that have built websites for their businesses from 2013 to 2018. There are only $44 \%$ of the enterprises indicated that they had already created websites. This rate was increased by only $1 \%$ and seemed to remain unchanged over the past few years (VECOM 2019). 


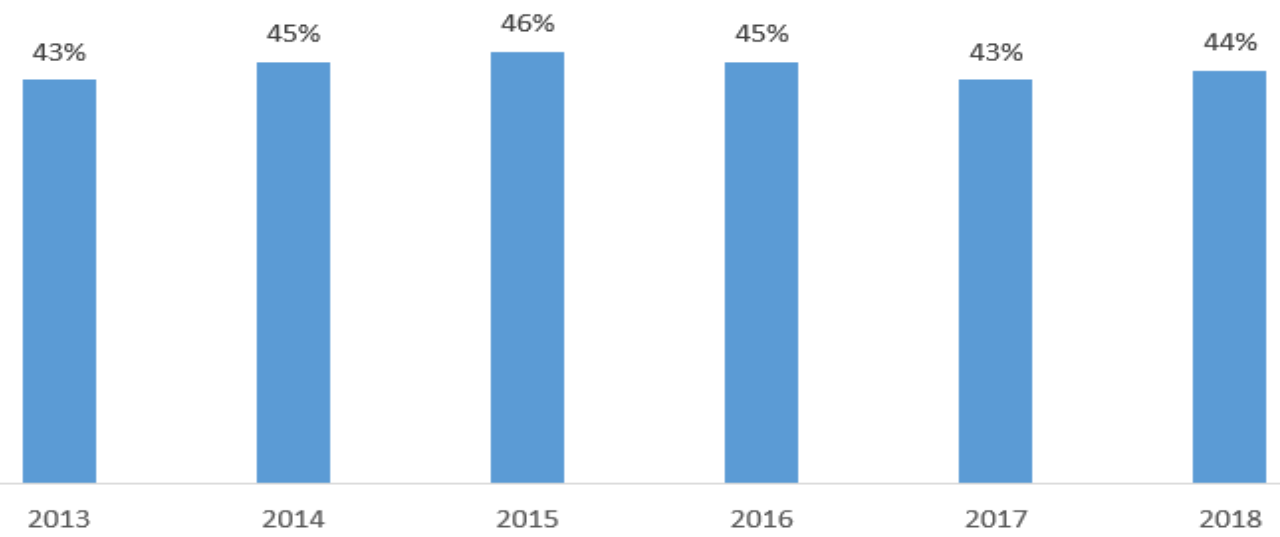

Figure 2.2 The percentage of business with websites over the years

The smartphone penetration rate in Vietnam in 2019 is approximate 37\% (Statista 2020). Smart consumers in Vietnam have changed their traditional ways of shopping into new and more convenient experiences through the use of mobile applications (VECOM 2019). This provides enterprises, especially SMEs, with numerous opportunities for exploring such a potential m-commerce market. The application of mobile platforms is, however, limited to only enterprises with large size. The national survey in 2018 indicates that there are only 17\% of enterprises having mobile-based websites. This rate did not have much difference over the last few years (VECOM 2019). Figure 2.3 outlines the percentage of websites having mobile versions over the years.

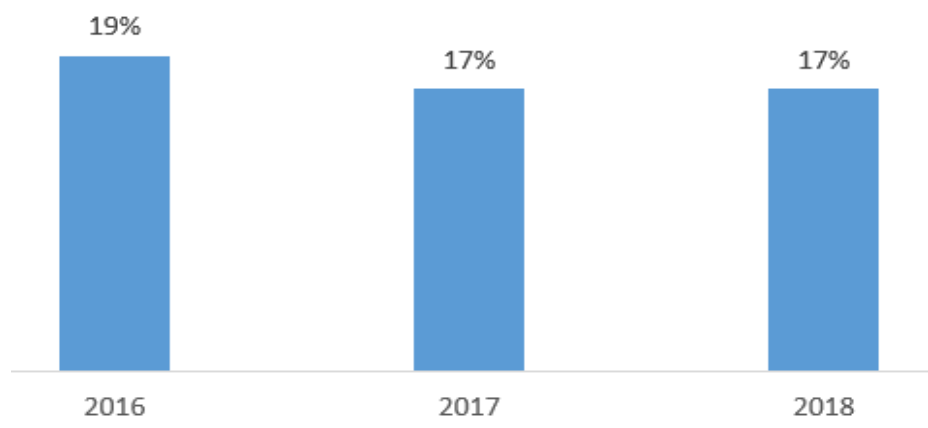

Figure 2.3 The percentage of mobile accessible websites over the years 
Similar to the rate of enterprises having mobile websites, the rate of enterprises processing sales via mobile applications accounts for only $14 \%$ in 2018 . This rate witnesses no change compared to previous years (VECOM 2019). Figure 2.4 describes the percentage of enterprises using mobile sales applications over the years. In general, the majority of enterprises, especially SMEs, are still not ready for changing to $\mathrm{m}$ commerce.

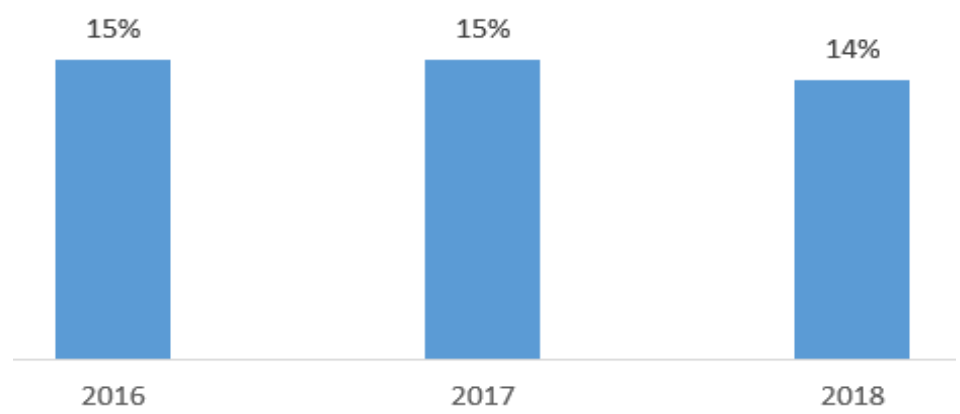

Figure 2.4 The percentage of mobile sales application usage over the years

Despite the tremendous benefits of $\mathrm{m}$-commerce, the adoption of $\mathrm{m}$-commerce is still quite low. As a result, the benefits of $\mathrm{m}$-commerce have not been fully utilized by Vietnamese SMEs. Such slow adoption can be attributed to many challenges. First, Vietnamese SMEs share the same barriers to the adoption of new technologies and mcommerce as SMEs in other developing countries. They are lack of ICT skills (Huy et al. 2012) and financial resources (Hamdan et al. 2016) and highly dependent on business partners (Stockdale \& Standing 2004). Vietnamese SMEs face other challenges in adopting $\mathrm{m}$-commerce. There is a perception in SMEs that the adoption of $\mathrm{m}$ commerce is costly. SMEs are also lack of opportunities to access investment funds and internal technical expertise. Last but not least, the habit of using cash and the concerns about security issues are also the main barriers to the adoption of internet commerce in 
general and m-commerce in particular (VCCI 2016). As a result, better understanding the critical determinants for the adoption of m-commerce in Vietnamese SMEs is desirable for promoting the adoption of $\mathrm{m}$-commerce in Vietnamese SMEs.

\subsection{Organizational M-Commerce Adoption Studies}

The importance of m-commerce adoption in enhancing the competitiveness of organizations attracts much attention to understanding such adoption in the literature (Chau \& Deng 2018a, 2021). An extensive review of the related literature reveals that existing studies on m-commerce adoption in organizations concentrate on better understanding how individual organizations can effectively adopt m-commerce under various circumstances (Chau \& Deng 2018a, 2018b, 2020). Such studies can be categorized into the conceptualization of organizational m-commerce adoption and the empirical validation of organizational m-commerce adoption.

\subsubsection{Conceptualization of Organizational M-Commerce Adoption}

The conceptualization of m-commerce adoption focuses on the development of specific conceptual frameworks for better understanding the adoption of $\mathrm{m}$-commerce in organizations. Such studies have been carried out through an intensive review of the related literature with respect to specific theoretical perspectives in technology adoption in organizations. This leads to the proposition of various dimensions and factors for conceptualizing the research framework to $\mathrm{m}$-commerce adoption in organizations. 
Stoica et al. (2005), for example, develop a conceptual framework for exploring mcommerce adoption in organizations. Grounded from the dimensions of socialeconomic readiness and government involvement, such a framework suggests ten propositions to be tested including organizational structure, business strategy, organizational culture, and environment. The proposed framework relates the adoption of m-commerce to the performance of organizations. It is, however, based mostly on structural factors with an underlying assumption that the adoption of m-commerce leads to better performance in organizations.

Zeeshan et al. (2007) present a conceptual framework for understanding the adoption of m-commerce in organizations along the supply chain. The proposed framework consists of ten factors including technological resources, financial resources, human resources, customer orientation, innovation orientation, perceived organizational collaboration advantages, top management support, institutional pressure, competitive pressure, and organizational size. Based on these factors, the study concludes with the hypotheses that need to be empirically tested in future research.

Alfahl et al. (2012) conceptualize a research framework for understanding m-commerce adoption in Saudi organizations. Grounded from the integrations of TOE, TAM, DOI, TRA, and TPB, such a framework proposes fifteen factors grouped into three dimensions including technological factors, environmental and organizational factors, and policy and legal environment factors. Such a comprehensive framework provides various perspectives for understanding m-commerce adoption. The proposed factors, 
however, need to be orientated to a specific type of organization for better understanding such adoption in organizations.

Njenga et al. (2016) propose a conceptual framework for identifying the determinants of organizational m-commerce adoption. Integrating the technology acceptance and information systems success concepts, the framework consists of organizational attributes including system quality, service quality, innovativeness, price structure and security, and individual attributes including technology literacy, hedonic motivation, and usability. The study paves the way for understanding m-commerce adoption in organizations through the proposition of various determinants. It is, however, lack consideration of a contextual analysis for the applicability of such a framework.

Alqatan et al. (2017) develop a conceptual framework for investigating the critical factors affecting the adoption of m-commerce in tourism SMEs in Jordan. Integrating TAM with TTF, the proposed framework consists of perceived usefulness, perceived ease of use, and the fit between mobile technologies and tasks. Such a framework, however, focuses on understanding the determinants of m-commerce adoption from the perspective of employees in tourism SMEs.

In summary, previous conceptualization-based m-commerce adoption studies have proposed various conceptual frameworks for better understanding such adoption in organizations under different theoretical perspectives. They, however, lack of empirical evidence for generalizing the findings. They also lack the consideration for specific research contexts and the types of organizations for empirically testing such 
frameworks. As a result, there is a need for empirically validating these frameworks under various circumstances for better understanding such adoption in organizations.

\subsubsection{Empirical Studies on M-Commerce Adoption in Organizations}

Empirical studies of m-commerce adoption concentrate on testing and validating specific conceptual frameworks for better understanding the adoption of $\mathrm{m}$-commerce in organizations (Chau \& Deng 2020; Chau et al. 2020). These studies have been conducted in different countries with respect to various types of organizations. Such studies often lead to the identification of the critical determinants for m-commerce adoption under various circumstances. Table 2.2 and Table 2.3 present the summary of the literature regarding the type of countries and organizations being investigated in these studies. 
Table 2.2 An overview of country types investigated in the literature

\begin{tabular}{ll}
\hline Countries & \multicolumn{1}{c}{ References } \\
\hline & Siau, Sheng and Nah (2003); Leger, Cassivi and Wamba (2004); Yang (2005); Al-Qirim \\
& (2006); Snowden et al. (2006); Lee et al. (2007); Swilley (2007); Tsai and Gururajan (2007); \\
& Doolin and Ali (2008); Mallat and Tuunainen (2008); Li and McQueen (2008); Chang et al. \\
& (2009); Danhui, Jinlong and Yuqing (2009); Shih and Huang (2009); Balocco, Mogre and \\
Developed & Toletti (2009); Shih et al. (2010); Martin et al. (2012); Picoto, Belanger and Palma-dos-Reis \\
countries & (2012); Picoto et al. (2014a); Picoto, Belanger and Palma-dos-Reis (2014b); Grandhi and \\
& Wibowo (2015); Lu et al. (2015); Martin and Jimenez (2015); Hu, Lu and Tzeng (2015); \\
& Grandhi and Wibowo (2016); Amegbe, Hanu and Nuwasiima (2017); Johnson et al. (2018); \\
& Rana et al. (2019). \\
\hline & Liang et al. (2007); Chen (2010); Hossain and Khandanker (2011); Jain et al. (2011); \\
& Mashagba, Mashagba and Nassar (2013); Rahman (2013); Alrawabdeh (2014); Otieno and \\
Developing & Kahonge (2014); Prasarry, Astuti and Suyadi (2015); Alqatan et al. (2016); Waithaka and \\
countries & Mnkandla (2017); Li and Wang (2018); Alfahl et al. (2017); Gao and Shao (2018); Sun and \\
& Chi (2018); Utami et al. (2019); Pipitwanichakarn and Wongtada (2019); Van den Berg and \\
& Van der Lingen (2019).
\end{tabular}

Table 2.3 An overview of organization types investigated in the literature

\begin{tabular}{ll}
\hline Organizations & \multicolumn{1}{c}{ References } \\
\hline & Siau, Sheng and Nah (2003); Leger, Cassivi and Wamba (2004); Yang (2005); Snowden \\
& et al. (2006); Lee et al. (2007); Liang et al. (2007); Swilley (2007); Tsai and Gururajan \\
& (2007); Doolin and Ali (2008); Mallat and Tuunainen (2008); Li and McQueen (2008); \\
& Chang et al. (2009); Danhui, Jinlong and Yuqing (2009); Shih and Huang (2009); \\
& Balocco, Mogre and Toletti (2009); Shih et al. (2010); Chen (2010); Hossain and \\
& Khandanker (2011); Martin et al. (2012); Picoto, Belanger and Palma-dos-Reis (2012); \\
& Mashagba, Mashagba and Nassar (2013); Rahman (2013); Picoto et al. (2014a); Picoto, \\
& Belanger and Palma-dos-Reis (2014b); Alrawabdeh (2014); Grandhi and Wibowo \\
& (2015); Martin and Jimenez (2015); Hu, Lu and Tzeng (2015); Grandhi and Wibowo \\
& (2016); Alqatan et al. (2016); Amegbe, Hanu and Nuwasiima (2017); Alfahl et al. \\
& (2017); Gao and Shao (2018); Sun and Chi (2018); Johnson et al. (2018); \\
& Pipitwanichakarn and Wongtada (2019); Van den Berg and Van der Lingen (2019). \\
\hline & Al-Qirim (2006); Jain et al. (2011); Otieno and Kahonge (2014); Prasarry, Astuti and \\
& Suyadi (2015); Lu et al. (2015); Waithaka and Mnkandla (2017); Li and Wang (2018); \\
& Rana et al. (2019); Utami et al. (2019). \\
\hline
\end{tabular}


Various theories have been employed for investigating the adoption of $\mathrm{m}$-commerce in organizations. These theories include TRA, TPB, TAM, UTAUT, DOI, TOE, RBT, TTF, FVM, the institutional theory, and the relational context (Dyer \& Singh 1998). The use of such theories in these studies provides various perspectives for better understanding the adoption of m-commerce in organizations. Table 2.4 presents a summary of the dominant theoretical perspectives commonly used in the literature.

Table 2.4 An overview of the dominant theoretical perspectives in the literature

\begin{tabular}{|c|c|c|}
\hline Theories & Main Factors or Dimensions & References \\
\hline TAM & $\begin{array}{l}\text { Perceived usefulness and perceived } \\
\text { ease of use. }\end{array}$ & $\begin{array}{l}\text { Snowden et al. (2006); Shih et al. (2010); } \\
\text { Mashagba et al. (2013); Pipitwanichakarn } \\
\text { and Wongtada (2019) }\end{array}$ \\
\hline TOE & $\begin{array}{l}\text { Technological dimension, } \\
\text { organizational dimension, and } \\
\text { environmental dimension. }\end{array}$ & $\begin{array}{l}\text { Yang (2005); Doolin and Ali (2008); } \\
\text { Chen (2010); Jain et al. (2011); Martin } \\
\text { and Jimenez (2015); Lu et al. (2015); } \\
\text { Rana et al. (2019) }\end{array}$ \\
\hline DOI & $\begin{array}{l}\text { Relative advantage, compatibility, } \\
\text { complexity, trialability, and } \\
\text { complexity. }\end{array}$ & Al-Qirim (2006); Johnson et al. (2018) \\
\hline TTF & $\begin{array}{l}\text { Task characteristics, technology } \\
\text { characteristics, task-technology fit. }\end{array}$ & Lee et al. (2007) \\
\hline FVM & Task-technology fit and viability. & Liang et al. (2007) \\
\hline UTAUT & $\begin{array}{l}\text { Performance expectancy, effort } \\
\text { expectancy, social influence and } \\
\text { facilitating conditions. }\end{array}$ & Gao and Shao (2018) \\
\hline Grounded theory & & $\begin{array}{l}\text { Waithaka and Mnkandla (2017); Utami et } \\
\text { al. (2019) }\end{array}$ \\
\hline Institutional theory & $\begin{array}{l}\text { Mimetic pressures, coercive } \\
\text { pressures, and normative pressures. }\end{array}$ & Li and Wang (2018) \\
\hline
\end{tabular}


The use of TAM for better understanding the adoption of $\mathrm{m}$-commerce in organizations assumes that the intention of an organization in adopting $\mathrm{m}$-commerce is influenced by the perceived usefulness and the perceived ease of use (Davis 1989). This theory has been widely applied with specific extensions in various contexts for exploring mcommerce adoption in organizations.

Snowden et al. (2006), for example, extend TAM for investigating the critical factors affecting the adoption of m-commerce in organizations. The study shows that the usefulness and the ease of use of mobile technologies, the technical complexity, individual differences, facilitating conditions, social influences, and wireless trust environments are critical for m-commerce adoption in organizations. Shih et al. (2010) extend TAM to study m-commerce adoption in real estate organizations. The study reveals that perceived usefulness, perceived ease of use, and the tool experience are critical for the adoption of m-commerce. Mashagba et al. (2013) revise TAM for investigating the technological factors affecting organizational $\mathrm{m}$-commerce adoption in Jordan. The study confirms that perceived usefulness, perceived ease of use, IT trust, level of e-commerce adoption, security, and IT infrastructure significantly impact the adoption of m-commerce. Pipitwanichakarn and Wongtada (2019) extend TAM for investigating organizational m-commerce adoption in Thailand. The study indicates that perceived usefulness, perceived ease of use, trust, and entrepreneurial orientation are the critical determinants for the adoption of m-commerce.

These studies have identified numerous critical determinants for $\mathrm{m}$-commerce adoption in organizations within the extension of TAM. They, however, have ignored the effect 
of the important factors from both within and outside the organization (Chau et al. 2020). Table 2.5 presents a summary of these studies.

Table 2.5 A summary TAM-based studies on organizational m-commerce adoption

\begin{tabular}{|c|c|c|c|}
\hline Organizations & References & Methods & Findings \\
\hline \multirow{4}{*}{ One size fits all } & $\begin{array}{l}\text { Snowden et al. } \\
(2006)\end{array}$ & $\begin{array}{l}\text { Action } \\
\text { research }\end{array}$ & $\begin{array}{l}\text { Perceived usefulness, perceived ease of use, } \\
\text { complexity, individual differences, facilitating } \\
\text { conditions, social influences, wireless trust } \\
\text { environment. }\end{array}$ \\
\hline & Shih et al. (2010) & Survey & $\begin{array}{l}\text { Perceived usefulness, perceived ease of use, tool } \\
\text { experience. }\end{array}$ \\
\hline & $\begin{array}{l}\text { Mashagba et al. } \\
\text { (2013) }\end{array}$ & Survey & $\begin{array}{l}\text { Perceived usefulness, perceived ease of use, IT } \\
\text { trust, level of e-commerce adoption, security, IT } \\
\text { infrastructure. }\end{array}$ \\
\hline & $\begin{array}{l}\text { Pipitwanichakarn } \\
\text { and Wongtada } \\
\text { (2019) }\end{array}$ & Survey & $\begin{array}{l}\text { Perceived usefulness, perceived ease of use, trust, } \\
\text { entrepreneurial orientation. }\end{array}$ \\
\hline
\end{tabular}

The adoption of TOE for exploring m-commerce adoption in organizations states that there are three main aspects of an organization that influence the adoption of $\mathrm{m}$ commerce, namely technological aspect, organizational aspect, and environmental aspect (Tornatzky \& Fleischer 1990). Such a framework has been widely examined in organizational m-commerce adoption from different perspectives (Chau et al. 2020).

Doolin and Ali (2008), for example, employ TOE for investigating the critical determinants for the adoption of $\mathrm{m}$-commerce in business in New Zealand. The results confirm that relative advantage, compatibility, top management support, information intensity, the degree of organizational readiness, competitive intensity, and partner 
influence are critical for the adoption of m-commerce. Chen (2010) adopts TOE for identifying the critical determinants for m-commerce adoption in China, leading to the confirmation of the same critical determinants as those in the study of Doolin and Ali (2008). Jain et al. (2011) employ TOE for exploring the factors favoring m-commerce adoption in Indian micro, small and medium-sized enterprises. The results indicate that IS infrastructure, relative advantage, complexity, trialability, firm size, financial commitment, IS expertise, trading partner readiness, and external IS support are the critical determinants for the adoption of m-commerce.

Lu et al. (2015) adopt TOE for evaluating the factors affecting the decision to implement m-commerce in SMEs in Taiwan. This study identifies nine critical determinants including data security, network reliability, technology complexity, top management emphasis, employees' IS knowledge, firm size, competitive pressure, partner support, and regulatory support. Martin and Jimenez (2015) employ TOE for investigating the adoption of $\mathrm{m}$-commerce in Spanish firms. The results confirm the significance of various critical determinants including motivation, perceived benefits, managers' and employees' support, impediments to implement, perceived customer value, competitive pressure, and the propensity to innovation and ICT. Rana et al. (2019) adopt TOE for exploring barriers of m-commerce adoption in SMEs in the UK. The results indicate that perceived cost, perceived risk, inconvenience of use, compatibility issues, privacy and security issues, lack of technology knowledge, forced changes to business strategy, unawareness of benefits, lack of customer trust and confidence, and lack of external pressure are the critical determinants for the adoption of m-commerce. 
These TOE-based studies above have identified various critical determinants for $\mathrm{m}$ commerce adoption in organizations within the three aspects of the TOE framework. They, however, have not considered managerial factors which have been confirmed as significant factors in technology adoption in organizations (Alrousan \& Jones 2016). Table 2.6 presents a summary of these studies.

Table 2.6 A summary of TOE-based studies on organizational m-commerce adoption

\begin{tabular}{|c|c|c|c|}
\hline Organizations & References & Methods & Findings \\
\hline \multirow{3}{*}{ One size fits all } & $\begin{array}{l}\text { Doolin and } \\
\text { Ali (2008) }\end{array}$ & Case study & $\begin{array}{l}\text { Relative advantage, compatibility, top management } \\
\text { support, information intensity, organizational readiness, } \\
\text { competitive intensity, partner influence. }\end{array}$ \\
\hline & $\begin{array}{l}\text { Chen } \\
(2010)\end{array}$ & Case study & $\begin{array}{l}\text { Relative advantage, compatibility, top management } \\
\text { support, information intensity, organizational readiness, } \\
\text { competitive intensity, partner influence. }\end{array}$ \\
\hline & $\begin{array}{l}\text { Martin and } \\
\text { Jimenez } \\
\text { (2015) }\end{array}$ & Survey & $\begin{array}{l}\text { Perceived benefits, motivation, managers' and } \\
\text { employees' support, impediments, perceived customer } \\
\text { value, competitive pressure, the propensity to } \\
\text { innovation, and ICT. }\end{array}$ \\
\hline \multirow{3}{*}{ SMEs } & $\begin{array}{l}\text { Jain et al. } \\
(2011)\end{array}$ & Case study & $\begin{array}{l}\text { IS infrastructure, relative advantage, complexity, } \\
\text { trialability, firm size, financial commitment, IS } \\
\text { expertise, trading partner readiness, and external IS } \\
\text { support. }\end{array}$ \\
\hline & $\begin{array}{l}\text { Lu et al. } \\
(2015)\end{array}$ & Survey & $\begin{array}{l}\text { Data security, network reliability, technology } \\
\text { complexity, top management emphasis, employees' IS } \\
\text { knowledge, firm size, competitive pressure, partner } \\
\text { support, regulatory support. }\end{array}$ \\
\hline & $\begin{array}{l}\text { Rana et al. } \\
\text { (2019) }\end{array}$ & $\begin{array}{l}\text { Interpretive } \\
\text { structural } \\
\text { modelling }\end{array}$ & $\begin{array}{l}\text { Perceived cost, perceived risk, inconvenience of use, } \\
\text { compatibility issues, privacy and security issues, lack of } \\
\text { technology knowledge, forced changes to business } \\
\text { strategy, unawareness of benefits, lack of customer trust } \\
\text { and confidence, lack of external pressure }\end{array}$ \\
\hline
\end{tabular}


The employment of DOI for investigating m-commerce adoption in organizations assumes that such adoption is determined by the five main innovation-related characteristics including relative advantage, compatibility, complexity, trialability, and complexity (Rogers 2010). This theory has been commonly extended for exploring mcommerce adoption in organizations in various contexts.

Al-Qirim (2006), for example, employs DOI for investigating the adoption of $\mathrm{m}$ commerce in SMEs in New Zealand. The results confirm the significance of five critical determinants including relative advantage, compatibility, complexity, cost, and support from technology vendors. Johnson et al. (2018) use DOI for investigating m-commerce adoption in organizations in the United States. The results indicate that ease of use, relative advantage, visibility, and perceived security are the critical determinants for the adoption of m-commerce.

The use of TTF for understanding m-commerce adoption in organizations states that $\mathrm{m}$ commerce is likely to have a positive impact on the performance of individuals in the organization. As a result, it is to be adopted if its capabilities match the tasks that employees must perform (Goodhue \& Thompson 1995). Lee et al. (2007), for example, employ TTF for exploring the factors affecting $\mathrm{m}$-commerce adoption in insurance organizations. The results confirm that the applicability of m-commerce technologies for the insurance industry is critical for such adoption. Liang et al. (2007) employ FVM as an extension of TFF for investigating the adoption of m-commerce in organizations. The results confirm the significance of the fitness and viability in the adoption of such technologies in organizations. 
The employment of UTAUT for investigating organizational m-commerce adoption states that there are four key constructs including performance expectancy, effort expectancy, social influence, and facilitating conditions that are the direct determinants of m-commerce usage intention and behavior (Venkatesh et al. 2003). Gao and Shao (2018), for example, extend UTAUT for examining m-commerce adoption in the shipping industry in China. The results confirm the significance of eight critical determinants including cost reduction, time-saving, effort expectancy, quality improvement, partner trust, technology trust, facilitating conditions, and intention of the up-down.

The use of the grounded theory for exploring m-commerce adoption in organizations is involved in the use of a deductive reasoning methodology, beginning with a question or the collection of qualitative data. From the analysis of such data, repeated ideas, concepts, or elements are extracted and grouped into categories. These categories become the critical determinants for the adoption of m-commerce. Waithaka and Mnkandla (2017), for example, employ the grounded theory for analyzing the interview data to explore the challenges facing the use of m-commerce in Kenyan SMEs in the manufacturing industry. The study finds that technological issues, security concerns, cost issues, environmental concerns, and computer literacy are the critical determinants for the use of m-commerce. Utami et al. (2019) adopt the grounded theory for analyzing the data from interviews, observation, and related documents to understand the critical factors affecting the adoption of $\mathrm{m}$-commerce in Indonesian SMEs. The study reveals that a wider business network, increasing sales, adding resellers and buyers, smooth business transactions, development of product innovation, process and marketing, the 
facilities provided by the government, and easy to use m-commerce applications are the critical determinants for m-commerce adoption.

The adoption of the institutional theory for examining organizational m-commerce adoption emphasizes that institutional environments have a strong influence on the decision to adopt m-commerce in organizations. It states that mimetic, coercive, and normative pressures significantly influence the adoption of $\mathrm{m}$-commerce in organizations. Li and Wang (2018), for example, employ the institutional theory for investigating m-commerce adoption in Chinese SMEs. The results indicate the direct effects of mimetic pressures, coercive pressures, and normative pressures on the intention of SMEs to adopt m-commerce. Table 2.7 presents a summary of these studies. 
Table 2.7 A summary of theory-specific studies on organizational m-commerce adoption

\begin{tabular}{|c|c|c|c|c|}
\hline Organizations & References & Theories & Methods & Findings \\
\hline \multirow{4}{*}{ One size fits all } & $\begin{array}{l}\text { Lee et al. } \\
(2007)\end{array}$ & TTF & Survey & $\begin{array}{l}\text { The fit between m-commerce } \\
\text { technology and insurance tasks, } \\
\text { individual differences. }\end{array}$ \\
\hline & $\begin{array}{l}\text { Liang et al. } \\
\text { (2007) }\end{array}$ & FVM & Survey & $\begin{array}{l}\text { The fitness and viability of } \\
\text { implementing mobile technologies in } \\
\text { organizations. }\end{array}$ \\
\hline & $\begin{array}{l}\text { Johnson et } \\
\text { al. (2018) }\end{array}$ & DOI & Survey & $\begin{array}{l}\text { Ease of use, relative advantage, } \\
\text { visibility, perceived security. }\end{array}$ \\
\hline & $\begin{array}{l}\text { Gao and } \\
\text { Shao (2018) }\end{array}$ & $\begin{array}{l}\text { Extended } \\
\text { UTAUT }\end{array}$ & Survey & $\begin{array}{l}\text { Cost reduction, time-saving, effort } \\
\text { expectancy, quality improvement, } \\
\text { partner trust, technology trust, } \\
\text { facilitating conditions, and intention of } \\
\text { the up-down. }\end{array}$ \\
\hline \multirow{4}{*}{ SMEs } & $\begin{array}{l}\text { Al-Qirim } \\
\text { (2006) }\end{array}$ & DOI & Survey & $\begin{array}{l}\text { Perceived usefulness, perceived ease of } \\
\text { use, complexity, individual differences, } \\
\text { facilitating conditions, social } \\
\text { influences, wireless trust environment. }\end{array}$ \\
\hline & $\begin{array}{l}\text { Waithaka } \\
\text { and } \\
\text { Mnkandla } \\
\text { (2017) }\end{array}$ & $\begin{array}{l}\text { Grounded } \\
\text { theory }\end{array}$ & Interview & $\begin{array}{l}\text { Technological issues, security } \\
\text { concerns, cost issues, environmental } \\
\text { concerns, computer literacy. }\end{array}$ \\
\hline & $\begin{array}{ll}\mathrm{Li} & \text { and } \\
\text { Wang } & \\
(2018) & \end{array}$ & $\begin{array}{l}\text { Institutional } \\
\text { theory }\end{array}$ & Survey & $\begin{array}{l}\text { Mimetic pressures, coercive pressure, } \\
\text { normative pressure, top management } \\
\text { support. }\end{array}$ \\
\hline & $\begin{array}{l}\text { Utami et al. } \\
\text { (2019) }\end{array}$ & $\begin{array}{l}\text { Grounded } \\
\text { theory }\end{array}$ & $\begin{array}{l}\text { Interview, } \\
\text { observations, } \\
\text { and } \\
\text { documents }\end{array}$ & $\begin{array}{l}\text { Wider business network, increasing } \\
\text { sales, adding resellers and buyers, } \\
\text { smooth business transactions, } \\
\text { development of product innovation, } \\
\text { process, and marketing, the facilities } \\
\text { provided by the government, easy to } \\
\text { use m-commerce applications. }\end{array}$ \\
\hline
\end{tabular}


Given the characteristics of mobile technologies and the complex environment in which an organization is operating, integrating several theories into a single framework offers a richer theoretical base for explaining organizational m-commerce adoption. As a result, a combination of several theories is commonly used for better investigating the critical determinants for $\mathrm{m}$-commerce adoption in organizations. Table 2.8 presents a summary of such integration in the literature.

Table 2.8 An overview of the integrated theoretical perspectives

\begin{tabular}{ll}
\multicolumn{1}{c}{ Integrated Theories } & \multicolumn{1}{c}{ References } \\
\hline TOE + DOI & Otieno and Kahonge (2014) \\
\hline TOE + RBT & Picoto et al. (2014b) \\
\hline TOE + Relational context & Martin et al. (2012) \\
\hline TOE + DOI + RBT & Picoto et al. (2012); Picoto et al. (2014a) \\
\hline TOE + TAM + DOI + TRA + TPB & Alfahl et al. (2017) \\
\hline TOE + TAM + DOI + FVM + UTAUT & Van den Berg and Van der Lingen (2019) \\
\hline TAM + DOI & Grandhi and Wibowo (2016); Amegbe et al. (2017) \\
\hline TAM + DOI + TRA & Alrawabdeh (2014); Sun and Chi (2018) \\
\hline UTAUT + TTF & Prasarry et al. (2015) \\
\hline Institutional theory + Relational context & Swilley (2007) \\
\hline
\end{tabular}

TOE is combined with other theories to have a better explanation for the adoption of $\mathrm{m}$ commerce in organizations. Martin et al. (2012), for instance, integrate TOE into a relational context for identifying the critical determinants for the adoption of $\mathrm{m}$ commerce. The results confirm three critical determinants including technological competence, fitness between the organization's activity and m-commerce, and perceived customer value. Picoto et al. (2012) and Picoto et al. (2014a) combine TOE 
with DOI and RBT for investigating the critical factors affecting the use of mobile business in Portugal organizations. The findings indicate that relative advantage, technology competence, technology integration, managerial obstacles, competitive pressure, partner pressure, and mobile environment significantly affect such adoption. Picoto et al. (2014b) conduct another study on the adoption of organizational mobile business with the combination of TOE and RBT. This study leads to the identification of four critical determinants including technology competence, managerial obstacles, competitive pressure, and partner pressure for mobile business adoption.

Otieno and Kahonge (2014) integrate TOE with DOI for investigating the adoption of mobile payment in Kenyan SMEs. The results indicate eleven critical determinants including benefits, friendliness, security, managerial support, organizational size, organizational readiness, firm scope, mimetic pressure from competitors, coercive pressure from clients, normative pressure, and intensity of competition. Alfahl et al. (2017) integrate TOE with TAM, DOI, TRA, and TPB for exploring m-commerce adoption in Saudi organizations. The results confirm that relative advantages, perceived usefulness, perceived ease of use, complexity, compatibility, job-fit, policy and legal environment, organizational policy, ICT infrastructure, organizational culture, top management support, subjective norms, social factors, security, and trust are the critical determinants for the adoption of m-commerce. Van den Berg and Van der Lingen (2019) integrate TOE with TAM, DOI, FVM, and UTAUT for examining the critical factors affecting the adoption of mobile enterprise applications in South Africa. The findings confirm the significance of nine critical determinants including performance utility, technology usability, enterprise readiness, technology infrastructure readiness, 
process readiness, the technology strategy of an organization, employee readiness, knowledge readiness, resource readiness, and external environment. Table 2.9 presents a summary of these studies discussed above.

Table 2.9 A summary of TOE integrated studies on organizational m-commerce adoption

\begin{tabular}{|c|c|c|c|c|}
\hline Organizations & References & $\begin{array}{c}\text { Integrated } \\
\text { Theories }\end{array}$ & Methods & Findings \\
\hline \multirow{5}{*}{ One size fits all } & $\begin{array}{l}\text { Martin et al. } \\
\text { (2012) }\end{array}$ & $\begin{array}{l}\text { Relational } \\
\text { context }\end{array}$ & Survey & $\begin{array}{l}\text { Technological Competence, the fit of the } \\
\text { organization's activity to m-commerce, the } \\
\text { value of the customer. }\end{array}$ \\
\hline & $\begin{array}{l}\text { Picoto et al. } \\
(2012) \text {; } \\
\text { Picoto et al. } \\
(2014 a)\end{array}$ & $\begin{array}{ll}\text { DOI and } \\
\text { RBT }\end{array}$ & Mixed & $\begin{array}{l}\text { Relative advantage, technology competence, } \\
\text { technology integration, managerial } \\
\text { obstacles, competitive pressure, partner } \\
\text { pressure, mobile environment. }\end{array}$ \\
\hline & $\begin{array}{l}\text { Picoto et al. } \\
\text { (2014b) }\end{array}$ & RBT & Survey & $\begin{array}{l}\text { Technology competence, managerial } \\
\text { obstacles, competitive pressure, partner } \\
\text { pressure. }\end{array}$ \\
\hline & $\begin{array}{l}\text { Alfahl et al. } \\
\text { (2017) }\end{array}$ & $\begin{array}{l}\text { TAM, } \\
\text { DOI, TPB } \\
\text { and TRA }\end{array}$ & Interview & $\begin{array}{l}\text { Relative advantage, perceived usefulness, } \\
\text { perceived ease of use, complexity, } \\
\text { compatibility, job-fit, organizational policy, } \\
\text { ICT infrastructure, organizational culture, } \\
\text { policy \& legal environment, top } \\
\text { management support, Subjective norms, } \\
\text { social factors, security, and trust. }\end{array}$ \\
\hline & $\begin{array}{ll}\text { Van } & \text { den } \\
\text { Berg } & \text { and } \\
\text { Van } & \text { der } \\
\text { Lingen } & \\
\text { (2019) } & \end{array}$ & $\begin{array}{l}\text { TAM, } \\
\text { DOI, FVM } \\
\text { and } \\
\text { UTAUT }\end{array}$ & Survey & $\begin{array}{l}\text { Performance utility, Technology usability, } \\
\text { enterprise readiness, Technology } \\
\text { infrastructure readiness, Process readiness, } \\
\text { The technology strategy of an organization, } \\
\text { Employee readiness, Knowledge readiness, } \\
\text { Resource readiness, external environment. }\end{array}$ \\
\hline SMEs & $\begin{array}{l}\text { Otieno and } \\
\text { Kahonge } \\
(2014)\end{array}$ & DOI & Survey & $\begin{array}{l}\text { Benefits, friendliness, security, managerial } \\
\text { support, organizational size, organizational } \\
\text { readiness, firm scope, mimetic pressure } \\
\text { from competitors, coercive pressure from } \\
\text { clients, normative pressure, the intensity of } \\
\text { competition. }\end{array}$ \\
\hline
\end{tabular}


TAM has been combined with other theories for investigating the adoption of $\mathrm{m}$ commerce in organizations. Alrawabdeh (2014), for example, combines TAM with DOI and TRA for investigating the environmental factors affecting $\mathrm{m}$-commerce adoption in telecommunication organizations in Jordan. The results confirm that competitive pressure, regulatory environment, social influence, support industries, customer pressure, and government pressure are the critical determinant of m-commerce adoption. Grandhi and Wibowo (2016) integrate TAM with DOI for examining the organizational factors affecting m-commerce adoption in Organizations in North America. The results indicate four critical determinants including organization strategy, perceived business benefits, inhibitors, and interface design features. Amegbe et al. (2017) combine TAM and DOI for investigating the use of mobile money and mcommerce in SMEs in Ghana. The results confirm the significance of seven critical determinants including perceived trust, perceived risk, technology failure, perceived usefulness, perceived cost-effectiveness, convenience, and perceived ease of use. Table 2.10 presents a summary of these studies. 
Table 2.10 A summary of TAM integrated studies on organizational m-commerce adoption

\begin{tabular}{|c|c|c|c|c|}
\hline Organizations & References & $\begin{array}{c}\text { Integrated } \\
\text { Theories }\end{array}$ & Methods & Findings \\
\hline \multirow[t]{2}{*}{ One size fits all } & $\begin{array}{l}\text { Alrawabdeh } \\
\text { (2014) }\end{array}$ & $\begin{array}{ll}\text { DOI and } \\
\text { TRA }\end{array}$ & Survey & $\begin{array}{l}\text { Competitive pressure, regulatory } \\
\text { environment, social influence, support } \\
\text { industries, customer pressure, } \\
\text { government pressure. }\end{array}$ \\
\hline & $\begin{array}{l}\text { Grandhi and } \\
\text { Wibowo } \\
\text { (2016) }\end{array}$ & DOI & $\begin{array}{l}\text { Secondary } \\
\text { data }\end{array}$ & $\begin{array}{l}\text { Organization strategy, perceived } \\
\text { business benefits, inhibitors, interface } \\
\text { design features. }\end{array}$ \\
\hline SMEs & $\begin{array}{l}\text { Amegbe et } \\
\text { al. (2017) }\end{array}$ & DOI & Survey & $\begin{array}{l}\text { Perceived trust, perceived risk, } \\
\text { technology failure, perceived usefulness, } \\
\text { perceived cost-effectiveness, } \\
\text { convenience, perceived ease of use. }\end{array}$ \\
\hline
\end{tabular}

In addition to popular theories such as TOE, TAM, and DOI, other theories have also been integrated for examining the critical determinants of organizational m-commerce adoption. Swilley (2007), for example, combines the institutional theory and the relational context for investigating the intention to adopt m-commerce in organizations in the United States. The results confirm seven critical determinants including perceived competitor adoption, perceived competitor success, top management championship, perceived governmental regulations, perceived dominance of supplier adopters, perceived dominance of customer adopters, and perceived social network adoption. Prasarry et al. (2015) integrate UTAUT with TTF for investigating the adoption of mcommerce in Indonesian SMEs. The results indicate three critical determinants, namely performance expectancy, effort expectancy, and the fit between m-commerce technologies and organizational tasks. Table 2.11 presents a summary of these studies. 
Table 2.11 A summary of other integrated studies on organizational m-commerce adoption

\begin{tabular}{|c|c|c|c|c|}
\hline Organizations & References & Theories & Methods & Findings \\
\hline One size fits all & Swilley (2007) & $\begin{array}{l}\text { Institutional } \\
\text { theory and } \\
\text { relational } \\
\text { context }\end{array}$ & Survey & $\begin{array}{l}\text { Perceived competitor adoption, } \\
\text { Perceived competitor success, top } \\
\text { management championship, perceived } \\
\text { governmental regulations, perceived } \\
\text { dominance of supplier adopters, } \\
\text { perceived dominance of customer } \\
\text { adopters, perceived social network } \\
\text { adoption. }\end{array}$ \\
\hline SMEs & $\begin{array}{l}\text { Prasarry et al. } \\
(2015)\end{array}$ & $\begin{array}{l}\text { UTAUT and } \\
\text { TTF }\end{array}$ & Survey & $\begin{array}{l}\text { Performance expectancy, effort } \\
\text { expectancy, fit between m-commerce } \\
\text { technologies and organizational tasks. }\end{array}$ \\
\hline
\end{tabular}

In summary, existing studies have proposed and tested different frameworks for investigating the adoption of $\mathrm{m}$-commerce in organizations from different perspectives. These lead to the identification of various critical determinants for organizational mcommerce adoption. These studies, however, do not have a general agreement on the critical determinants for m-commerce adoption in organizations. Furthermore, the findings of these studies cannot be fully applied to explain m-commerce adoption in SMEs in developing countries. This is due to (a) the lack of empirical evidence for the generalizability of the findings, (b) overlooking the unique characteristics of SMEs in the adoption of m-commerce, (c) overlooking the characteristics of developing countries in the adoption of new technologies and (d) the lack of empirical results for mcommerce adoption in SMEs in the context of developing countries. These limitations call for the development of a comprehensive framework for exploring the critical determinants for m-commerce adoption in SMEs in the context of developing countries. 


\subsection{Concluding Remarks}

This chapter provides a comprehensive review of the related literature relevant to the adoption of m-commerce in Vietnamese SMEs. This highlights the significance of conducting this research. More specifically, different definitions of SMEs are discussed, leading to the selection of a common definition of Vietnamese SMEs using for the context of this study. It also discusses the role of SMEs in the Vietnamese economy for highlighting the importance of promoting the adoption of the latest technologies in Vietnamese SMEs to maintain their competitive advantages. The unique characteristics of SMEs in the adoption of technology are discussed to raise the need for an appropriate framework for investigating the critical determinants of m-commerce adoption in Vietnamese SMEs. A comprehensive analysis of existing organizational m-commerce adoption studies is conducted, justifying the need for conducting the current research. This paves the way for the identification of the critical determinants to be included in the conceptual framework in Chapter 3. 


\section{Chapter 3}

\section{A Conceptual Framework}

\subsection{Introduction}

A conceptual framework consists of a set of constructs and their hypothesized relationships to be empirically tested for better understanding specific phenomena in a given situation (Almukhlifi, Deng \& Kam 2019). It is critical for the success of specific research projects. This is because such a conceptual framework help to show the logical sense of the relationships between the identified constructs that provide the foundation for testing these relationships (Sekaran \& Bougie 2016).

This study aims to explore the critical determinants for m-commerce adoption in Vietnamese SMEs. To adequately accomplish this aim, a conceptual framework is required for facilitating the identification of the critical determinants for $\mathrm{m}$-commerce adoption in Vietnamese SMEs. Such a framework provides a basis for developing the questionnaire that helps to answer the research question in the study.

This chapter develops a conceptual framework for investigating the critical determinants of m-commerce adoption in Vietnamese SMEs based on a comprehensive review of the related literature in the context of m-commerce adoption from different perspectives. Such a framework supports to hypothesize the critical determinants for the adoption of 
m-commerce in Vietnamese SMEs. This facilitates the implementation of the quantitative methodology for achieving the objective of this research.

The rest of the chapter is organized into four sections. Section 3.2 presents a review of the existing theories of technology adoption in organizations for guiding the development of the conceptual framework. Section 3.3 discusses the integration of several theories for investigating the adoption of technology in organizations and justifying the selection of TOE and DOI as the theoretical foundation for this study. Section 3.4 conceptualizes the framework with a focus on the critical determinants for m-commerce adoption in Vietnamese SMEs. Section 3.5 ends the chapter with some concluding remarks.

\subsection{Theoretical Background}

There are numerous theories for investigating the adoption of technology from the perspective of individuals and organizations. This study aims to identify the critical determinants for m-commerce adoption in Vietnamese SMEs. As a result, this section reviews and discusses the prominent theories for exploring the adoption of technology in organizations including the diffusion of innovation theory, the technologyorganization-environment framework, the resource-based theory, and the institutional theory. These theories investigate the adoption of technology in organizations by (a) examining specific stages in the adoption of technology in organizations (Rogers 1995) and (b) proposing a variety of factors for investigating the adoption of technology in organizations (Jeyaraj, Rottman \& Lacity 2006). 


\subsubsection{The Diffusion of Innovation Theory}

DOI is a process-based framework for explaining how, why, and at what rate that technology is adopted in an organization (Rogers 2003). It describes the pattern of adoption, illustrates the process, and assists in understanding whether and how the adoption of technology will be successful (Rogers 1995). DOI is also used to describe the process of technology diffusion as the process by which an innovation is communicated through certain channels over time among the members of a social system (Rogers 1995).

The innovation diffusion process occurs in stages before and after the adoption decision (Rogers 1995). These stages assist investigators in understanding the factors and events in the diffusion process. Figure 3.1 presents Rogers's five stages of the diffusion decision process including knowledge, persuasion, decision, implementation, and decision. In the knowledge stage, the organization gains an initial understanding of the innovation and its issues and outcomes to proceed. In the persuasion stage, the organization seeks reassurance from the innovator regarding the issues they raise. In the decision stage, the organization accepts or rejects the innovation based on existing knowledge, experience, and information from the innovator. In the implementation

stage, the organization harbors concern regarding the innovation, balanced by enthusiasm based on the innovator's claims. Finally, the decision regarding the adoption or rejection of the innovation is confirmed or reversed in the confirmation stage. 
1. Previous Practice

2. Felt needs/problems

3. Innovativeness

4. Norms of the social systems

Characteristics of the Decision-Making Unit

1. Socioeconomic Characteristics

2. Personality Variables

3. Communication Behaviour

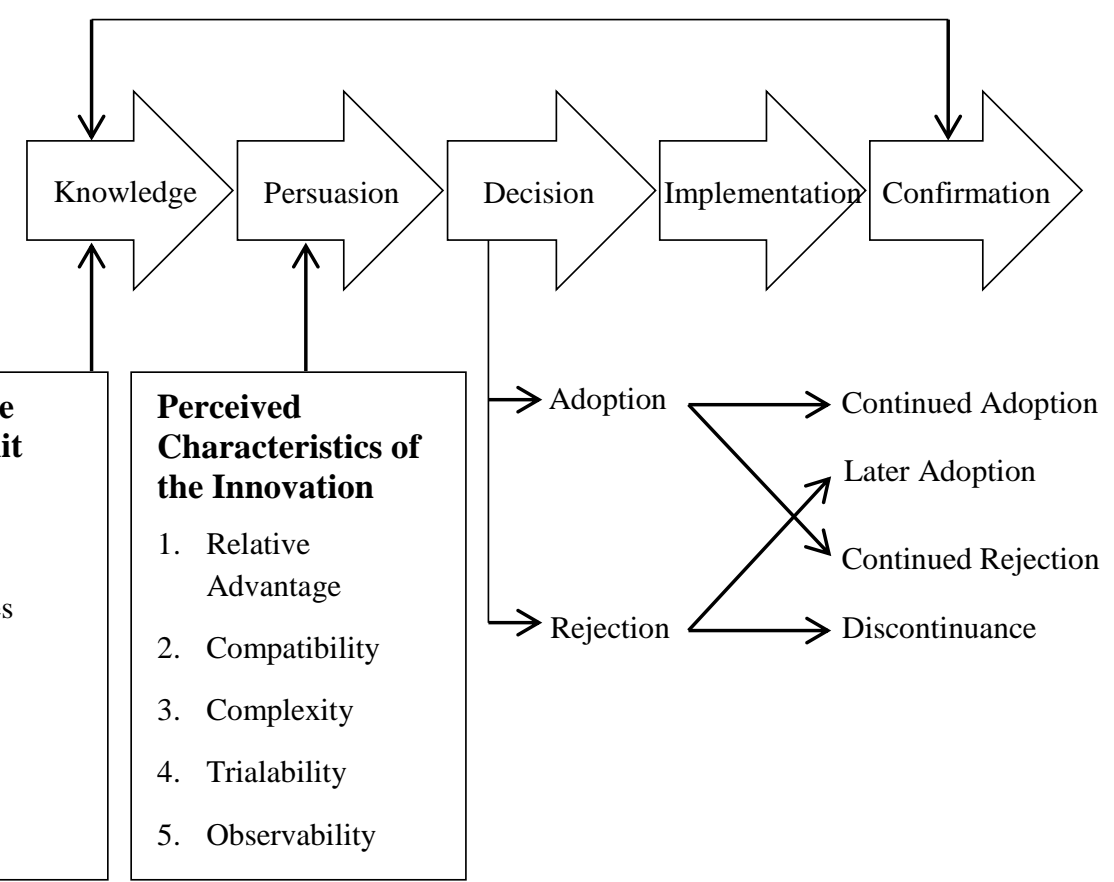

Figure 3.1 Stages in the innovation diffusion process

DOI identifies five characteristics of a specific technology that influence the adoption of such a technology in organizations including relative advantage, compatibility, complexity, trialability, and observability. The relative advantage refers to the degree to which the technology is perceived as better than the one it supersedes (Rogers 1995). The compatibility is about the degree to which the technology is perceived as being consistent with the existing experiences, values, and needs of potential adopters (Rogers 1995). The complexity refers to the degree to which the technology is perceived as difficult to understand and use (Rogers 1995). The trialability is about the degree to which the technology may be experimented with on a limited basis (Rogers 1995). The observability is related to the degree to which the results of adopting the technology are visible to others (Rogers 1995). These characteristics affect the process of technology adoption under various circumstances. 
DOI is the most influential theory in innovation adoption studies as it proposes a comprehensive framework for understanding the technology adoption process in organizations (Chau et al. 2020). It proposes the fundamental determinants for investigating the adoption of technology by organizations. As a result, the DOI theory, particular the characteristics of the technology are widely used as the theoretical basis in numerous empirical studies for identifying the critical determinants of technology adoption in organizations, especially SMEs (Karahanna, Straub \& Chervany 1999; Beatty, Shim \& Jones 2002; Bradford \& Florin 2003; Zhu, Kraemer \& Xu 2006; Seyal, Rahman \& Mohammad 2007; Alam et al. 2008; Wu \& Chuang 2010). Karahanna et al. (1999), for example, employ DOI for exploring the adoption of IT in organizations. Beatty et al. (2002) adopt DOI for investigating website adoption in organizations. Bradford and Florin (2003) use DOI for examining the adoption of ERP in organizations. Zhu et al. (2006) apply DOI for investigating the adoption of e-business in organizations. Seyal et al. (2007) adopt DOI to exploring the adoption of electronic data interchange (EDI) in SMEs. Alam et al. (2008) employ DOI for investigating the adoption of e-commerce in SMEs. Wu and Chuang (2010) apply DOI for examining the adoption of the e-supply chain in organizations.

DOI remains a popular model for investigating the adoption of innovation in organizations. It, however, has received substantial criticism in its application at the organizational level (Chau \& Tam 1997). First, DOI cannot address the full technology implementation process. It does not provide a rationale for determining whether the innovation is put into use by the adopter. Second, it does not provide a lens for examining the nature of the relationship between organizational and individual decision- 
making and the complex social contexts in which organizations make decisions (Parker \& Castleman 2009). Third, DOI tends to ignore the influence of the organizational and environmental factors in the adoption of technology (Lee \& Cheung 2004). It assumes that the adoption of technology is a rationalistic decision that mainly aims to improve the technical efficiency of organizations (Teo, Wei \& Benbasat 2003).

M-commerce is complex organizational technology. The adoption of such a technology is influenced by organizational factors and external environments in which SMEs are embedded in (Alrousan \& Jones 2016). As a result, the classical assimilation variables by the DOI are unlikely to be strong predictors of such adoption. This means that a proper consideration of organizational and environmental factors for the adoption of $\mathrm{m}$ commerce in SMEs is highly desirable for better outcomes (Perez et al. 2004).

\subsubsection{Technology-Organization-Environment Framework}

TOE examines the overall contextual basis for the adoption of technology in organizations. It is an organization-level theory of technology adoption that describes how the firm context influences the adoption of technological innovations (Baker 2012). TOE consists of three contexts for identifying the factors that can influence the process by which an organization adopts a technological innovation including the organizational context, the technological context, and the external environment context.

The technological context is about the availability of technologies that are external or internal to the organization (Tornatzky \& Fleischer 1990). The organizational context is related to the characteristics of an organization and the internal resources available to an 
organization that encourages or discourages the adoption of technological innovation. The environmental context is linked to the business environment of an organization and its dealings with trading partners, competitors, and governments (Tornatzky \& Fleischer 1990). These contexts make a useful analytical framework for investigating the adoption of various technological innovations (Scupola 2003; Chuang et al. 2007; Chau, Deng \& Tay 2021). As a result, TOE becomes a comprehensive theoretical lens for understanding technology adoption at the organizational level (Sila 2013).

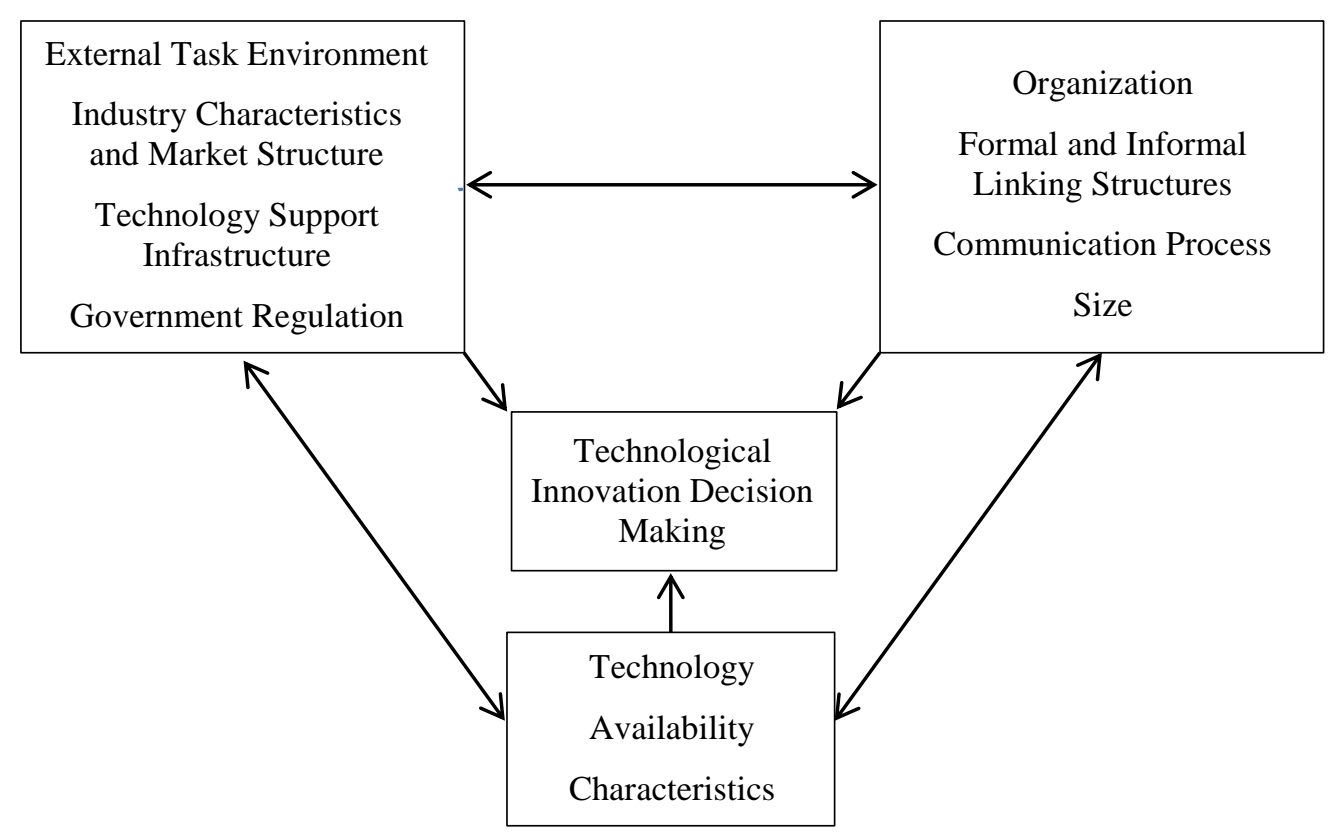

Figure 3.2 The TOE framework

The usefulness of TOE in studying the adoption of technology in organizations is well demonstrated in the existing research (Iacovou, Benbasat \& Dexter 1995; Zhu, Kraemer \& Dedrick 2004; Teo, Ranganathan \& Dhaliwal 2006; Pan \& Jang 2008; Gibbs \& Kraemer 2010; Sila 2013). Iacovou et al. (1995), for example, employ TOE for investigating the adoption of EDI in small businesses. Zhu et al. (2004) adopt TOE for 
comparing the adoption of e-business between organizations in developing and developed countries. Teo et al. (2006) adopt TOE to identify the inhibitors of the adoption of B2B e-commerce. Pan and Jang (2008) apply TOE for examining the determinants for adopting enterprise resource planning systems (ERP) in the communication industry in Taiwan. Teo, Lin and Lai (2009) employ TOE for investigating the critical factors associated with the adoption of e-procurement in organizations in Singapore. Gibbs and Kraemer (2010) extend TOE for investigating the determinants of e-commerce adoption in organizations. Sila (2013) adopt TOE to identify the critical factors affecting the adoption of B2B e-commerce technologies in organizations in Canada.

TOE is a solid theoretical basis for identifying the critical determinants for technology adoption in organizations (Oliveira \& Martins 2010). It does not, however, identify in depth the managerial factors where SME managers are considered the most critical decision-makers in adopting technologies (Hashim 2007). As a result, there is a need for expanding TOE by adding the fourth context that comprehensively describes the role of managerial factors in investigating technology adoption in organizations (Thong 1999; Bao \& Sun 2010; Alamro \& Tarawneh 2011).

In summary, TOE is a flexible framework that can be extended to accept more categories and factors that help to identify the critical determinants for technology adoption in organizations (Zhu et al. 2006). Additionally, a possible advantage of the TOE framework is that it introduces a broader scope and provides links between the three contextual elements. As a result, it provides the potential for including broader 
aspects associated with cultural differences and industry type in exploring technology adoption in organizations (Oliveira \& Martins 2011).

\subsubsection{Resource-Based Theory}

RBT looks inward into the organization's resources for competitive advantages (Peppard \& Ward 2004; Wade \& Hulland 2004). It states that an organization can gain a sustainable competitive advantage by carefully exploiting and developing the various resources it has (Barney 1991; Caldeira \& Ward 2003; Galbreath 2005; Parker \& Castleman 2009) or those that are in the external environment (Jarvenpaa \& Leidner 1998; Ray \& Ray 2006). RBT indicates that organizational resources must possess the following characteristics for contributing to competitive organizational advantages: (a) they must have strategic value to the organization, (b) they must be unique and rare to find, (c) they must not be possible to perfectly imitate or copy, and (d) the competitors cannot substitute these resources by other alternative resources to achieve the same results.

\begin{tabular}{|c|c|c|c|c|}
\hline \multicolumn{3}{|c|}{ Competitive Advantage Phase } & & Sustainability Phase \\
\hline $\begin{array}{l}\text { Productive use of } \\
\text { firm resources } \\
\text { which are... } \\
\text { - } \quad \text { Valuable } \\
\text { - } \quad \text { Rare } \\
\text { - } \quad \text { Appropriable }\end{array}$ & leads to & $\begin{array}{l}\text { Short term } \\
\text { competitive } \\
\text { advantage }\end{array}$ & which & $\begin{array}{l}\text { Is sustained over } \\
\text { time due to } \\
\text { resource... } \\
\text { - } \quad \text { Imitability } \\
\text { - } \quad \text { Substitutability } \\
-\quad \text { Mobility }\end{array}$ \\
\hline
\end{tabular}

Figure 3.3 The resource-based view over time 
RBT takes an "inside-out" or organization-specific perspective by focusing on the internal resources as the major determinant of its competitive success (Dicksen 1996). Based on the perspective of RBT, innovation does not come simply from scanning the external environment in searching for market opportunities, but from looking inside the organization to develop and build on core competencies. This indicates that the ability to innovate is related to the resources that an organization has (Del Canto \& Gonzalez 1999). As a result, an organization may not be able to adopt an innovation if it does not have the mix of required assets or capabilities.

With these above discussions, there is an important relationship between the resources and capabilities of an organization and its ability to adopt an innovation. Innovation is partly a function of the internal resources of the organization. As a result, it should consider not only the factors related to the innovation itself but also the ability of the organization to adopt the innovation, which is reflected by the resources and capabilities possessed by the organization when investigating innovation adoption in organizations.

The usefulness of RBT in studying the adoption of technologies in organizations is well demonstrated in the existing research (Conner 1991; Mata, Fuerst \& Barney 1995; Campbell \& Luchs 1997; Caldeira \& Ward 2003). Conner (1991), for example, employs RBT for investigating the adoption of new technologies in organizations, leading to the identification of the technical knowledge and skills of employees as the critical determinants. Mata et al. (1995) apply RBT for examining the adoption of IT and sustained competitive advantages of organizations, leading to the identification of managerial IT skills as the critical determinants. Campbell and Luchs (1997) adopt RBT 
for exploring technology adoption in organizations, leading to the identification of past experiences, organizational culture, and competences as the critical determinants. Caldeira and Ward (2003) employ RBT for investigating IS and technology adoption in manufacturing SMEs, leading to the identification of IT and IS capabilities including IT and IS leadership business system thinking, relationship building, architecture planning, making technology work, informed buying, contract monitoring, and vendor development as the critical determinants.

RBT has been widely adopted for investigating technology adoption in organizations. This is due to its ability to (a) provide a theoretical basis for understanding the role of technologies as the internal resources for the organization to gain competitive advantages (Zhu \& Kraemer 2005) and (b) investigate the importance of internal resources of an organization in the adoption of technology (Caldeira \& Ward 2003). It, however, focuses on the properties of internal resources for explaining the adoption of technology in organizations. It does not investigate the influence of environmental factors on the decision to adopt technologies in organizations (Oliver 1997). Technology adoption in organizations is a complex process with the involvement of various factors (Chau et al. 2020). For this reason, RBT is not sufficient for explaining the adoption of technology in SMEs.

\subsubsection{Institutional Theory}

The institutional theory is used for understanding how specific social behaviors are created, diffused, adopted, and adapted over space and time (Alkalbani, Deng \& Kam 2019). It investigates how social behavior falls into decline and disuse, provided with 
the existence of the schemas, rules, norms, and routines as authoritative guidelines for such a social behavior (Selznick 1948).

The institutional theory has traditionally been used to describe how individual entities in an institutional field, in the context of their environment, face pressures to conform to shared behavior and norms. It then investigates how these pressures shape their decisions over time, leading to a certain isomorphism in behavior and structure (Chatterjee, Grewal \& Sambamurthy 2002). As organizations compete for resources, customers, political power, and economic and social fitness (Carroll \& Delacroix 1982), they face pressures to conform to these shared notions of appropriate forms and behaviors (DiMaggio \& Powell 1983; Tolbert 1985).

There are three basic types of institutional pressures including mimetic pressures, coercive pressures, and normative pressures (DiMaggio \& Powell 1983; Alkalbani, Deng \& Kam 2015). Mimetic pressures are copying or mimicking behaviors that are the result of organizational response to the uncertainty. Coercive pressures stem from political influence and organizational legitimacy, often conveyed through laws, regulations, and accreditation processes. Normative pressures are associated with professional values (DiMaggio \& Powell 1983). Such types of pressures reflect three analytically-distinct processes of institutionalization. Figure 3.4 illustrates the influence of these types of pressures on organizational decision-making and strategic organizational responses. 


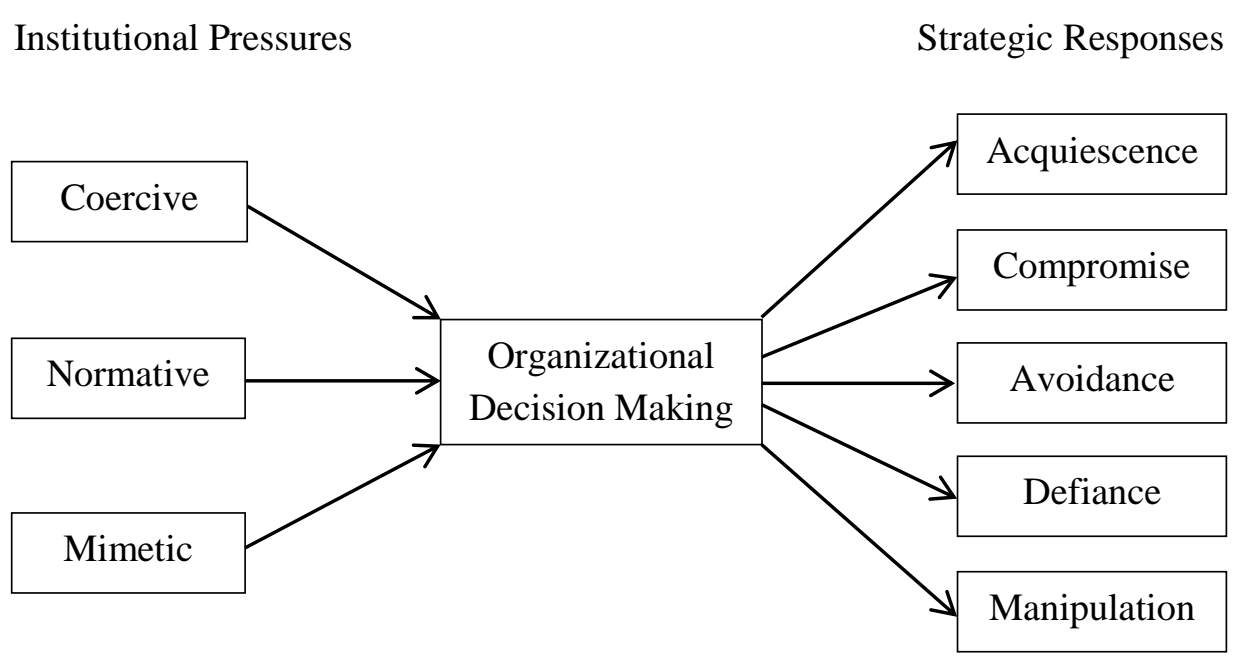

Figure 3.4 Institutional theory

Mimetic pressures imply that organizations become more similar to other organizations in their environment over time (DiMaggio \& Powell 1983). An organization imitates the actions of other structurally equivalent organizations because those organizations occupy a similar economic network position in the same industry. As a result, they share similar goals, produce similar commodities, share similar customers and suppliers, and experience similar constraints (Burt 1987). An organization faces high levels of mimetic pressure when an increasing number of organizations in its environment is beneficial or successful in adopting technologies for improving their competitive advantages (Duan 2012).

Coercive pressures are about formal or informal pressures exerted on organizations by other organizations upon which they are dependent (DiMaggio \& Powell 1983). Such organizations include trading partners such as customers and suppliers in exchange for relationships, investors, government regulatory agencies, and parent corporations (Srinivasan, Lilien \& Rangaswamy 2002). These pressures may take several forms such 
as force, threats, persuasion, and invitations to join in collusion (DiMaggio \& Powell 1983).

Normative pressures imply that strategic processes taken by organizations are subject to the values and norms shared among the members of their social networks (Scott 2004). Organizations will likely adjust their behavior based on their beliefs about what members in their social networks view as appropriate (Deephouse 1996). There are a variety of sources that may exert normative pressures. Such sources include trade associations, professional associations, accreditation agencies, and channel members (Grewal \& Dharwadkar 2002).

The institutional theory has been widely used in social science and management literature (Mizruchi \& Fein 1999). In the technology adoption context, the institutional theory posits that the decision making in organizations about the adoption of technologies is influenced by various pressures arising from the external environment (DiMaggio \& Powell 1983; Scott 2004). From this basis, the institutional theory has been widely applied in IS research. Chatterjee et al. (2002), for example, adopt the institutional theory for investigating institutional enablers of the organizational assimilation of web technologies. Teo et al. (2003) adopt the institutional theory for investigating the adoption of inter-organizational linkages. Wang and Cheung (2004) adopt the institutional theory for examining the adoption of e-business by travel agencies in Taiwan. Hu, Hart and Cooke (2006) employ the institutional theory for exploring organizational information security practices. Liang et al. (2007) adopt the institutional theory for investigating the assimilation of enterprise systems. Son and 
Benbasat (2007) employ the institutional theory for identifying the factors influencing the adoption of B2B e-marketplaces. Bharati, Zhang and Chaudhury (2014) employ the institutional theory for investigating the assimilation of social media in organizations.

The institutional theory, with its focus on the environment of the organization, provides a theory on how members of an institutional field could be playing a role in the adoption of new technologies (Chatterjee et al. 2002). It, however, ignores other factors reflecting the technological and organizational characteristics of SMEs in the adoption of technologies (Mehrtens, Cragg \& Mills 2001; Joo \& Kim 2004). For this reason, the institutional theory is not fully-effective for explaining and predicting the adoption of technologies in SMEs.

\subsection{Theoretical Background for the Study}

There are numerous theories for investigating technology adoption in organizations including DOI, TOE, RBV, and the institutional theory. An intensive literature review on technology adoption in organizations indicates that most technology adoption studies are based on a combination of several theories for better understanding the adoption (Chau et al. 2020). Given the characteristics of specific technologies and the complex environment in which an organization is operating, integrating several theories into a single framework offers a richer theoretical basis for explaining technology adoption in organizations (Awiagah, Kang \& Lim 2016). 
A comprehensive analysis of existing studies on m-commerce adoption in organizations shows that DOI and TOE are the dominant theories for investigating organizational $\mathrm{m}$ commerce adoption (Chau \& Deng 2018b; Chau et al. 2020). As a result, the DOI theory and TOE framework are combined for guiding the development of the conceptual framework in this study with the following justifications. First, m-commerce adoption in organizations is a complex process with the involvement of various factors (Crabbe et al. 2009; Yaseen 2010). As a result, the use of multiple theories in exploring the adoption of $\mathrm{m}$-commerce in organizations would provide more comprehensive explanations of such an adoption. Second, with the analysis of existing organizational m-commerce adoption studies in the literature review section, it is evident that DOI and TOE are the dominant theories for investigating the critical determinants of organizational $\mathrm{m}$-commerce adoption. These theories help achieve a robust explanation in m-commerce adoption by organizations (Chau et al. 2020). Third, the DOI theory is proven to be consistent with the TOE framework (Zhu, Kraemer \& Xu 2003; Oliveira \& Martins 2011). Specifically, DOI emphasizes not only the individual characteristics but also the internal and external characteristics of the organization in the adoption of innovation. The individual and internal characteristics of DOI are consistent with the technological and organizational contexts of the TOE framework. Furthermore, the TOE framework includes more detailed information on the DOI external characteristics, which is known as the environmental context (Oliveira \& Martins 2011).

The applicability of the combination of DOI and TOE for investigating the critical determinants of the adoption of technology in organizations is exemplified in existing IS literature (Chwelos, Benbasat \& Dexter 2001; Bradford \& Florin 2003; Chan \& Ngai 
2007; Li 2008). Chwelos et al. (2001), for example, integrate DOI with TOE for investigating information systems adoption in organizations, leading to the identification of six critical determinants including perceived benefits, financial resources, IT sophistication, trading partner readiness, competitive pressures, enabled trading partner power. Bradford and Florin (2003) combine DOI and TOE for examining the adoption of ERP in organizations, leading to the identification of four critical determinants including perceived complexity, top management support, training, and competitive pressures. Chan and Ngai (2007) integrate DOI with TOE for investigating internet adoption in organizations, leading to the identification of three critical determinants including perceived benefits, organizational readiness, and external pressures. Li (2008) combines DOI and TOE for examining the adoption of eprocurement in organizations, leading to the identification of four critical determinants including relative advantages, top management support, external pressures, and external support.

The usefulness of the combination of DOI and TOE in studying the adoption of technology in SMEs is well demonstrated in the existing research (Thong 1999; Lertwongsatien \& Wongpinunwatana 2003; Scupola 2003; Otieno \& Kahonge 2014). Thong (1999), for example, integrate DOI with TOE for investigating information systems adoption in SMEs, leading to the identification of three critical determinants including business size, employees' IS knowledge, and information intensity. Scupola (2003) combines DOI and TOE for examining the adoption of e-commerce in SMEs, leading to the identification of eleven critical determinants including e-commerce barriers, e-commerce benefits, related technologies, financial and technological 
resources, employees' IS knowledge, innovation champion, company size, pressures from competitors, buyers, and suppliers, the role of government and technology support infrastructure. Lertwongsatien and Wongpinunwatana (2003) integrate DOI with TOE for investigating e-commerce adoption in SMEs, leading to the identification of six critical determinants including perceived benefits, perceived compatibility, firm size, top management support, the existence of IT department, and competitiveness. Otieno and Kahonge (2014) combine DOI and TOE for examining the adoption of $\mathrm{m}$ commerce in SMEs, leading to the identification of eleven critical determinants including perceived benefits, operational friendliness, security concerns, top management support, organizational size, organizational readiness, organizational scope, mimetic pressure from competitors, coercive pressure from clients, normative pressure and intensity of competition.

M-commerce is a technological innovation in the organization. This means that its adoption is influenced by not only the characteristics of m-commerce but also the organizational environment factors. As a result, a combination of several theories provides a better explanation for such adoption. The use of DOI, for example, focuses on technological characteristics in exploring the adoption of a specific technology (Lee \& Cheung 2004). The adoption of TOE presents a useful framework for investigating technology adoption from several perspectives of organizations (Huy et al. 2012; Alrousan \& Jones 2016). This shows that integrating DOI with TOE provides a holistic view of the organizational perspective on m-commerce adoption (Awiagah et al. 2016; Chau \& Deng 2018b; Chau et al. 2020). 


\subsection{A Conceptual Framework}

This section presents a conceptual framework, as shown in Figure 3.5, for investigating the critical determinants for m-commerce adoption in Vietnamese SMEs. The perceived cost and perceived security are included in the technological context for extending the DOI theory. Furthermore, the managerial context is added for extending the TOE framework to have a comprehensive framework for a more robust explanation of $\mathrm{m}$ commerce adoption in SMEs. The proposed framework conceptualizes that the critical factors affecting the adoption of m-commerce can be categorized into four main contexts including technological context, organizational context, environmental context, and managerial context. The influence of these four groups of determinants on the adoption of m-commerce is controlled by the organizational size and the type of industries that the SME is operating. 




Figure 3.5 A conceptual framework

\subsubsection{Technological Context}

The technological context is related to the characteristics of technologies available in SMEs (Rogers 2003). It represents a pool of technologies available for the adoption of m-commerce (Lu et al. 2015). Tornatzky and Fleischer (1990) argue that technology adoption in an organization depends not only on the availability of technologies in the market but also on how such technologies fit with the technologies that an organization 
already processes. There are five technological factors for investigating the adoption of technology in organizations including relative advantage, compatibility, complexity, observability, and trialability (Rogers 1995).

The reviewed literature in organizational m-commerce adoption shows that perceived benefits and perceived compatibility are the most critical factors for m-commerce adoption in organizations. Additionally, twenty-one technological factors are identified from the literature, as shown in Table 3.1. Some of these factors are similar and reflect the same aspect of measurement. For example, the relative advantage, perceived benefits, and perceived usefulness express the benefits of m-commerce adoption for the organization. The compatibility, integrity, job-fit, task-technology fit, and suitability express the fitness of m-commerce with the current technologies and business operations of the organization. The complexity, familiarity, convenience, perceived ease of use, and operational unfriendliness reflect the level of effort for understanding and using m-commerce. The trust, security, network security, perceived risk, and privacy focus on the security concerns of the organization when considering adopting mcommerce.

A review of technology adoption in organizations studies reveals that security affects the willingness of SMEs to adopt technologies (Tan \& Eze 2008). The cost of adoption is a concern for SMEs, especially SMEs in developing countries (Kurnia, Karnali \& Rahim 2015; Chau \& Deng 2018b). In Vietnam, the slow adoption of e-business technologies in SMEs is attributed to many challenges including the perceived adoption cost and the security concern (VCCI 2016). As a result, perceived cost and perceived 
security are included in the technological context to have a more robust explanation of m-commerce adoption in Vietnamese SMEs. This leads to the determination of four technological determinants in the conceptual model: perceived benefits, perceived compatibility, perceived security, and perceived costs. 
Table 3.1 Technological determinants of organizational m-commerce adoption

\begin{tabular}{|c|c|}
\hline Critical Determinants & Literature Sources \\
\hline Relative advantage & $\begin{array}{l}\text { AlHaj Ali (2005); Al-Qirim (2006); Doolin and Ali (2008); Chen (2010); } \\
\text { Jain et al. (2011); Picoto et al. (2012, 2014a, 2014b); Alfahl et al. (2017). }\end{array}$ \\
\hline Compatibility & $\begin{array}{l}\text { Al-Qirim (2006); Doolin and Ali (2008); Mallat and Tuunainen (2008); } \\
\text { Chen (2010); Hu et al. (2015); Alfahl et al. (2017). }\end{array}$ \\
\hline Complexity & $\begin{array}{l}\text { Al-Qirim (2006); Snowden et al. (2006); Mallat and Tuunainen (2008); Jain } \\
\text { et al. (2011); Lu et al. (2015); Alfahl et al. (2017). }\end{array}$ \\
\hline Trialability & Jain et al. (2011). \\
\hline Integrity & Hu et al. (2015). \\
\hline Familiarity & Hu et al. (2015). \\
\hline Convenience & Tsai and Gururajan (2007); Amegbe et al. (2017). \\
\hline Perceived benefits & $\begin{array}{l}\text { Yang (2005); Swilley (2007); Mallat and Tuunainen (2008); Picoto, } \\
\text { Belanger and Palma-dos-Reis (2013); Otieno and Kahonge (2014); Martin } \\
\text { and Jimenez (2015); Grandhi and Wibowo }(2015,2016) \text {. }\end{array}$ \\
\hline Perceived usefulness & $\begin{array}{l}\text { Snowden et al. (2006); Tsai and Gururajan (2007); Shih et al. (2010); } \\
\text { Mashagba et al. (2013); Hu et al. (2015); Alfahl et al. (2017); Amegbe et al. } \\
\text { (2017); Alqatan et al. (2017). }\end{array}$ \\
\hline Perceived ease of use & $\begin{array}{l}\text { Shih et al. (2010); Mashagba et al. (2013); Hu et al. (2015); Alfahl et al. } \\
\text { (2017); Amegbe et al. (2017); Alqatan et al. (2017). }\end{array}$ \\
\hline Operational unfriendliness & Otieno and Kahonge (2014). \\
\hline Perceived costs & $\begin{array}{l}\text { Yang (2005), Al-Qirim (2006); Hossain and Khandanker (2011); Mallat and } \\
\text { Tuunainen (2008); Rahman (2013); Waithaka and Mnkandla (2017); } \\
\text { Amegbe et al. (2017). }\end{array}$ \\
\hline Trust & $\begin{array}{l}\text { Li and McQueen (2008); Mallat and Tuunainen (2008); Hossain and } \\
\text { Khandanker (2011); Rahman (2013); Mashagba et al. (2013); Lu et al. } \\
\text { (2015); Alqatan et al. (2016); Amegbe et al. (2017). }\end{array}$ \\
\hline Security & $\begin{array}{l}\text { Hossain and Khandanker (2011); Mashagba et al. (2013); Otieno and } \\
\text { Kahonge (2014); Lu et al. (2015); Waithaka and Mnkandla (2017). }\end{array}$ \\
\hline Network reliability & Lu et al. (2015). \\
\hline Perceived risk & Li and McQueen (2008); Rahman (2013); Amegbe et al. (2017). \\
\hline Privacy & Hossain and Khandanker (2011). \\
\hline Interface design & Grandhi and Wibowo $(2015,2016)$. \\
\hline Job-fit & Alfahl et al. (2017). \\
\hline Task-technology fit & Liang et al. (2007); Prasarry et al. (2015); Alqatan et al. (2017). \\
\hline Suitability & AlHaj Ali (2005). \\
\hline
\end{tabular}




\section{Perceived benefits}

Perceived benefits are a set of anticipated advantages that can be gained by an organization when such a technology has been adopted (Chwelos et al. 2001). They are reflected in the degree to which the technology is expected to bring better business performance and the extent to which business activities are covered when technology is adopted (Jeon et al., 2006). The adoption of technologies in organizations leads to various benefits including reducing costs, reaching customers, enhancing productivity, increasing profitability, gaining competitive advantages, promoting products and services, and expanding into a new market (Apulu and Latham, 2011). Table 3.2 presents an overview of the measurement items for perceived benefits. 
Table 3.2 A summary of the measurement items for Perceived Benefits

\begin{tabular}{|c|c|c|}
\hline Measurement Items & Description & References \\
\hline $\begin{array}{l}\text { Operating } \\
\text { savings }\end{array}$ & $\begin{array}{l}\text { Operating cost saving refers to the reduction of expenses } \\
\text { associated with the maintenance and administration of } \\
\text { business when adopting m-commerce. }\end{array}$ & $\begin{array}{l}\text { Zhu et al. (2006); } \\
\text { Ifinedo (2011) }\end{array}$ \\
\hline $\begin{array}{l}\text { Simplification of the } \\
\text { operating procedures }\end{array}$ & $\begin{array}{l}\text { Simplification of the operating procedures is about the } \\
\text { cutting of some administrative procedures in traditional } \\
\text { commerce when the m-commerce is adopted. }\end{array}$ & $\begin{array}{l}\text { Zhu et al. (2006); } \\
\text { Alam et al. (2011) }\end{array}$ \\
\hline $\begin{array}{l}\text { Increase in market } \\
\text { share }\end{array}$ & $\begin{array}{l}\text { The increase in the market share refers to the increase in } \\
\text { the percentage of total sales volume in the market of a } \\
\text { company when adopting m-commerce. }\end{array}$ & $\mathrm{Scu}_{1}$ \\
\hline Growth of revenue & $\begin{array}{l}\text { The growth of the revenue refers to the increase in sales of } \\
\text { a company after adopting m-commerce. }\end{array}$ & $\begin{array}{l}\text { Zhu et al. (2006); } \\
\text { Ifinedo (2011); } \\
\text { Martin et al. (2012) }\end{array}$ \\
\hline $\begin{array}{l}\text { Creation of } \\
\text { marketing channels }\end{array}$ & $\begin{array}{l}\text { The creation of marketing channels refers to the use of } \\
\text { new channels (mobile channel) for marketing activities } \\
\text { when adopting m-commerce. }\end{array}$ & $\begin{array}{l}\text { Scupola (2009); } \\
\text { Ghobakhloo and } \\
\text { Tang (2013) }\end{array}$ \\
\hline $\begin{array}{l}\text { Improvement of the } \\
\text { company's image }\end{array}$ & $\begin{array}{l}\text { Improvement of the company's image is about the increase } \\
\text { in the total of impressions left on the company's customers } \\
\text { and community due to the reputation for innovation or } \\
\text { technological prowess when adopting m-commerce. }\end{array}$ & $\begin{array}{l}\text { Zhu et al. (2006); } \\
\text { Alam et al. (2011) }\end{array}$ \\
\hline $\begin{array}{l}\text { Improvement } \\
\text { competitiveness }\end{array}$ & $\begin{array}{l}\text { Improvement of competitiveness is about the increase in } \\
\text { the level of productivity of a company when using the m- } \\
\text { commerce. }\end{array}$ & $\begin{array}{l}\text { Teo et al. (2009); } \\
\text { Alam et al. (2011) }\end{array}$ \\
\hline $\begin{array}{l}\text { Enhancement of } \\
\text { customer service }\end{array}$ & $\begin{array}{l}\text { Enhancement of customer services refers to better services } \\
\text { that an organization can offer to its customers after } \\
\text { adopting m-commerce. }\end{array}$ & $\begin{array}{l}\text { Scupola (2009); } \\
\text { Ifinedo (2011) }\end{array}$ \\
\hline
\end{tabular}

The adoption of m-commerce in SMEs can help them re-engineer their business processes for better performance. Some business activities such as ordering, paying, and after-sales services can be integrated, resulting in cost reduction for business operations (Lal 2005). SMEs can better compete in the global market as the entry barrier to the 
market is lowered with the adoption of m-commerce (Wang \& Ahmed 2009). This shows that perceived benefits are critical for the adoption of m-commerce in SMEs (Ghobakhloo \& Tang 2013; Picoto et al. 2013; Otieno \& Kahonge 2014). Technologies are more likely to be adopted in SMEs if their benefits are perceived to outweigh their risks (Ghobakhloo \& Tang 2013). This means that the higher the perceived benefits, the greater the intention to adopt the technology (Chwelos et al. 2001). This leads to the following hypothesis:

H1: Perceived benefits positively affect the adoption of m-commerce.

\section{Perceived compatibility}

Compatibility is the degree to which a technology is consistent with the existing values and experience of an organization (Rogers 2010). It is measured by the fit of the technology with suppliers and customers, the fit with the organizational structure, and the perceived suitability of the business to adopt such a technology (Salah 2013). Table 3.3 presents an overview of the measurement items for perceived compatibility. 
Table 3.3 A summary of the measurement items for Perceived Compatibility

\begin{tabular}{|c|c|c|}
\hline Measurement Items & Description & References \\
\hline $\begin{array}{l}\text { Alignment with the } \\
\text { ICT infrastructure }\end{array}$ & $\begin{array}{l}\text { Alignment with the ICT infrastructure refers to the } \\
\text { compatibility of m-commerce applications with the current } \\
\text { hardware and software in the company. }\end{array}$ & $\begin{array}{l}\text { Zhu et al. (2006); } \\
\text { Lin and Lin } \\
\text { (2008) }\end{array}$ \\
\hline $\begin{array}{l}\text { Integration } \\
\text { current } \\
\text { processes }\end{array}$ & $\begin{array}{l}\text { Integration with current business processes is about the } \\
\text { suitability of m-commerce with the current business } \\
\text { activities of the company to achieve organizational } \\
\text { objectives. }\end{array}$ & $\begin{array}{l}\text { Zhu et al. (2006); } \\
\text { Ghobakhloo, } \\
\text { Aranda and } \\
\text { Amado (2011) }\end{array}$ \\
\hline $\begin{array}{l}\text { Adaptability of } \\
\text { existing distribution } \\
\text { channels }\end{array}$ & $\begin{array}{l}\text { The adaptability of existing distribution channels refers to } \\
\text { the flexible change of the current distribution channels for } \\
\text { m-commerce. }\end{array}$ & $\begin{array}{l}\text { Zhu et al. (2006); } \\
\text { Picoto et al. } \\
(2014 a)\end{array}$ \\
\hline $\begin{array}{l}\text { Consistency with the } \\
\text { organizational culture }\end{array}$ & $\begin{array}{l}\text { Consistency with the culture of an organization is about } \\
\text { the consistency of m-commerce with the expectations, } \\
\text { experiences, philosophy, and values of the organization. }\end{array}$ & $\begin{array}{l}\text { Ghobakhloo et al. } \\
\text { (2011); Picoto et } \\
\text { al. (2014a) }\end{array}$ \\
\hline $\begin{array}{l}\text { Suitability with } \\
\text { customers' ways of } \\
\text { doing business }\end{array}$ & $\begin{array}{l}\text { Suitability with customers' ways of doing business refers } \\
\text { to the suitability of m-commerce with customers' tendency } \\
\text { of online shopping, as well as their perception and } \\
\text { attitudes towards online transactions. }\end{array}$ & $\begin{array}{l}\text { Ghobakhloo et al. } \\
\text { (2011); Alam et } \\
\text { al. (2011) }\end{array}$ \\
\hline $\begin{array}{l}\text { The richness of the } \\
\text { experience in adopting } \\
\text { technological } \\
\text { innovations }\end{array}$ & $\begin{array}{l}\text { The richness of the experience in adopting technological } \\
\text { innovations is about the sufficiency of knowledge and } \\
\text { experience in technology adoption of the company that can } \\
\text { facilitate their adoption of m-commerce. }\end{array}$ & $\begin{array}{l}\text { Picoto et } \\
(2014 a)\end{array}$ \\
\hline
\end{tabular}

Perceived compatibility can either speed up or slow down the technology adoption in organizations. Technologies are more likely to be adopted when they are compatible with the work practices, values, and beliefs of organizations (Hung et al. 2011). A higher level of perceived compatibility is associated with an increased intention to adopt the technology (Alam et al. 2011). 
Compatibility is the most critical determinant for technology adoption in SMEs (Kurnia et al. 2015; Alfahl et al. 2017). Grandon and Pearson (2004), for example, find out that compatibility is the critical determinant for the adoption of e-commerce in SMEs in USA. Al-Qirim (2006) confirms that compatibility is the critical determinant for mobile technologies adoption in SMEs in New Zealand. Huy et al. (2012) indicate that compatibility is a critical determinant for e-commerce adoption in Vietnamese SMEs. As SMEs in developing countries are more vulnerable to m-commerce adoption barriers such as resource constraints and lack of IT/m-commerce knowledge, the impact of perceived compatibility on the adoption is expected to be significant. This leads to the following hypothesis:

H2: Perceived compatibility positively affects the adoption of m-commerce

\section{Perceived security}

Perceived security is the awareness of organizations about the security concern of $\mathrm{m}$ commerce technologies. The security of specific e-business technologies is commonly reflected in three different aspects including transaction security, facility security, and antivirus capability (Xu et al., 2010). In organizational technology adoption studies, the perceived security of a technology is usually measured by the awareness of the security of such a technology, the availability of industry standards for the security of that technology, and the availability of laws and regulations for such a technology. Table 3.4 presents an overview of the measurement items for perceived security. 
Table 3.4 A summary of the measurement items for Perceived Security

\begin{tabular}{|c|c|c|}
\hline Measurement Items & Description & References \\
\hline $\begin{array}{l}\text { Awareness of the } \\
\text { security of m- } \\
\text { commerce }\end{array}$ & $\begin{array}{l}\text { Awareness of the security of } \mathrm{m} \text {-commerce is about the } \\
\text { organization's understanding of the security of m-commerce, } \\
\text { leading to their confidence in adopting m-commerce. }\end{array}$ & $\begin{array}{l}\text { Alam et al. } \\
(2011)\end{array}$ \\
\hline $\begin{array}{l}\text { Availability of } \\
\text { industry standards for } \\
\text { the security of m- } \\
\text { commerce }\end{array}$ & $\begin{array}{l}\text { The availability of industry standards for the security of m- } \\
\text { commerce refers to the sufficiency of industry security standards, } \\
\text { as well as data protection and fraud detection technologies, } \\
\text { increasing the company's confidence in adopting m-commerce. }\end{array}$ & $\begin{array}{l}\text { Alam et al. } \\
(2011)\end{array}$ \\
\hline $\begin{array}{l}\text { Availability of laws } \\
\text { and regulations for } \\
\text { m-commerce }\end{array}$ & $\begin{array}{l}\text { The availability of laws and regulations for } \mathrm{m} \text {-commerce refers to } \\
\text { the sufficiency of the legal environment for regulating } \mathrm{m} \text { - } \\
\text { commerce. }\end{array}$ & $\begin{array}{l}\text { Alam et al. } \\
(2011)\end{array}$ \\
\hline
\end{tabular}

Security is the main concern for the adoption of technologies in small businesses in developing countries (Tan et al. 2009; Alam et al. 2011; Garg \& Choeu 2015). It is the critical determinant for adopting technologies in SMEs (Zhu et al. 2006; Wu \& Chuang 2010). The concern about security is the most important barrier to the use of ecommerce in SMEs in Malaysia. It is the main barrier to the adoption of internet commerce in Vietnam (VCCI 2016). Furthermore, the fear of losing trade secrets stops SMEs from adopting e-commerce (Alam et al. 2011). This shows that a higher level of perceived security increases the intention of SMEs to adopt m-commerce. This leads to the following hypothesis:

H3: Perceived security positively affects the adoption of m-commerce

\section{Perceived cost}

The cost of technology adoption is about the relative cost to the benefits of adopting the technology. It includes the cost of technologies, the cost of maintaining the 
technologies, and the cost of training employees to use such technologies. Table 3.5 presents an overview of the measurement items for perceived cost.

Table 3.5 A summary of the measurement items for Perceived Cost

\begin{tabular}{|c|c|c|c|}
\hline \multicolumn{2}{|c|}{ Measurement Items } & Description & \multirow{2}{*}{\begin{tabular}{l}
\multicolumn{1}{c}{ References } \\
Al-Qirim (2006); \\
Ghobakhloo et \\
al. (2011)
\end{tabular}} \\
\hline $\begin{array}{l}\text { M-commerce } \\
\text { infrastructure } \\
\text { requirements }\end{array}$ & & $\begin{array}{l}\text { Requirement costs of m-commerce technologies } \\
\text { infrastructure are about the amount of money to buy } \\
\text { technology devices and tools for the adoption of m- } \\
\text { commerce. }\end{array}$ & \\
\hline $\begin{array}{l}\text { Training } \\
\text { requirements }\end{array}$ & & $\begin{array}{l}\text { Requirement costs of training for } \mathrm{m} \text {-commerce applications } \\
\text { are about the amount of money for training employees to use } \\
\text { m-commerce applications. }\end{array}$ & $\begin{array}{l}\text { Al-Qirim (2006); } \\
\text { Ghobakhloo et } \\
\text { al. (2011) }\end{array}$ \\
\hline $\begin{array}{l}\text { Maintenance } \\
\text { requirements }\end{array}$ & cost & $\begin{array}{l}\text { Maintenance costs for } \mathrm{m} \text {-commerce applications are about } \\
\text { the amount of money for maintaining m-commerce systems } \\
\text { during the post-adoption stage. }\end{array}$ & $\begin{array}{l}\text { Al-Qirim (2006); } \\
\text { Ghobakhloo et } \\
\text { al. (2011) }\end{array}$ \\
\hline
\end{tabular}

Cost is critical for SMEs, especially SMEs in developing countries in adopting specific technologies (Tan et al. 2009). In Vietnam, the slow technology adoption in SMEs is attributed to many challenges, including the cost of adoption (VCCI, 2016). SMEs are operating under severe resource constraints, particularly financial constraints. This compels SMEs to be cautious about their investment in technology adoption (Ghobakhloo et al. 2011). The cost has a significant association with the adoption of specific technologies (Mallat \& Tuunainen 2008; Hsiao et al. 2009; Tan et al. 2009; Amegbe et al. 2017). The higher the adoption cost of the technology, the slower the pace of its adoption (Alam et al. 2011). When the manager of Vietnamese SMEs perceives that $\mathrm{m}$-commerce adoption is not financially worthwhile, they would be less willing to adopt it. This leads to the following hypothesis: 


\subsubsection{Organizational Context}

The organizational context is related to the characteristics of an organization in technology adoption. It represents the internal factors that affect the adoption of technologies (Lippert \& Govindarajulu 2006).

There are eighteen important organizational factors extracted from the literature, as presented in Table 3.6. The technology competence, little knowledge of technology, lack of literacy, availability of internal IT experts and expertise, employees' IS knowledge are very much the same as employees' IT knowledge and expertise. Top management championship, top management intend, financial commitment, and managerial obstacles are close to top management support. It is considered in the managerial context of the conceptual framework. The propensity to innovation and business and product innovation are measured in the organizational innovativeness.

In general, employees' IT knowledge and organizational readiness are the critical determinants for m-commerce adoption (Chau \& Deng 2018a). Often, the innovativeness ability of an organization is the prerequisite and facilitator for technology adoption. The success of adoption depends on the degree to which organizational structures and processes respond to the use of technologies (Armbruster et al. 2008). As a result, the proposed organizational determinants for organizational mcommerce adoption are employees' IT knowledge, organizational readiness, and organizational innovativeness. 
Table 3.6 Organizational determinants of organizational m-commerce adoption

\begin{tabular}{|c|c|}
\hline Critical Determinants & Literature Sources \\
\hline Organizational culture & Stoica et al. (2005); Shih and Huang (2009); Alfahl et al. (2017). \\
\hline Business strategy & Stoica et al. (2005); Grandhi and Wibowo $(2015,2016)$. \\
\hline Organizational readiness & $\begin{array}{l}\text { Yang (2005), Zeeshan et al. (2007); Doolin and Ali (2008); Li and } \\
\text { McQueen (2008); Chen (2010); Otieno and Kahonge (2014). }\end{array}$ \\
\hline Top management support & $\begin{array}{l}\text { AlHaj Ali (2005); Swilley (2007); Zeeshan et al. (2007); Doolin and Ali } \\
\text { (2008); Shih and Huang (2009); Chang et al. (2009); Chen (2010); Alfahl et } \\
\text { al. (2012); Otieno and Kahonge (2014); Lu et al. (2015); Martin and } \\
\text { Jimenez (2015); Li and Wang (2018). }\end{array}$ \\
\hline $\begin{array}{l}\text { Top management } \\
\text { championship }\end{array}$ & Swilley (2007). \\
\hline Top management intend & Yang (2005). \\
\hline $\begin{array}{l}\text { Employees' information } \\
\text { technology } \\
\text { knowledge and expertise }\end{array}$ & $\begin{array}{l}\text { AlHaj Ali (2005); Chang et al. (2009); Balocco et al. (2009); Jain et al. } \\
\text { (2011); Rahman (2013); Lu et al. (2015). }\end{array}$ \\
\hline Managerial obstacles & Picoto et al. (2012); Picoto et al. (2014a). \\
\hline Information intensity & Doolin and Ali (2008); Chen (2010). \\
\hline Technology competence & Martin et al. (2012); Picoto et al. (2012); Picoto et al. (2014a). \\
\hline Financial commitment & Jain et al. (2011). \\
\hline $\begin{array}{l}\text { Little knowledge/ Lack of } \\
\text { literacy }\end{array}$ & Balocco et al. (2009); Alfahl et al. (2017). \\
\hline Propensity to innovation & Martin and Jimenez (2015). \\
\hline Firm size & $\begin{array}{l}\text { Leger, Cassivi and Wamba (2004); Balocco et al. (2009); Jain et al. (2011); } \\
\text { Otieno and Kahonge (2014); Lu et al. (2015). }\end{array}$ \\
\hline $\begin{array}{l}\text { The availability of internal } \\
\text { IT experts and expertise }\end{array}$ & AlHaj Ali (2005). \\
\hline Employees' IS knowledge & Lu et al. (2015). \\
\hline $\begin{array}{l}\text { Business \& product } \\
\text { innovativeness }\end{array}$ & Salimon et al. (2017). \\
\hline Firm scope & Otieno and Kahonge (2014). \\
\hline
\end{tabular}




\section{Employees' IT knowledge}

Employees' IT knowledge is an understanding of the IT of employees through practice and training. In organizational technology adoption studies, the IT knowledge of employees is reflected in their understanding of such a technology, their proficiency in using IT, and their competence in the new technology (Huy et al. 2012; Alrousan 2015). Table 3.7 presents an overview of the measurement items for employees' IT knowledge.

Table 3.7 A summary of the measurement items for Employees' IT knowledge

\begin{tabular}{lll}
\hline \multicolumn{1}{l}{ Measurement Items } & \multicolumn{1}{c}{ Description } & \multicolumn{1}{c}{ References } \\
\hline $\begin{array}{l}\text { Understanding of } \mathrm{m}- \\
\text { commerce }\end{array}$ & $\begin{array}{l}\text { Understanding m-commerce refers to the employees' } \\
\text { knowledge of m-commerce. }\end{array}$ & $\begin{array}{l}\text { Huy et al. (2012); } \\
\text { Alrousan (2015) }\end{array}$ \\
\hline $\begin{array}{l}\text { Proficiency in using IT } \\
\text { of the employees. }\end{array}$ & Alrousan (2015) \\
\hline $\begin{array}{l}\text { Competence in the } \\
\text { new technology }\end{array}$ & $\begin{array}{l}\text { Competence in the new technology is about the ability of } \\
\text { employees to learn to use the latest technology. }\end{array}$ & $\begin{array}{l}\text { Huy et al. (2012); } \\
\text { Alrousan (2015) }\end{array}$ \\
\hline
\end{tabular}

The IT knowledge of employees significantly affects the adoption of technologies in SMEs (Wang \& Hou 2012). SMEs are unlikely to adopt sophisticated technologies when there is lack of IT knowledge in their employees (Huy et al. 2012). Due to the obstacles in developing necessary skills and knowledge, SMEs are tempted to postpone the adoption of technologies (Kurnia et al. 2015). Employees' IT knowledge is a significant factor in ICT and e-commerce adoption in SMEs (Alam \& Noor 2009; Scupola 2009; Huy et al. 2012; Loukis, Arvanitis \& Kyriakou 2017). The higher level of employees' IT knowledge, the higher the rate of m-commerce adoption in SMEs. This leads to the following hypothesis: 
H5: Employees' IT knowledge positively affects the adoption of m-commerce

\section{Organizational Readiness}

Organizational readiness is about the availability of technological, financial, and human resources in organizations for technology adoption. It consists of technological readiness, financial readiness, and human resources readiness (Chau et al. 2020). Technological readiness is related to the accessibility of organizations to ICT resources for the adoption of technologies. Financial readiness is concerned about the availability of financial resources for adopting technologies (Pham et al. 2011). Human resources readiness is linked to the availability of IT expertise and staffs for the adoption of technologies in organizations (Kurnia et al. 2015). Table 3.8 presents an overview of the measurement items for organizational readiness.

Table 3.8 A summary of the measurement items for Organizational Readiness

\begin{tabular}{|c|c|c|}
\hline Measurement Items & Description & References \\
\hline Financial readiness & $\begin{array}{l}\text { Financial readiness is about the availability of financial } \\
\text { resources for adopting m-commerce in the organization. }\end{array}$ & $\begin{array}{l}\text { Alam et al. (2011); } \\
\text { Huy et al. (2012) }\end{array}$ \\
\hline $\begin{array}{l}\text { Technological } \\
\text { readiness }\end{array}$ & $\begin{array}{l}\text { Technological readiness is about the availability of } \\
\text { technological resources for adopting m-commerce in the } \\
\text { organization. }\end{array}$ & $\begin{array}{l}\text { Alam et al. (2011); } \\
\text { Huy et al. (2012) }\end{array}$ \\
\hline $\begin{array}{l}\text { Human } \\
\text { readiness }\end{array}$ & $\begin{array}{l}\text { Human resource readiness is about the sufficiency of IT } \\
\text { staffs and expertizes for adopting m-commerce in the } \\
\text { organization. }\end{array}$ & $\begin{array}{l}\text { Alam et al. (2011); } \\
\text { Huy et al. (2012) }\end{array}$ \\
\hline
\end{tabular}

Organizational readiness is closely related to the adoption of specific technologies (Alam et al. 2011). The inadequacy of financial resources in SMEs is a major impediment to technology adoption. A low level of computerization in SMEs often 
makes the installation and operation of sophisticated IS problematic (Wang \& Ahmed 2009). The higher level of organizational readiness is a predictor of successful technology adoption in SMEs (Jain et al. 2011; Donaldson, Lee \& Wright 2012; Huy et al. 2012; Otieno \& Kahonge 2014; Kurnia et al. 2015). This leads to the following hypothesis:

H6: Organizational readiness positively affects the adoption of $m$-commerce

\section{Organizational Innovativeness}

Innovation is about the intentional introduction and application of new ideas, processes, products, or procedures in organizations for better performance (Siamagka et al. 2015). The innovativeness of an organization is reflected by the innovativeness ability, the ability to adopt new approaches, and the ability to improve processes continuously (Michaelidou, Siamagka \& Christodoulides 2011; Wamba \& Carter 2013). Table 3.9 presents an overview of the measurement items for organizational innovativeness.

Table 3.9 A summary of the measurement items for Organizational Innovativeness

\begin{tabular}{lll}
\hline Measurement Items & \multicolumn{1}{c}{ Description } & References \\
\hline & $\begin{array}{l}\text { The degree of innovativeness is about the organization's } \\
\text { propensity and capability to incorporate the change to business } \\
\text { practices through the adoption of innovation to increase their } \\
\text { competitiveness and sustainability. }\end{array}$ & $\begin{array}{l}\text { Wamba } \\
\text { Innovativeness ability }\end{array}$ \\
\hline \multirow{2}{*}{$\begin{array}{l}\text { The adoption of new management approaches is about the } \\
\text { management }\end{array}$} & $\begin{array}{l}\text { application of new methods to manage the organization, } \\
\text { resources, and processes to improve the planning, organizing, and } \\
\text { approaches }\end{array}$ & $\begin{array}{l}\text { (2013) } \\
\text { the performance of managerial functions. }\end{array}$ \\
\hline $\begin{array}{l}\text { Ability to improve } \\
\text { business processes } \\
\text { continuously }\end{array}$ & $\begin{array}{l}\text { Continuous business process improvement is about the continuous } \\
\text { improvement of business operations to encourage smoother }\end{array}$ & $\begin{array}{l}\text { and Carter } \\
\text { procedures, more efficient workflow, and overall business growth. }\end{array}$ \\
\hline
\end{tabular}


Organizational innovativeness is essential for gaining competitive advantages. It is an organizational capability where organizations are open to ideas and solutions for better performance (Wamba \& Carter 2013). The adoption of technologies depends upon an innovative climate in organizations (Siamagka et al. 2015). Organizational innovativeness is significant for technology adoption in organizations (Michaelidou et al. 2011; Wamba \& Carter 2013; Martin \& Jimenez 2015; Sun \& Chi 2018). The more innovative an organization, the more likely it will adopt technologies. As m-commerce is an important model that could easily get prompted by technological innovation, organizational innovativeness can produce a positive attitude toward the adoption of $\mathrm{m}$ commerce (Salimon et al. 2017). This leads to the following hypothesis:

H7: Organizational innovativeness positively affects the adoption of $m$-commerce

\subsubsection{Environmental Context}

The environmental context is related to the surrounding of organizations with respect to competitors, government, suppliers, and customers (Baker 2012). It includes the size and structure of the industry, competitors, macroeconomic context, and regulatory environment (Tornatzky \& Fleischer 1990).

The literature review on organizational $\mathrm{m}$-commerce adoption has identified twelve most important environmental factors, as presented in Table 3.10. Government regulation, government involvement, and policy and legal environment are similar to government support. Competition and competitive intensity are similar to competitive pressures. M-commerce in this study focuses on the buying and selling of goods and 
services. As a result, only the pressures from customers are proposed to be examined in the conceptual model. This leads to the determination of three environmental determinants for the conceptual framework: competitive pressures, customer pressures, and government support.

Table 3.10 Environmental determinants of organizational m-commerce adoption

\begin{tabular}{|c|c|}
\hline Critical Determinants & Literature Sources \\
\hline Competitive pressure & $\begin{array}{l}\text { AlHaj Ali (2005); Swilley (2007); Zeeshan et al. (2007); Picoto et al. } \\
\text { (2012, 2014a, 2014b); Alrawabdeh (2014); Otieno and Kahonge (2014); } \\
\text { Lu et al. (2015); Li and Wang (2018). }\end{array}$ \\
\hline Competitive intensity & Doolin and Ali (2008); Chen (2010). \\
\hline Competition & Otieno and Kahonge (2014). \\
\hline $\begin{array}{l}\text { Support from the } \\
\text { technology vendor }\end{array}$ & AlHaj Ali (2005); Al-Qirim (2006); Chang et al. (2009); Jain et al. (2011). \\
\hline Customer pressure & $\begin{array}{l}\text { Swilley (2007); Alrawabdeh (2014); Otieno and Kahonge (2014); Li and } \\
\text { Wang (2018). }\end{array}$ \\
\hline Trading partner pressure & $\begin{array}{l}\text { Doolin and Ali (2008); Chen (2010); Jain et al. (2011); Picoto et al. (2012, } \\
\text { 2014a, 2014b); Lu et al. (2015); Li and Wang (2018). }\end{array}$ \\
\hline External pressure & Yang (2005). \\
\hline Government regulation & Swilley (2007); Rahman (2013); Alrawabdeh (2014). \\
\hline Government involvement & Stoica et al. (2005). \\
\hline Policy \& legal environment & Alfahl et al. (2017). \\
\hline ICT infrastructure & $\begin{array}{l}\text { Liang et al. (2007); Hossain and Khandanker (2011); Jain et al. (2011); } \\
\text { Mashagba et al. (2013); Lu et al. (2015). }\end{array}$ \\
\hline Regulatory support & Lu et al. (2015). \\
\hline
\end{tabular}




\section{Competitive pressures}

Competitive pressures are about the degree to which an organization is affected by competitors in the market (Porter 1985). Porter and Millar (1985, p. 11) indicate that "the structure of an industry is embodied in five competitive forces that collectively determine industry profitability: the power of buyers, the power of suppliers, the threats of new entrants, the threat of substitute products and the rivalry among existing competitors". This study focuses on B2C m-commerce. As a result, the threats from existing competitors, new entrants, and substitute products are used for measuring competitive pressures. Table 3.11 presents an overview of the measurement items for competitive pressures.

Table 3.11 A summary of the measurement items for Competitive Pressures

\begin{tabular}{|c|c|c|}
\hline Measurement Items & Description & References \\
\hline $\begin{array}{l}\text { Availability of } \\
\text { similar } \\
\text { products/services of } \\
\text { competitors }\end{array}$ & $\begin{array}{l}\text { The availability of similar products/services of the } \\
\text { established rivals refers to the pressure to adopt m- } \\
\text { commerce due to the high competition with established } \\
\text { rivals. }\end{array}$ & $\begin{array}{l}\text { Thong and Yap } \\
\text { (1995); Ghobakhloo } \\
\text { et al. (2011) }\end{array}$ \\
\hline $\begin{array}{l}\text { Availability of } \\
\text { similar } \\
\text { products/services of } \\
\text { new entrants }\end{array}$ & $\begin{array}{l}\text { The availability of similar products/services of the new } \\
\text { entrants refers to the pressure to adopt m-commerce due } \\
\text { to the high competition with the new entrants. }\end{array}$ & $\begin{array}{l}\text { Thong and Yap } \\
\text { (1995); Ghobakhloo } \\
\text { et al. (2011) }\end{array}$ \\
\hline $\begin{array}{l}\text { Availability of } \\
\text { substitute } \\
\text { products/services }\end{array}$ & $\begin{array}{l}\text { The availability of substitute products/services refers to } \\
\text { the pressure to adopt m-commerce due to the high } \\
\text { competition among companies providing substitute } \\
\text { products/services. }\end{array}$ & $\begin{array}{l}\text { Thong and Yap } \\
\text { (1995); Ghobakhloo } \\
\text { et al. (2011) }\end{array}$ \\
\hline
\end{tabular}

Competitive pressures are a major factor for technology adoption in SMEs (Otieno \& Kahonge 2014; Lu et al. 2015; Awa, Ukoha \& Emecheta 2016; Ilin, Ivetic \& Simic 
2017). An SME may feel the pressure when there are more competitors in the industry who have adopted such technologies (Ahmad et al. 2015). The relationship between competitive pressures and technology adoption can be extended to m-commerce for enhancing international competitiveness for SMEs. This leads to the following hypothesis:

H8: Competitive pressures positively affect the adoption of $m$-commerce

\section{Customer pressures}

Customer pressures are about the pressures from customers for the adoption of technologies in organizations. It is usually measured via the requirements from customers for adopting a specific technology, the expectation of customers for adopting such a technology, and the need to adopt such technology to maintain relationships with customers (Teo et al. 2009; Alrousan 2015; Chau et al. 2020). Table 3.12 presents an overview of the measurement items for customer pressures.

Table 3.12 A summary of the measurement items for Customer Pressures

\begin{tabular}{lll}
\hline \multicolumn{1}{c}{ Measurement Items } & \multicolumn{1}{c}{ Description } & References \\
\hline $\begin{array}{l}\text { The requirement for } \\
\text { adopting m-commerce } \\
\text { from customers }\end{array}$ & $\begin{array}{l}\text { The requirement of customers refers to the pressure to } \\
\text { adopt m-commerce to meet the demands of customers. }\end{array}$ & Teo et al. (2009); \\
\hline & The expectation of customers refers to the essential for & \\
The expectation for & $\begin{array}{l}\text { The } \\
\text { the company to adopt m-commerce to meet the }\end{array}$ & Teo et al. (2009); \\
adopting m-commerce & $\begin{array}{l}\text { expectation of their customers and to increase customer } \\
\text { from customers }\end{array}$ & Alrousan (2015) \\
\hline $\begin{array}{l}\text { The need for maintaining } \\
\text { relationships }\end{array}$ & $\begin{array}{l}\text { Maintain relationships with customers refer to the } \\
\text { pressure to adopt m-commerce to maintain and develop }\end{array}$ & Teo et al. (2009); \\
customers & relationships with customers. & Alrousan (2015) \\
\hline
\end{tabular}


The pressure from customers is critical for the adoption of technologies in organizations, especially SMEs (Chau et al. 2020). When the dominant customer of the organization has adopted specific technologies, the organization may have to adopt these technologies to show its fitness as a business partner (Al-Bakri \& Katsioloudes 2015). The pressures from customers are a facilitator for technology adoption in SMEs (Otieno \& Kahonge 2014; Lu et al. 2015; Rahayu \& Day 2015). SMEs tend to innovate when they come under pressure from customers (Chatzoglou \& Chatzoudes 2016). SMEs in developing countries adopt e-commerce because of high pressures from their customers (Ahmad et al. 2015). As a result, the greater the pressures from customers perceived by SMEs, the more likely they are to adopt specific technologies (Duan et al. 2012). This leads to the following hypothesis:

H9: Customer pressures are positively related to the adoption of m-commerce

\section{Government support}

Government support is about the availability of government policies and initiatives for promoting the adoption of technologies in organizations. It is manifested in three different aspects including policies and legislation, funding, and ICT infrastructure (Saprikis \& Vlachopoulou 2012). Table 3.13 presents an overview of the measurement items for government support. 
Table 3.13 A summary of the measurement items for Government Support

\begin{tabular}{|c|c|c|}
\hline Measurement Items & Description & References \\
\hline $\begin{array}{l}\text { Legal considerations } \\
\text { for } \mathrm{m} \text {-commerce }\end{array}$ & $\begin{array}{l}\text { The legal considerations for } \mathrm{m} \text {-commerce refer to the role of } \\
\text { the government in providing effective laws and regulations } \\
\text { for guiding and regulating m-commerce activities. }\end{array}$ & $\begin{array}{l}\text { Huy et al. (2012); } \\
\text { Al-Alawi and Al- } \\
\text { Ali (2015) }\end{array}$ \\
\hline Financial support & $\begin{array}{l}\text { Financial support refers to the role of the government in } \\
\text { providing necessary financial support for businesses to } \\
\text { adopt m-commerce. }\end{array}$ & $\begin{array}{l}\text { Jeon, Han and } \\
\text { Lee (2006); Huy } \\
\text { et al. (2012) }\end{array}$ \\
\hline $\begin{array}{l}\text { Availability of the } \\
\text { training and } \\
\text { educational programs }\end{array}$ & $\begin{array}{l}\text { The availability of the training and educational programs } \\
\text { refers to the role of the government in providing necessary } \\
\text { training and educational programs for businesses to improve } \\
\text { their knowledge and skills for the adoption of m-commerce. }\end{array}$ & Alrousan (2015) \\
\hline
\end{tabular}

Government support plays a facilitating role in assisting SMEs in adopting technologies (Kurnia et al. 2015). Governmental incentives in the form of economic, financial, and technological support lower the barrier of technology adoption (Alrousan \& Jones 2016). Government policies encourage businesses including SMEs to adopt technologies (Chatzoglou \& Chatzoudes 2016). The perceived level of available support from the government affects SMEs' decisions to adopt technologies such as e-market, ebusiness, e-commerce, and m-commerce (Duan et al. 2012; Kurnia et al. 2015; Chatzoglou \& Chatzoudes 2016; Miao \& Tran 2018). This leads to the following hypothesis:

H10: Government support positively affects the adoption of m-commerce 


\subsubsection{Managerial Context}

The managerial context is related to the employees who play important roles in deciding to adopt technologies in their organizations. Technology adoption is significantly correlated with the innovation-decision process, particularly when the attitude of decision-makers is either negative or positive toward the technology (Rogers 2010). This is more significant in SMEs because both operational and strategic decisions in SMEs may be taken by a single person (Ghobakhloo \& Tang 2013). As a result, the attitudes, skills, and ICT background of SMEs' managers work as a driving force for the adoption of technologies. It is often a single person's responsibility to establish goals and needs for assessing the potential of technologies in their organizations (Rahayu \& Day 2015). Consequently, the support from top management and managers' IT knowledge are considered for investigating the adoption of $\mathrm{m}$-commerce in Vietnamese SMEs.

\section{Top management support}

Top management support is about the involvement, enthusiasm, motivation, and encouragement of the management toward the adoption of technologies (Ramdani, Kawalek \& Lorenzo 2009). It is expressed in the mission of the business, the willingness to provide resources for the adoption, and the championship for the adoption (Alrousan \& Jones 2016). Table 3.14 presents an overview of the measurement items for top management support. 
Table 3.14 A summary of the measurement items for Top Management Support

\begin{tabular}{|c|c|c|}
\hline Measurement Items & Description & References \\
\hline $\begin{array}{l}\text { Awareness of m- } \\
\text { commerce benefits }\end{array}$ & $\begin{array}{l}\text { Awareness of m-commerce benefits is about the managers' } \\
\text { understanding of the benefits and importance of m- } \\
\text { commerce, leading to their support for the adoption of m- } \\
\text { commerce. }\end{array}$ & $\begin{array}{l}\text { Lin and Wu } \\
\text { (2004); Seyal and } \\
\text { Rahim (2006) }\end{array}$ \\
\hline $\begin{array}{l}\text { Allocation of } \\
\text { necessary resources } \\
\text { for m-commerce } \\
\text { adoption }\end{array}$ & $\begin{array}{l}\text { Resources allocation for m-commerce adoption is about the } \\
\text { support of the top management in allocating necessary } \\
\text { resources for the adoption of m-commerce in the } \\
\text { organization. }\end{array}$ & $\begin{array}{l}\text { Premkumar } \\
\text { (2003); Seyal and } \\
\text { Rahim (2006) }\end{array}$ \\
\hline $\begin{array}{l}\text { Championship of } \\
\text { management for m- } \\
\text { commerce }\end{array}$ & $\begin{array}{l}\text { Championship management for } \mathrm{m} \text {-commerce is about the } \\
\text { effort of top management in communicating, evangelizing, } \\
\text { and forcing for the adoption m-commerce in the } \\
\text { organization. }\end{array}$ & $\begin{array}{l}\text { Ifinedo (2011); } \\
\mathrm{Li} \text { and Wang } \\
(2018)\end{array}$ \\
\hline
\end{tabular}

Top management support is critical for technology adoption in SMEs. This is because the decision-making process in SMEs is mostly centralized in a few persons (Ghobakhloo \& Tang 2013). Such persons can provide a vision, support, and commitment to creating a positive environment for technology adoption (Huy et al. 2012). This shows that management support is associated with the adoption of technologies (Al-Alawi \& Al-Ali 2015). Top management support is the most important factor for the adoption of technologies in SMEs (Otieno \& Kahonge 2014; Al-Alawi \& Al-Ali 2015; Lu et al. 2015; Alfahl et al. 2017). This leads to the following hypothesis:

H11: Top management support positively affects the adoption of m-commerce 


\section{Managers' IT knowledge}

Managers' IT knowledge is about the IT knowledge and skills of the decision-maker that can influence the adoption of technologies. In organizational technology adoption studies, the IT knowledge of managers is reflected in their understanding of such a technology, their proficiency in using IT, and their competence in the new technology (Jeon et al. 2006; Huy et al. 2012). Table 3.15 presents an overview of the measurement items for managers' IT knowledge.

Table 3.15 A summary of the measurement items for Managers' IT knowledge

\begin{tabular}{llll}
\hline Measurement Items & \multicolumn{1}{c}{ Description } & References \\
\hline $\begin{array}{l}\text { Understanding of } \mathrm{m}- \\
\text { commerce }\end{array}$ & $\begin{array}{l}\text { Understanding m-commerce refers to the managers' } \\
\text { knowledge of m-commerce. }\end{array}$ & $\begin{array}{l}\text { Jeon et al. (2006); } \\
\text { Huy et al. (2012) }\end{array}$ \\
\hline $\begin{array}{l}\text { Proficiency in using } \\
\text { IT }\end{array}$ & $\begin{array}{l}\text { Proficiency in IT uses refers to the high level of IT skills of } \\
\text { the managers. }\end{array}$ & Jeon et al. (2006); \\
\hline $\begin{array}{l}\text { Competence in the } \\
\text { new technology }\end{array}$ & $\begin{array}{l}\text { Competence in the new technology is about the ability of } \\
\text { managers to learn to use the latest technology. }\end{array}$ & Huy et al. (2012) \\
\hline
\end{tabular}

A knowledgeable manager can champion the adoption of such technologies (Chatzoglou \& Chatzoudes 2016). Managers' IT knowledge is a critical determinant of technology adoption in organizations, especially in SMEs (Huy et al. 2012; Alrousan \& Jones 2016). As SMEs face significant risks in technology adoption, greater IT knowledge of managers can reduce the degree of uncertainty entangled with the technology adoption (Ghobakhloo et al. 2011). As a result, the IT knowledge of managers increases the opportunity for technology adoption in SMEs (Apulu \& Latham 2011). This leads to the following hypothesis: 


\subsubsection{Control Variables}

The control variables adopted in this study are organizational size and industry. As this study is conducted in the Vietnamese context, the definition of SMEs in Vietnam is adopted. This means that SMEs are independent businesses with the registered capital not exceeding 100 billion VND or the annual number of permanent employees not exceeding 300 (Business Insides 2011). As a result, both the total registered capital and the annual number of permanent employees are used for measuring the size of SMEs from two different perspectives.

Organizational size has been found to have a positive influence on the adoption of technologies in organizations (Balocco et al. 2009; Ifinedo 2011; Huy et al. 2012; Chatzoglou \& Chatzoudes 2016). This is because large organizations have the necessary resources to facilitate the adoption of technologies. There are, however, several adoption studies that fail to confirm such a positive relationship (Picoto et al. 2014b; Rahayu \& Day 2015; Ilin et al. 2017). This shows the need to include organization size in this study to better understand the adoption of m-commerce in Vietnamese SMEs.

The industry is the sector in which an organization operates. It has been found to have an influence on the adoption of technologies in organizations (Hsu, Kraemer \& Dunkle 2006; Jeon et al. 2006; Li, Lai \& Wang 2010). Jeon et al. (2006), for example, find that service businesses are more predisposed toward adopting the internet for business than other sectors. Hsu et al. (2006) reveal that manufacturing organizations are more 
predisposed toward adopting e-business than organizations in the finance sector. This view, however, is not affirmed in several IS adoption studies (Seyal \& Rahman 2003; Ifinedo 2011). This shows the need to include the industry in this study for better understanding the adoption of m-commerce in Vietnamese SMEs.

In summary, the proposed conceptual framework for investigating the critical determinants for m-commerce adoption in Vietnamese SMEs consists of four dimensions with twelve hypothesized factors. Specifically, the technological dimension includes perceived benefits, perceived compatibility, perceived security, and perceived cost. The organizational dimension consists of employees' IT knowledge, organizational readiness, and organizational innovativeness. The environmental dimension includes competitive pressures, customer pressures, and government support. The managerial dimension includes top management support and managers' IT knowledge. The adoption of m-commerce is also proposed to be controlled by the organizational size and industry in which SMEs are operating.

\subsection{Concluding Remarks}

This chapter presents a comprehensive review of the most dominant theories in technology adoption in organizations including DOI, TOE, RBT, and the institutional theory. This leads to a justification of the appropriateness of each theory, resulting in the selection of DOI and TOE for guiding the development of a conceptual framework for investigating the critical determinants for $\mathrm{m}$-commerce adoption in Vietnamese SMEs. The proposed conceptual framework consists of four dimensions including 
technological, organizational, environmental, and managerial. The technological dimension consists of four factors, namely perceived benefits, perceived compatibility, perceived security, and perceived costs. The organizational dimension consists of three factors including employees' IT knowledge, organizational readiness, and organizational innovativeness. The environment dimension consists of three factors including competitive pressures, customer pressures, and government support. The managerial dimension consists of two factors, namely top management support and managers' IT knowledge. The chapter also discusses the controlling roles of organizational size and type of industries. Such a framework forms the basis for the development of the survey instrument for data collection. The proposed framework lays the foundation for designing and implementing the quantitative study to better understand the adoption of $\mathrm{m}$-commerce in Vietnamese SMEs. 


\section{Chapter 4}

\section{Research Methodology}

\subsection{Introduction}

A research methodology is specific procedures or techniques for identifying, selecting, processing, and analyzing a research problem from the theoretical underpinning of the research to the interpretation of the research findings (Sekaran \& Bougie 2016). It includes various research activities including data collection, data analysis, and result interpretation that facilitate answering the research question (Saunders 2011). An appropriate research methodology determines the success of a research project. This is because such a methodology can guide how the research can be conducted (Saunders 2011; Collis \& Hussey 2013; Creswell \& Clark 2017).

The selection of an appropriate research methodology in a research project is challenging. It is very much dependent on the nature of the research and the availability of research methods and techniques (Chen \& Hirschheim 2004; Kothari 2004; Creswell 2017). The selection of the research methodology involves the selection of the research paradigm, the research design, and the adoption of specific research methods (Creswell \& Clark 2017). The research paradigm provides the research project with the philosophical principle that guides the selection of the research methodology. This, in 
turn, guides the selection of the research methods and the implementation of suitable research design.

The objective of this chapter is to discuss the selection of the research methodology for addressing the research question in this study. It first explains the research philosophy and the paradigm that guides this study. This paves the way for the selection of an appropriate research methodology for the study. It then discusses the process of data collection with respect to the instrument design, the sample selection, and the implementation of survey data collection. Finally, the chapter discusses the adoption of data analysis methods and techniques for the research.

The rest of the chapter is organized into six sections. Section 4.2 discusses different research paradigms for guiding the selection of an appropriate research methodology for this study. Section 4.3 presents the research methodology and the research methods and techniques that this study adopts. Section 4.4 describes the process of data collection. Section 4.5 outlines data analysis methods and techniques. Section 4.6 specifies the ethics-related issues of conducting the research. Section 4.7 ends the chapter with some concluding remarks.

\subsection{Research Paradigms}

A research paradigm is a set of basic beliefs and perceptions about the nature of the world that guide researchers to carry out a specific research project (Lincoln, Lynham \& Guba 2011). It helps researchers to achieve the research objective through answering 
four questions including (a) how the world works, (b) how the knowledge is excerpted from the world, (c) what types of questions are to be asked, and (d) what methodologies can be used in answering these questions (Dills \& Romiszowski 1997).

There are three underlying principles that a research paradigm follows. These principles including (a) ontologies, (b) epistemologies, and (c) methodologies frame the nature of the research and determine the role of the researcher in conducting specific scientific inquiries. Ontologies are related to the existence and the nature of the reality. Epistemologies are about the perceived relationship between the researcher and the object being studied. Methodologies are linked to the process and the means of knowing something in a study (Khazanchi \& Munkvold 2003; Becker \& Niehaves 2007).

Ontologies are the theory of "reality" that studies the nature of the world or the nature of the reality (Creswell 2012). They assume that the objective reality stands independently of human thought and speech. Such a reality is independent of the method of inquiry of the researcher. It is a construct that depends on human consciousness (Becker \& Niehaves 2007).

Epistemologies are about how knowledge about the reality should be acquired. They focus on the relationship between researchers and the reality (Khazanchi \& Munkvold 2003; Ritchie et al. 2013). Epistemologies concern whether the knowledge is formulated and evaluated by empirically verifying the theory or the knowledge is constructed by engaging with the researcher in a social context (Rowland 2003; Saunders, Lewis \& Thornhill 2012). 
Methodologies are linked to how a researcher approaches the conducting of his or her empirical research in search of knowing the phenomena. They are concerned about the use of specific methods and techniques for data collection and analysis. This leads to the determination of specific approaches including quantitative, qualitative, or mixedmethods for collecting the research data (Lincoln et al. 2011; Saunders et al. 2012). Methodologies are adopted for translating the ontology and epistemology principles into research activities that need to be conducted for addressing the research question of a specific research project.

Ontology, epistemology, and methodology principles are the core components of a research paradigm (Guba \& Lincoln 1994). Such principles guide, inform, and shape how a researcher perceives the world in a study. As a result, the selection of a research paradigm for a research project is based on the perception of the researcher about these principles (Guba \& Lincoln 1994; Lincoln et al. 2011).

There are commonly three paradigms including the positivism paradigm, the interpretivism paradigm, and the critical realism paradigm (Orlikowski \& Baroudi 1991). Overall, the positivism and interpretivism paradigms are the two prominent philosophies in the social science and business research, especially in the information systems research (Orlikowski \& Baroudi 1991; Mingers 2003; Saunders et al. 2012). These paradigms differ by ontologies, epistemologies, and methodologies. Table 4.1 presents a summary of the basic beliefs of these three paradigms above. 
Table 4.1 A summary of the three paradigms

\begin{tabular}{|c|c|c|c|}
\hline Assumption & Positivism & Interpretivism & Critical Realism \\
\hline Ontologies & $\begin{array}{l}\text { Reality exists objectively } \\
\text { and independently from the } \\
\text { researcher. } \\
\text { The formulation of } \\
\text { hypotheses, models, or } \\
\text { causal relationships } \\
\text { between constructs. }\end{array}$ & $\begin{array}{l}\text { Reality is constructed and } \\
\text { reconstructed through a researcher } \\
\text { and social interaction process. } \\
\text { The data are not detachable from } \\
\text { theory because they are } \\
\text { determined in light of the } \\
\text { theoretical interpretation of } \\
\text { individuals. }\end{array}$ & $\begin{array}{l}\text { Reality can be only } \\
\text { captured } \\
\text { imperfectly and } \\
\text { probabilistically. } \\
\text { The reality cannot } \\
\text { be perfectly } \\
\text { measured. }\end{array}$ \\
\hline Episte & $\begin{array}{l}\text { The use of quantitative } \\
\text { methods to test theories or } \\
\text { hypotheses. } \\
\text { Generalization is derived } \\
\text { from the experience that is } \\
\text { independent of the } \\
\text { researchers, their methods, } \\
\text { and the object of their } \\
\text { study. }\end{array}$ & $\begin{array}{l}\text { Knowledge of reality should be } \\
\text { obtained through the } \\
\text { understanding of human and } \\
\text { social interaction by which the } \\
\text { subjective meaning of the reality } \\
\text { is constructed. } \\
\text { Generalization derived from } \\
\text { experience is dependent upon the } \\
\text { researchers and their methods. }\end{array}$ & $\begin{array}{l}\text { Knowledge of } \\
\text { reality is impacted } \\
\text { by social } \\
\text { conditions, and } \\
\text { thus they cannot be } \\
\text { understood } \\
\text { independently of } \\
\text { the social context. }\end{array}$ \\
\hline Methodologies & $\begin{array}{l}\text { The researcher should be in } \\
\text { the value-free position to } \\
\text { employ objective } \\
\text { measurement to collect } \\
\text { research evidence using } \\
\text { quantitative methods. }\end{array}$ & $\begin{array}{l}\text { Qualitative methods are normally } \\
\text { employed. }\end{array}$ & $\begin{array}{l}\text { It supports the use } \\
\text { of methods of both } \\
\text { positivism and } \\
\text { interpretivism. }\end{array}$ \\
\hline
\end{tabular}

The positivism paradigm is a philosophy of social science that explains what occurs in the phenomenon by investigating the causal relationship between existing constituent constructs (Collis \& Hussey 2013). It is mostly depicted through (a) the development of hypotheses, models, or causal relationships between constructs, (b) the adoption of a quantitative methodology to test and validate specific theories followed in the research, 
and (c) the objective and value-free interpretation of the research data (Chen \& Hirschheim 2004; Saunders et al. 2012).

The interpretivism paradigm is a philosophy of social science supporting the opinion that the social world can only be fully understood through the subjective interpretation of the reality and the related intervention (Saunders et al. 2012; Creswell \& Clark 2017). Interpretivism is completely depicted through (a) the involvement of the researcher in the specific social setting in the investigation, (b) the adoption of the qualitative methodology for collecting and analyzing the research data, and (c) the subjective interpretation of the research data (Chen \& Hirschheim 2004; Saunders et al. 2012).

The critical realism is not committed to any systems of philosophy or reality. It has an ontological stance similar to the positivism. It follows the same epistemological stance to the interpretivism. The critical realism paradigm aims to mix existing research methods in specific ways for answering the research question in a research project (Johnson \& Onwuegbuzie 2004). It focuses on the "what" and "how" of the research problem to apply all the appropriate data collection and analysis methods for solving such problems regardless of the underlying philosophical assumptions (Creswell \& Clark 2017). It poses the question that can be answered using the methods of both positivism and interpretivism (Myers 2013; Creswell 2017).

This study focuses on identifying the critical determinants for m-commerce adoption in Vietnamese SMEs. As a result, a positivism research paradigm is the most appropriate 
selection for conducting this research. The suitability of the positivism paradigm for this study is based on three main reasons. First, this study develops a conceptual framework for better understanding the critical determinants for m-commerce adoption in Vietnamese SMEs. Such a framework is based on specific theories drawn from previous organizational m-commerce adoption studies. Second, the proposed conceptual framework is empirically tested and validated using numerical data for identifying the critical determinants for m-commerce adoption in Vietnamese SMEs. Third, the data is collected using measurement instruments that are completed by the manager of the selected Vietnamese SME. As a result, there is no interaction between the researcher and the critical determinants being observed. The researcher mainly focuses on interpreting the results and does not influence the data collected. The knowledge is then derived from the thinking of the researcher.

\subsection{Research Methodologies}

A research methodology is a strategic blueprint to be followed for answering a particular research question in a research project (Wiersema \& Bowen 2009). It involves formulating the research question, operationalizing the theoretical constructs, identifying the sample, gathering the data, selecting the statistical method for data analysis, and interpreting and reporting the research findings (Wiersema \& Bowen 2009; Creswell 2017). An appropriate research methodology improves the research findings of a research project. This is because the use of such a research methodology provides the researcher with specific guidelines for conducting the research to 
effectively fulfill the research objective. It helps the researcher to complete the research project within the limited time and resources (Creswell \& Clark 2017).

The selection of a research methodology for a specific study depends on the nature of the research, the research question, the research objective, and the research hypotheses. It also depends on the available resources and skills that the researcher has for conducting the study (Hair et al. 2010; Saunders 2011). In the selection of a specific research methodology, four questions need to be addressed including (a) what are the questions to be answered, (b) what is the relevant data, (c) how to collect the data, and (d) how to analyze the data (Sekaran \& Bougie 2016).

There are three categories of research methodologies that are widely used in a research project including a qualitative research methodology, a quantitative research methodology, and a mixed research methodology (Johnson \& Onwuegbuzie 2004; Creswell \& Clark 2017). The use of a qualitative research methodology follows the interpretivism paradigm for exploring and understanding how individuals respond to a social phenomenon in detail (Saunders et al. 2012). It focuses on the description of a scenario using words in the collection and analysis of data (Bryman \& Bell 2015; Sekaran \& Bougie 2016). The collected data is analyzed to identify and interpret the pattern. This leads to the generation of a theory (Creswell 2017; Creswell \& Clark 2017). With the adoption of qualitative methodologies, specific research methods can be used including interviews, case studies, and action research (Saunders et al. 2012; Creswell \& Clark 2017). 
The application of a quantitative research methodology follows a positivism paradigm for confirming the theory proposed by the researcher on a certain phenomenon (Saunders et al. 2012). It focuses on the quantification of specific relationships between some theoretical constructs for expressing a specific phenomenon in a given study (Kothari 2004; Bryman \& Bell 2015). Such a methodology uses inference analysis and statistical analysis to draw meaningful conclusions from the empirical results (Creswell \& Clark 2017). It is helpful for testing the hypotheses of a study through the use of numerical data representing the viewpoint of a population (Vanderstoep \& Johnson 2008). The most popular quantitative methods are surveys, lab experiments, field experiments, and simulation (Collis \& Hussey 2013).

The use of a mixed research methodology follows a critical realism paradigm for collecting, analyzing, and mixing both qualitative and quantitative approaches in many stages of the research process within a single research project (Creswell \& Clark 2017). Its central premise is that the use of qualitative and quantitative approaches in combination provides better understanding of the research problem than either approach alone. The most popular strategies of the mixed methodology are the sequential mixed methodology, the concurrent mixed methodology, and the transformative mixed methodology (Creswell 2017). Under the sequential mixed methodology, the researcher builds on or reinforces the research findings of one methodology with another (Creswell 2017). With the concurrent mixed methodology, the qualitative and quantitative approaches are merged throughout the research process to provide a comprehensive analysis of the research problem (Creswell 2017). Under the transformative mixed 
methodology, the researcher employs a theory-based framework that entails a research design embracing both qualitative and quantitative data (Creswell 2017).

This study follows the positivism paradigm. As a result, it adopts a quantitative research methodology to accomplish the research objective (Creswell 2012). This is because this study aims to investigate the critical determinants for m-commerce adoption in Vietnamese SMEs, which is confirmatory in nature (Chau et al. 2020). The use of a quantitative methodology is suitable for this study due to two main reasons. First, a quantitative methodology is capable of assessing the validity of the proposed hypotheses developed on m-commerce adoption in Vietnamese SMEs by collecting and analyzing the collected numerical data. Second, a quantitative methodology is useful for increasing the generalizability of the research findings on the critical determinants for $\mathrm{m}$-commerce adoption in this study as these determinants are based on the perceptions of a large population of SMEs in Vietnam (Straub et al. 2004; Vanderstoep \& Johnson 2008; Saunders et al. 2012).

This study adopts the survey method with the use of the quantitative research methodology for collecting data. This is because a survey is commonly used for studying the cause of a phenomenon, as well as the attitudes and behaviors of the sample population with empirical evidence (Sekaran \& Bougie 2016; Creswell 2017). The adoption of a survey is suitable for this study as it employs direct questioning to gather the opinions of respondents on a specific topic. This facilitates (a) the investigation of the emerging pattern of $\mathrm{m}$-commerce adoption in Vietnamese SMEs 
and (b) the validation of the proposed conceptual framework with respect to the critical determinants for m-commerce adoption in Vietnamese SMEs.

There are different survey methods including face-to-face interviews, telephone interviews, postal questionnaires, and internet surveys (Saunders 2011). The selection of a specific survey method depends on the consideration of several criteria such as the sample size, time and cost, geographical coverage, response rate, and survey length. Table 4.2 presents a comparison of different survey methods.

Table 4.2 A comparison of different survey methods

\begin{tabular}{|c|c|c|c|c|}
\hline & $\begin{array}{c}\text { Face-to-Face } \\
\text { Interview }\end{array}$ & $\begin{array}{l}\text { Telephone } \\
\text { Interview }\end{array}$ & Mail Survey & Internet Survey \\
\hline Sample size & Low & Medium & Large & Large \\
\hline Survey length & Up to 2 hours & Up to 30 minutes & Up to 20 minutes & Up to 20 minutes \\
\hline Cost & High & Medium & Low & Very low \\
\hline Response rate & High & Medium & Medium & Very low \\
\hline Privacy & Less comfortable & Uncomfortable & Comfortable & Comfortable \\
\hline Bias & Yes & Yes & No & No \\
\hline Missing data & Low & Low & Medium & Medium \\
\hline Required training & Yes & Yes & No & No \\
\hline Reaching respondents & Difficult & Easy & Medium & Easy \\
\hline Geographical coverage & Difficult & Easy & Easy & Very easy \\
\hline
\end{tabular}

This study adopts both the internet survey and the paper-based survey for data collection. This adoption is based on the following reasons. First, an internet survey is considered the most effective, inexpensive, and fastest way of collecting a large amount 
of primary data from a large sample size that is geographically distributed (Williams et al. 2009). Second, the participants of this study are the managers of Vietnamese SMEs that are expected to be always busy and difficult to approach. As a result, an internet survey is the most convenient method for such participants to get involved. Third, this study focuses on the evaluation of the critical determinants for m-commerce adoption from the perspective of SMEs' managers. Consequently, an internet survey enables them to answer self-administrated questionnaires freely, adequately, and at their convenience (Babbie 2010), leading to an accurate description of their evaluation of the investigated determinants. Fourth, there is no interviewer bias in the internet survey, which results in more accuracy for the research outputs. However, the main disadvantage of the internet survey is the low response rate. As a result, a paper-based survey is followed with support from the Vietnam Association of Small and Medium Enterprises (VINASME) in delivering the questionnaire to the managers of the selected SMEs to increase the response rate for the whole research (Ditsa 2004; Babbie 2010).

\subsection{Data Collection}

Data collection is the process of collecting and preparing relevant data for answering the research question (Creswell \& Clark 2017). The survey data collection process for this study consists of three steps including (a) developing a reliable and valid survey instrument, (b) selecting an appropriate sample size and sample frame, and (c) conducting the survey with the manager of Vietnamese SMEs within the selected sample frame. The details of each step are discussed in the following sections. 


\subsubsection{Survey Instrument Development}

The instrument development process in this study operationalizes the critical determinants and the adoption decision to make them measurable and quantifiable (Karunasena, Deng \& Singh 2011; Duan et al. 2012). This study adopts a two-stage process of instrument development proposed by Churchill (1979) and Straub (1989), including (a) developing the survey instrument and (b) refining the survey instrument. Figure 4.1 presents a summary of such a process.

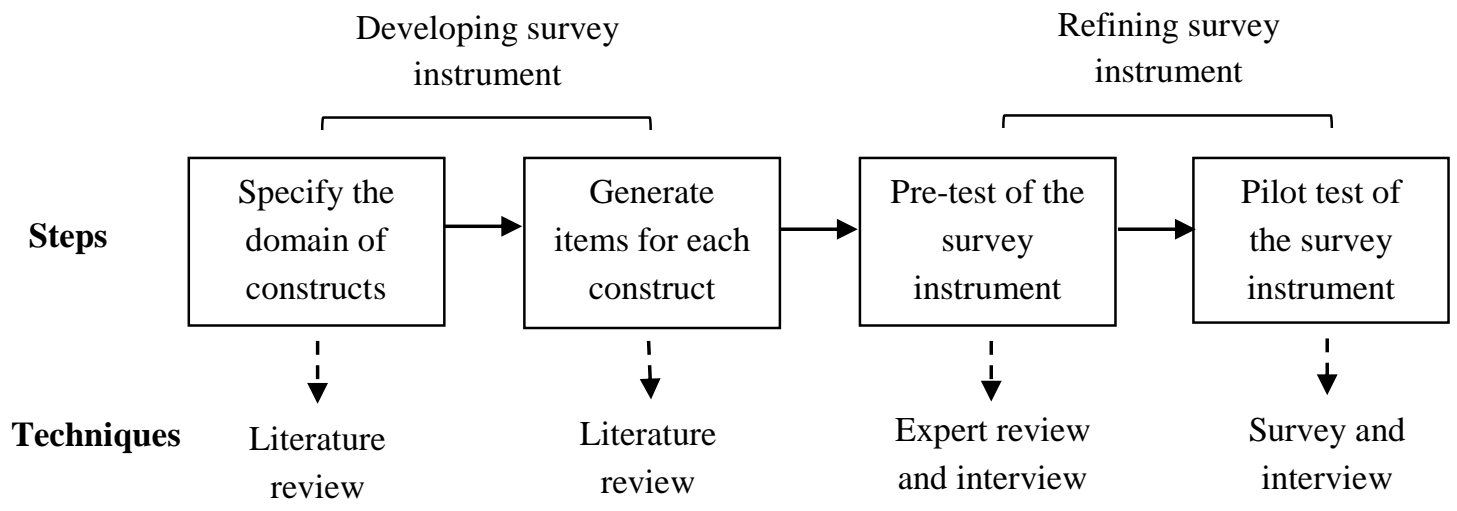

Figure 4.1 The survey instrument development process

The survey instrument development stage consists of (a) the domain specification of the constructs and (b) the generation of sample items to operationalize individual constructs. The domain specification aims to provide a clear conceptual definition of the construct by indicating its sub-elements or dimensions (Lewis, Templeton \& Byrd 2005). Such a specification is accomplished through a comprehensive review of the literature on m-commerce and technology adoption in SMEs, as presented in Chapter 2 and Chapter 3. The literature review leads to the identification of the perceived benefits, 
perceived compatibility, perceived security, perceived cost, employees' IT knowledge, organizational readiness, organizational innovativeness, competitive pressures, customer pressures, government support, top management support, managers' IT knowledge, organizational size and industry as the critical factors that may influence the adoption of m-commerce in Vietnamese SMEs. Table 4.3 to Table 4.7 provide the descriptions for the constructs that comprise the conceptual framework presented in Chapter 3.

Table 4.3 The description of technological determinants of m-commerce adoption in SMEs

\begin{tabular}{ll}
\hline \multicolumn{1}{c}{ Critical Determinants } & \multicolumn{1}{c}{ Descriptions } \\
\hline Perceived benefits & $\begin{array}{l}\text { A set of anticipated advantages that can be gained by an organization when } \\
\text { m-commerce has been adopted (Seyal et al. 2004). }\end{array}$ \\
\hline Perceived compatibility & $\begin{array}{l}\text { Compatibility is the extent that organizations think m-commerce will fit into } \\
\text { all aspects of their existing business (Scupola 2003). }\end{array}$ \\
\hline Perceived security & The perceived confidence about the security of m-commerce transactions by \\
& the organization (Kamaroddin, Cheong \& Ahmad 2008; Hung et al. 2011). \\
\hline & The financial expenses that are required to adopt m-commerce (Wymer \& \\
Perceived costs & Regan 2005).
\end{tabular}

Table 4.4 The description of organizational determinants of m-commerce adoption in SMEs

\begin{tabular}{ll}
\hline \multicolumn{1}{l}{$\begin{array}{l}\text { Critical Determinants } \\
\text { Employees' } \\
\text { knowledge }\end{array}$} & \multicolumn{1}{c}{ Descriptions } \\
\hline IT & $\begin{array}{l}\text { Level of IT knowledge among employees in the organization (Zhu et al. } \\
2003) .\end{array}$ \\
Organizational readiness & $\begin{array}{l}\text { Availability of the organizational resources needs for the adoption of m- } \\
\text { commerce (Iacovou et al. 1995). }\end{array}$ \\
\hline $\begin{array}{l}\text { Organizational } \\
\text { innovativeness }\end{array}$ & $\begin{array}{l}\text { The openness of an organization to new ideas and solutions in the context of } \\
\text { technology adoption (Kunz, Schmitt \& Meyer 2011; Wamba \& Carter 2013). }\end{array}$ \\
\hline
\end{tabular}


Table 4.5 The description of environmental determinants of m-commerce adoption in SMEs

\begin{tabular}{ll}
\hline Critical Determinants & \multicolumn{1}{c}{ Descriptions } \\
\hline Competitive pressures & $\begin{array}{l}\text { The degree that a firm is affected by competitors in the market (Shaharudin } \\
\text { et al. 2012). }\end{array}$ \\
\hline Customer pressures & $\begin{array}{l}\text { The pressure from the customer leading to the adoption of a particular } \\
\text { innovation by an organization (Ifinedo 2011). }\end{array}$ \\
\hline Government support & $\begin{array}{l}\text { Government policies and initiatives to promote innovation adoption in the } \\
\text { organization (Hameed, Counsell \& Swift 2012). }\end{array}$ \\
\hline
\end{tabular}

Table 4.6 The description of managerial determinants of m-commerce adoption in SMEs

\begin{tabular}{ll}
\hline Critical Determinants & \multicolumn{1}{c}{ Descriptions } \\
\hline Top management support & $\begin{array}{l}\text { The involvement, enthusiasm, motivation, and encouragement provided by } \\
\text { management toward the adoption of m-commerce (Masrek, Karim \& } \\
\text { Hussein 2008). }\end{array}$ \\
\hline Manager's IT knowledge & $\begin{array}{l}\text { IT knowledge and skills of decision-makers that can influence the adoption } \\
\text { of m-commerce (Almoawi 2011). }\end{array}$ \\
\hline
\end{tabular}

Table 4.7 The description of control variables of m-commerce adoption in SMEs

\begin{tabular}{ll}
\hline Critical Determinants & \multicolumn{1}{c}{ Descriptions } \\
\hline Organizational size & The number of permanent employees or total registered capital. \\
\hline Industry & The industrial sector in which the SME operates. \\
\hline
\end{tabular}

The item generation for individual constructs is about the "operationalization of constructs" that is concerned "ascribing meaning to a construct by specifying operations that the researcher must perform to measure or manipulate the construct" (Ary et al. 2018, p. 36). The item generation for each construct is accomplished through a review 
of the related literature and the consideration of the unique circumstance of the research problem. In this research, each critical determinant and the construct of organizational decision to adopt m-commerce are justified and derived from the literature review. As a result, the items that measure these constructs are derived from previous studies to ensure their validity and reliability. Additionally, several new items are developed from the context of this research. Table 4.8 to Table 4.12 present the associated items for measuring the individual constructs in specific dimensions and the origins of these items. 
Table 4.8 Measurement items for technological constructs

\begin{tabular}{|c|c|c|c|}
\hline Constructs & Items & Code & References \\
\hline \multirow{8}{*}{$\begin{array}{l}\text { Perceived } \\
\text { benefits } \\
(\mathrm{BENE})\end{array}$} & Operating costs savings & BENE1 & Zhu et al. (2006) \\
\hline & Simplification of the operating procedures & BENE2 & Zhu et al. (2006) \\
\hline & Increase in market share & BENE3 & Scupola (2009) \\
\hline & Growth of revenue & BENE4 & Zhu et al. (2006) \\
\hline & Creation of marketing channels & BENE5 & Scupola (2009) \\
\hline & Improvement of the company's image & BENE6 & Zhu et al. (2006) \\
\hline & Improvement in competitiveness & BENE7 & Teo et al. (2009) \\
\hline & Enhancement of customer services & BENE8 & Scupola (2009) \\
\hline \multirow{6}{*}{$\begin{array}{l}\text { Perceived } \\
\text { compatibility } \\
\text { (CMPA) }\end{array}$} & Alignment with the ICT infrastructure & CMPA1 & Zhu et al. (2006) \\
\hline & Integration with current business processes & CMPA2 & Zhu et al. (2006) \\
\hline & Adaptability of existing distribution channels & CMPA3 & Zhu et al. (2006) \\
\hline & Consistency with the organizational culture & CMPA4 & Ghobakhloo et al. (2011) \\
\hline & $\begin{array}{l}\text { Suitability with customers' ways of doing } \\
\text { business }\end{array}$ & CMPA5 & Ghobakhloo et al. (2011) \\
\hline & $\begin{array}{l}\text { The richness of the experience in adopting } \\
\text { technological innovations }\end{array}$ & CMPA6 & Ghobakhloo et al. (2011) \\
\hline \multirow{3}{*}{$\begin{array}{l}\text { Perceived } \\
\text { security } \\
\text { (SECU) }\end{array}$} & Awareness of the security of $m$-commerce & SECU1 & Alam et al. (2011) \\
\hline & $\begin{array}{l}\text { Availability of industry standards for the } \\
\text { security of m-commerce }\end{array}$ & SECU2 & Alam et al. (2011) \\
\hline & $\begin{array}{l}\text { Availability of laws and regulations for } \mathrm{m} \text { - } \\
\text { commerce }\end{array}$ & SECU3 & Alam et al. (2011) \\
\hline \multirow{3}{*}{$\begin{array}{l}\text { Perceived cost } \\
\text { (CSTS) }\end{array}$} & Infrastructure cost requirements & CSTS1 & Al-Qirim (2006) \\
\hline & Training cost requirements & CSTS2 & Al-Qirim (2006) \\
\hline & Maintenance cost requirements & CSTS3 & Al-Qirim (2006) \\
\hline
\end{tabular}


Table 4.9 Measurement items for organizational constructs

\begin{tabular}{|c|c|c|c|}
\hline Constructs & Items & Code & References \\
\hline Employees' IT & Understanding of m-commerce & EMPL1 & Huy et al. (2012) \\
\hline knowledge & Proficiency in using IT & EMPL2 & Huy et al. (2012) \\
\hline$($ EMPL) & Competence in the new technology & EMPL3 & Huy et al. (2012) \\
\hline \multirow{2}{*}{$\begin{array}{l}\text { Organizational } \\
\text { readiness }\end{array}$} & Financial readiness & READ1 & Alam et al. (2011) \\
\hline & Technological readiness & READ2 & Alam et al. (2011) \\
\hline (READ) & Human resource readiness & READ3 & Alam et al. (2011) \\
\hline \multirow{3}{*}{$\begin{array}{l}\text { Organizational } \\
\text { innovativeness }\end{array}$} & Innovativeness ability & INNO1 & Wamba and Carter (2013) \\
\hline & Ability to adopt new management approaches & INNO2 & Wamba and Carter (2013) \\
\hline & $\begin{array}{l}\text { Ability to improve business processes } \\
\text { continuously }\end{array}$ & INNO3 & Wamba and Carter (2013) \\
\hline
\end{tabular}

Table 4.10 Measurement items for environmental constructs

\begin{tabular}{|c|c|c|c|}
\hline Constructs & Items & Code & References \\
\hline \multirow{3}{*}{$\begin{array}{l}\text { Competitive } \\
\text { pressures } \\
(\mathrm{CMPE})\end{array}$} & Availability of similar products/services of competitors & CMPE1 & $\begin{array}{l}\text { Thong and Yap } \\
\text { (1995) }\end{array}$ \\
\hline & Availability of similar products/services of new entrants & CMPE2 & $\begin{array}{l}\text { Thong and Yap } \\
\text { (1995) }\end{array}$ \\
\hline & Availability of substitute products/services & CMPE3 & $\begin{array}{l}\text { Thong and Yap } \\
\text { (1995) }\end{array}$ \\
\hline \multirow{3}{*}{$\begin{array}{l}\text { Customer } \\
\text { pressures } \\
\text { (CUST) }\end{array}$} & $\begin{array}{l}\text { The requirement for adopting m-commerce from } \\
\text { customers }\end{array}$ & CUST1 & Teo et al. (2009) \\
\hline & The expectation for adopting $\mathrm{m}$-commerce from customers & CUST2 & Teo et al. (2009) \\
\hline & The need for maintaining relationships with customers & CUST3 & Teo et al. (2009) \\
\hline \multirow{2}{*}{$\begin{array}{l}\text { Government } \\
\text { support }\end{array}$} & Legal considerations for $\mathrm{m}$-commerce & GOVE1 & Huy et al. (2012) \\
\hline & Financial support & GOVE2 & Huy et al. (2012) \\
\hline (GOVE) & Availability of the training and educational programs & GOVE3 & Huy et al. (2012) \\
\hline
\end{tabular}


Table 4.11 Measurement items for managerial constructs

\begin{tabular}{|c|c|c|c|}
\hline Constructs & Items & Code & References \\
\hline \multirow{3}{*}{$\begin{array}{l}\text { Top } \\
\text { management } \\
\text { support } \\
\text { (TMSP) }\end{array}$} & Awareness of m-commerce benefits & TMSP1 & $\begin{array}{l}\text { Seyal and Rahim } \\
\text { (2006) }\end{array}$ \\
\hline & $\begin{array}{l}\text { Allocation of necessary resources for } \mathrm{m} \text {-commerce } \\
\text { adoption }\end{array}$ & TMSP2 & $\begin{array}{l}\text { Seyal and Rahim } \\
\text { (2006) }\end{array}$ \\
\hline & Championship of management for m-commerce & TMSP3 & $\begin{array}{l}\text { Seyal and Rahim } \\
\text { (2006) }\end{array}$ \\
\hline \multirow{3}{*}{$\begin{array}{l}\text { Managers' IT } \\
\text { knowledge }\end{array}$} & Understanding of m-commerce & TMIT1 & Huy et al. (2012) \\
\hline & Proficiency in using IT & TMIT2 & Huy et al. (2012) \\
\hline & Competence in the new technology & TMIT3 & Huy et al. (2012) \\
\hline
\end{tabular}

Table 4.12 Measurement items for dependent construct

\begin{tabular}{llrr}
\hline Constructs & \multicolumn{1}{c}{ Items } & Code & References \\
\hline Adoption & Intend to adopt m-commerce & ADPT1 & Davis (1989) \\
\cline { 2 - 4 } intention & Have a certain plan to adopt m-commerce & ADPT2 & Davis (1989) \\
\cline { 2 - 4 } (ADPT) & Have a strong commitment to adopting m-commerce & ADPT3 & Davis (1989) \\
\hline
\end{tabular}

Three constructs are directly operationalized by the observed variables including the organizational size by the number of permanent employees, organizational size by the total registered capital and industry. The size of SMEs has measured by the number of permanent employees and the total registered capital. In particular, the number of permanent employees ranged from 1 to 300 , and the total capital is not exceeding VND 100 billion as the definition for Vietnamese SMEs is presented in Chapter 2. The industry construct is the sector that an SME is operating. Other constructs are operationalized as multi-item constructs that are measured using a five-point Likert 
scale, ranging from strongly disagree (1) to strongly agree (5). The five-point Likert scale is chosen due to the following reasons. First, it is the most common questioning format to obtain opinion data (Saunders 2011). Second, it is suitable for measuring dissimilarity in attitudes and perceptions among individuals (Sekaran \& Bougie 2016). Third, it is considered easy and fast for understanding and answering questions by respondents (Malhotra 2010). Finally, it is easy to code and manage the answers of the Likert scale in various statistical software (Malhotra 2010).

The survey instrument refinement stage consists of the pre-test and the pilot test of the survey instrument to purify the measures. The purpose of the pre-test for the survey instrument is to evaluate the content validity of the survey designed for collecting the research data (Hair et al. 2010). The content validity is about the extent to which measurement items capture different dimensions or aspects of a specific construct (Straub et al. 2004; Hair et al. 2010). In this step, experts in the field of business information systems are invited to validate the survey instrument based on the wording comprehensibility, interpretation consistency, logical sequencing, and the overall impression from the look and feel of the survey (Hair et al. 2010; Sekaran \& Bougie 2016).

In this study, a pre-test is conducted with a panel of experts in the field of m-commerce. Five academics in the area of technology adoption and $\mathrm{m}$-commerce adoption and five doctoral students in business information systems are invited to pre-test the survey questionnaire as a panel of experts. An email package including the invitation letter and an English version of the questionnaire is sent to invite the participants. Three 
academics and five doctoral students have accepted the invitation. These experts are asked to carefully examine each question of the survey and provide comments on the wording, content relevancy, and structure of the survey. They are also encouraged to write additional comments on the survey as a whole regarding the completeness of its contents, the order of the measurement items, and the need for additional items or questions. Based on the comments from the panel of experts, a final modification is made to the survey instrument.

The survey instrument used in the pre-test is initially written in English. The survey, however, is taken place in Vietnam, where the official language is Vietnamese. As a result, the survey instrument is translated into Vietnamese using a parallel translation technique to ensure an accurately-worded translation (Usunier 1998). Specifically, one translator converts the survey questionnaire from English to Vietnamese, and then another translator converts it back from Vietnamese to English. To ensure the meaning in the Vietnamese version conveys the same meaning as the English version, the translation of the survey questionnaire into Vietnamese and then into English is independently done by two Vietnamese English lecturers who are linguistic specialists. The final Vietnamese version of the survey questionnaire is transformed into an online version using Qualtrics, which is then used for the pilot study.

A pilot test is conducted with a small sample size before the actual data collection to ensure the reliability of the survey instrument (Straub 1989; Deng, Duan \& Luo 2019). It helps to assess the validity of the questions in the questionnaire and the reliability of the data collected (Saunders 2011). The use of a pilot test also provides the researcher 
with early warning signs of any weaknesses of the proposed research such as the inappropriateness of the research method or the research tool used in a given situation.

It is suggested conducting a pilot test over a small number of target respondents (Bell, Brooks \& Prokopczuk 2013). The minimum number of participants in the pilot test depends on the proposed sample size, the research context, and the research topic. Barker (1994), for example, suggests that $10 \%$ to $20 \%$ of the research sample size is sufficient for a pilot study. In this research, the top managers of fifty selected Vietnamese SMEs are invited to be participants in the pilot test. An email package that includes the invitation letter and the link to the online pilot questionnaire is sent to such participants. They are invited to complete the questionnaire, give notes on any unclear questions, present opinions on the design layout, and provide suggestions for improving the questionnaire. There are thirty-two respondents who have agreed to participate and provided their feedback on the survey in this situation.

The feedback from the pilot study leads to a minor revision on the survey instrument and its design. Regarding the wording and clarity, some statements are reworded. This makes the statement in the survey clearer and more understandable. Regarding the design layout, most participants suggest changing the font style and increasing the font size to make the questionnaire more legible when it is accessed by mobile devices. They also recommend having a detailed first page with step-by-step instructions for completing the questionnaire. Finally, most participants suggest increasing the number of questions on each screen that can help to reduce the number of times they have to 
click "Next" for screen transition. Based on the feedback from the pilot study, the final version of the survey questionnaire is produced.

Construct reliability is about the consistency of the measurement items composing a particular construct in the research (Lu, Lai \& Cheng 2007; Karunasena \& Deng 2012; Cui et al. 2019). It is critical to ensure the reliability of the constructs before conducting the main data collection in this study. As a result, the data collected from the pilot study is used for preliminarily assessing the reliability of the research constructs.

Cronbach's alpha coefficient is the common indicator for examining the reliability of a particular construct (George 2011). A Cronbach's alpha value greater than 0.7 indicates the reliability of the research construct (Hair et al. 2010). The Cronbach's alpha coefficients for all constructs are calculated using the pilot data. The results reveal that these coefficients are ranged from 0.817 to 0.914 . The construct reliability of the survey instrument is, therefore, supported in this study.

The survey is designed for achieving two objectives including (a) identifying the emerging pattern of m-commerce adoption in Vietnamese SMEs across different organizational sizes and different industries and (b) exploring the critical determinants for the adoption of m-commerce in Vietnamese SMEs. The survey is designed with three sections. The first section gathers the demographic information of the surveyed SMEs and their status in the adoption of $\mathrm{m}$-commerce. The second section includes questions for capturing the perception of top managers of Vietnamese SMEs on the critical determinants for the adoption of m-commerce from technological, 
organizational, environmental, and managerial perspectives based on the items proposed in Table 4.4. The third section gathers the demographic information of the managers of the selected SMEs as the respondents of the survey.

\subsubsection{Sample Design}

Sampling techniques allow researchers to collect data from subsets of populations that can reasonably represent the larger population (Saunders 2011). As a result, sample design is an extremely important process contributing to the success of a research project. This study follows the five-step sequence for the sample design including target population, sample frame, sample method, sample unit, and sample size (Saunders 2011).

A target population is a group of individuals or organizations that share some common defining characteristics that researchers can identify for the study (Creswell 2017). Based on this population, the representative sample can be chosen using an appropriate sample method. This study aims to explore the critical determinants for m-commerce adoption in Vietnamese SMEs. As a result, the target population in this study is SMEs in Vietnam.

The sample frame refers to a list of members of the target population that can be used to draw the sample (Wrenn, Stevens \& Loudon 2007). The sample frame is commonly obtained from the yellow page, the internet, telephone directory, government, or any other trusted resources related to the target population of the research. The sampling frame is a very important process of the sample design because it significantly affects 
the cost and the quality of the survey. This study targets Vietnamese SMEs. As a result, the VINASME is used as the sample frame for this study. The website of VINASME lists all of its members including name, type of business, address, telephone number, and email (if applicable). The sampling frame is obtained from the VINASME website with the official support from the leaders of the VINASME.

The sampling method is the way to identify the unit of analysis and the process to obtain the information from the target sample (Saunders et al. 2012). This method helps to reduce any possible errors in the sampling process (Davis 2004). There are several sampling techniques including probability sampling and non-probability sampling. Probability sampling assumes that the probability of selecting each participant from the research population is known (Zikmund, Carr \& Griffin 2013). In probability sampling, each individual of the population has an equal possibility of being selected for the desired sample. It is an appropriate method for collecting data from a large population to ensure the representation of the sample in a given study (Teddlie \& Yu 2007). This allows researchers to generalize the research findings to the entire population of the study (Bryman 2016).

The non-probability sampling is a sampling technique that does not involve the selection of sample elements by chance (Wrenn et al. 2007). It assumes that the probability of selecting each participant from the whole research population is unknown (Zikmund et al. 2013). As a result, it is not suitable for studies investigating a phenomenon based on a large number of participants (Sekaran \& Bougie 2016). The non-probability sampling techniques do not represent the entire population. It is, 
therefore, more appropriate for studies collecting data from a small number of participants (Teddlie \& Yu 2007). In this regard, non-probability sampling techniques suffer some restrictions on the generalizability of the research findings for a given study (Bryman 2016).

Selecting the sampling method depends on the nature of the study, the availability of samples, and the constraints of time and financial resources in a given situation (Hair et al. 2010). The probability sampling should be selected when the representativeness of the sample is important for generalization, while that non-probability sampling is used when time or other factors are more important than generalizability (Sekaran \& Bougie 2016). Based on these reasons, probability sampling is chosen in this research as this research targets the whole population of SMEs in Vietnam.

The type of probability sampling that is used in this study is a simple random sampling (Wrenn et al. 2007; Saunders et al. 2012). The heterogeneity of the target population makes the simple random method the most appropriate option for selecting samples in this study (Saunders et al. 2012). Furthermore, there is no need to divide the population into sub-populations when using a simple random technique. Finally, using the simple random sampling allows each member of the larger population has an equal probability of selection, resulting in the high generalizability of the findings derived from the sample for the entire population.

This study aims to investigate the critical determinants for the adoption of m-commerce in Vietnamese SMEs. As a result, the dependent construct is the organizational decision 
to adopt or reject m-commerce. The independent constructs are the critical determinants as perceived in the proposed conceptual framework, as in Chapter 3. These constructs would be best evaluated by business executives or top managers who have an important role in the decision-making process in an SME.

Technology adoption decisions in SMEs are usually handled by a single person that is the manager (Rodriguez 2005). Such a person usually decides whether to adopt or reject ICT. As a result, top managers of Vietnamese SMEs are expected to make a comprehensive evaluation of the critical determinants affecting organizational mcommerce adoption decisions. As a result, they become the sample unit for this research.

Determining the appropriate sample size is important for any empirical research as the appropriate sample size is critical for generating consistent and reliable statistical results in the subsequent data analysis (Hair et al. 2010). A too-large sample can lead to inefficiencies and a waste of resources. On the other hand, a too-small sample can create invalid information for making inferences about the population (Blaikie 2009). For these reasons, many suggestions are proposed for the appropriate sample size for empirical research. Roscoe (1975), for example, suggests that a number between 30 and 500 is suitable sample size for most research. Bryman and Cramer (1997) suggest a rule of thumb that the minimum sample size is five respondents per independent variable, while Vittinghoff and McCulloch (2007) suggest ten respondents per predictor variable. Yuksel, Yuksel and Bilim (2010) recommend a critical sample size of 200 to provide sufficient statistical power for data analysis while obtaining reliable results. 
The use of specific statistical techniques for data analysis directly affects the selection of the sample size (Hair et al. 2010). The use of SEM analysis, for example, requires careful consideration of sample size. The preliminary requirement for conducting SEM is that the absolute minimum sample size must be at least greater than the number of correlations in the input data matrix, with the ratio of 5 to 10 respondents per item (Hair et al. 2010). In this research, a total of 47 variables are used to measure twelve independent constructs and one dependent construct in the proposed conceptual framework, as shown in Table 4.5. It means that the minimum sample size is between 235 and 470 to ensure the appropriate use of SEM.

Another approach for calculating the appropriate sample size is based on power analysis (Hair et al. 2010; Rudestam \& Newton 2014). It is an approach that is used for measuring how large the sample size is for enabling reliable and accurate statistical results, and how likely the statistical results can detect an effect of the given sample to the population (Hair et al. 2010). It requires the consideration of three parameters when using the power analysis for calculating the sample size including the effect size, the statistical power, and the significance level (Rudestam \& Newton 2014). The effect size measures the strength of the relationship between the sample and the population (Hair et al. 2010; Cohen 2013). The statistical power is the probability of detecting a statistically significant effect (Hair et al. 2010; Cohen 2013). The significance level measures a false rejection of the null hypothesis (Hair et al. 2010; Cohen 2013). In most survey-based research, the effect size of 0.20 , the statistical power of 0.80 , and the significance level of 0.05 are considered adequate for the prediction of the appropriate sample size (Hair et al. 2010). 
Given the total approximate number of 507800 active SMEs in Vietnam at the time of data collection (General Statistics Office of Vietnam 2018a) and the recommended value for these above parameters, the appropriate sample size based on the power analysis calculation is 384 , as shown in Figure 4.2. To summarize the results from different approaches used for determining the sample size in this study, the recommended sample size is 384 . Such a sample size suggests that the findings of this study can be generalized to SMEs in Vietnam if more than 384 valid surveys are collected from the managers of SMEs in Vietnam for data analysis.

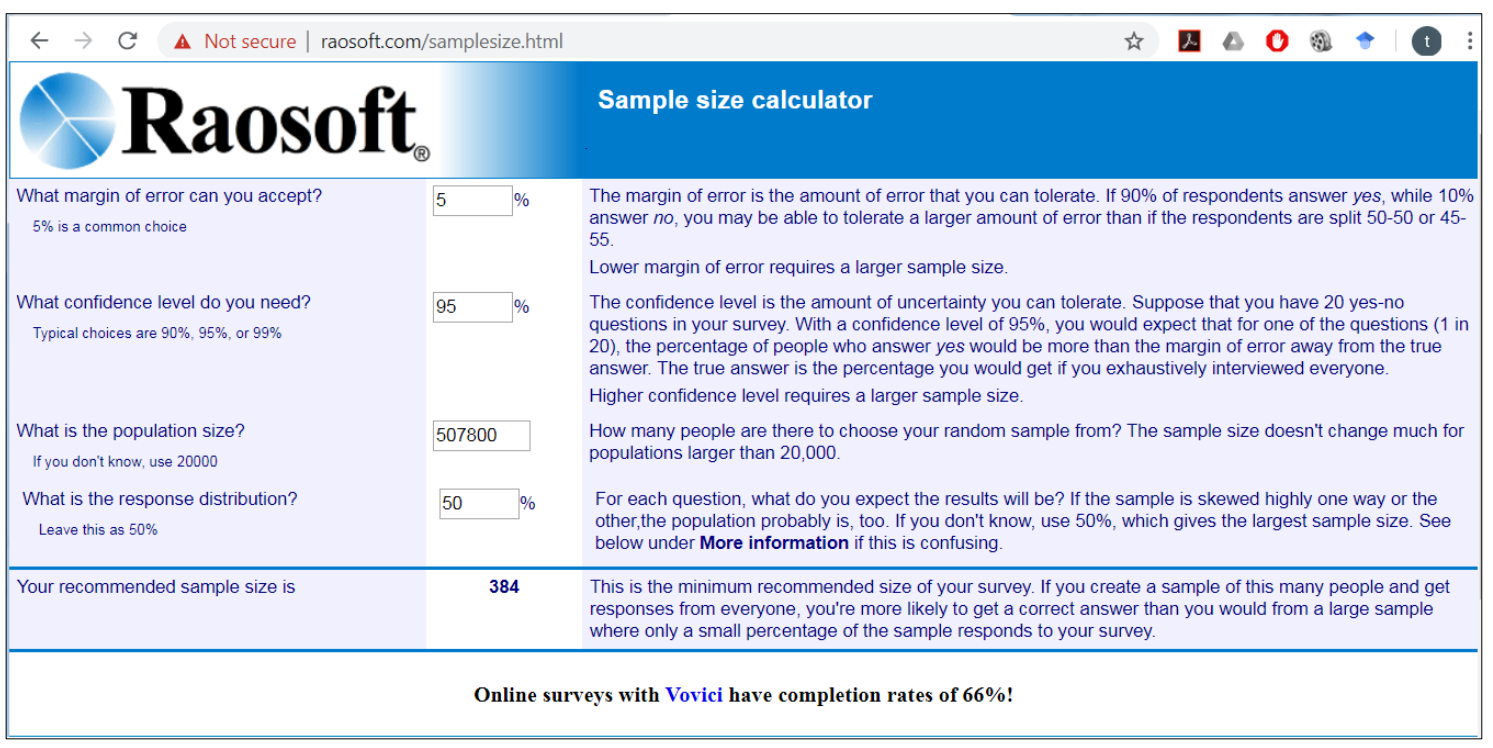

Figure 4.2 Sample size calculation using power analysis

\subsubsection{Survey Data Collection}

Data was collected through a self-administered survey conducted in Vietnam from April to October 2018. The target population is Vietnamese SMEs. The sample frame is obtained from the website of VINASME using the probability sampling method. The sample unit is the manager of Vietnamese SMEs. The survey questionnaire is 
distributed both online surveys via Qualtrics and paper-based surveys. The simple random method is used to select a total of 1000 SMEs including 500 SMEs for online surveys and 500 SMEs for the paper-based survey. Online random generator "www.random.org" is used for obtaining the desired sample size that is representative of the population.

For an online survey, an e-mail package, which includes a Vietnamese version of the invitation letter and the Qualtrics link to the online Vietnamese version of the questionnaire, was sent by the VINASME to emails of the manager of selected Vietnamese SMEs. The online survey was conducted in Vietnam between April 2018 and July 2018. Two follow-up reminds were sent to the emails of those managers that have not responded to the survey after four weeks. For a paper-based survey, a mail package that includes a printed version of the questionnaire and the invitation letter along with a postage-paid return envelope were delivered to the managers of selected Vietnamese SMEs. The paper-based survey was conducted in Vietnam between July 2018 and October 2018. A total of 556 responses are received in which there are 184 responses from the online survey and 372 responses from the paper-based survey.

\subsection{Data Analysis}

Data analysis is the process of examining, cleaning, transforming, and modeling the collected data for providing the result to answer the research question (Creswell \& Clark 2017). The employment of appropriate analytical methods and techniques for analyzing the collected data is significant. This is much dependent on the research 
design and the nature of the data collection (Zikmund et al. 2013). In quantitative research, multivariate data analysis is commonly used for examining the relationship between independent and dependent constructs, providing evidence for testing the research hypotheses of the study (Hair et al. 2010).

This study employs a multi-analytical approach by combining SEM and neural network to analyze the quantitative data for investigating the critical determinants for $\mathrm{m}$ commerce adoption in Vietnamese SMEs. The use of SEM and neural network in this research is due to their outstanding advantages including (a) the ability to include unobserved variables for representing abstract concepts with the consideration of the measurement error, (b) the ability to simultaneously assess the multiple correlations and covariance between variables to validate the conceptual framework, and (c) the ability to examine both linear and non-linear relationships between variables, resulting in higher prediction accuracy of the critical determinants for m-commerce adoption in Vietnamese SMEs (Hair et al. 2010; Chong 2013a; Kline 2015).

The quantitative data analysis using SEM and neural network is performed in eight steps, as shown in Figure 4.3. In the first step, a preliminary data analysis is conducted for preparing the dataset to be ready for further analysis. In this step, the collected data is processed by analyzing missing data, dealing with outliers, testing the normality, and assessing non-response bias, the common method bias, and the bias between online and paper-based surveys. In the second step, a demographics analysis is conducted for answering the first research question. In this step, the descriptive statistics are used for illustrating the demographics characteristics of the sample SMEs with respect to the 
location, size, duration of business, and the industry. The demographics characteristics of the managers of the sample SMEs are also analyzed with respect to their gender, age, position, experience, and educational level. The descriptive statistics and the variance analysis are then used for investigating the emerging pattern of $\mathrm{m}$-commerce adoption in Vietnamese SMEs under three different perspectives including (a) the overall adoption, (b) the size-based adoption, and (c) the industry-based adoption. The details of this step are presented in Chapter 6. In the third step, the dimensionality assessment is performed for examining the extent to which a set of measurement items fit together to reflect a theoretical construct (Hair et al. 2010). This is performed through exploratory factor analysis (EFA). These first three steps of data analysis are conducted with the use of Microsoft excel 2016 and the statistical package for social sciences (SPSS) version 25.

The fourth step assesses the validity of the full measurement model for exploring the extent to which the proposed conceptual framework fits the collected data (Hair et al. 2010). In this step, constructs in the proposed conceptual framework are tested to ensure the discriminant validity and convergent validity (Byrne 2016). This is done through confirmatory factor analysis (CFA) with the use of analysis of the moment structure (AMOS) version 25 software. Specifically, the validity of the initial full measurement model is examined by considering the goodness of fit (GOF) indices. If the initial full measurement model does not present acceptable GOF values, a one-factor congeneric model analysis is conducted. The evaluation of the model validation process is continued with the refinement and re-testing until the validity of one-factor congeneric 
models and the full measurement model is acceptable. The details of the validity assessment for the full measurement model are presented in Chapter 5.

The fifth step is about the validity assessment for the structural model. Such validity is assessed through the consideration of the magnitude of variance explained for each dependent variable $\left(R^{2}\right)$, the coefficient of paths between the constructs in the proposed conceptual framework, and their significance levels ( $p$-value) (Byrne 2013). Based on the validity of the structural model, the results of the structural model analysis are summarized and discussed in the sixth step. Both of these two steps are conducted using AMOS version 25 software. The details of these two steps are presented in Chapter 7.

The seventh step is the analysis of neural networks for evaluating the relative importance of the critical determinants of m-commerce adoption that are identified in the sixth step. In this step, multilayer perceptron networks with feed-forward backpropagation algorithms are adopted. Ten-fold cross-validation is then performed for validating such neural networks. The root means square error, as well as the average and standard deviation of both training and testing datasets, are then computed for measuring the predictive accuracy of the network model. Finally, a sensitivity analysis is performed for evaluating the relative importance of each determinant. This step is conducted using SPSS version 25. The ninth step summarizes and discusses the result of SEM-neural network analysis. The details of these final two steps are presented in Chapter 7. 


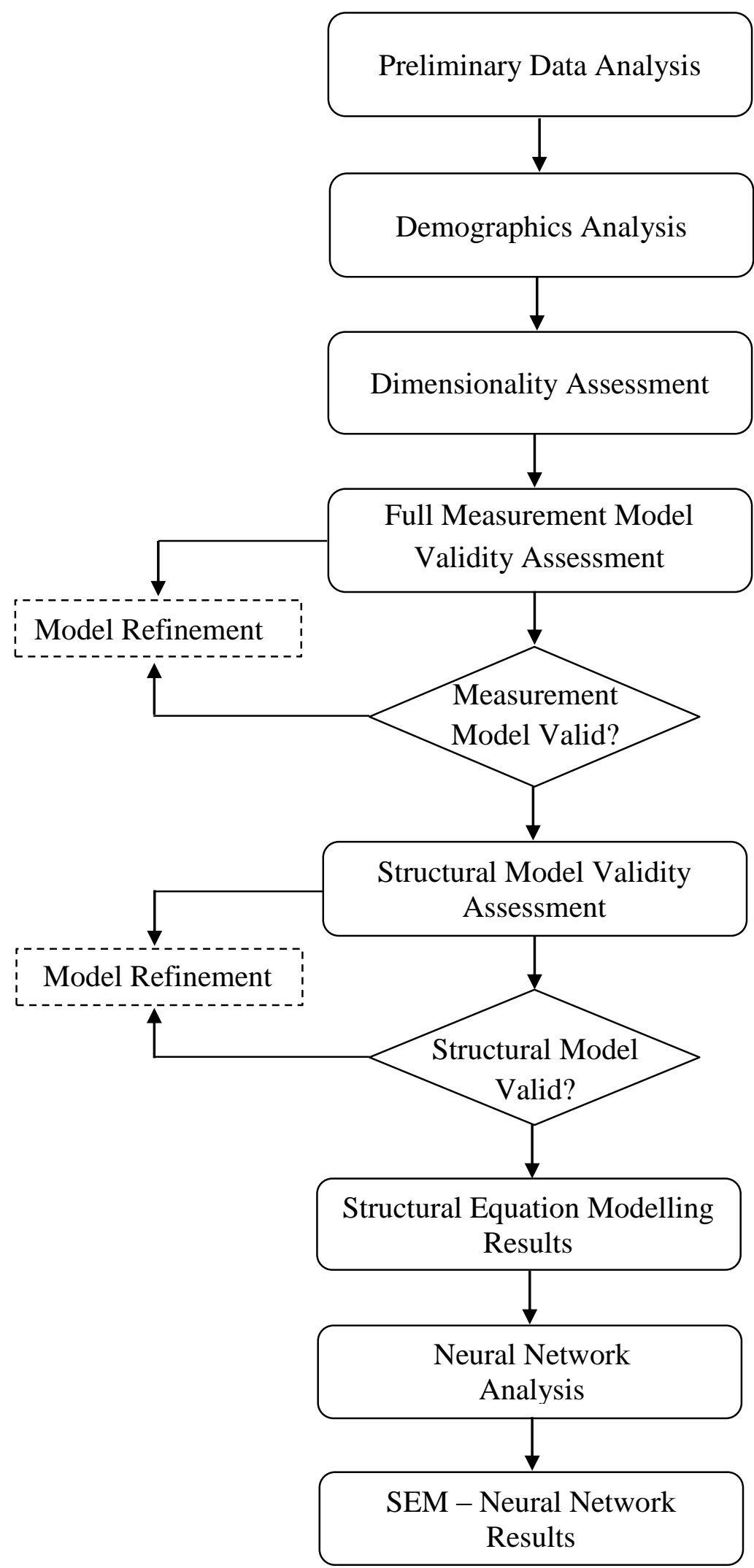

Figure 4.3 An overview of the data analysis process 


\subsection{Ethics}

The research is undertaken following RMIT's ethics guidelines. The research is classified as the low-risk research by the College of Business Human Ethics Advisory Network (BCHEAN), RMIT University. The researcher was granted ethics approval to conduct the survey in Vietnam for the period from 22 February 2018 to 26 February 2021. The ethics approval letter for the survey is attached in Appendix E.

\subsection{Concluding Remarks}

This chapter presents the selection of an appropriate research methodology for answering the research question in the study. Based on the nature of this study, a quantitative research methodology is adopted due to its capability for investigating the causal relationships between the proposed constructs through the collection and analysis of the numerical data and its potential for generalizing the research findings to a large population. Follow the quantitative research methodology, a survey is adopted as the research method for data collection. A rigorous procedure is followed for the instrument development and design including specifying the domain of the constructs, generating items for variables, pre-test, and pilot test. The sample design is specified regarding the target population, sample frame, sample method, sample unit, and sample size. Data collection is conducted in Vietnam using both online and paper-based surveys. A multianalytical approach by combining SEM and artificial neural network is used for testing and validating the proposed conceptual framework based on the survey data collected from the top managers of Vietnamese SMEs. This helps identify the current pattern of 
m-commerce adoption. This also leads to the identification of the critical determinants for the adoption of m-commerce in Vietnamese SMEs. A comprehensive discussion of the survey data analysis is presented in the subsequent chapters. 


\section{Chapter 5}

\section{Data Examination and Preparation}

\subsection{Introduction}

Understanding the fundamental properties of the dataset is critical for properly conducting multivariate analysis (Straub et al. 2004; Hair et al. 2010). This is because such understanding can help to save considerable time, prevent mistakes, and minimize potential measurement errors in the data analysis process in research projects (Tabachnick \& Fidell 2013). It helps to fit the data with the requirements of modern data analysis tools so that the data can be easily stored, transformed, retrieved and maintained (Hair et al. 2010).

Data examination and preparation processes are important preliminary steps for understanding the dataset (Hair et al. 2010). Such a process involves analyzing missing values, identifying and handling outliers, testing for normality departure, testing for non-response bias and common method bias, and testing for the bias between online and paper-based surveys (Straub et al. 2004). This also involves assessing the reliability of the constructs, as well as the content validity, factorial validity, and construct validity of the measurement instrument (Hair et al. 2010). 
This chapter aims to describe the data preparation process for analyzing the collected data in the research. It focuses on the discussion of the procedure followed for examining the data for detecting any anomalies in the dataset. The chapter then details any remedies undertaken to prepare the data for further intended analysis.

The rest of this chapter is organized into seven sections. Section 5.2 describes the process of data preparation and examination. Section 5.3 presents the results of the content validity examination. Section 5.4 outlines the results of the initial reliability assessment. Section 5.5 describes the steps taken to assess the factorial validity of the measurement instrument. Section 5.6 presents the results of the construct validity including convergent validity and discriminant validity. Section 5.7 provides the results of the final reliability assessment. Section 5.8 ends the chapter with some concluding remarks.

\subsection{Data Preparation}

The data collection process is conducted in Vietnam via online and paper-based surveys. A total of 556 responses have been received. This includes 184 responses from the online survey and 372 responses from the paper-based survey. Each collected questionnaire is reviewed for completeness necessary to the analysis. The data has been entered for the data examination and preparation process with the use of Microsoft excel 2016 and SPSS 25 software. The detail of such a process is discussed in the following. 


\subsubsection{Data Coding}

Coding is "the process of assigning numerals or other symbols to the answers so that the responses can be put into a limited number of categories or classes" (Kothari 2004, p. 123). It can be done by allocating a specific code for each category of the answers in the questionnaire so that the researcher can easily transfer it into a form identifiable by the computer to make the subsequent analysis easier (Saunders 2011). In this study, the continuous response scale (questions 14 to 26) uses a pre-coded technique by allocating numbers for each question, with number 1 meaning "strongly disagree" and number 5 meaning "strongly agree". Questions 1 to 13 and questions 27 to 31 are entered into the coding scheme before being entered into the SPSS software. Codes are labeled for each variable to illustrate the meaning of codes.

\subsubsection{Initial Data Screening}

The initial 556 responses from the survey are screened to eliminate invalid responses. This step leads to the deletion of seven incomplete responses, resulting in 549 responses for further analysis. Excluding eighteen non-metric variables, the total number of metric variables is 47 .

\subsubsection{Missing Data Analysis}

Missing data is about a situation in which valid values on one or more variables are not available for analysis (Hair et al. 2010). It could be at two levels including the unit level and the item level (Dong \& Peng 2013). The existence of the missing data affects data 
analysis by reducing the sample size (Hair et al. 2010). The missing data also influences the accuracy of the estimated parameters and the fitness of the SEM model (Kaplan 2008). As a result, it is important to effectively handle the missing data for improving the accuracy of the research findings in a given study.

A rule of thumb for deleting specific variables or cases is based on the proportion of missing data (Hair et al. 2010). Specifically, variables with as little as $15 \%$ missing data are the candidates for deletion. Additionally, missing data under $10 \%$ for an individual case can be generally ignored.

To effectively handle the missing data, a four-step process is followed in this study (Hair et al. 2010). The first step is to understand the type of missing data involved in the dataset in which the missing data are part of the research design, "ignorable", or "not ignorable". The second step is about making further essential assessments when the missing data are not ignorable. The third step involves diagnosing the randomness of the missing value. The final step is the selection of the appropriate inputting method to replace the missing data with certain values.

In this study, all the missing data are due to the non-response by the respondents. As a result, they are not ignorable. The overall extent of the missing data is assessed by calculating the number of cases with missing data for each variable and the number of variables missing in a specific case (Hair et al. 2010). Table 5.1 presents the result of missing data analysis by variables. 
Table 5.1 A summary of missing data analysis

\begin{tabular}{|c|c|c|c|c|c|c|c|c|c|c|c|}
\hline \multirow{2}{*}{ Variables } & \multirow{2}{*}{$\mathbf{N}$} & \multicolumn{2}{|c|}{ Missing } & \multirow{2}{*}{ Variables } & \multirow{2}{*}{$\mathbf{N}$} & \multicolumn{2}{|c|}{ Missing } & \multirow{2}{*}{ Variables } & \multirow{2}{*}{$\mathbf{N}$} & \multicolumn{2}{|c|}{ Missing } \\
\hline & & Count & $\%$ & & & Count & $\%$ & & & Count & $\%$ \\
\hline BENE1 & 544 & 5 & .9 & SECU3 & 549 & 0 & .0 & CUST1 & 549 & 0 & .0 \\
\hline BENE2 & 546 & 3 & .5 & COST1 & 549 & 0 & .0 & CUST2 & 549 & 0 & .0 \\
\hline BENE3 & 549 & 0 & .0 & COST2 & 549 & 0 & .0 & CUST3 & 546 & 3 & .5 \\
\hline BENE4 & 547 & 2 & .4 & COST3 & 549 & 0 & .0 & GOVE1 & 548 & 1 & .2 \\
\hline BENE5 & 548 & 1 & .2 & EMPL1 & 548 & 1 & .2 & GOVE2 & 549 & 0 & .0 \\
\hline BENE6 & 547 & 2 & .4 & EMPL2 & 549 & 0 & .0 & GOVE3 & 549 & 0 & .0 \\
\hline BENE7 & 549 & 0 & .0 & EMPL3 & 548 & 1 & .2 & TMSP1 & 549 & 0 & .0 \\
\hline BENE8 & 549 & 0 & .0 & READ1 & 548 & 1 & .2 & TMSP2 & 549 & 0 & .0 \\
\hline CMPA1 & 549 & 0 & .0 & READ2 & 548 & 1 & .2 & TMSP3 & 548 & 1 & .2 \\
\hline CMPA2 & 549 & 0 & .0 & READ3 & 548 & 1 & .2 & TMIT1 & 549 & 0 & .0 \\
\hline CMPA3 & 549 & 0 & .0 & INNO1 & 547 & 2 & .4 & TMIT2 & 545 & 4 & .7 \\
\hline CMPA4 & 547 & 2 & .4 & INNO2 & 549 & 0 & .0 & TMIT3 & 548 & 1 & .2 \\
\hline CMPA5 & 549 & 0 & .0 & INNO3 & 549 & 0 & .0 & ADPT1 & 546 & 3 & .5 \\
\hline CMPA6 & 549 & 0 & .0 & CMPE1 & 549 & 0 & .0 & ADPT2 & 546 & 3 & .5 \\
\hline SECU1 & 549 & 0 & .0 & CMPE2 & 547 & 2 & .4 & ADPT3 & 545 & 4 & .7 \\
\hline SECU2 & 548 & 1 & .2 & CMPE3 & 548 & 1 & .2 & & & & \\
\hline
\end{tabular}

There are ten missing values in three variables of the dependent construct. As a result, an analysis of missing data by cases is conducted for such three variables to identify the cases with having missing data on these variables. Such cases are deleted to avoid any artificial increase in the relationships with the independent variable (Hair et al. 2010). This process leads to the removal of 4 cases including case 131 , case 174 , case 348 , and case 378 , resulting in the remain of 545 cases for further analysis. Table 5.2 present a summary of this analysis. 
Table 5.2 Dependent variable based missing data analysis

\begin{tabular}{cccccc}
\hline Case & \# Missing & \% Missing & ADPT1 & ADPT2 & ADPT3 \\
\hline 131 & 1 & 33.3 & & & $\mathrm{~S}$ \\
\hline 174 & 3 & 100.0 & $\mathrm{~S}$ & $\mathrm{~S}$ & $\mathrm{~S}$ \\
\hline 348 & 3 & 100.0 & $\mathrm{~S}$ & $\mathrm{~S}$ & $\mathrm{~S}$ \\
\hline 378 & 3 & 100.0 & $\mathrm{~S}$ & $\mathrm{~S}$ & $\mathrm{~S}$ \\
\hline
\end{tabular}

A further analysis of missing data on the remaining 545 cases is conducted. The result shows that there are 38 missing values $(0.15 \%)$ out of 25615 data values (that is, 47 metric variables by 545 cases), excluding non-metric data values. An analysis of the pattern of missing data of 47 metric variables reveals that the amount of missing value per variable is ranged from zero to five. Table 5.3 presents a summary of the number of variables for the different numbers of missing values.

Table 5.3 A summary of variable-based missing data analysis

\begin{tabular}{cccccc}
\hline \# Missing & \# Variables & Percentage & \# Missing & \# Variables & Percentage \\
\hline 0 & 31 & $65.96 \%$ & 3 & 2 & $4.26 \%$ \\
\hline 1 & 13 & $27.66 \%$ & 4 & 1 & $2.13 \%$ \\
\hline 2 & 5 & $10.64 \%$ & 5 & 1 & $2.13 \%$ \\
\hline
\end{tabular}

Similarly, an analysis of the pattern of missing data of the 545 cases reveals that the number of missing data per case is ranged from zero to four missing values. Table 5.4 presents a summary of missing data analysis by cases. 
Table 5.4 A summary of case-based missing data analysis

\begin{tabular}{cccccc}
\hline \# Missing & \# Cases & Percentage & \# Missing & \# Cases & Percentage \\
\hline 0 & 519 & $95.23 \%$ & 3 & 2 & $0.37 \%$ \\
\hline 1 & 18 & $3.30 \%$ & 4 & 1 & $0.18 \%$ \\
\hline 2 & 5 & $0.92 \%$ & & & \\
\hline
\end{tabular}

In summary, the amount of missing data by variables and cases is less than $15 \%$ and $10 \%$ respectively. This shows that the amount of missing data does not exceed the rule of thumb (Hair et al. 2010). Such missing data, therefore, do not affect the research findings of this study. As a result, they can be ignored and replaced with appropriate values (Kaplan 2008; Hair et al. 2010).

\subsubsection{Examination for Outliers}

Outliers are the observations with extreme values when compared with the rest of the dataset (Kline 2015; Byrne 2016). They are "a case with such an extreme value on one variable (a univariate outlier) or such a strange combination of scores on two or more variables (a multivariate outlier) that it distorts statistics" (Tabachnick \& Fidell 2013, p. 72). Outliers are presented due to various reasons including observation errors, data entry errors, and instrument errors based on the layout or instructions (Lomax \& Schumacker 2012).

Outliers can lead to incorrect results on the statistical analysis, reducing the statistical power of the study in different ways such as influencing the model estimation and parameters estimation and increasing the error variance (Byrne 2016). Consequently, 
outliers must be detected, explained, or accommodated by using robust statistic procedures (Byrne 2016). This study employs an SEM-based multivariate analysis for investigating the critical determinants of m-commerce adoption. As a result, a multivariate test for outliers is required for investigating multivariate outliers.

There are two popular measures for identifying the outliers including Mahalanobis distance $\left(D^{2}\right)$ and Cook's distance $\left(D_{i}\right) . D^{2}$ measures the distance in standard deviation units between one variable, and the sample means for all variables. It assesses the extent of the dissimilarity between individual observations regarding their respective distance from the mean center of all observations across a set of variables.

An observation with a $D^{2}$ value standing distinctively apart from all the other $D^{2}$ values is an outlier (Hair et al. 2010). As a rule of thumb, it is suggested identifying any cases in which the $D^{2} / d f$ value exceeds three or four, or p-value less than 0.001 in large samples where the sample size of greater than or equal 200. These cases are considered as outliers (Hair et al. 2010).

$D_{i}$ is used to find the influential outliers in a set of predictor variables (Hair et al. 2010). It is a way to identify the points that negatively affect the regression model. $D_{i}$ can be measured by a combination of each observation's leverage and residual values. Specifically, the higher the leverage and the residuals, the higher the $D_{i}$ value. A general rule of thumb is that the observation with a $D_{i}$ value of more than three times the mean is a possible outlier. An alternative interpretation is that observation with the $D_{i}$ value 
over $4 / n$ where $n$ is the number of observations can also be considered as an outlier (Hair et al. 2010).

In this study, a total of 545 observations by 47 metric variables are examined for the presence of multivariate outliers based on Cook's distance. The threshold used for the Cook's distance is 0.00734 ( 4 divided by 545). Table 5.5 presents the top 40 observations with the highest $D_{i}$ values. The result indicates 32 observations with the $D_{i}$ value greater than 0.00734 . They are considered as outliers that have been then dropped from the dataset. Finally, the remaining 513 cases are used for subsequent analysis.

Table 5.5 A summary of multivariate outlier test results

\begin{tabular}{cccccccccc}
\hline Case & $\mathbf{D}_{\mathbf{i}}$ & $\mathbf{C a s e}$ & $\mathbf{D}_{\mathbf{i}}$ & $\mathbf{C a s e}$ & $\mathbf{D}_{\mathbf{i}}$ & $\mathbf{C a s e}$ & $\mathbf{D}_{\mathbf{i}}$ & Case & $\mathbf{D}_{\mathbf{i}}$ \\
\hline 21 & 0.04508 & 100 & 0.01843 & 240 & 0.01257 & 36 & 0.00985 & 255 & 0.00723 \\
\hline 191 & 0.04312 & 152 & 0.01843 & 239 & 0.0119 & 147 & 0.00911 & 414 & 0.00719 \\
\hline 487 & 0.03487 & 168 & 0.01843 & 118 & 0.0106 & 139 & 0.00861 & 294 & 0.00717 \\
\hline 288 & 0.02755 & 469 & 0.01712 & 133 & 0.0106 & 425 & 0.00859 & 485 & 0.00709 \\
\hline 422 & 0.02338 & 194 & 0.01613 & 466 & 0.01006 & 246 & 0.00842 & 334 & 0.00689 \\
\hline 379 & 0.02116 & 228 & 0.01434 & 484 & 0.01001 & 115 & 0.00828 & 492 & 0.00683 \\
\hline 167 & 0.02088 & 148 & 0.01421 & 238 & 0.00987 & 247 & 0.00821 & 121 & 0.00675 \\
\hline 412 & 0.02019 & 236 & 0.01385 & 20 & 0.00985 & 97 & 0.00809 & 54 & 0.00671 \\
\hline
\end{tabular}

\subsubsection{Multivariate Normality Testing}

Normality is about the shape of the distribution and the characteristics of its statistics for a single variable that approximates the normal distribution (Hair et al. 2010). The normality assessment of a dataset is an important prerequisite for multivariate analysis, 
particularly for SEM that is conducted in this study. This is because the non-normal data distribution seriously reduces the statistical power of the study. It undermines the efficiency of standard errors. This may lead to invalid research findings in specific situations (Tabachnick \& Fidell 2013; Byrne 2016). As a result, it is critical for examining the normality of the dataset to obtain more accurate results of the study (Hopkins \& Weeks 1990; Chau \& Deng 2020).

The normality assessment can be done both graphically and statistically (Chau \& Deng 2020). Graphically, the normality is assessed through a visual check of the histogram or the normality plot. Statistically, the normality is empirically tested through the distribution's shape using the skewness and kurtosis measures for each variable (Byrne 2016). In this study, the normality of the dataset is examined by assessing the values of Skewness and Kurtosis.

Skewness is about the symmetry of the data distribution (Tabachnick \& Fidell 2013). It is concerned whether the distribution of the data is shifted to the left or right (Hair et al. 2010). A positive skew reflects a distribution that is shifted to the left. A negative skew represents a distribution that is shifted to the right. The presence of skewness influences the algorithms used for testing the mean of the data set (Byrne 2016).

Kurtosis is linked to the peakedness of the data distribution (Tabachnick \& Fidell 2013). It concerns the flatness or the peakedness of the data distribution compared to the normal data distribution (Hair et al. 2010). A negative kurtosis value indicates a flatter distribution. A positive kurtosis value denotes a peaked distribution. The presence of 
kurtosis influences the calculation of variance and covariance in the dataset (Kline 2015; Byrne 2016).

It is important to examine the skewness and kurtosis of the data distribution in this study. To ensure the normality of the dataset, the values of skewness and kurtosis are acceptable when these values fall within the range of $+/-2.58$ at the 0.01 significance level and +/-1.96 at 0.05 significance level respectively (Hair et al. 2010).

The skewness and kurtosis of the dataset in this study are examined using the SPSS 25 software. Table 5.6 presents the results of the normality test using the skewness and kurtosis measures. The results indicate that the skewness values are ranged between 0.951 and -0.138 . The kurtosis values are in the range of -0.305 and 1.915 . This shows that the dataset in this study is consistent with the normal distribution. 
Table 5.6 A summary of normality assessment results

\begin{tabular}{ccccccccc}
\hline Item & Skew & Kurt & Item & Skew & Kurt & Item & Skew & Kurt \\
\hline BENE1 & -0.451 & -0.187 & SECU3 & -0.334 & -0.256 & CUST1 & -0.951 & 1.180 \\
\hline BENE2 & -0.452 & -0.282 & CSTS1 & -0.693 & 0.470 & CUST2 & -0.633 & 0.244 \\
\hline BENE3 & -0.430 & -0.305 & CSTS2 & -0.608 & -0.020 & CUST3 & -0.718 & 0.888 \\
\hline BENE4 & -0.138 & 1.915 & CSTS3 & -0.473 & 0.066 & GOVE1 & -0.588 & 0.739 \\
\hline BENE5 & -0.767 & 0.968 & EMPL1 & -0.801 & 0.501 & GOVE2 & -0.663 & 0.373 \\
\hline BENE6 & -0.673 & 0.773 & EMPL2 & -0.793 & 0.353 & GOVE3 & -0.656 & 0.537 \\
\hline BENE7 & -0.545 & 0.435 & EMPL3 & -0.924 & 0.739 & TMSP1 & -0.688 & 1.591 \\
\hline BENE8 & -0.521 & 0.673 & READ1 & -0.664 & 0.722 & TMSP2 & -0.521 & 0.544 \\
\hline CMPA1 & -0.482 & 0.180 & READ2 & -0.697 & 0.910 & TMSP3 & -0.567 & 1.337 \\
\hline CMPA2 & -0.287 & -0.168 & READ3 & -0.524 & 0.747 & TMIT1 & -0.557 & 0.513 \\
\hline CMPA3 & -0.401 & -0.030 & INNO1 & -0.678 & 1.146 & TMIT2 & -0.694 & 0.400 \\
\hline CMPA4 & -0.440 & -0.008 & INNO2 & -0.497 & 0.227 & TMIT3 & -0.718 & 0.680 \\
\hline CMPA5 & -0.476 & 0.261 & INNO3 & -0.624 & 0.655 & ADPT1 & -0.327 & -0.215 \\
\hline CMPA6 & -0.425 & -0.017 & CMPE1 & -0.752 & 0.849 & ADPT2 & -0.293 & -0.131 \\
\hline SECU1 & -0.589 & 0.229 & CMPE2 & -0.590 & 0.041 & ADPT3 & -0.180 & -0.207 \\
\hline SECU2 & -0.417 & -0.120 & CMPE3 & -0.621 & 0.203 & & & \\
\hline
\end{tabular}

\subsubsection{Non-Response Bias Testing}

Non-response occurs when there is a considerable amount of variation between those who responded and those who did not respond to the survey (Hair et al. 2010). This happens due to a variety of reasons including (a) some people refuse to participate, (b) the survey is poorly constructed, (c) some people simply forget to return the survey, (d) the survey does not reach all members in the sample, and (e) certain groups are more inclined to answer. 
The existence of non-response bias is a concern when collecting data via a survey instrument (Dillman 2011; Fowler \& Floyd 2013). It may cause sample bias as the answers of respondents may differ from the potential answers of those who did not respond (Dillman 2011). As a result, non-response bias results in the low accuracy of estimations when the research findings are generalized to the population (Ygge \& Arnetz 2004; Hair et al. 2010).

Non-response bias is tested based on the comparison of the pattern of "early" and "late" respondents on the variables of the study. If there are no significant differences between early and late responses, the study results can be generalized to the population (Lindner, Murphy \& Briers 2001). There are no common characteristics for comparing early with late respondents. As a result, it is suggested that respondents that are more interested in the survey would respond earlier than those who have no interest that is therefore assumed not to respond (Beck, Bryman \& Liao 2003).

This study uses both an online survey and a paper-based survey for data collection. As a result, the non-response bias tests are conducted for both of these surveys. The identification of earlier respondents from late respondents of the online survey is based on the date of accomplishment. For the paper-based survey, each returned survey questionnaire is affixed with a date of the return for such identification. These surveys focus on four dimensions of the critical determinants for m-commerce adoption in Vietnamese SMEs including technological dimension, organizational dimension, environmental dimension, and managerial dimension. As a result, the non-response bias is estimated based on the mean of such dimensions. 
A total of 80 responses including the first 40 responses and the last 40 responses of the online survey, are selected for testing the non-response bias. A two-sample $t$-test is run to compare the mean difference in the four dimensions of the critical determinants from these two groups of respondents. Table 5.7 presents the results of such an independent sample $t$-test. The results indicate no significant differences between earlier and later responses at a $95 \%$ confidence interval for the chosen variables.

Table 5.7 A summary of the non-response bias test for the online survey

\begin{tabular}{ccccccccc}
\hline Online Survey & $\mathbf{t}$ & $\mathbf{d f}$ & $\mathbf{p}$ & \multicolumn{3}{c}{ Mean } & Std. Error \\
\cline { 5 - 7 } & & & & Earlier & Later & Difference & Difference \\
\hline Mean of Technology & .735 & 98 & .464 & 3.9224 & 3.8443 & .0780 & .1062 \\
\hline Mean of Organization & .552 & 98 & .582 & 3.8000 & 3.7267 & .0733 & .1327 \\
\hline Mean of Environment & .753 & 98 & .453 & 3.8685 & 3.7778 & .0907 & .1204 \\
\hline Mean of Management & .466 & 98 & .642 & 3.9400 & 3.8800 & .0600 & .1287 \\
\hline
\end{tabular}

The number of responses from the paper-based survey is larger than those from the online survey. As a result, a total of 100 responses including the first 50 responses and the last 50 responses of the paper-based survey, are selected for testing the non-response bias. A two-sample $t$-test is run to compare the mean difference in the four dimensions of the critical determinants from these two groups of respondents. Table 5.8 presents the results of such an independent sample $t$-test. The results indicate no significant differences between earlier and later responses at a $95 \%$ confidence interval for the chosen variables. 
Table 5.8 A summary of the non-response bias test for the paper-based survey

\begin{tabular}{lcccccccc}
\hline Paper-Based Survey & $\mathbf{t}$ & $\mathbf{d f}$ & $\mathbf{p}$ & \multicolumn{3}{c}{ Mean } & $\begin{array}{r}\text { Std. Error } \\
\text { Difference }\end{array}$ \\
\hline Mean of Technology & .864 & 98 & .390 & 3.8887 & 3.8191 & .0696 & .0806 \\
\hline Mean of Organization & -.299 & 98 & .766 & 3.8844 & 3.9132 & -.0287 & .0961 \\
\hline Mean of Environment & .637 & 98 & .526 & 3.8974 & 3.8351 & .0623 & .0978 \\
\hline Mean of Management & -1.169 & 98 & .245 & 3.9771 & 4.0933 & -.1161 & .0993 \\
\hline
\end{tabular}

In summary, the results of the independent sample $t$-test for the selected respondents of the online survey and the paper-based survey indicate that there are no significant differences between early and late respondents. These findings suggest that even if there is a non-response bias, it is not statistically significant to bias the data and prevent generalizing the research findings from the sample to the population.

\subsubsection{Survey Type Bias Testing}

The data in this study is collected via both online and paper-based surveys. As a result, this study assumes that respondents from the online survey are more likely to have the same demographic characteristics as the respondents from the paper-based survey. If the difference is not significant, the dataset from both types of surveys can be merged for further analysis (Hair et al. 2010).

The dataset is examined for the potential bias between the online survey and the paperbased survey (Bryman \& Bell 2015). A two-sample $t$-test is run to compare the difference in the mean of four dimensions of the critical determinant for m-commerce 
adoption in Vietnamese SMEs between the respondents from both types of surveys. 513 responses including 159 responses from the online survey and 354 responses from the paper-based survey, are used for this test. Table 5.9 presents the results of such an independent $t$-test. These results indicate no significant differences between online and paper-based responses at a $95 \%$ confidence interval for the chosen variables. As a result, both groups of the respondents can be combined for further analysis.

Table 5.9 Independent sample t-test for survey types bias

\begin{tabular}{|c|c|c|c|c|c|c|c|}
\hline \multirow[b]{2}{*}{ Dimensions } & \multirow[b]{2}{*}{$\mathbf{t}$} & \multirow[b]{2}{*}{ df } & \multirow[b]{2}{*}{$\mathbf{p}$} & \multicolumn{3}{|c|}{ Mean } & \multirow{2}{*}{$\begin{array}{l}\text { Std. Error } \\
\text { Difference }\end{array}$} \\
\hline & & & & $\begin{array}{l}\text { Online } \\
(n=159)\end{array}$ & $\begin{array}{c}\text { Paper } \\
(n=354)\end{array}$ & Difference & \\
\hline Mean of Technology & 1.478 & 511 & .140 & 3.9276 & 3.8549 & .0727 & .0492 \\
\hline Mean of Organization & -1.912 & 511 & .056 & 3.8599 & 3.9606 & -.1007 & .0527 \\
\hline Mean of Environment & -.099 & 511 & .921 & 3.8852 & 3.8906 & -.0054 & .0546 \\
\hline Mean of Management & -1.777 & 511 & .076 & 3.9957 & 4.0904 & -.0947 & .0533 \\
\hline
\end{tabular}

\subsubsection{Common Method Bias Testing}

Common method bias is about the variation in responses that are caused by the instrument rather than the related research model or any other causal relationships (Podsakoff et al. 2003). It causes a systematic error. As a result, the common method bias inflates or deflates the observed relationship between the theoretical constructs in the conceptual model in research projects (Podsakoff et al. 2003). 
Several methods can be used for testing the common method bias (Richardson, Simmering \& Sturman 2009). Among these methods, Harman's single-factor test is widely used in the literature (Podsakoff et al. 2003). This method suggests loading all the measurement items into the factor analysis and examining the unrotated factor solution of the EFA to determine the number of factors accounting for the variance in the measurement instrument. According to this method, the common method bias exists if either (a) a single factor emerges from the factor analysis or (b) one general factor accounts for the majority of the covariance between the measures, which is above $50 \%$ (Podsakoff et al. 2003).

Harman's single-factor test is conducted for understanding the extent of the common method bias in this study. Table 5.10 provides the EFA results of the one-factor analysis using the unrotated principal component analysis (Podsakoff et al. 2003). Such results indicate the presence of as many as eleven factors with an eigenvalue greater than 1 , accounting for $71.275 \%$ of the variances in the measures. The greatest factor, however, explains only $37.825 \%$ of the variance in the measures. This is less than $50 \%$ required indicating the existence of the common method bias. There is also not a single factor that emerges to represent the variance among all the measurement items. This suggests the presence of no significant bias in the dataset due to the use of the research method. 
Table 5.10 Test for common method bias - Total variance explained

\begin{tabular}{ccccccc}
\hline \multirow{2}{*}{ Component } & \multicolumn{3}{c}{ Initial Eigenvalues } & \multicolumn{3}{c}{ Extraction Sums of Squared Loadings } \\
\cline { 2 - 7 } & Total & \% of Variance & Cumulative & Total & \% of Variance & Cumulative \\
\hline 1 & 18.912 & 37.825 & 37.825 & 18.912 & 37.825 & 37.825 \\
\hline 2 & 3.050 & 6.100 & 43.925 & 3.050 & 6.100 & 43.925 \\
\hline 3 & 2.341 & 4.681 & 48.607 & 2.341 & 4.681 & 48.607 \\
\hline 4 & 2.168 & 4.336 & 52.943 & 2.168 & 4.336 & 52.943 \\
\hline 5 & 1.745 & 3.491 & 56.433 & 1.745 & 3.491 & 56.433 \\
\hline 6 & 1.538 & 3.076 & 59.509 & 1.538 & 3.076 & 59.509 \\
\hline 7 & 1.307 & 2.614 & 62.124 & 1.307 & 2.614 & 62.124 \\
\hline 8 & 1.207 & 2.414 & 64.538 & 1.207 & 2.414 & 64.538 \\
\hline 9 & 1.188 & 2.376 & 66.915 & 1.188 & 2.376 & 66.915 \\
\hline 10 & 1.145 & 2.290 & 69.205 & 1.145 & 2.290 & 69.205 \\
\hline 11 & 1.035 & 2.071 & 71.275 & 1.035 & 2.071 & 71.275 \\
\hline
\end{tabular}

The discussion above shows that the data examination and preparation process is performed to prepare the dataset for the SEM analysis in the study. 556 responses including 184 responses from the online survey and 372 responses from the paper-based survey, are first reviewed for completeness necessary to the analysis. The data is then examined for missing data analysis, multivariate outlier detection, and normality test. These processes lead to the deletion of forty-three observations including those with incomplete responses, missing data on dependent variables, and outliers.

The remained dataset is used for testing the non-response bias, the common method bias, and the bias between online and paper-based surveys. The findings suggest that even if there is any bias, they are not statistically significant to bias the data and prevent 
generalizing the research findings from the sample to the population. A final dataset including 513 observations with 47 metric items is used for reliability and validity assessments presented in the next sections.

\subsection{Content Validity}

Validity is about whether the items of the scale can correctly measure the relevant instrument without additional features (Hair et al. 2010). A validity test is used to determine if the instrument truly reflects what it is intended to measure (Carmines \& Zeller 1979). Although the constructs used in this study are adopted from previous studies, the translation process of the questionnaire from its original language, the difference in research contexts, and the purpose of generalizing the findings for this study require the conduct of validity assessment (Hair et al. 2010). In this study, the

validity is checked by examining the (a) content validity, (b) factorial validity, and (c) construct validity (Straub et al. 2004).

Content validity is about the degree to which measurement items reflect the content universe to which the instrument will be generalized (Boudreau, Gefen \& Straub 2001). It is "the degree to which elements of an assessment instrument are relevant to and representative of the targeted construct for a particular assessment purpose" (Haynes, Richard \& Kubany 1995). It is generally established through the literature review and expert opinions (Straub et al. 2004). Pre-test and pilot tests are common methods for establishing content validity. The pre-test is a preliminary trial of some or all aspects of the instrument to ensure that there are no unanticipated difficulties. The pilot test is a 
brief preliminary survey that uses a small convenience sample of the same population in which the final survey will be conducted.

In this study, content validity is ensured through the process of literature review, as described in Chapter 2, as well as the development of a conceptual framework in Chapter 3 based on pre-existing relationships between the constructs. The items are then assessed by a panel of experts and pilot tested, as presented in Section 4.4.1. These processes of instrument development ensure the sufficient content validity of the constructs in the study.

\subsection{Initial Reliability}

Reliability is about the stability of measurement instrument through time (Deng, Duan, et al. 2019; Chau et al. 2020). It measures whether an instrument is consistent across different situations or on repeated occasions (Field 2013). Particularly, reliability testing examines the construct independent of its theoretical connections to ensure that the items are sufficiently inter-correlated to produce representative constructs (Straub et al. 2004). As each construct in the conceptual framework is measured by multiple items, the reliability must be assessed for ensuring their internal consistency. This leads to better data quality and reliable research findings.

The initial reliability test is used to assess the stability of the measures tested at various times with the same respondents using the same standard (Creswell 2017). Cronbach's alpha $(\alpha)$ coefficient is the most commonly used measure for assessing the reliability of 
the measurement instrument. It measures the average ratio of item variance to scale variance (Hair et al. 2010). It depends on the number of items and the mean of the correlation coefficient between two items.

This study uses the $\alpha$ coefficient for assessing the reliability of each construct. The value of the $\alpha$ coefficient ranges from 0 (completely unreliable) to 1.00 (perfectly reliable). The closer the $\alpha$ coefficient value is to 1.00 , the greater the reliability of the item in the instrument (George \& Mallery 2003).

There has been no agreement among researchers on an acceptable cut-off value for the $\alpha$ coefficient. Hair et al. (2010) suggest that the $\alpha$ value of 0.5 to 0.6 is considered acceptable for exploratory research. Such a value is 0.7 or above is highly acceptable. George and Mallery (2003) present a rule of thumb for the $\alpha$ coefficient categorizing reliability values, as shown in Table 5.11.

Table 5.11 Rule of thumb for Cronbach's alpha coefficients

\begin{tabular}{cc}
\hline Cronbach's Alpha & Internal Consistency \\
\hline$\alpha \geq 0.9$ & Excellent \\
\hline $0.8 \leq \alpha<0.9$ & Good \\
\hline $0.7 \leq \alpha<0.8$ & Acceptable \\
\hline $0.6 \leq \alpha<0.7$ & Questionable \\
\hline $0.5 \leq \alpha<0.6$ & Poor \\
\hline$\alpha<0.5$ & Unacceptable \\
\hline
\end{tabular}


In addition to the $\alpha$ coefficient, the item-to-total correlation is suggested for the measure purification (Hair et al. 2010). It assesses how each item of a construct relates to other items (Hair et al. 2010). The item-to-total correlation shows the correlation between an item and the summated score of the rest of the items. The lower item-to-total correlation value indicates that an item may not be relevant to the construct. Such an item is therefore warranted deletion to avoid potential measurement errors (Field 2013).

There are many arguments among researchers regarding the accepted cut-off values for the item-to-total correlation value for dropping an item to improve the reliability. Specifically, a correlation value of less than 0.3 indicates that the corresponding item does not correlate very well with other items. The value of more than 0.95 indicates the existence of multicollinearity and the possibility that respondents have not answered objectively (Straub et al. 2004). As a result, the item-to-total coefficient of an item should range between 0.3 and 0.9 so that it should not be dropped from the scale (Squires et al. 2011).

Twelve proposed independent constructs and one dependent construct in this study are estimated for the reliability examination by calculating their $\alpha$ coefficients. Table 5.12 shows a summary of the examination results. The results indicate that the average of the $\alpha$ coefficient ranges from 0.827 for perceived security to 0.917 for employees' IT knowledge. Out of the thirteen constructs, three constructs have excellent reliability with the $\alpha$ value from 0.9 . Ten constructs have good reliability with a $\alpha$ value between 0.8 and 0.9 . These results indicate that the internal consistency of the instrument is acceptable and reliable. 
Table 5.12 A summary of initial reliability analysis

\begin{tabular}{lllcc}
\hline \multirow{2}{*}{ Dimensions } & \multicolumn{1}{c}{ Variables } & $\begin{array}{c}\text { Number of } \\
\text { Items }\end{array}$ & $\begin{array}{c}\text { Cronbach's } \\
\text { Alpha }\end{array}$ & $\begin{array}{c}\text { Reliability } \\
\text { Strength }\end{array}$ \\
\hline \multirow{2}{*}{ Technological factors } & Perceived Benefits & 8 & 0.890 & Good \\
\cline { 2 - 5 } & Perceived Compatibility & 6 & 0.878 & Good \\
\cline { 2 - 5 } & Perceived Security & 3 & 0.827 & Good \\
\cline { 2 - 5 } Organizational factors & Perceived Cost & 3 & 0.849 & Good \\
\cline { 2 - 5 } & Employees' IT Knowledge & 3 & 0.917 & Excellent \\
\cline { 2 - 5 } Organizational Readiness & 3 & 0.843 & Good \\
\hline \multirow{2}{*}{ Environmental factors } & Organizational Innovativeness & 3 & 0.858 & Good \\
\cline { 2 - 5 } & Competitive Pressures & 3 & 0.862 & Good \\
\cline { 2 - 5 } & Customer Pressures & 3 & 0.898 & Good \\
\cline { 2 - 5 } Managerial factors & Government support & 3 & 0.902 & Excellent \\
\hline Dop Management Support & 3 & 0.870 & Good \\
\hline & Managers' IT Knowledge & 3 & 0.893 & Good \\
\hline & Adoption & 3 & 0.915 & Excellent \\
\hline
\end{tabular}

The corrected item-total correlation and the Cronbach's alpha if an item is deleted are calculated for each construct separately to purify the measure as shown in Appendix E. The results indicate that all items of each construct are in the acceptable range of the corrected item-total correlation. None of the $\alpha$ value if an item is deleted is greater than the current $\alpha$ coefficient of its construct. As a result, all items of such thirteen constructs are retained.

In summary, the $\alpha$ coefficient and the corrected item-total correlation coefficient are examined for assessing the internal consistency of the constructs. These results show that all the $\alpha$ coefficients of the constructs are greater than 0.7 . The item-to-total 
correlation value of each item to its designated construct is greater than the cut-off value of 0.3. These indicate that the internal consistency of the instrument is acceptable and reliable.

\subsection{Factorial Validity}

Factorial validity is about the extent to which a set of measurement items fit together to reflect a theoretical construct in a study (Chau et al. 2020). It is used for uncovering the underlying construct for the set of measurement items of the instrument. Factorial validity identifies if the underlying structure among the constructs extracted from the data is consistent with those proposed in the conceptual framework (Straub et al. 2004). It is an important assessment that needs to do before performing the SEM analysis (Venkatraman 1989).

EFA is one of the most common tools for assessing factorial validity. It discovers the structure of a set of measurement items in terms of its representation of a particular construct (Williams, Onsman \& Brown 2010). EFA is used to reduce a large number of measurement items into a smaller number that can be identified in terms of the underlying constructs measuring different constructs. Such a reduction aims to maximize the explained variance in the construct (Hair et al. 2010; Tabachnick \& Fidell 2013). As factorial validity examines the constructs independent of the theoretical connections, it is suggested running EFA for each construct or each dimension separately. In this study, the proposed conceptual framework consists of four 
dimensions of the critical determinants and one dependent construct. As a result, five separate EFA models are run for assessing factorial validity with the use of SPSS 25.

The appropriateness for running EFA is determined by (a) the factorability of the data and (b) the appropriate sample size. The factorability of the data is tested through the Kaiser-Meyer-Olkin (KMO) measure of sampling adequacy and Bartlett's test of sphericity (BTOS).

The KMO measure is the proportion of variance among constructs. It suggests the sampling adequacy for each construct in the proposed conceptual framework and the entire framework. KMO values are usually ranged from 0 to 1 . Generally, data are factorable if the KMO is between 0.5 and 1, and the BTOS is significant with a significant value below 0.05 (Hair et al. 2010). The KMO value is closer to 1 indicates the most appropriate data for factor analysis (Field 2013).

Table 5.13 summarizes the results of KMO tests and BTOS tests for five EFA models in this study. The results show that all the KMO values are acceptable. All the BTOS tests are significant. These suggest that the data are suitable for running such EFA models. 
Table 5.13 KMO and BTOS tests

\begin{tabular}{lccccc}
\hline \multirow{2}{*}{ Dimensions } & KMO & \multicolumn{3}{c}{ BTOS tests } & \multirow{2}{*}{ Remarks } \\
\cline { 3 - 5 } & & Approx. Chi-square & df & Sig. & \\
\hline Technological factors & 0.889 & 3659.310 & 91 & 0.000 & EFA supported \\
\hline Organizational factors & 0.853 & 2843.050 & 36 & 0.000 & EFA supported \\
\hline Environmental factors & 0.824 & 3024.200 & 36 & 0.000 & EFA supported \\
\hline Managerial factors & 0.825 & 1870.519 & 15 & 0.000 & EFA supported \\
\hline Dependent variable & 0.730 & 1134.434 & 3 & 0.000 & EFA supported \\
\hline
\end{tabular}

The sample size that meets the minimum requirement of the subject-to-variable ratio is important as it determines the accuracy of the EFA (MacCallum \& Tucker 1991). Hair et al. (2010) suggest a case-to-variable ratio of 5:1 to 10:1 to guarantee a reliable EFA procedure. In this study, there are 47 measurement items and a sample size of 513, which is equivalent to an 11:1 ratio. This means that the selected sample size satisfies the subject-to-variable ratio. This indicates the appropriateness of the dataset for running EFA.

Once the suitability of the data for EFA is determined, the following rules are established to extract the factors. These rules include (a) the selection of the factor extraction method, (b) the determination of the number of factors extracted, (c) the selection of the factor rotation method, and (d) the determination of minimum factor loading to allocate an item to a factor. These rules must be followed properly to get an appropriate factor structure for the factor analysis. 
There are three common factor extraction methods in the factor analysis including principal component analysis, principal axis factoring, and maximum likelihood (Hair et al. 2010). There is no evidence regarding which method should be preferred for different types of factor patterns and sample sizes. Among these methods, the maximum likelihood is the best choice when the data are relatively normally distributed. This is because it allows for the computation of a wide range of the goodness of fit indexes of the model. It permits statistical significance testing of factor loadings and correlations among factors (Fabrigar et al. 1999). The results of the multivariate normality test in section 5.2.5 confirm that the dataset in this study is consistent with the normal distribution. As a result, the maximum likelihood extraction method is adopted for factor analysis.

Factors are extracted using eigenvalues. The number of factors in each of the five EFA models are determined based on Kaiser's criterion of retaining factors with eigenvalues greater than 1.0 (Hair et al. 2010). In addition to the eigenvalue, the determination of the number of extracted factors needs to meet a specified percentage of variance explained, usually $60 \%$ or higher (Hair et al. 2010).

For better interpretability, the factors are rotated using promax rotation, an oblique rotation method, which allows factors to be correlated. Such a rotation method can be calculated quickly and is useful for large datasets (Hair et al. 2010). The minimum factor loading to allocate an item to a factor is suggested at 0.5 (Field 2013). The minimum factor loading, however, should be set depending on the sample size. Particularly, smaller samples require higher factor loadings, whereas larger samples 
require relatively factor loadings. Hair et al. (2010), for example, suggest a minimum factor loading at 0.4 for a sample size of more than 200. Tabachnick and Fidell (2013) suggest a minimum factor loading at 0.3 for such the sample size above. This study adopts a minimum factor loading of 0.5 for the sample size of 513 .

Five separate EFA models are run with the use of the maximum likelihood extraction method and the promax rotation method. A minimum eigenvalue of 1.0 is chosen as the condition for factor extraction. A minimum factor loading for allocating an item to a factor is set at 0.5 . Single item factors and items with loading values less than 0.5 and/or items with cross-loaded values are dropped. The procedure is repeated until a clear factor structure emerges.

Table 5.14 presents the results of EFA for the technological dimension. Fourteen items are retained from twenty initial items that are extracted into four factors with $61.646 \%$ of total variance explained. Specifically, the first factor, "perceived compatibility", accounts for $40.661 \%$ of the variance. The second factor, "perceived benefits", accounts for $8.468 \%$ of the variance. The third factor, "perceived cost", accounts for $6.780 \%$ of the variance. The fourth factor, "perceived security", accounts for $5.738 \%$ of the variance. The results show that items related to the perceived compatibility construct are loaded on the first factor. Item CMPA5 and item CMPA6, however, have the loading values less than 0.5 . They are therefore dropped. The perceived benefits construct is initially measured on eight items. Item BENE1 and item BENE2, however, do not load on any factors. Additionally, item BENE3 and item BENE4 have the loading values less than 0.5. As a result, these four items are dropped. The perceived cost construct is 
measured on three items that are all loaded significantly on the third factor. The perceived security construct is measured on three items that are all loaded significantly on the fourth factor. In total, four factors are extracted with fourteen items for the technological dimension.

Table 5.14 Factor analysis results for the technological dimension

\begin{tabular}{|c|c|c|c|c|}
\hline Items & F1 & F2 & F3 & F4 \\
\hline CMPA2 & .938 & & & \\
\hline CMPA1 & .798 & & & \\
\hline CMPA3 & .690 & & & \\
\hline CMPA4 & .519 & & & \\
\hline BENE7 & & .834 & & \\
\hline BENE8 & & .782 & & \\
\hline BENE5 & & .684 & & \\
\hline BENE6 & & .669 & & \\
\hline CSTS2 & & & .840 & \\
\hline CSTS3 & & & .800 & \\
\hline CSTS1 & & & .756 & \\
\hline SECU2 & & & & .965 \\
\hline SECU3 & & & & .763 \\
\hline SECU1 & & & & .622 \\
\hline Eigenvalues & 6.106 & 1.613 & 1.324 & 1.036 \\
\hline
\end{tabular}

F1: Perceived Compatibility, F2: Perceived Benefits, F3: Perceived Cost, F4: Perceived Security

Table 5.15 presents the results of EFA for the organizational dimension. The initial nine items are extracted into three factors with $70.657 \%$ of total variance explained. Specifically, the first factor, "employees' IT knowledge", accounts for $47.635 \%$ of the 
variance. The second factor, "organizational innovativeness", accounts for $15.756 \%$ of the variance. The third factor, "organizational readiness", accounts for $7.266 \%$ of the variance. The results show that items related to the employees' IT knowledge construct are cleanly loaded on the first factor. Three items related to the organizational innovativeness construct are cleanly loaded on the second factor. Three items related to the organizational readiness construct are cleanly loaded on the third factor. In total, three factors are extracted with nine items for the organizational dimension.

Table 5.15 Factor analysis results for the organizational dimension

\begin{tabular}{llll}
\hline Items & F1 & F2 & F3 \\
\hline EMPL2 & .949 & & \\
\hline EMPL1 & .887 & .920 & \\
\hline EMPL3 & .822 & .789 & \\
\hline INNO2 & & .703 & .878 \\
\hline INNO3 & & & .821 \\
\hline INNO1 & & & .648 \\
\hline READ2 & & 1.557 & 1.067 \\
\hline READ1 & 4.687 & & \\
\hline READ3 & & & \\
\hline Eigenvalues & & & \\
\hline
\end{tabular}

$F 1=$ Employees' $I T$ Knowledge, $F 2=$ Organizational Innovativeness, $F 3=$ Organizational Readiness

Table 5.16 presents the results of EFA for the environmental dimension. The initial nine items are extracted into three factors with $73.729 \%$ of total variance explained. Specifically, the first factor, "government support", accounts for $46.800 \%$ of the variance. The second factor, "customer pressures", accounts for $17.375 \%$ of the 
variance. The third factor, "competitive pressures", accounts for $9.555 \%$ of the variance. The results show that items related to the government support construct are cleanly loaded on the first factor. Three items related to the customer pressures construct are cleanly loaded on the second factor. Three items related to the competitive pressures construct are cleanly loaded on the third factor. In total, three factors are extracted with nine items for the environmental dimension.

Table 5.16 Factor analysis results for the environmental dimension

\begin{tabular}{llll}
\hline Items & F1 & F2 & F3 \\
\hline GOVE3 & .919 & & \\
\hline GOVE2 & .912 & & \\
\hline GOVE1 & .766 & .942 & \\
\hline CUST2 & & .881 & .964 \\
\hline CUST1 & & & .730 \\
\hline CUST3 & & & .711 \\
\hline CMPE2 & & 1.795 & 1.100 \\
\hline CMPE3 & & 4.487 & \\
\hline CMPE1 & & & \\
\hline Eigenvalues & & & \\
\hline
\end{tabular}

F1=Government Support, F2=Customer Pressures, F3=Competitive Pressures

Table 5.17 presents the results of EFA for the managerial dimension. The initial six items are extracted into two factors with $71.945 \%$ of total variance explained. Specifically, the first factor, "managers' IT knowledge", accounts for $56.828 \%$ of the variance. The second factor, "top management support", accounts for $15.117 \%$ of the variance. The results show that items related to the managers' IT knowledge construct 
are cleanly loaded on the first factor. Three items related to the top management support construct are cleanly loaded on the second factor. In total, two factors are extracted with six items for the managerial dimension.

Table 5.17 Factor analysis results for the managerial dimension

\begin{tabular}{lcc}
\hline Items & F1 & F2 \\
\hline TMIT2 & .943 & \\
\hline TMIT3 & .884 & \\
\hline TMIT1 & .710 & .858 \\
\hline TMSP1 & & .838 \\
\hline TMSP2 & & .778 \\
\hline TMSP3 & 3.721 & 1.142 \\
\hline Eigenvalues & & \\
\hline F1=Managers ${ }^{\prime}$ IT Knowledge, F2 $=$ Top Management Support & \\
\hline
\end{tabular}

Table 5.18 presents the results of EFA for the dependent construct. The initial three items are cleanly loaded on one factor with $78.827 \%$ of total variance explained.

Table 5.18 Factor analysis results for the dependent construct

\begin{tabular}{ll}
\hline Items & F1 \\
\hline ADPT2 & .964 \\
\hline ADPT1 & .848 \\
\hline ADPT3 & .845 \\
\hline Eigenvalues & 2.568 \\
\hline F1=Adoption & \\
\hline
\end{tabular}


In summary, the EFA leads to the deletion of six items that do not meet one or more of the factor extraction criteria, resulting in the retention of forty-one items grouped into thirteen factors. These results establish factorial validity and represent an initial specification of the measurement model. Table 5.19 provides a summary of the final EFA output.

Table 5.19 Summary of the EFA output

\begin{tabular}{lcccc}
\hline Constructs & $\begin{array}{c}\text { Number of } \\
\text { Items }\end{array}$ & $\begin{array}{c}\text { Range of Factor } \\
\text { Loading }\end{array}$ & $\begin{array}{c}\text { Number of } \\
\text { Dropped Items }\end{array}$ & Reason for Dropping \\
\hline BENE & 8 & $(0.669-0.834)$ & 4 & $\begin{array}{c}\text { No loading value; Loading } \\
\text { value less than } 0.5\end{array}$ \\
\hline CMPA & 6 & $(0.519-0.938)$ & 2 & Loading value less than 0.5 \\
\hline SECU & 3 & $(0.622-0.965)$ & 0 & N/A \\
\hline CSTS & 3 & $(0.756-0.840)$ & 0 & N/A \\
\hline EMPL & 3 & $(0.822-0.949)$ & 0 & N/A \\
\hline READ & 3 & $(0.648-0.878)$ & 0 & N/A \\
\hline INNO & 3 & $(0.703-0.920)$ & 0 & N/A \\
\hline CMPE & 3 & $(0.711-0.964)$ & 0 & N/A \\
\hline CUST & 3 & $(0.730-0.942)$ & 0 & N/A \\
\hline GOVE & 3 & $(0.766-0.919)$ & 0 & N/A \\
\hline TMSP & 3 & $(0.778-0.858)$ & 0 & 0 \\
\hline TMIT & 3 & $(0.710-0.943)$ & 0 & N/A \\
\hline ADPT & 3 & $(0.845-0.964)$ & 0 & 0 \\
\hline
\end{tabular}




\subsection{Construct Validity}

Once the factorial validity is determined through EFA, it is necessary to assess the construct validity before assessing the structural model and testing the research hypotheses (Hair et al. 2010; Byrne 2016). Construct validity assesses the extent to which a set of measurement items reflect the underlying constructs that those items are designed to measure (Hair et al. 2010). It focuses on two assessments including (a) convergent validity and (b) discriminant validity. Both of these assessments are first undertaken for each factor or dimension, and finally, for the full measurement model (Lewis et al. 2005). Such validity assessments are conducted through CFA with the help of various model fit indices.

CFA is a statistical technique that verifies how well measurement items represent a small number of constructs. It is used to ensure that the measurement model has a good fitness to the dataset in a given situation (Hair et al. 2010). CFA provides better understanding of the shared variance among the measurement items (Brown \& Moore 2012). Such variance is used to reflect the aggregated measurement items, which together represent a certain construct. As a result, CFA presents the contribution of each measurement item within a specific construct included in the measurement model (Hair et al. 2010).

To run CFA, the sample size that needs to be taken into consideration is critical. Usually, a sample size of above 200 is considered as good to reveal the association between the observed variables and the underlying construct (Lewis et al. 2005; Hair et al. 2010). The sample size for this study is 513 , which meet the minimum sample size 
requirement for CFA. In the next section, convergent validity and discriminant validity are assessed through CFA with the use of AMOS 25 software.

\subsubsection{Goodness of Fit}

The GOF statistics explain the divergence between observed values and those expected in a proposed model. They reflect the ability of the model to represent the data (Hair et al. 2010). As a result, when the GOF statistics show the poor fitness of the theorized model, the model needs to be re-specified. There are four categories of GOF indices, including Chi-square, absolute fit indices, incremental fit indices, and parsimony fit indices. Table 5.20 presents the most common indices in these categories and their definitions. 
Table 5.20 An overview of the GOF indices

\begin{tabular}{|c|c|c|}
\hline Category & Statistics & Definition \\
\hline \multirow{3}{*}{ Chi-square $(\chi 2)$} & Chi-square & $\begin{array}{l}\text { Assessment of differences between groups using } \\
\text { nominal data }\end{array}$ \\
\hline & Degree of freedom & $\begin{array}{l}\text { Estimated parameters subtracted from total } \\
\text { coefficients }\end{array}$ \\
\hline & Probability statistic ( $p$-value) & $\begin{array}{l}\text { Probability of closeness between the observed } \\
\text { and covariance matrices }\end{array}$ \\
\hline \multirow{5}{*}{$\begin{array}{l}\text { Absolute } \\
\text { indices }\end{array}$} & GOF index & $\begin{array}{l}\text { Indicator for model reproducibility to } \\
\text { demonstrate variance or covariance of the } \\
\text { observed sample }\end{array}$ \\
\hline & $\begin{array}{l}\text { Root mean square error of } \\
\text { approximation (RMSEA) }\end{array}$ & $\begin{array}{l}\text { A measure of fit/misfit in SEM applications to } \\
\text { explain how well a model fits a population }\end{array}$ \\
\hline & Root mean square residual (RMR) & $\begin{array}{l}\text { The mean absolute value of the covariance } \\
\text { residuals }\end{array}$ \\
\hline & $\begin{array}{l}\text { Standardized root mean square } \\
\text { residual (SRMR) }\end{array}$ & $\begin{array}{l}\text { Standardized root mean square residual compares } \\
\text { fit across models }\end{array}$ \\
\hline & Normed chi-square & $\begin{array}{l}\text { The ratio of } \chi^{2} \text { to the degrees of freedom for a } \\
\text { model }\end{array}$ \\
\hline \multirow{4}{*}{$\begin{array}{l}\text { Incremental } \\
\text { indices }\end{array}$} & Normed fit index (NFI) & \multirow{4}{*}{$\begin{array}{l}\text { Assesses how well a specified model fits relative } \\
\text { to some alternative baseline model (often a null } \\
\text { model that assumes all observed variables are } \\
\text { uncorrelated) }\end{array}$} \\
\hline & Tucker-Lewis index (TLI) & \\
\hline & Comparative fit index (CFI) & \\
\hline & Incremental fit index (IFI) & \\
\hline \multirow{2}{*}{$\begin{array}{l}\text { Parsimony } \\
\text { indices }\end{array}$} & $\begin{array}{l}\text { Parsimony comparative fit index } \\
\text { (PCFI) }\end{array}$ & \multirow{2}{*}{$\begin{array}{l}\text { Evaluates the parsimony ratio of the model } \\
\text { compared to the GOF such as CFI and NFI }\end{array}$} \\
\hline & Parsimony normed fit index (PNFI) & \\
\hline PClose & Close-fitting model & $P$-value of a test on RMSEA \\
\hline
\end{tabular}

It is common to use at least three fit indices for examining the model fitness in the structured analysis (Hair et al. 2010; Kline 2015). Hooper, Coughlan and Mullen (2008), for example, use the chi-square test, RMSEA, GFI, AGFI, RMR, and SRMR to 
demonstrate the fitness between the proposed model and the data. Hair et al. (2010) recommend that in addition to the chi-square value and degree of freedom $(d f)$, at least one incremental index (CFI or TLI) and at least one absolute index (RMSEA or SRMR) should be reported. In addition to the selection of specific indices to demonstrate the model fitness, the determination of their optimal cut-off values is important, which may change according to the sample size. The smaller the sample size, the lower cut-off values of GOF indices are observed (Hair et al. 2010). Table 5.21 presents a summary of widely-used fit indices with their acceptable values for such a sample size of 513 of this study.

Table 5.21 A summary of widely-used fit measures and established criteria

\begin{tabular}{|c|c|c|c|}
\hline Dimensions & Selected GOF Statistics & Acceptable Value Range & Sources \\
\hline Chi-square & $\chi^{2}\left(\mathrm{df}, \mathrm{p}^{*}\right)$ & $\mathrm{p}<0.05$ & $\begin{array}{l}\text { Barrett (2007); Hair et al. } \\
(2010)\end{array}$ \\
\hline \multirow{3}{*}{$\begin{array}{l}\text { Absolute fit } \\
\text { indices }\end{array}$} & $\chi^{2} / \mathrm{df}$ & $<5(\leq 3$ preferred $)$ & $\begin{array}{l}\text { Hair et al. (2010); Tabachnick } \\
\text { and Fidell (2013) }\end{array}$ \\
\hline & RMSEA & $\leq 0.05-0.1$ & Hoe (2008); Hair et al. (2010) \\
\hline & RMR and SRMR & $<0.09$ & Hair et al. (2010); Byrne (2016) \\
\hline $\begin{array}{l}\text { Incremental } \\
\text { fit indices }\end{array}$ & IFI, TLI, and CFI & $\geq 0.9$ & Hooper et al. (2008) \\
\hline $\begin{array}{l}\text { Parsimony } \\
\text { fit indices }\end{array}$ & PNFI and PCFI & $>0.5$ & $\begin{array}{l}\text { Hooper et al. (2008); Hair et al. } \\
\text { (2010) }\end{array}$ \\
\hline PClose & PClose & $>0.05$ & Hair et al. (2010) \\
\hline
\end{tabular}




\subsubsection{Convergent Validity}

Convergent validity examines the extent to which measurement items of a specific construct converge or share a high proportion of variance in common (Hair et al. 2010). It can be established by demonstrating the correspondence between two similar constructs. Several indicators are suggested for establishing convergent validity including factor loading size, average variance extracted (AVE), and construct reliability (CR). In the AMOS software, convergent validity can be established using one or a combination of the following measures including (a) goodness of fit (GOF) measures, (b) the standardized factor loading (SFL), (c) the squared multiple correlations (SMC), (d) AVE, and (e) CR.

The assessment of the factor loading size is performed through the assessment of the SFL value of each single valid measurement item included in the re-specified measurement models (Fornell \& Larcker 1981; Hair et al. 2010). The evidence of convergent validity exists if the SFL for each measurement item is at least 0.5 or higher (Hair et al. 2010).

AVE measures the measurement item captured by a particular construct (Gefen \& Straub 2007). It is computed by dividing the sum of all squared SFL values of individual items by the total number of measurement items of the single construct (Fornell \& Larcker 1981). For each construct, an AVE value of 0.5 or greater is appropriate for supporting the convergent validity (Hair et al. 2010). 
SCM is the communality estimate for a measurement item. The communality measures the percent of the variance in a given item explained by its latent construct (Byrne 2016). It may be interpreted as the reliability of the measurement item. The communality is equal to the squared standardized regression weight. If a measurement item has a low communality, it may be targeted for removal in the model-modification. The evidence of convergent validity exists if the SMC values of all items are greater than 0.4 (Hair et al. 2010).

$\mathrm{CR}$ is a measure of internal consistency in scale items (Netemeyer, Bearden \& Sharma 2003). It is an indicator of the shared variance among the items used as indicators of a latent construct (Fornell \& Larcker 1981). CR is computed by squaring the sum of SFL values of individual items within a particular construct and dividing it by the squared sum of SFL square of each item and sum of error variance of each item with such a construct (Hair et al. 2010). The evidence of convergent validity exists if the CR value is at least 0.7 (Hair et al. 2010).

To calculate these measures, six separate CFA models are run for four distinct theoretical dimensions of the critical determinants for organizational m-commerce adoption, dependent construct, and the full measurement model. The results of such individual CFA models for assessing convergent validity are presented in Section 5.6.4 to Section 5.6.9 below. 


\subsubsection{Discriminant Validity}

Discriminant validity is about the extent to with a latent construct is truly distinct from other latent constructs both in terms of how much it correlates with other latent constructs and how distinctly measurement items represent only this single construct (Hair et al. 2010; Byrne 2016). Such validity is employed to ensure that there is no correlation between constructs. A low correlation between the two constructs indicates that one construct is distinct from another. Discriminant validity can be assessed at both the item level and the construct level (Fornell \& Larcker 1981; Henseler, Ringle \& Sinkovics 2009).

The discriminant validity at the item level is assessed by examining the items loading values of the construct. Particularly, all items need to be loaded on their construct higher than on other constructs in the conceptual framework (Henseler et al. 2009). In this study, the results of five separate EFA models in section 5.5, presented in Table 5.14 to Table 5.18 indicate strong loadings of all items to their constructs. These confirm the item-level discriminant validity of the constructs.

The discriminant validity at the construct level indicates that the average variance shared between a construct and its measurement items should be greater than the variance shared by that construct and any other constructs in the conceptual framework (Fornell \& Larcker 1981; Hair et al. 2010). As a result, discriminant validity at the construct level is assessed by comparing the AVE for each construct with the squared correlation between this construct and any other constructs (Hair et al. 2010). Particularly, the AVE value for each construct should be greater than any of the squared 
correlation value between that construct and other constructs supports the discriminant validity of the constructs (Hair et al. 2010; Creswell \& Clark 2017).

To assess the discriminant validity for the constructs in this study, a CFA model for the full measurement model is run. The correlation matrix is then calculated. All of these results are presented in Section 5.6.9.

\subsubsection{Measurement Model for the Technological Determinants}

This section presents the convergent validity of four constructs in the technological dimension including perceived benefits, perceived compatibility, perceived security, and perceived cost. The perceived benefits construct is hypothesized to consist of four items. The perceived compatibility construct is hypothesized to consist of four items. The perceived security construct is hypothesized to consist of three items. The perceived cost construct is hypothesized to consist of three items. Figure 5.1 shows the measurement model for the technological dimension. 


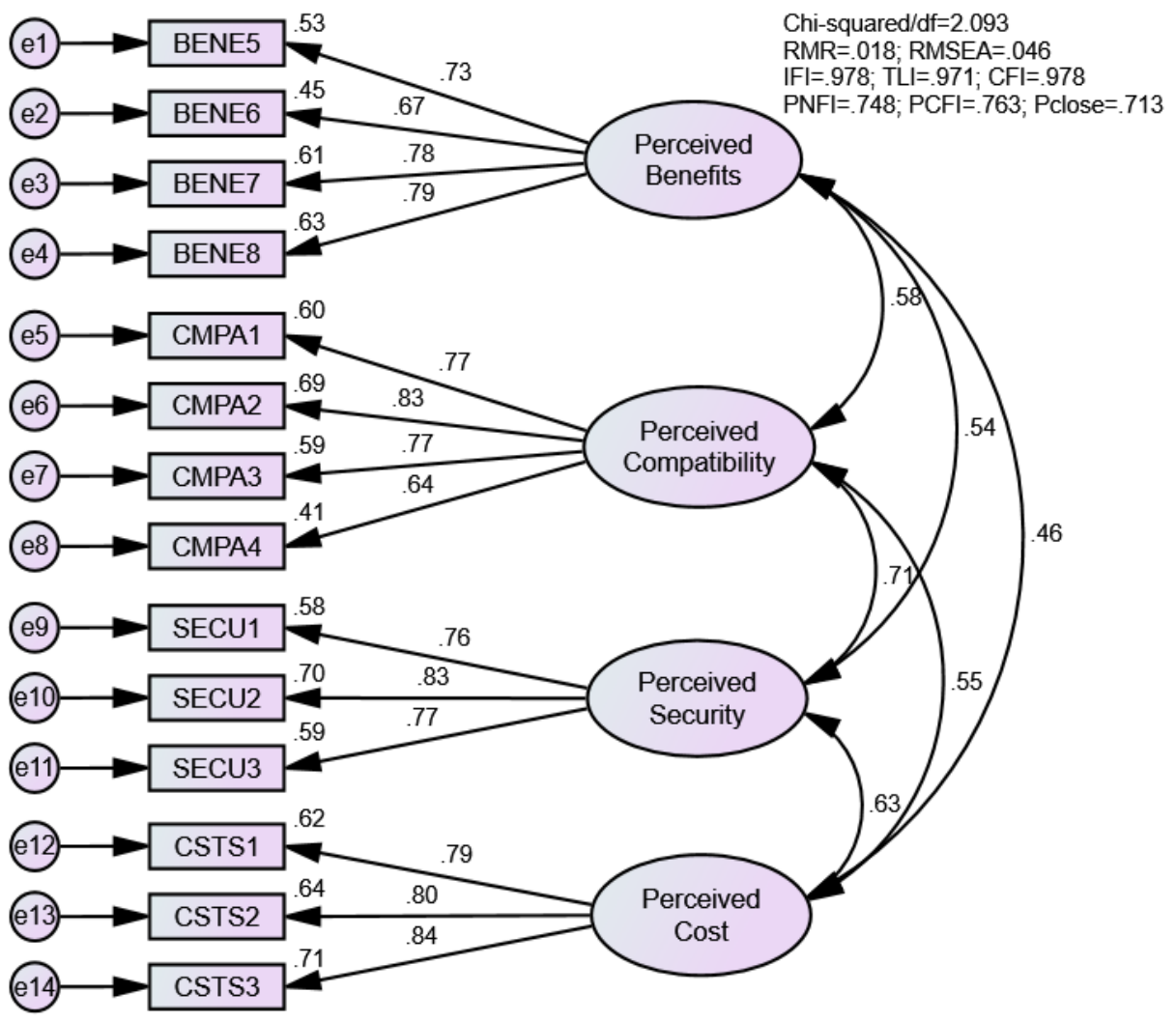

Figure 5.1 Measurement model for technological dimension

Table 5.22 presents the results for GOF statistics and convergent validity tests for constructs in the technological dimension. The GOF statistics suggest an acceptable fitness. Specifically, the normed chi-square value $(\chi 2 / \mathrm{df})$ of 2.093 is within the acceptable range. The absolute fit indices (RMSEA, RMR, and SRMR), incremental fit indices (IFI, TLI, and CFI), and parsimony fit indices (PNFI and PCFI) values are found to be within an acceptable range. The Pclose value of 0.713 also suggests good model fitness. 
Table 5.22 GOF statistics and convergent validity measures for technological dimension

\begin{tabular}{lccccccc}
\hline \multicolumn{2}{c}{ Chi-square } & \multicolumn{2}{c}{ Absolute Fit Indices } & \multicolumn{2}{c}{ Incremental Fit Indices } & \multicolumn{2}{c}{ Parsimony Fit Indices } \\
\hline$\chi 2$ & $148.632(0.00)$ & RMSEA & 0.046 & IFI & 0.978 & PNFI & 0.748 \\
\hline df & 71 & RMR & 0.018 & TLI & 0.971 & PCFI & 0.763 \\
\hline$\chi 2 /$ df & 2.093 & SRMR & 0.030 & CFI & 0.978 & Pclose & 0.713 \\
\hline
\end{tabular}

Factor loadings $(* * * p<0.001, * * p<0.01$, and $* p<0.05)$

\begin{tabular}{|c|c|c|c|c|c|c|c|}
\hline Factors & $\mathrm{CR}$ & AVE & Items & SFL & Sig. & SMC & Comments \\
\hline \multirow{4}{*}{$\begin{array}{l}\text { Perceived } \\
\text { Benefits }\end{array}$} & \multirow{4}{*}{0.834} & \multirow{4}{*}{0.557} & BENE5 & 0.731 & $* * *$ & 0.534 & \multirow{14}{*}{$\begin{array}{l}\text { Model fit is excellent } \\
\text { Convergent validity holds }\end{array}$} \\
\hline & & & BENE6 & 0.674 & $* * *$ & 0.454 & \\
\hline & & & BENE7 & 0.781 & $* * *$ & 0.610 & \\
\hline & & & BENE8 & 0.795 & $* * *$ & 0.631 & \\
\hline \multirow{4}{*}{$\begin{array}{l}\text { Perceived } \\
\text { Compatibility }\end{array}$} & \multirow{4}{*}{0.842} & \multirow{4}{*}{0.573} & CMPA1 & 0.773 & $* * *$ & 0.589 & \\
\hline & & & CMPA2 & 0.831 & $* * *$ & 0.690 & \\
\hline & & & CMPA3 & 0.768 & $* * *$ & 0.589 & \\
\hline & & & CMPA4 & 0.644 & $* * *$ & 0.414 & \\
\hline \multirow{3}{*}{$\begin{array}{l}\text { Perceived } \\
\text { Security }\end{array}$} & \multirow{3}{*}{0.830} & \multirow{3}{*}{0.620} & SECU1 & 0.758 & $* * *$ & 0.575 & \\
\hline & & & SECU2 & 0.834 & $* * *$ & 0.696 & \\
\hline & & & SECU3 & 0.768 & $* * *$ & 0.590 & \\
\hline \multirow{3}{*}{ Perceived Cost } & \multirow{3}{*}{0.850} & \multirow{3}{*}{0.653} & CSTS1 & 0.786 & $* * *$ & 0.618 & \\
\hline & & & CSTS2 & 0.798 & $* * *$ & 0.636 & \\
\hline & & & CSTS3 & 0.840 & $* * *$ & 0.705 & \\
\hline
\end{tabular}

Regarding the convergent validity, CR values and AVE values of four constructs are greater than 0.7 and 0.5 respectively. The SFL values and SMC values of all items are greater than 0.5 and 0.4 respectively. These values establish the convergent validity of four constructs in the technological dimension. 


\subsubsection{Measurement Model for the Organizational Determinants}

This section presents the convergent validity of three constructs in the organizational dimension including employees' IT knowledge, organizational readiness, and organizational innovativeness. The employees' IT knowledge construct is hypothesized to consist of three items. The organizational readiness construct is hypothesized to consist of three items. The organizational innovativeness construct is hypothesized to consist of three items. Figure 5.2 shows the measurement model for the organizational dimension.

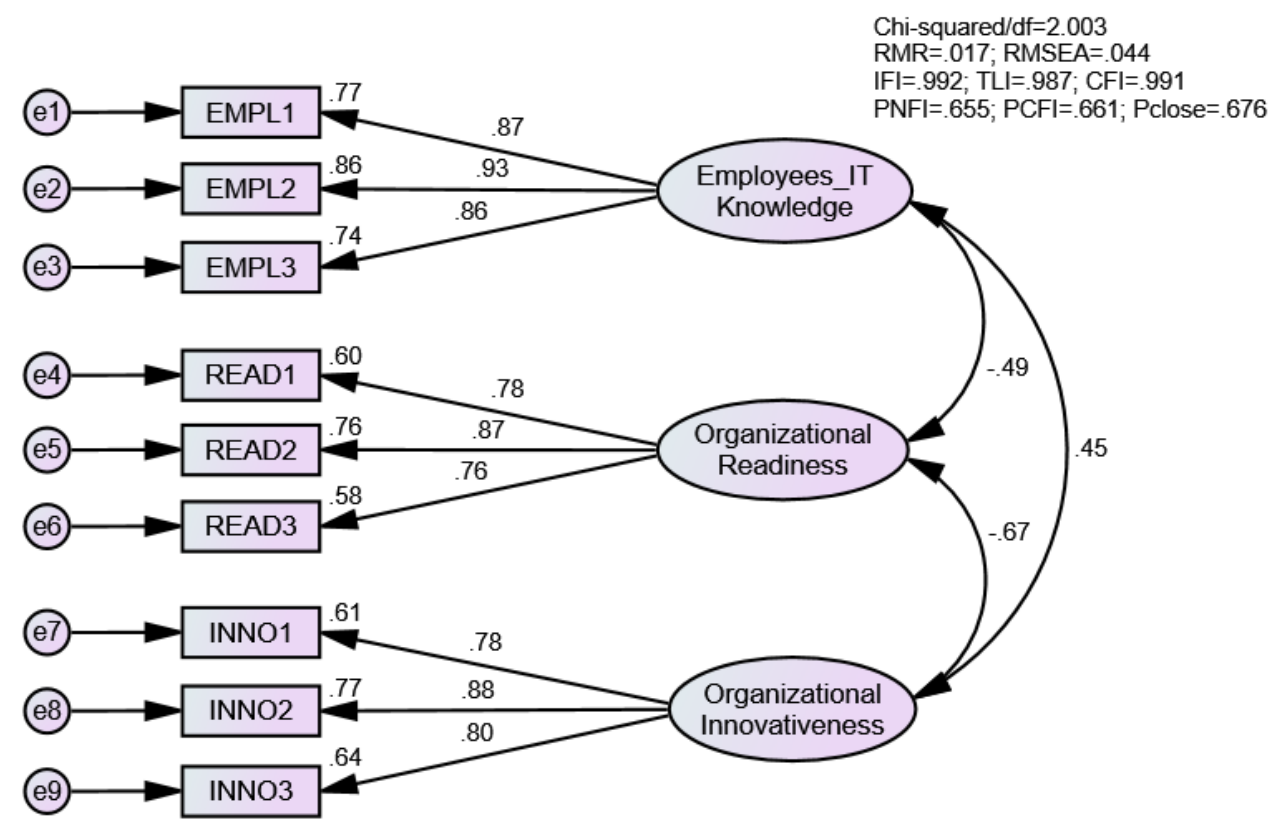

Figure 5.2 Measurement model for organizational dimension

Table 5.23 presents the results for GOF statistics and convergent validity tests for constructs in the organizational dimension. The GOF statistics suggest an acceptable fitness. Specifically, the $\chi 2 / \mathrm{df}$ value of 2.003 is within the acceptable range. The absolute fit indices (RMSEA, RMR, and SRMR), incremental fit indices (IFI, TLI, and 
$\mathrm{CFI}$ ), and parsimony fit indices (PNFI and PCFI) values are found to be within an acceptable range. The Pclose value of 0.676 also suggests good model fitness.

Table 5.23 GOF statistics and convergent validity measures for organizational dimension

\begin{tabular}{llcccccc}
\hline & Chi-square & \multicolumn{2}{c}{ Absolute Fit Indices } & \multicolumn{2}{c}{ Incremental Fit Indices } & \multicolumn{2}{c}{ Parsimony Fit Indices } \\
\hline$\chi 2$ & $48.070(0.002)$ & RMSEA & 0.044 & IFI & 0.992 & PNFI & 0.655 \\
\hline df & 24 & RMR & 0.017 & TLI & 0.987 & PCFI & 0.661 \\
\hline$\chi 2 /$ df & 2.003 & SRMR & 0.028 & CFI & 0.991 & Pclose & 0.676 \\
\hline
\end{tabular}

Factor loadings $(* * * p<0.001, * * p<0.01$, and $* p<0.05)$

\begin{tabular}{|c|c|c|c|c|c|c|c|}
\hline Factors & $\mathrm{CR}$ & AVE & Items & SFL & Sig. & SMC & Comments \\
\hline \multirow{3}{*}{$\begin{array}{l}\text { Employees' IT } \\
\text { Knowledge }\end{array}$} & \multirow{3}{*}{0.918} & \multirow{3}{*}{0.788} & EMPL1 & 0.875 & $* * *$ & 0.765 & \multirow{9}{*}{$\begin{array}{l}\text { Model fit is acceptable } \\
\text { Convergent validity holds }\end{array}$} \\
\hline & & & EMPL2 & 0.929 & $* * *$ & 0.863 & \\
\hline & & & EMPL3 & 0.859 & $* * *$ & 0.737 & \\
\hline \multirow{3}{*}{$\begin{array}{l}\text { Organizational } \\
\text { Readiness }\end{array}$} & \multirow{3}{*}{0.846} & \multirow{3}{*}{0.647} & READ1 & 0.775 & $* * *$ & 0.601 & \\
\hline & & & READ2 & 0.875 & $* * *$ & 0.765 & \\
\hline & & & READ3 & 0.759 & $* * *$ & 0.576 & \\
\hline \multirow{3}{*}{$\begin{array}{l}\text { Organizational } \\
\text { Innovativeness }\end{array}$} & \multirow{3}{*}{0.861} & \multirow{3}{*}{0.673} & INNO1 & 0.781 & $* * *$ & 0.610 & \\
\hline & & & INNO2 & 0.879 & $* * *$ & 0.772 & \\
\hline & & & INNO3 & 0.799 & $* * *$ & 0.638 & \\
\hline
\end{tabular}

Regarding the convergent validity, CR values and AVE values of three constructs are greater than 0.7 and 0.5 respectively. The SFL values and SMC values of all items are greater than 0.5 and 0.4 respectively. These values establish the convergent validity of three constructs in the organizational dimension. 


\subsubsection{Measurement Model for the Environmental Determinants}

This section presents the convergent validity of the three constructs in the environmental dimension including competitive pressures, customer pressures, and government support. The competitive pressures construct is hypothesized to consist of three items. The customer pressures construct is hypothesized to consist of three items. The government support construct is hypothesized to consist of three items. Figure 5.3 shows the measurement model for the environmental dimension.

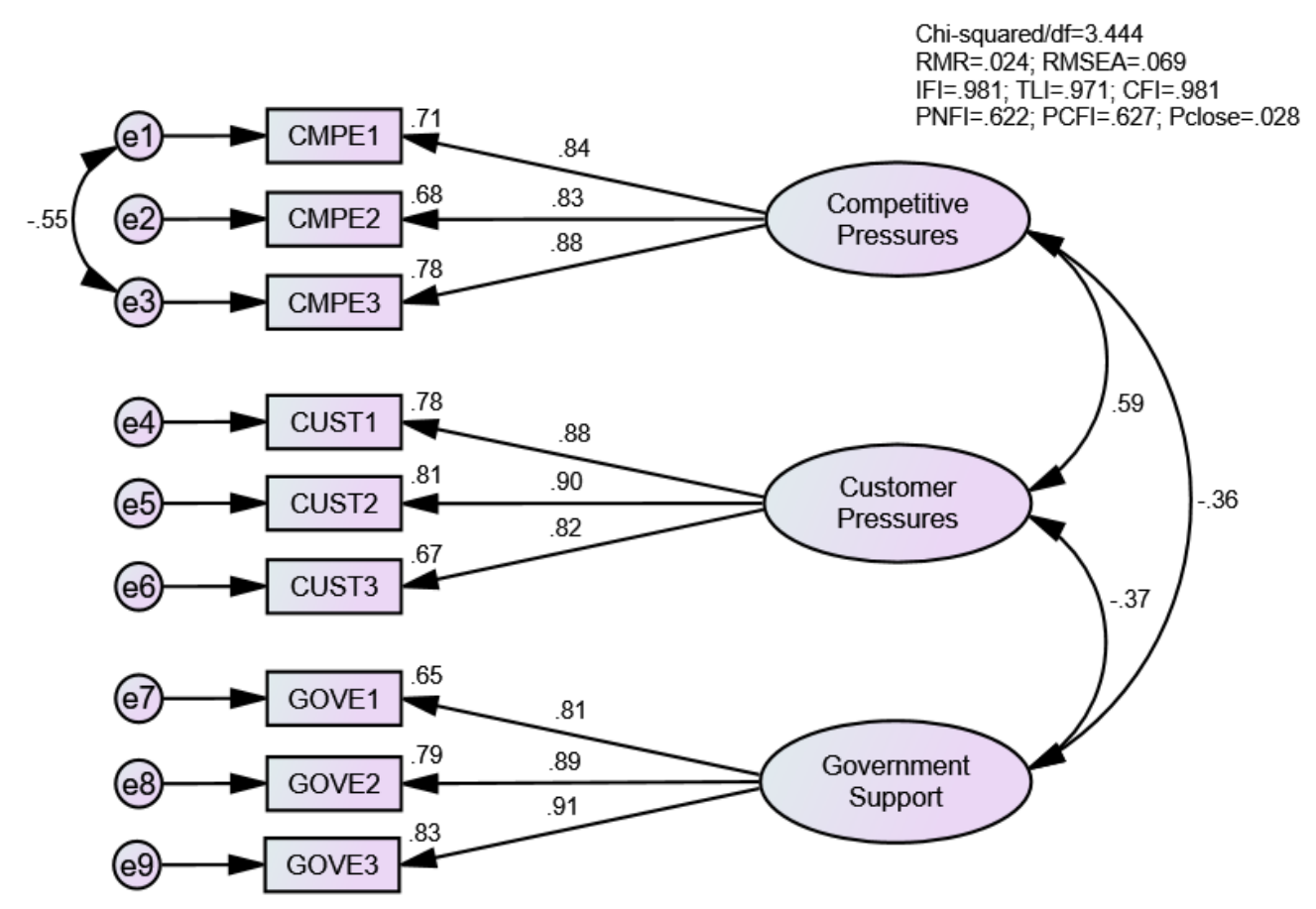

Figure 5.3 Measurement model for the environmental dimension

Table 5.24 presents the results for GOF statistics and convergent validity tests for constructs in the environmental dimension. The GOF statistics suggest an acceptable fitness. Specifically, the $\chi 2 / \mathrm{df}$ value of 3.444 is within the acceptable range. The 
absolute fit indices (RMSEA, RMR, and SRMR), incremental fit indices (IFI, TLI, and $\mathrm{CFI}$ ), and parsimony fit indices (PNFI and PCFI) values are found to be within an acceptable range, suggesting acceptable model fitness.

Table 5.24 GOF statistics and convergent validity measures for environmental dimension

\begin{tabular}{lllccccc}
\hline & Chi-square & \multicolumn{2}{c}{ Absolute Fit Indices } & Incremental Fit Indices & \multicolumn{2}{c}{ Parsimony Fit Indices } \\
\hline$\chi 2$ & $79.215(0.000)$ & RMSEA & 0.069 & IFI & 0.981 & PNFI & 0.622 \\
\hline df & 23 & RMR & 0.024 & TLI & 0.971 & PCFI & 0.627 \\
\hline$\chi 2 /$ df & 3.444 & SRMR & 0.0373 & CFI & 0.981 & Pclose & 0.028 \\
\hline
\end{tabular}

Factor loadings $(* * * p<0.001, * * p<0.01$, and $* p<0.05)$

\begin{tabular}{|c|c|c|c|c|c|c|c|}
\hline Factors & $\mathrm{CR}$ & AVE & Items & SFL & Sig. & SMC & Comments \\
\hline \multirow{3}{*}{$\begin{array}{l}\text { Competitive } \\
\text { Pressures }\end{array}$} & \multirow{3}{*}{0.886} & \multirow{3}{*}{0.723} & CMPE1 & 0.843 & $* * *$ & 0.765 & \multirow{9}{*}{$\begin{array}{l}\text { Model fit is acceptable } \\
\text { Convergent validity holds }\end{array}$} \\
\hline & & & CMPE2 & 0.826 & $* * *$ & 0.863 & \\
\hline & & & CMPE3 & 0.881 & $* * *$ & 0.737 & \\
\hline \multirow{3}{*}{$\begin{array}{l}\text { Customer } \\
\text { Pressures }\end{array}$} & \multirow{3}{*}{0.900} & \multirow{3}{*}{0.751} & CUST1 & 0.881 & $* * *$ & 0.601 & \\
\hline & & & CUST2 & 0.900 & $* * *$ & 0.765 & \\
\hline & & & CUST3 & 0.818 & $* * *$ & 0.576 & \\
\hline \multirow{3}{*}{$\begin{array}{l}\text { Government } \\
\text { Support }\end{array}$} & \multirow{3}{*}{0.904} & \multirow{3}{*}{0.758} & GOVE1 & 0.807 & $* * *$ & 0.610 & \\
\hline & & & GOVE2 & 0.889 & $* * *$ & 0.772 & \\
\hline & & & GOVE3 & 0.912 & $* * *$ & 0.638 & \\
\hline
\end{tabular}

Regarding the convergent validity, CR values and AVE values of three constructs are greater than 0.7 and 0.5 respectively. The SFL values and SMC values of all items are greater than 0.5 and 0.4 respectively. These values establish the convergent validity of three constructs in the environmental dimension. 


\subsubsection{Measurement Model for the Managerial Determinants}

This section presents the convergent validity of the two constructs in the managerial dimension including top management support and managers' IT knowledge. The top management support construct is hypothesized to consist of three items. The managers' IT knowledge construct is hypothesized to consist of three items. Figure 5.4 shows the measurement model for the managerial dimension.

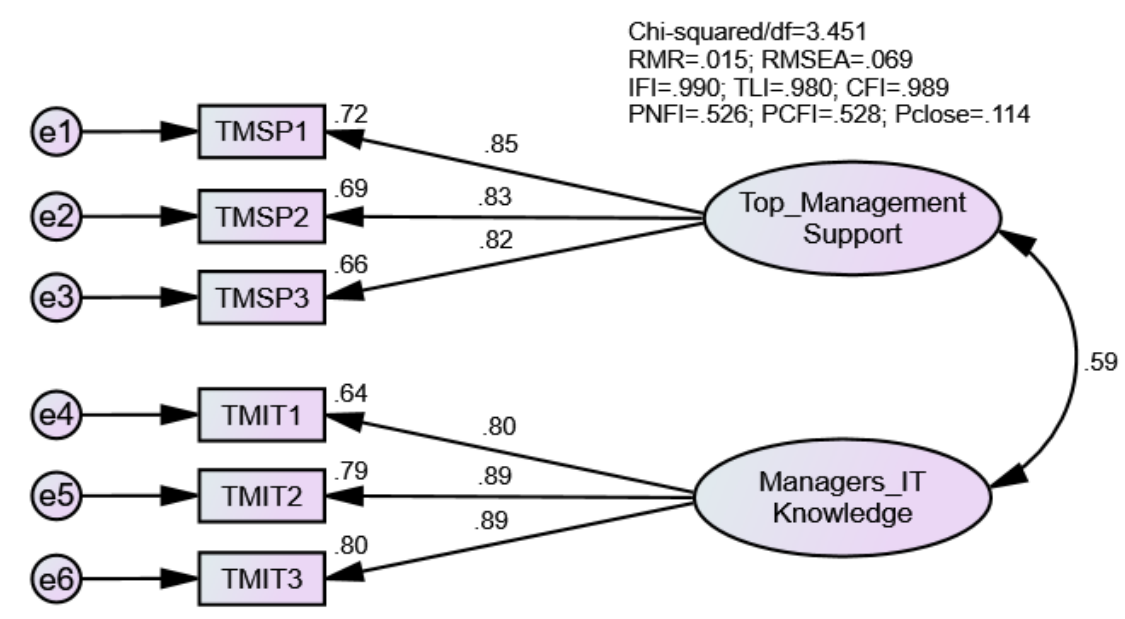

Figure 5.4 Measurement model for the managerial dimension

Table 5.25 presents the results for GOF statistics and convergent validity tests for constructs in the managerial dimension. The GOF statistics suggest an acceptable fitness. Specifically, the $\chi 2 / \mathrm{df}$ value of 3.451 is within the acceptable range. The absolute fit indices (RMSEA, RMR, and SRMR), incremental fit indices (IFI, TLI, and CFI), and parsimony fit indices (PNFI and PCFI) values are found to be within an acceptable range. The Pclose value of 0.114 also suggests good model fitness. 
Table 5.25 GOF statistics and convergent validity measures for managerial dimension

\begin{tabular}{lccccccc}
\hline \multicolumn{2}{l}{ Chi-square } & \multicolumn{2}{c}{ Absolute Fit Indices } & \multicolumn{2}{c}{ Incremental Fit Indices } & \multicolumn{2}{c}{ Parsimony Fit Indices } \\
\hline$\chi 2$ & $27.605(0.001)$ & RMSEA & 0.069 & IFI & 0.990 & PNFI & 0.526 \\
\hline df & 8 & RMR & 0.015 & TLI & 0.980 & PCFI & 0.528 \\
\hline$\chi 2 / d f$ & 3.451 & SRMR & 0.0321 & CFI & 0.989 & Pclose & 0.114 \\
\hline
\end{tabular}

Factor loadings $(* * * p<0.001, * * p<0.01$, and $* p<0.05)$

\begin{tabular}{|c|c|c|c|c|c|c|c|}
\hline Factors & CR & AVE & Items & SFL & Sig. & SMC & Comments \\
\hline Top & \multirow{3}{*}{0.870} & \multirow{3}{*}{0.691} & TMSP1 & 0.850 & $* * *$ & 0.723 & \multirow{6}{*}{$\begin{array}{l}\text { Model fit is acceptable } \\
\text { Convergent validity holds }\end{array}$} \\
\hline \multirow{2}{*}{$\begin{array}{l}\text { Management } \\
\text { Support }\end{array}$} & & & TMSP2 & 0.828 & $* * *$ & 0.685 & \\
\hline & & & TMSP3 & 0.815 & $* * *$ & 0.665 & \\
\hline \multirow{3}{*}{$\begin{array}{l}\text { Managers' IT } \\
\text { Knowledge }\end{array}$} & \multirow{3}{*}{0.895} & \multirow{3}{*}{0.741} & TMIT1 & 0.798 & $* * *$ & 0.636 & \\
\hline & & & TMIT2 & 0.889 & $* * *$ & 0.791 & \\
\hline & & & TMIT3 & 0.892 & $* * *$ & 0.796 & \\
\hline
\end{tabular}

Regarding the convergent validity, CR values and AVE values of three constructs are greater than 0.7 and 0.5 respectively. The SFL values and SMC values of all items are greater than 0.5 and 0.4 respectively. These values establish the convergent validity of two constructs in the managerial dimension.

\subsubsection{Measurement Model for the Dependent Construct}

This section presents the convergent validity of the adoption construct. This construct is hypothesized to consist of three items. Figure 5.5 shows the measurement model for such a construct. 


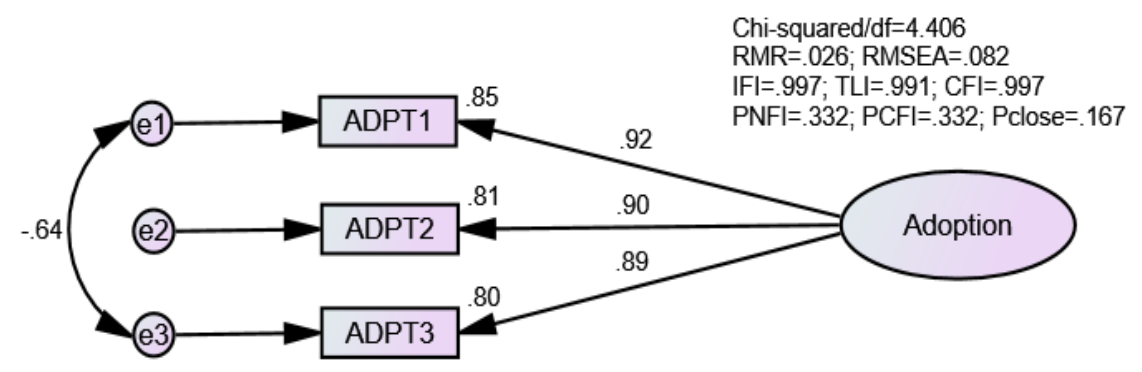

Figure 5.5 Measurement model for the adoption construct

Table 5.26 presents the results for GOF statistics and convergent validity tests for the adoption construct. The GOF statistics suggest an acceptable fitness. Specifically, the $\chi 2 / \mathrm{df}$ value of 4.406 is within the acceptable range. The absolute fit indices (RMSEA, RMR, and SRMR), incremental fit indices (IFI, TLI, and CFI), and parsimony fit indices (PNFI and PCFI) values are found to be within an acceptable range. The Pclose value of 0.167 also suggests good model fitness.

Table 5.26 GOF statistics and convergent validity measures for adoption construct

\begin{tabular}{lllccccc}
\hline & Chi-square & \multicolumn{2}{c}{ Absolute Fit Indices } & \multicolumn{2}{c}{ Incremental Fit Indices } & \multicolumn{2}{c}{ Parsimony Fit Indices } \\
\hline$\chi 2$ & $4.406(0.036)$ & RMSEA & 0.082 & IFI & 0.997 & PNFI & 0.332 \\
\hline df & 1 & RMR & 0.026 & TLI & 0.991 & PCFI & 0.332 \\
\hline$\chi 2 / \mathrm{df}$ & 4.406 & SRMR & 0.0071 & CFI & 0.997 & Pclose & 0.167 \\
\hline
\end{tabular}

Factor loadings $(* * * p<0.001, * * p<0.01$, and $* p<0.05)$

\begin{tabular}{llllllll}
\hline Factor & \multirow{2}{*}{ CR } & AVE & Items & SFL & Sig. & SMC & Comments \\
\hline \multirow{3}{*}{ Adoption } & 0.931 & 0.818 & ADPT2 & 0.897 & $* * *$ & 0.805 & Model fit is admissible \\
\cline { 3 - 6 } & & & ADPT3 & 0.923 & $* * *$ & 0.852 & Convergent validity holds \\
\cline { 4 - 6 } & & & ADPT3 & $* * *$ & 0.798 & \\
\hline
\end{tabular}


Regarding the convergent validity, CR values and AVE values are greater than 0.7 and 0.5 respectively. The SFL values and SMC values of all the items are greater than 0.5 and 0.4 respectively. These values establish the convergent validity for the adoption construct.

\subsubsection{Full Measurement Model}

The earlier sections present measurement models for technological dimension, organizational dimension, environmental dimension, managerial dimension, and the adoption construct. These models confirm the convergent validity of all constructs, which form the basis for the full measurement model, as shown in Figure 5.6. 


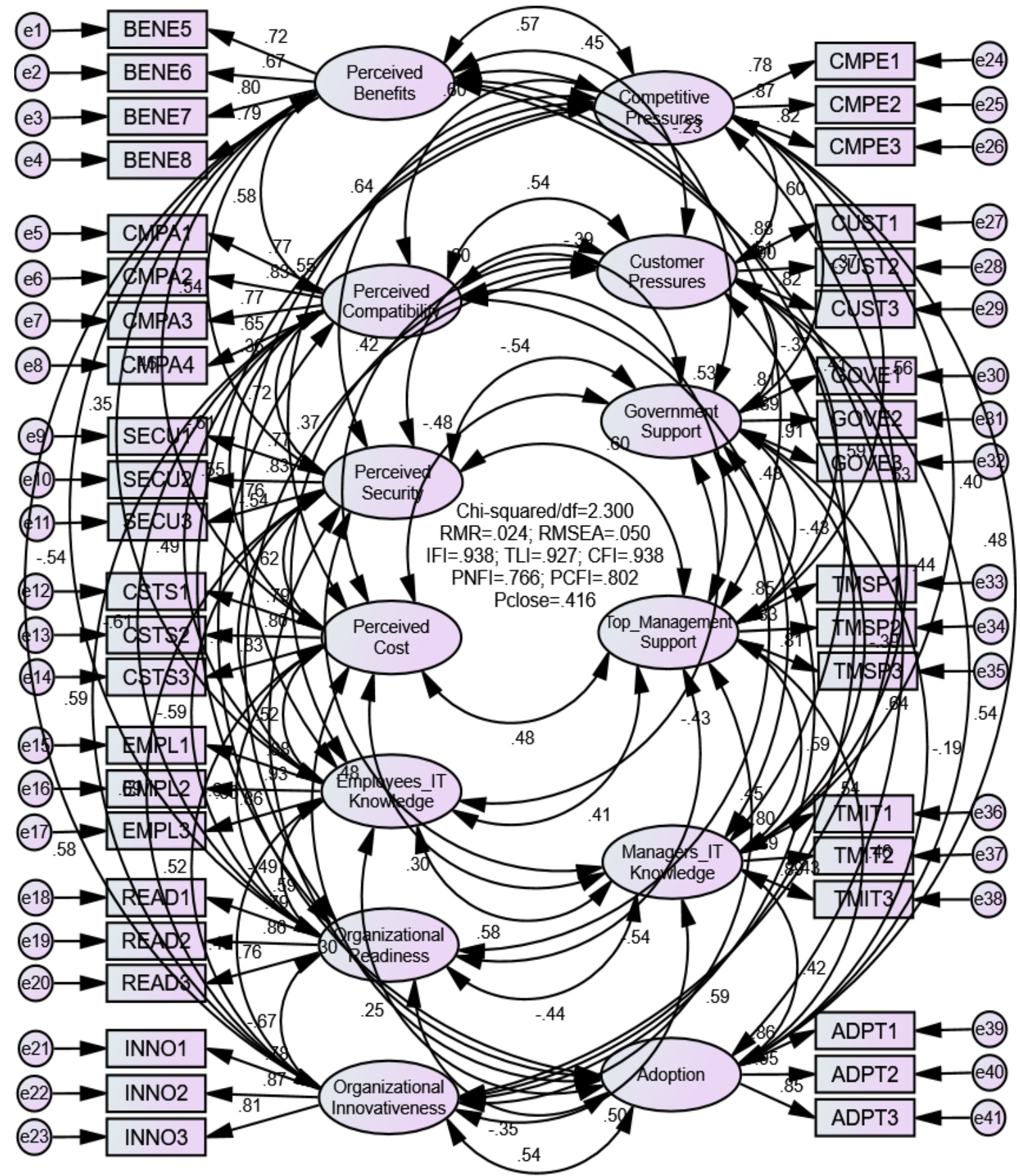

Figure 5.6 A full measurement model

Table 5.27 presents the results for GOF statistics for the full measurement model. Such GOF statistics suggest an acceptable fitness. Specifically, the $\chi 2 / \mathrm{df}$ value of 2.300 is within the acceptable range. The absolute fit index (RMSEA, RMR, and SRMR) values 
are $0.050,0.024$, and 0.0401 respectively, which are less than 0.09 . The incremental fit index (IFI, TLI, and CFI) values are 0.938, 0.927, and 0.938, which are above 0.9. The parsimony fit index (PNFI and PCFI) values are 0.766 and 0.802 respectively, which are above 0.5 . The Pclose value is 0.416 , which is above 0.05 , suggesting good model fitness.

Table 5.27 Goodness of fit statistics for the full measurement model

\begin{tabular}{llcccccc}
\hline \multicolumn{2}{l}{ Chi-square } & \multicolumn{2}{c}{ Absolute Fit Indices } & \multicolumn{2}{c}{ Incremental Fit Indices } & \multicolumn{2}{c}{ Parsimony Fit Indices } \\
\hline$\chi 2$ & $1612.405(0.000)$ & RMSEA & 0.050 & IFI & 0.938 & PNFI & 0.766 \\
\hline df & 701 & RMR & 0.024 & TLI & 0.927 & PCFI & 0.802 \\
\hline$\chi 2 /$ df & 2.300 & SRMR & 0.0401 & CFI & 0.938 & Pclose & 0.416 \\
\hline
\end{tabular}

Table 5.28 and Table 5.29 present the convergent validity assessment results for all constructs. The CR values and AVE values are greater than 0.7 and 0.5 respectively. The SFL values and SMC values of all the items are greater than 0.5 and 0.4 respectively. These values establish convergent validity for all constructs in the full measurement model. 
Table 5.28 Convergent validity assessment results

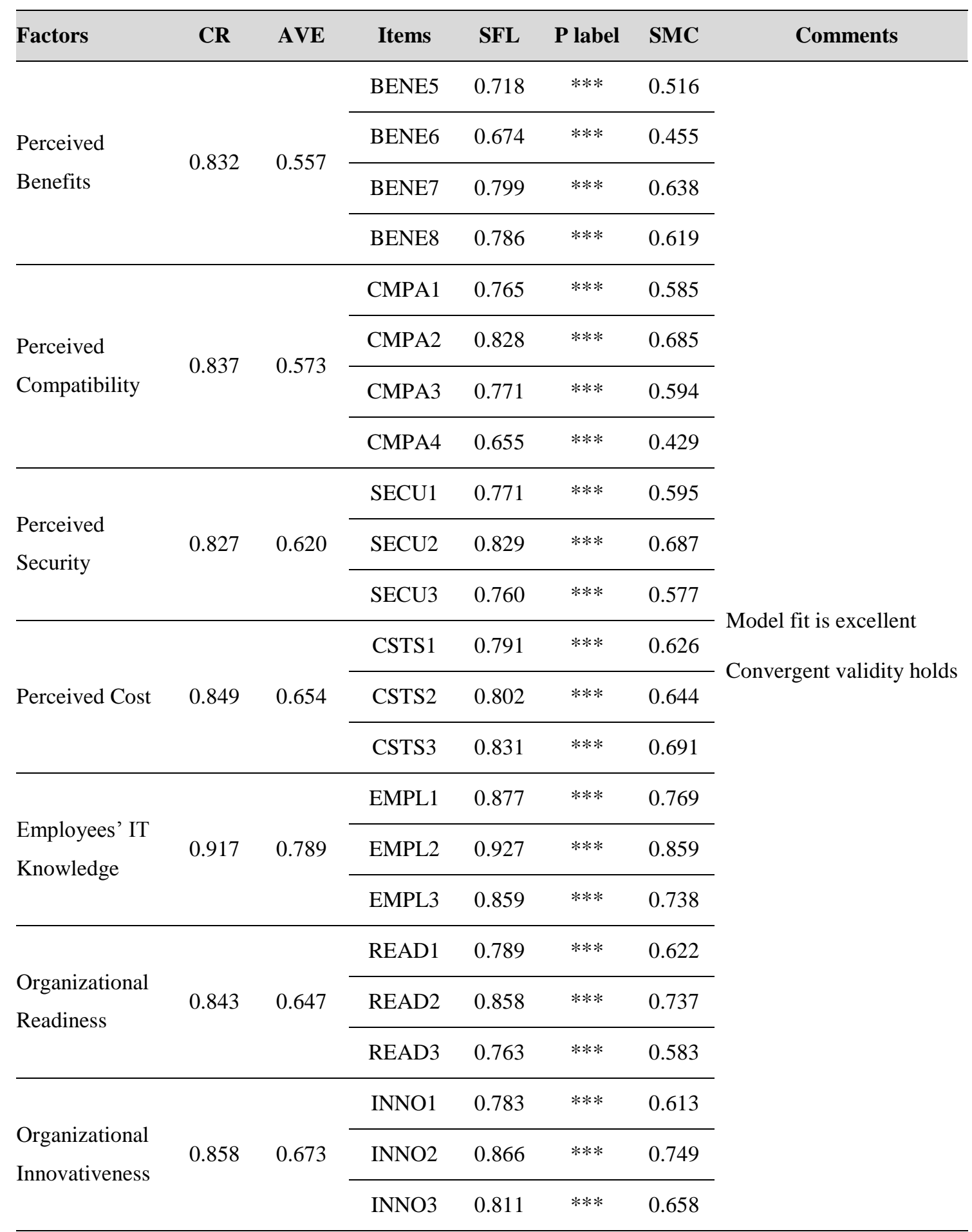

Factor loadings $(* * * p<0.001, * * p<0.01$, and $* p<0.05)$ 
Table 5.29 Convergent validity assessment results (cont'd)

\begin{tabular}{|c|c|c|c|c|c|c|c|}
\hline Factors & CR & AVE & Items & SFL & P label & SMC & Comments \\
\hline \multirow{3}{*}{$\begin{array}{l}\text { Competitive } \\
\text { Pressures }\end{array}$} & \multirow{3}{*}{0.862} & \multirow{3}{*}{0.682} & CMPE1 & 0.785 & $* * *$ & 0.616 & \multirow{18}{*}{$\begin{array}{l}\text { Model fit is excellent } \\
\text { Convergent validity holds }\end{array}$} \\
\hline & & & CMPE2 & 0.873 & $* * *$ & 0.762 & \\
\hline & & & CMPE3 & 0.818 & $* * *$ & 0.669 & \\
\hline \multirow{3}{*}{$\begin{array}{l}\text { Customer } \\
\text { Pressures }\end{array}$} & \multirow{3}{*}{0.898} & \multirow{3}{*}{0.751} & CUST1 & 0.877 & $* * *$ & 0.769 & \\
\hline & & & CUST2 & 0.902 & $* * *$ & 0.814 & \\
\hline & & & CUST3 & 0.819 & $* * *$ & 0.671 & \\
\hline \multirow{3}{*}{$\begin{array}{l}\text { Government } \\
\text { Support }\end{array}$} & \multirow{3}{*}{0.902} & \multirow{3}{*}{0.759} & GOVE1 & 0.812 & $* * *$ & 0.659 & \\
\hline & & & GOVE2 & 0.892 & $* * *$ & 0.796 & \\
\hline & & & GOVE3 & 0.906 & $* * *$ & 0.820 & \\
\hline Top & \multirow{3}{*}{0.870} & \multirow{3}{*}{0.691} & TMSP1 & 0.854 & $* * *$ & 0.729 & \\
\hline \multirow{2}{*}{$\begin{array}{l}\text { Management } \\
\text { Support }\end{array}$} & & & TMSP2 & 0.834 & $* * *$ & 0.695 & \\
\hline & & & TMSP3 & 0.806 & $* * *$ & 0.649 & \\
\hline \multirow{3}{*}{$\begin{array}{l}\text { Managers' IT } \\
\text { Knowledge }\end{array}$} & \multirow{3}{*}{0.893} & \multirow{3}{*}{0.742} & TMIT1 & 0.804 & $* * *$ & 0.647 & \\
\hline & & & TMIT2 & 0.889 & $* * *$ & 0.789 & \\
\hline & & & TMIT3 & 0.888 & $* * *$ & 0.788 & \\
\hline \multirow{3}{*}{ Adoption } & \multirow{3}{*}{0.915} & \multirow{3}{*}{0.790} & ADPT1 & 0.862 & $* * *$ & 0.743 & \\
\hline & & & ADPT2 & 0.948 & $* * *$ & 0.899 & \\
\hline & & & ADPT3 & 0.854 & $* * *$ & 0.730 & \\
\hline
\end{tabular}

Factor loadings $(* * * p<0.001, * * p<0.01$, and $* p<0.05)$

The discriminant validity of the full measurement model for all the constructs is assessed through the calculation of the correlation matrix, as shown in Table 5.30. These results indicate that there is no correlation between the constructs. Specifically, all the correlation coefficients between constructs fail to exceed 0.9. Additionally, the square roots of the AVE for a given construct indicated as a diagonal element are greater than the off-diagonal element in the corresponding rows and columns. This 
shows that the measurement model presents adequate discriminant validity for further analysis. Furthermore, these results also suggest that the full measurement model is well fit with the data. As a result, the full measurement model can be processed for further hypothesis testing.

Table 5.30 Latent construct correlation matrix

\begin{tabular}{|c|c|c|c|c|c|c|c|c|c|c|c|c|}
\hline & (1) & (2) & (3) & (4) & (5) & (6) & (7) & (8) & (9) & (10) & (11) & (12) \\
\hline 1) & .746 & & & & & & & & & & & \\
\hline 2) & .583 & .757 & & & & & & & & & & \\
\hline 3) & .543 & .716 & .787 & & & & & & & & & \\
\hline 4) & .460 & .551 & .625 & .808 & & & & & & & & \\
\hline 5) & .346 & .489 & .436 & .523 & .888 & & & & & & & \\
\hline 6) & -.536 & -.606 & -.595 & -.635 & -.493 & .804 & & & & & & \\
\hline 7) & .581 & .590 & .690 & .522 & .456 & -.673 & .821 & & & & & \\
\hline 8) & .572 & .600 & .641 & .545 & .359 & -.615 & .637 & .826 & & & & \\
\hline 9) & .448 & .537 & .599 & .416 & .371 & -.543 & .537 & .595 & .867 & & & \\
\hline 10) & -.228 & -.389 & -.537 & -.481 & -.427 & .447 & -.432 & -.371 & -.371 & .871 & & \\
\hline 11) & .509 & .525 & .601 & .480 & .408 & -.541 & .588 & .561 & .592 & -.430 & .831 & \\
\hline 12) & .406 & .481 & .484 & .300 & .578 & -.435 & .501 & .399 & .443 & -.395 & .586 & .861 \\
\hline 13) & .534 & .551 & .595 & .295 & .255 & -.347 & .538 & .478 & .538 & -.194 & .459 & .423 \\
\hline \multicolumn{13}{|c|}{$\begin{array}{l}\text { (1) Perceived benefits, (2) Perceived compatibility, (3) Perceived security, (4) Perceived cost, (5) } \\
\text { Employees' IT knowledge, (6) Organizational readiness, (7) Organizational innovativeness, (8) } \\
\text { Competitive pressures, (9) Custome pressures, (10) Government support, (11) Top management support, } \\
\text { (12) Managers' IT knowledge, (13) Adoption. }\end{array}$} \\
\hline
\end{tabular}




\subsection{Final Reliability}

Once all the measurement constructs underlying the conceptual framework have been empirically derived and validated, they need to have a further examination of internal consistency for retained items resulting from the EFA. This helps to evaluate the final reliability of these constructs before proceeding with the structural model (Straub et al. 2004; Casalo, Flavian \& Guinaliu 2011). As discussed in earlier sections of this chapter, $\alpha$ coefficient is a common statistic for evaluating the reliability of the measurement instrument. Additionally, the composite reliability is suggested applying to have a better reliability assessment (Ifinedo 2011). As a result, both $\alpha$ coefficient and composite reliability coefficient are applied for assessing the final reliability of the retained constructs of this study. To ensure the reliability of all constructs, the acceptable cut-off values of $\alpha$ coefficients and composite reliability coefficients are 0.7 and 0.65 respectively (Hair et al. 2010).

An examination of $\alpha$ coefficients and composite reliability coefficients for all the retained constructs is conducted. Table 5.31 presents the results of such a reliability assessment. The results indicate that all $\alpha$ coefficients and composite reliability coefficients exceed the minimum recommended cut-off values. These indicate adequate reliability of the research constructs. 
Table 5.31 A summary of final reliability assessment

\begin{tabular}{lllcc}
\hline \multirow{2}{*}{ Dimensions } & \multicolumn{1}{c}{ Variables } & $\begin{array}{c}\text { Number } \\
\text { of Items }\end{array}$ & $\begin{array}{c}\text { Cronbach's } \\
\text { Alpha }\end{array}$ & $\begin{array}{c}\text { Composite } \\
\text { Reliability }\end{array}$ \\
\hline \multirow{2}{*}{ Technological factors } & Perceived Benefits & 4 & 0.832 & 0.832 \\
\cline { 2 - 5 } & Perceived Compatibility & 4 & 0.837 & 0.833 \\
\cline { 2 - 5 } & Perceived Security & 3 & 0.827 & 0.834 \\
\cline { 2 - 5 } Organizational factors & Perceived Cost & 3 & 0.849 & 0.841 \\
\cline { 2 - 5 } & Employees' IT Knowledge & 3 & 0.917 & 0.917 \\
\cline { 2 - 5 } Organizational Readiness & 3 & 0.843 & 0.829 \\
\hline \multirow{2}{*}{ Environmental factors } & Organizational Innovativeness & 3 & 0.858 & 0.849 \\
\cline { 2 - 5 } & Competitive Pressures & 3 & 0.862 & 0.857 \\
\cline { 2 - 5 } Managerial factors & Government Support & 3 & 0.898 & 0.890 \\
\hline Top Management Support & 3 & 0.870 & 0.865 \\
\hline Dependent factor & Managers' IT Knowledge & 3 & 0.893 & 0.886 \\
\hline & Adoption & 3 & 0.915 & 0.917 \\
\hline
\end{tabular}

\subsection{Concluding Remarks}

This chapter presents the data examination and preparation process. The process for assessing the reliability and validity of the measurement instrument to prepare a final dataset for SEM analysis is discussed. This discussion leads to the deletion of 43 observations from the initial 556 collected observations. The reliability and validity assessment process are subjected to very rigorous procedures involving reliability assessment, content validity, factorial validity, convergent validity, and discriminant validity. Such procedures lead to the deletion of 6 items from the initial 47 measurement items. Finally, the measurement instrument underlying the proposed conceptual 
framework has been determined to be valid and reliable for the structural model validation and hypotheses tests, presented in Chapter 7. 


\section{Chapter 6}

\section{Emerging Patterns for the Adoption of Mobile}

\section{Commerce}

\subsection{Introduction}

M-commerce is about buying and selling of goods and services through wireless handheld devices such as cellular phones and personal digital assistants (Zhiping 2009; Chau \& Deng 2018a; Chau et al. 2020). It is becoming a cost-effective way for businesses, especially SMEs to promote their products and services online (Alfahl et al. 2017). As a result, there is a significant increase in revenue in m-commerce in the global market from $\$ 1.357$ trillion in 2017 to $\$ 1.804$ trillion in 2018 . The revenues are set to surpass \$2.321 trillion in 2019 (eMarketer 2018).

M-commerce is becoming increasingly popular due to a variety of benefits that it can provide businesses including improving productivity, increasing customer satisfaction, and lowering operational costs (Varshney \& Vetter 2002). Particularly, m-commerce helps businesses reach customers anywhere at any-time. It provides customers with timely services effectively (Njenga et al. 2016; Duan et al. 2019). The adoption of mcommerce enables businesses to directly sell to customers, thereby significantly reducing operating costs (Kotler \& Armstrong 2010). Such benefits attract much 
attention of the Vietnam E-commerce Association and the Vietnamese government in promoting the adoption of m-commerce in Vietnamese SMEs. As a result, a series of policies and programs have been developed for creating a favorable environment for stimulating SMEs in the adoption of m-commerce (Chau \& Deng 2020).

To fully appreciate the adoption of m-commerce in Vietnamese SMEs, an investigation of the emerging patterns for the adoption of m-commerce in Vietnamese SMEs is highly desirable. Such an investigation is needed for (a) providing an incentive for stakeholders of SMEs to develop appropriate strategies and cost-effective interventions to enhance the diffusion of m-commerce and (b) providing useful insights for policy-makers in Vietnam to formulate and develop specifics policies and strategies that promote the wide adoption of $\mathrm{m}$-commerce in SMEs.

This chapter examines the emerging pattern of m-commerce adoption in Vietnamese SMEs. Such an examination is conducted with respect to three perspectives including (a) the overall adoption, (b) the size-based adoption, and (c) the industry-based adoption.

The rest of the chapter is organized into four sections. Section 6.2 describes the demographic characteristics of the samples including the general profile of the surveyed SMEs and the characteristics of the top managers taking part in the survey. Section 6.3 presents the current pattern of the adoption of m-commerce in Vietnamese SMEs. Section 6.4 presents a discussion of the findings, leading to the identification of the 
emerging patterns for the adoption of m-commerce in Vietnamese SMEs. Section 6.5 provides a summary with some concluding remarks.

\subsection{Demographic Characteristics of the Sample}

Demographics are the characteristics of a targeted group that are used for distinguishing the group (Preston, Patrick \& Michel 2001). Commonly, the demographic information is used for describing an organization including the organizational size with respect to the number of permanent employees, the annual revenue, the total registered capital, the geographic location, the duration of business, and the industry type (Zhu et al. 2003; Teo et al. 2009). Furthermore, the profile of the decision-maker in the organization such as gender, age, educational background, and position is also included in the demographic analysis for exploring their potential influence on the adoption of technology in organizations (Teo et al. 2009).

An analysis of the demographic characteristics of the surveyed SMEs has been conducted in this study from two perspectives including (a) the general profile of the surveyed SMEs and (b) the characteristics of the top managers in such SMEs. The general profile of the surveyed SMEs is analyzed by location, size, duration of business, and industry type. The characteristics of the top manager are demonstrated from gender, age, educational background, position, and experience.

Table 6.1 presents the general profile of the surveyed SMEs in terms of the location and the duration of business. With respect to the location, $23.2 \%$ of SMEs are located in 
North Vietnam, 52.2\% of SMEs are in the Central region and Highlands Vietnam, and $24.6 \%$ of SMEs are located in the South of Vietnam. Regarding the duration of business, most SMEs have been running their businesses for less than five years (36.2\%), 32.6\% between 5 to 10 years, $17.7 \%$ of SMEs have been running their businesses for more than 15 years, and $13.5 \%$ between 5 to 10 years.

Table 6.1 The general profile of the surveyed SMEs: location and duration of the business

\begin{tabular}{llcc}
\hline \multicolumn{1}{c}{ Category } & \multicolumn{1}{c}{ Sub-Category } & Frequency & Percentage \\
\hline \multirow{2}{*}{ Location } & North Vietnam & 119 & $23.2 \%$ \\
\cline { 2 - 4 } & \multicolumn{1}{c}{ Central \& Highlands Vietnam } & 268 & $52.2 \%$ \\
\cline { 2 - 4 } & South Vietnam & 126 & $24.6 \%$ \\
\hline \multirow{3}{*}{ Duration of business } & $<5$ years & 186 & $36.2 \%$ \\
\cline { 2 - 4 } & $5-10$ years & 167 & $32.6 \%$ \\
\cline { 2 - 4 } & $11-15$ years & 69 & $13.5 \%$ \\
\cline { 2 - 4 } & $>15$ years & 91 & $17.7 \%$ \\
\hline
\end{tabular}

Table 6.2 presents the general profile of the surveyed SMEs in terms of organizational size. The size of the SMEs is measured by the number of employees and the total registered capital (Business Insides 2011). As shown in Table 6.2, 37.6\% of SMEs are very small enterprises with less than 10 employees, $56.2 \%$ of SMEs are small enterprises with 10 to 200 employees, and $6.2 \%$ of SMEs are medium enterprises with 201 to 300 employees. Regarding the size characterized by the total registered capital, $45.6 \%$ of SMEs are very small enterprises with total capital less than 10 billion VND, $38.6 \%$ of SMEs are small enterprises with total capital from 10 billion VND to 50 billion VND, and $15.8 \%$ of SMEs are medium enterprises with total capital from 50 billion VND to 100 billion VND. 
Table 6.2 The general profile of the surveyed SMEs: organizational size

\begin{tabular}{|c|c|c|c|}
\hline Category & Sub-Category & Frequency & Percentage \\
\hline \multirow{6}{*}{ Number of employees } & $<10$ & 193 & $37.6 \%$ \\
\hline & $10-50$ & 201 & $39.2 \%$ \\
\hline & $51-100$ & 57 & $11.1 \%$ \\
\hline & $101-200$ & 30 & $5.9 \%$ \\
\hline & $201-300$ & 32 & $6.2 \%$ \\
\hline & $>300$ & 0 & $0 \%$ \\
\hline \multirow{5}{*}{ Total capital (billion VND) } & $<10$ & 234 & $45.6 \%$ \\
\hline & $10-20$ & 164 & $32.0 \%$ \\
\hline & $20-50$ & 34 & $6.6 \%$ \\
\hline & $50-100$ & 81 & $15.8 \%$ \\
\hline & $>100$ & 0 & $0 \%$ \\
\hline
\end{tabular}

Table 6.3 presents the general profile of the surveyed SMEs in terms of the type of business. Most SMEs are from services and trading sectors with $27.9 \%$ and $27.5 \%$ respectively, followed by SMEs in the construction sector (14\%). There are $10.5 \%$ of SMEs in the manufacturing sector and $7 \%$ of SMEs in the transportation sector. The rest are the SMEs from other sectors such as finance and insurance, ICT, and healthcare. The diverse industries covered in the surveyed SMEs indicate that the survey data are a representative sample for the population. 
Table 6.3 The general profile of the surveyed SMEs: type of business

\begin{tabular}{llcc}
\hline \multicolumn{1}{c}{ Category } & \multicolumn{1}{c}{ Sub-Category } & Frequency & Percentage \\
\hline & Services & 143 & $27.9 \%$ \\
\cline { 2 - 4 } Trading & 141 & $27.5 \%$ \\
\cline { 2 - 4 } Industry & Construction & 72 & $14.0 \%$ \\
\cline { 2 - 4 } & Manufacturing & 54 & $10.5 \%$ \\
\cline { 2 - 4 } & Transportation & 36 & $7.0 \%$ \\
\cline { 2 - 4 } & Finance \& Insurance & 30 & $5.9 \%$ \\
\cline { 2 - 4 } & ICT & 23 & $4.5 \%$ \\
\cline { 2 - 4 } & Healthcare & 14 & $2.7 \%$ \\
\hline
\end{tabular}

Table 6.4 presents the characteristics of the top managers in the surveyed SMEs. With respect to gender, more than half of managers are males $(57.3 \%)$ and $42.7 \%$ of them are females. Regarding age, the majority of managers are in groups of 36 to 45 and 26 to 35 , accounting for $45.4 \%$ and $33.1 \%$ respectively. Positions of the respondents in the surveyed SMEs are mainly the director in SMEs, accounting for $42.1 \%$. This suggests a high quality of the data source. $28.7 \%, 16.5 \%$, and $12.7 \%$ hold the position of head of a department, deputy head of department, and vice-director respectively. A large percentage of respondents have more than five-year experience in their managerial positions (41.3\%). This also suggests for high quality and reliable responses. Regarding the educational background, a big percentage of such managers have undergraduate and postgraduate degrees, accounting for $74.3 \%$ and $14.4 \%$ respectively. This indicates a high quality of respondents for the survey. 
Table 6.4 Characteristics of top managers of the surveyed SMEs

\begin{tabular}{|c|c|c|c|}
\hline Category & Sub-Category & Frequency & Percentage \\
\hline \multirow{2}{*}{ Gender } & Male & 294 & $57.3 \%$ \\
\hline & Female & 219 & $42.7 \%$ \\
\hline \multirow{5}{*}{ Age } & $18-25$ & 9 & $1.8 \%$ \\
\hline & $26-35$ & 170 & $33.1 \%$ \\
\hline & $36-45$ & 233 & $45.4 \%$ \\
\hline & $46-55$ & 83 & $16.2 \%$ \\
\hline & $>55$ & 18 & $3.5 \%$ \\
\hline \multirow{4}{*}{ Position } & Director & 216 & $42.1 \%$ \\
\hline & Vice Director & 65 & $12.7 \%$ \\
\hline & Head of Department & 147 & $28.7 \%$ \\
\hline & Deputy Head of Department & 85 & $16.5 \%$ \\
\hline \multirow{4}{*}{ Experience } & $<1$ year & 27 & $5.3 \%$ \\
\hline & $1-3$ years & 146 & $28.5 \%$ \\
\hline & $3-5$ years & 128 & $24.9 \%$ \\
\hline & $>5$ years & 212 & $41.3 \%$ \\
\hline \multirow{5}{*}{ Education } & Postgraduate & 74 & $14.4 \%$ \\
\hline & Bachelor & 381 & $74.3 \%$ \\
\hline & Diploma & 39 & $7.6 \%$ \\
\hline & High school & 19 & $3.7 \%$ \\
\hline & Below high school & 0 & $0 \%$ \\
\hline
\end{tabular}

In summary, the analysis of the demographic characteristics of the surveyed SMEs provides insight into the general profile of such SMEs, as well as the profile of the top managers in these SMEs. As shown in Table 6.1, Table 6.2, Table 6.3, and Table 6.4, the surveyed SMEs come from three main geographical areas of Vietnam. The surveyed SMEs are also in diverse industries with respect to a variety of sizes and the duration of 
business. As a result, the sample in this study is sufficient for a representation of the whole population. Furthermore, the high proportion of the top manager holding the bachelor and higher degrees, as well as the high proportion of managers with more than five-year experience in their management positions, indicate a high quality of respondents for the survey.

\subsection{M-Commerce Adoption Patterns in Vietnamese SMEs}

A pattern is an empirically proven solution to a recurring problem that occurs in a particular context (Borchers 2008; Kamthan 2011). It provides a description of a problem and the solution to adequately addressing such a problem in a specific situation (Alexander 1977). The identification of the pattern is critical as it provides a solution for potential future events based on the exploration of the current recurring problems (Borchers 2008). The main focus of analyzing the pattern for m-commerce adoption in Vietnamese SMEs is on providing an overview of the current trends of how Vietnamese SMEs adopt $\mathrm{m}$-commerce for their online business.

There are several ways to describe a pattern in the adoption of technology in organizations (Bajwa \& Lewis 2003; Zhu et al. 2003; Duan et al. 2012). Bajwa and Lewis (2003), for example, examine patterns for the IT adoption in US organizations with respect to sizes and various technologies. Zhu et al. (2003) investigate the emerging patterns for the adoption of e-business in European organizations with respect to countries and industries. Duan et al. (2012) examine the emerging patterns for the adoption of e-market in Australian SMEs with respect to sizes and industries. Such 
studies confirm the significance of assessing the patterns for the adoption of technology in organizations.

To pinpoint the emerging patterns for the adoption of m-commerce in Vietnamese SMEs, this section presents the m-commerce adoption pattern in Vietnamese SMEs from three perspectives including (a) the overall adoption, (b) the size-based adoption, and (c) the industry-based adoption.

Table 6.5 presents an overall profile of the adoption of m-commerce in Vietnamese SMEs. The data reveals that nearly half of the surveyed SMEs have built a website for their businesses (48.9\%). This indicates that a majority of Vietnamese SMEs are not ready for the transition to online business.

Table 6.5 General m-commerce adoption scenarios

\begin{tabular}{llll}
\multicolumn{1}{c}{ Category } & \multicolumn{1}{c}{ Sub-Category } & Frequency & Percentage \\
\hline \multirow{2}{*}{ Website Presence } & Yes & 251 & $48.9 \%$ \\
\cline { 2 - 4 } & No & 262 & $51.1 \%$ \\
\hline \multirow{3}{*}{ Selling Methods } & Using traditional commerce & 444 & $86.5 \%$ \\
\cline { 2 - 4 } & Using e-commerce & 253 & $49.3 \%$ \\
\cline { 2 - 4 } & Using m-commerce & 157 & $30.6 \%$ \\
\hline Intention to adopt m-commerce & Yes & 163 & $45.8 \%$ \\
\cline { 2 - 4 } & No & 193 & $54.2 \%$ \\
\hline
\end{tabular}

The data reveals that $\mathrm{m}$-commerce is not widely adopted in the Vietnamese SMEs. Only $30.6 \%$ of the surveyed SMEs have been conducting their selling activities with the use of m-commerce. $69.4 \%$ of them have not adopted m-commerce. Among these non- 
adopters of m-commerce, only $45.8 \%$ of them are the potential adopters that have a plan to adopt m-commerce in the next 12 months. Figure 6.1 presents a summary of three different categories of surveyed SMEs in terms of m-commerce adoption.

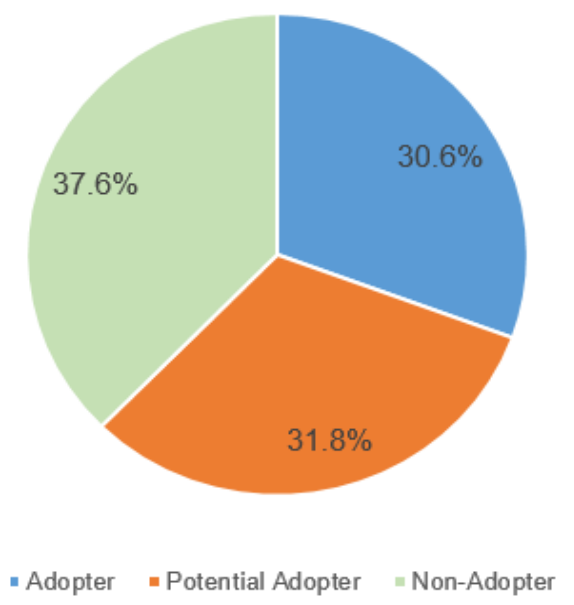

Figure 6.1 An overview of m-commerce adoption in Vietnamese SMEs

Figure 6.2 presents different purposes of SMEs' websites. The commonly used functions of a website for facilitating the operation of SMEs include (a) displaying the company information, (b) promoting company products and services, and (c) conducting online transactions. The data shows that a majority of SMEs use the website for promoting their products and services $(84.9 \%)$. $73.3 \%$ of them use websites for displaying company information. Only $39.4 \%$ of SMEs use websites for conducting online transactions. This indicates that the use of the website for an online business is still quite low. 


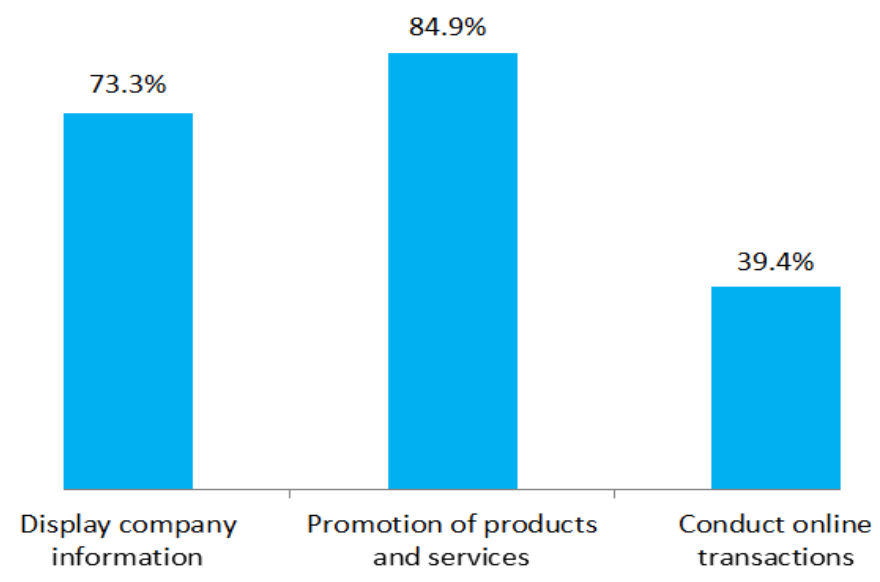

Figure 6.2 An overview of website functions

Figure 6.3 presents the distribution for m-commerce adoption in Vietnamese SMEs with a different number of permanent employees. Overall, there is not much difference in the adoption of m-commerce across such surveyed SMEs. The first two highest adoption rates are at $43.33 \%$ and $40.35 \%$ in SMEs with 101 to 200 employees and those with 51 to 100 employees respectively. They are followed by a rate of $31.25 \%$ in SMEs with 201 to 300 employees and $30.35 \%$ in SMEs with 10 to 50 employees. The lowest adoption rate is at $25.91 \%$ in SMEs with less than 10 employees.

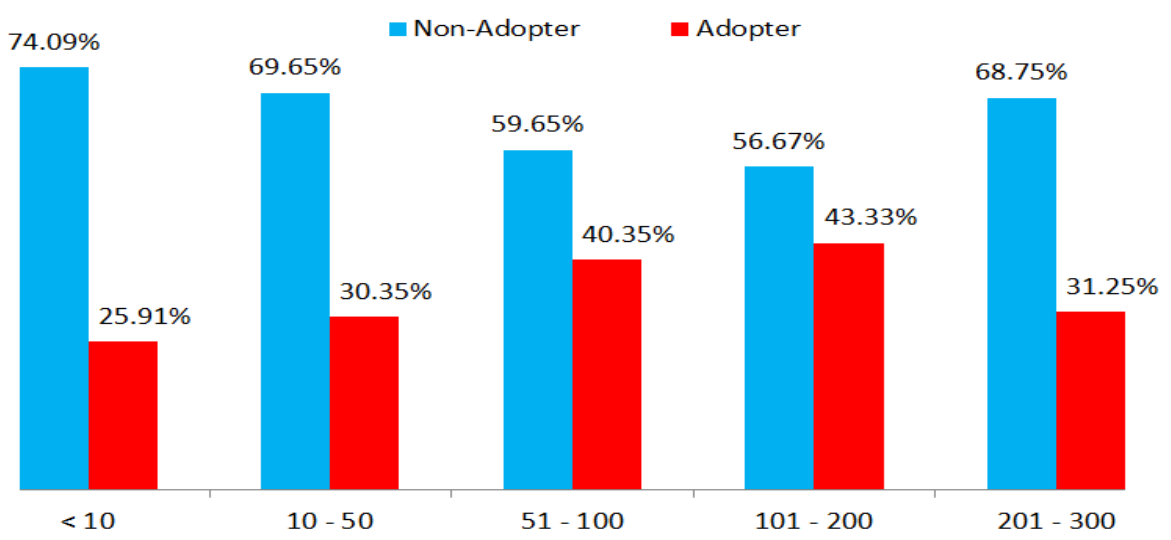

Figure 6.3 Distribution of m-commerce adoption by size (number of employees) 
An analysis of variance (ANOVA) for comparing "between groups" differences is conducted to have in-deep understanding the adoption of m-commerce in different sizes of the surveyed SMEs with respect to the number of permanent employees. Table 6.6 presents a summary of such an ANOVA. The results indicate that the difference in the m-commerce adoption between such groups of the surveyed SMEs is significant ( $p$ value $=0.002)$.

Table 6.6 Summary of ANOVA results for different size groups: number of employees

\begin{tabular}{lccccc}
\hline & Sum of Squares & df & Mean Square & F & Sig. \\
\hline Between Groups & 9.733 & 4 & 2.433 & 4.257 & .002 \\
\hline Within Groups & 290.341 & 508 & .572 & & \\
\hline Total & 300.074 & 512 & & \\
\hline
\end{tabular}

Table 6.7 shows the details of the difference comparison analysis from the ANOVA results. These results indicate two significant differences in the adoption of $\mathrm{m}$ commerce between different size groups of the surveyed SMEs with respect to the number of employees. These include (a) the difference between SMEs with 201 to 300 employees and SMEs with less than 10 employees $(p$-value $=0.008)$ and $(\mathrm{b})$ the difference between SMEs with 201 to 300 employees and SMEs with 10 to 50 employees $(p$-value $=0.028)$. 
Table 6.7 Multiple comparisons for different size groups of SMEs: number of employees

\begin{tabular}{|c|c|c|c|c|}
\hline (I) Size & (J) Size & Mean Difference (I-J) & Std. Error & Sig. \\
\hline \multirow{4}{*}{$<10$} & $10-50$ & -.05677 & .07619 & 1.000 \\
\hline & $51-100$ & -.22828 & .11397 & .457 \\
\hline & $101-200$ & -.33472 & .14837 & .245 \\
\hline & $201-300$ & $-.48888^{*}$ & .14430 & .008 \\
\hline \multirow{4}{*}{$10-50$} & $<10$ & .05677 & .07619 & 1.000 \\
\hline & $51-100$ & -.17151 & .11345 & 1.000 \\
\hline & $101-200$ & -.27794 & .14797 & .609 \\
\hline & $201-300$ & $-.43211^{*}$ & .14389 & .028 \\
\hline \multirow{4}{*}{$51-100$} & $<10$ & .22828 & .11397 & .457 \\
\hline & $10-50$ & .17151 & .11345 & 1.000 \\
\hline & $101-200$ & -.10643 & .17052 & 1.000 \\
\hline & $201-300$ & -.26060 & .16700 & 1.000 \\
\hline \multirow{4}{*}{$101-200$} & $<10$ & .33472 & .14837 & .245 \\
\hline & $10-50$ & .27794 & .14797 & .609 \\
\hline & $51-100$ & .10643 & .17052 & 1.000 \\
\hline & $201-300$ & -.15417 & .19212 & 1.000 \\
\hline \multirow{4}{*}{$201-300$} & $<10$ & $.48888^{*}$ & .14430 & .008 \\
\hline & $10-50$ & $.43211^{*}$ & .14389 & .028 \\
\hline & $51-100$ & .26060 & .16700 & 1.000 \\
\hline & $101-200$ & .15417 & .19212 & 1.000 \\
\hline
\end{tabular}

Notes: $* p<0.05$

Figure 6.4 presents the distribution for m-commerce adoption in Vietnamese SMEs with a different total of registered capital. Overall, there is a clear gap in the m-commerce adoption across different groups of such surveyed SMEs. The highest adoption rate is at $58.82 \%$ in SMEs with total registered capital from 20 to 50 billion VND. It is followed 
by a rate of $39.51 \%$ in SMEs with total registered capital from 50 to 100 billion VND and $33.54 \%$ in SMEs with total registered capital from 10 to 20 billion VND. The lowest adoption rate is at $21.37 \%$ in SMEs with total registered capital less than 10 billion VND.

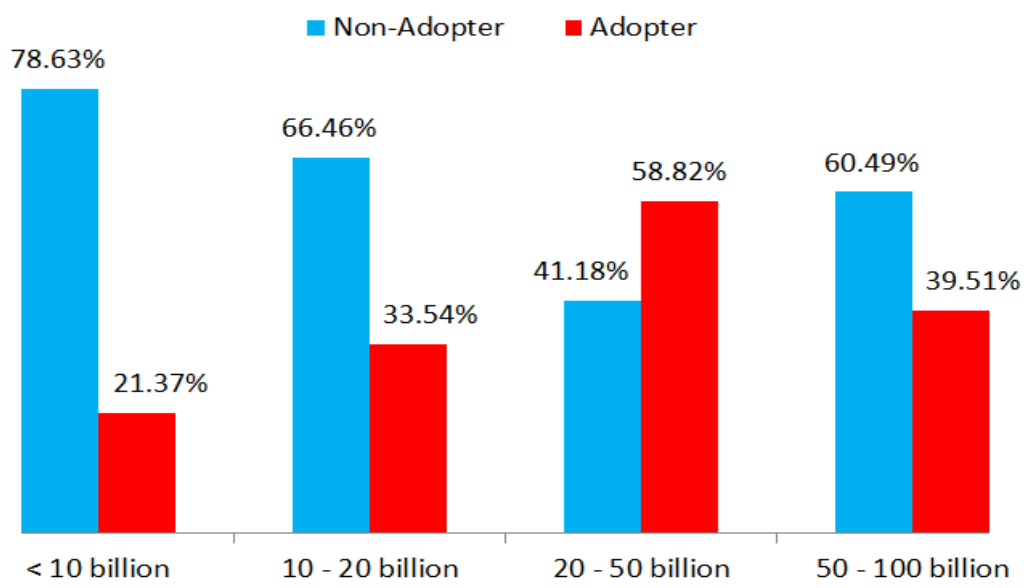

Figure 6.4 Distribution of m-commerce adoption by size (total registered capital)

An ANOVA for comparing "between groups" differences is conducted to have in-deep understanding the adoption of m-commerce in different sizes of the surveyed SMEs with respect to the total registered capital. Table 6.8 presents a summary of such an ANOVA. The results indicate that the difference in the m-commerce adoption between such groups of the surveyed SMEs is strongly significant ( $p$-value $=0.000$ ).

Table 6.8 Summary of ANOVA results for different size groups: total capital

\begin{tabular}{lccccc}
\hline & Sum of Squares & df & Mean Square & F & Sig. \\
\hline Between Groups & 20.184 & 4 & 6.728 & 12.235 & .000 \\
\hline Within Groups & 279.890 & 509 & .550 & & \\
\hline Total & 300.074 & 512 & & \\
\hline
\end{tabular}


Table 6.9 shows the details of the difference comparison analysis from the ANOVA results. These results indicate three significant differences in the adoption of $\mathrm{m}$ commerce between different size groups of the surveyed SMEs with respect to the total registered capital. These include (a) the difference between SMEs with a total capital less than 10 billion VND and SMEs with a total capital from 20 billion VND to 50 billion VND ( $p$-value $=0.014)$, (b) the difference between SMEs with a total capital less than 10 billion VND and SMEs with the total capital from 50 billion VND to 100 billion VND ( $p$-value $=0.000$ ), and $(\mathrm{c})$ the difference between SMEs with the total capital from 10 billion VND to 20 billion VND and SMEs with the total capital from 50 billion VND to 100 billion VND ( $p$-value $=0.000$ ).

Table 6.9 Multiple comparisons for different size groups of SMEs: total capital (VND)

\begin{tabular}{|c|c|c|c|c|}
\hline (I) Size & (J) Size & Mean Difference (I-J) & Std. Error & Sig. \\
\hline \multirow{3}{*}{$<10$ billion } & $10-20$ billion & -0.04857 & 0.07552 & 1.000 \\
\hline & $20-50$ billion & $-.41730 *$ & 0.13610 & 0.014 \\
\hline & $50-100$ billion & $-.52042 *$ & 0.09560 & 0.000 \\
\hline \multirow{3}{*}{$10-20$ billion } & $<10$ billion & 0.04857 & 0.07552 & 1.000 \\
\hline & $20-50$ billion & -0.36872 & 0.13974 & 0.051 \\
\hline & $50-100$ billion & $-.47185^{*}$ & 0.10071 & 0.000 \\
\hline \multirow{3}{*}{$20-50$ billion } & $<10$ billion & $.41730 *$ & 0.13610 & 0.014 \\
\hline & $10-20$ billion & 0.36872 & 0.13974 & 0.051 \\
\hline & $50-100$ billion & -0.10312 & 0.15153 & 1.000 \\
\hline \multirow{3}{*}{$50-100$ billion } & $<10$ billion & $.52042 *$ & 0.09560 & 0.000 \\
\hline & $10-20$ billion & $.47185^{*}$ & 0.10071 & 0.000 \\
\hline & $20-50$ billion & 0.10312 & 0.15153 & 1.000 \\
\hline
\end{tabular}

Notes: $* p<0.05$ 
Figure 6.5 presents the distribution for $\mathrm{m}$-commerce adoption across different industries of the surveyed SMEs. Overall, there is much difference in the adoption of m-commerce across different industries of the surveyed SMEs. The top two industries with comparatively high m-commerce adoption rates are the services industry and the finance and insurance industry with the adoption rate of $44.76 \%$ and $43.33 \%$ respectively. The healthcare industry, construction industry, and ICT industry, in contrast, have a relatively low adoption rate of $14.29 \%, 16.67 \%$, and $17.39 \%$ respectively. Other industries including transportation, manufacturing, and trading have the m-commerce adoption rate of $30.56 \%, 27.78 \%$, and $25.53 \%$ respectively.

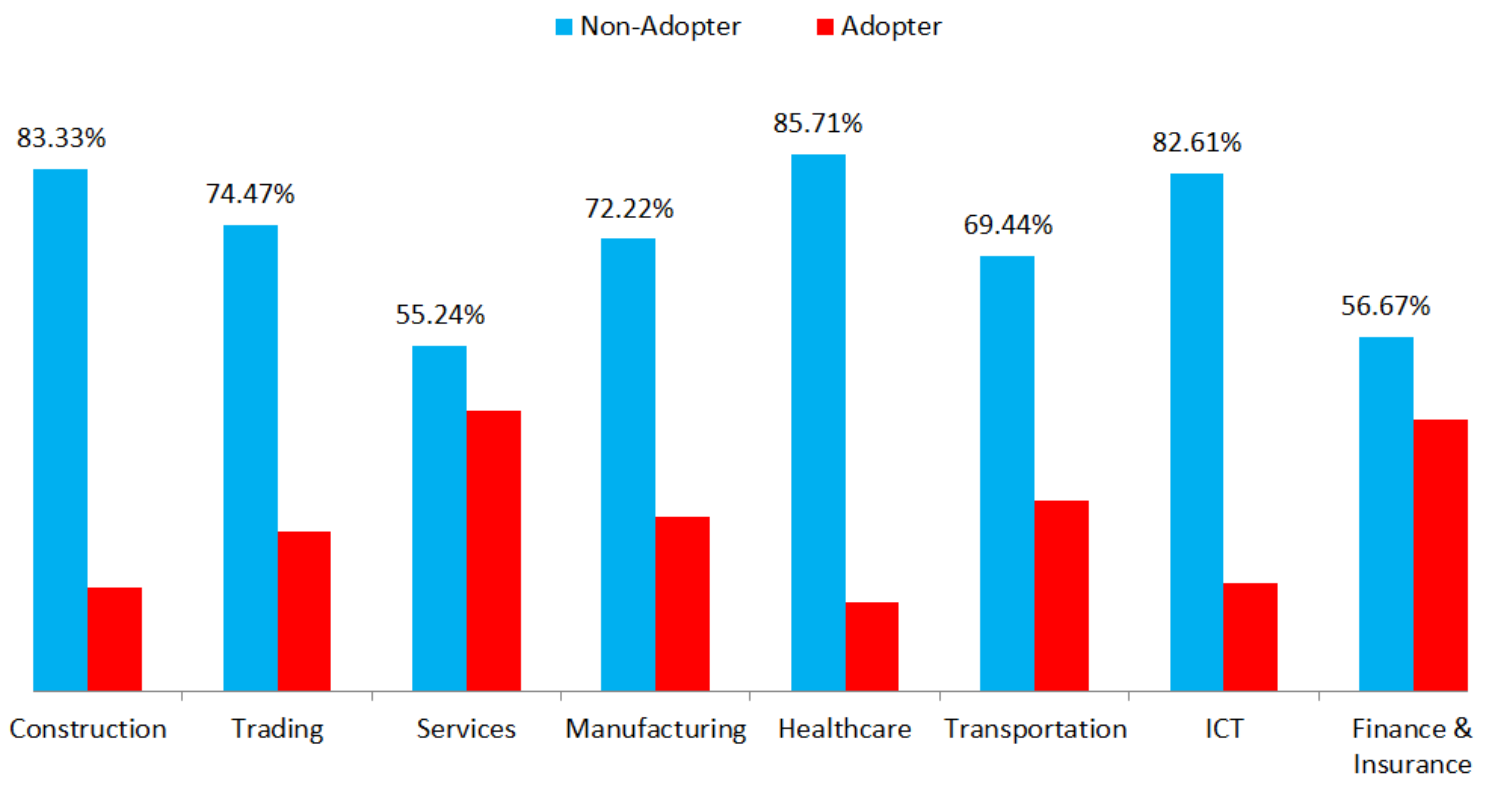

Figure 6.5 Distribution of m-commerce adoption by industries

An ANOVA for comparing "between groups" differences is conducted to have in-deep understanding the adoption of m-commerce in different sizes of the surveyed SMEs. Table 6.10 presents a summary of such an ANOVA. The results indicate that there are 
strong significant differences in the m-commerce adoption between such industries of the surveyed SMEs $(p$-value $=0.000)$.

Table 6.10 Summary of ANOVA results for different industries of surveyed SMEs

\begin{tabular}{lccccc}
\hline & Sum of Squares & df & Mean Square & F & Sig. \\
\hline Between Groups & 24.771 & 7 & 3.539 & 6.491 & .000 \\
\hline Within Groups & 275.303 & 505 & .545 & & \\
\hline Total & 300.074 & 512 & & \\
\hline
\end{tabular}

Table 6.11 and Table 6.12 show the details of difference comparison analysis from the ANOVA results. These results indicate nine significant differences in the adoption of m-commerce between SMEs in different industries. These include (a) the difference between SMEs in construction and services $(p$-value $=0.008)$, (b) the difference between SMEs in construction and finance and insurance ( $p$-value $=0.009)$, (c) the difference between SMEs in trading and services $(p$-value $=0.012),(d)$ the difference between SMEs in trading and finance \& insurance ( $p$-value $=0.022),(\mathrm{e})$ the difference between SMEs in services and manufacturing ( $p$-value $=0.022)$, (f) the difference between SMEs in transportation and services $(p$-value $=0.003),(\mathrm{g})$ the difference between SMEs in finance and insurance and manufacturing ( $p$-value $=0.014),(\mathrm{h})$ the difference between SMEs in transportation and ICT ( $p$-value $=0.012$ ), and (i) the difference between SMEs in transportation and finance and insurance ( $p$-value $=0.002)$. 
Table 6.11 Multiple comparisons for different industries of the surveyed SMEs

\begin{tabular}{|c|c|c|c|c|}
\hline (I) Industry & (J) Industry & Mean Difference (I-J) & Std. Error & Sig. \\
\hline \multirow{7}{*}{ Construction } & Trading & -.08028 & .10695 & 1.000 \\
\hline & Services & $-.39002^{*}$ & .10670 & .008 \\
\hline & Manufacturing & .00772 & .13292 & 1.000 \\
\hline & Healthcare & -.44114 & .21566 & 1.000 \\
\hline & Transportation & .15278 & .15071 & 1.000 \\
\hline & ICT & -.54569 & .17684 & .060 \\
\hline & Finance \& Insurance & $-.58241^{*}$ & .16045 & .009 \\
\hline \multirow{7}{*}{ Trading } & Construction & .08028 & .10695 & 1.000 \\
\hline & Services & $-.30974^{*}$ & .08763 & .012 \\
\hline & Manufacturing & .08800 & .11816 & 1.000 \\
\hline & Healthcare & -.36086 & .20690 & 1.000 \\
\hline & Transportation & .23306 & .13788 & 1.000 \\
\hline & ICT & -.46541 & .16604 & .147 \\
\hline & Finance \& Insurance & $-.50213^{*}$ & .14845 & .022 \\
\hline \multirow{7}{*}{ Services } & Construction & $.39002^{*}$ & .10670 & .008 \\
\hline & Trading & $.30974^{*}$ & .08763 & .012 \\
\hline & Manufacturing & $.39774^{*}$ & .11793 & .022 \\
\hline & Healthcare & -.05112 & .20677 & 1.000 \\
\hline & Transportation & $.54280^{*}$ & .13768 & .003 \\
\hline & ICT & -.15567 & .16588 & 1.000 \\
\hline & Finance \& Insurance & -.19239 & .14827 & 1.000 \\
\hline \multirow{7}{*}{ Manufacturing } & Construction & -.00772 & .13292 & 1.000 \\
\hline & Trading & -.08800 & .11816 & 1.000 \\
\hline & Services & $-.39774^{*}$ & .11793 & .022 \\
\hline & Healthcare & -.44885 & .22144 & 1.000 \\
\hline & Transportation & .14506 & .15887 & 1.000 \\
\hline & ICT & -.55341 & .18384 & .077 \\
\hline & Finance \& Insurance & $-.59012^{*}$ & .16813 & .014 \\
\hline
\end{tabular}

Notes: $* p<0.05$ 
Table 6.12 Multiple comparisons for different industries of the surveyed SMEs (cont'd)

\begin{tabular}{|c|c|c|c|c|}
\hline (I) Industry & (J) Industry & Mean Difference (I-J) & Std. Error & Sig. \\
\hline \multirow{7}{*}{ Healthcare } & Construction & .44114 & .21566 & 1.000 \\
\hline & Trading & .36086 & .20690 & 1.000 \\
\hline & Services & .05112 & .20677 & 1.000 \\
\hline & Manufacturing & .44885 & .22144 & 1.000 \\
\hline & Transportation & .59392 & .23256 & .307 \\
\hline & ICT & -.10455 & .25028 & 1.000 \\
\hline & Finance \& Insurance & -.14127 & .23898 & 1.000 \\
\hline \multirow{7}{*}{ Transportation } & Construction & -.15278 & .15071 & 1.000 \\
\hline & Trading & -.23306 & .13788 & 1.000 \\
\hline & Services & $-.54280^{*}$ & .13768 & .003 \\
\hline & Manufacturing & -.14506 & .15887 & 1.000 \\
\hline & Healthcare & -.59392 & .23256 & .307 \\
\hline & ICT & $-.69847^{*}$ & .19709 & .012 \\
\hline & Finance \& Insurance & $-.73519^{*}$ & .18252 & .002 \\
\hline \multirow{7}{*}{ ICT } & Construction & .54569 & .17684 & .060 \\
\hline & Trading & .46541 & .16604 & .147 \\
\hline & Services & .15567 & .16588 & 1.000 \\
\hline & Manufacturing & .55341 & .18384 & .077 \\
\hline & Healthcare & .10455 & .25028 & 1.000 \\
\hline & Transportation & $.69847^{*}$ & .19709 & .012 \\
\hline & Finance \& Insurance & -.03671 & .20463 & 1.000 \\
\hline \multirow{7}{*}{ Finance \& Insurance } & Construction & $.58241^{*}$ & .16045 & .009 \\
\hline & Trading & $.50213^{*}$ & .14845 & .022 \\
\hline & Services & .19239 & .14827 & 1.000 \\
\hline & Manufacturing & $.59012^{*}$ & .16813 & .014 \\
\hline & Healthcare & .14127 & .23898 & 1.000 \\
\hline & Transportation & $.73519^{*}$ & .18252 & .002 \\
\hline & ICT & .03671 & .20463 & 1.000 \\
\hline
\end{tabular}

Notes: $* p<0.05$ 


\subsection{Research Findings and Discussion}

The analysis of the general m-commerce adoption scenarios as well as the patterns for m-commerce adoption in different sizes and industries of Vietnamese SMEs above shed light on four major findings. Such findings include (a) the m-commerce adoption rate in Vietnamese SMEs is still quite low, (b) the adoption of m-commerce does not differ much between SMEs with a different number of permanent employees, (c) there is a significant difference in the adoption of $\mathrm{m}$-commerce between SMEs with different total registered capital, and (d) there is a clear gap in the adoption of m-commerce across SMEs in different industries. These findings provide an answer to the first research question of this study. The following section discusses the interpretation based on these findings.

The m-commerce adoption rate in Vietnamese SMEs is still low. The observed $\mathrm{m}$ commerce adoption rate in Vietnamese SMEs in this study is at 30.6\%. 69.4\% of SMEs are the non-adopter of m-commerce. More than half of such non-adopters $(54.2 \%)$ do not have a plan to adopt $\mathrm{m}$-commerce in the near future. Additionally, more than half of the surveyed SMEs $(51.1 \%)$ have not built a website for their businesses. These reveal the relatively low adoption rate of m-commerce in Vietnamese SMEs.

Such a finding is consistent with the conclusion that m-commerce has not been fully utilized by SMEs in many developing countries even though there are potential mcommerce markets in such countries (Nafea \& Younas 2014; Zhang et al. 2017; Chau \& Deng 2020). The relatively low rate of m-commerce adoption in SMEs in Vietnam further justifies the significance of this study, giving that Vietnam is ranked the thirty- 
third in the world and the fifth in Asia with respect to the smartphone penetration rate in the population (Statista 2019b).

The adoption of m-commerce in Vietnamese SMEs does not differ much with respect to their number of permanent employees. The m-commerce adoption rates are steadily distributed across SMEs with a different number of employees. This indicates the number of employees does not significantly affect the adoption of m-commerce in Vietnamese SMEs.

Such a finding is consistent with the findings of previous studies on the adoption of ecommerce and e-business in SMEs (Seyal \& Rahman 2003; Jeon et al. 2006; Rahayu \& Day 2015). Seyal and Rahman (2003), for example, investigate the adoption of ecommerce in SMEs in Brunei, leading to the identification that the organizational size is irrelevant to the adoption of e-commerce. Jeon et al. (2006) investigate the adoption of e-business in Korean SMEs, leading to the confirmation that business size does not play an important role in adopting e-business. Rahayu and Day (2015) investigate the adoption of e-commerce in Indonesian SMEs, leading to the conclusion that the organizational size is not a critical determinant for the adoption of e-commerce. The effect of the size with respect to the number of employees to the adoption of mcommerce will be further tested as the role of a control variable in Chapter 7 .

The adoption of m-commerce in Vietnamese SMEs significantly differs with respect to their total registered capital. The analytical results show that small enterprises with a total capital from 20 to 50 billion VND have the highest m-commerce adoption rate of 
$58.82 \%$, whereas very small enterprises with a total capital less than 10 billion VND have the lowest adoption rate of only $21.37 \%$. This indicates that SMEs with sufficient financial resources are more likely to adopt m-commerce for their businesses. This finding is further reflected in the role of organizational readiness determinant on the adoption of m-commerce in Vietnamese SMEs discussed in Chapter 7. The effect of the organizational size in terms of the total registered capital to the adoption of $\mathrm{m}$ commerce will be further tested as the role of a control variable in Chapter 7.

There is a clear gap in the adoption of m-commerce across SMEs in different industries. The analytical results show that SMEs in the services industry and finance and insurance industry are those that have the highest m-commerce adoption rates, followed by SMEs in transportation, manufacturing, and trading. SMEs in ICT, construction, and healthcare, on the other hand, are those that have the lowest m-commerce adoption rates.

Such a finding is supported by the existing literature that confirms a correlation between the nature of the specific industry and the adoption of technology in organizations (Jeon et al. 2006; Rosenzweig, Laseter \& Roth 2011). Jeon et al. (2006), for example, investigate the adoption of e-business in Korean SMEs. The study confirms that industries are relevant to the adoption of e-business. Particularly, the findings indicate that the service industry has the highest e-business adoption rate.

Rosenzweig et al. (2011) investigate the influence of the industrial sector on the emarket adoption in organizations, leading to the development of a conceptual typology 
for exploring the success rate of the e-market adoption in different industries. Such a typology is conceptualized using two key criteria including the information dependence and the information tacitness. The information dependence is about the extent to which the value-added among businesses is through information rather than materials. The information tacitness is about the extent to which the business relies on the uncoded and the standardized information content (Rosenzweig et al. 2011). Such a typology categorizes specific industries into three sectors including (a) sweet spot sectors, (b) customer-facing service sectors, and (c) mature-product-based sectors, as shown in Figure 6.6.

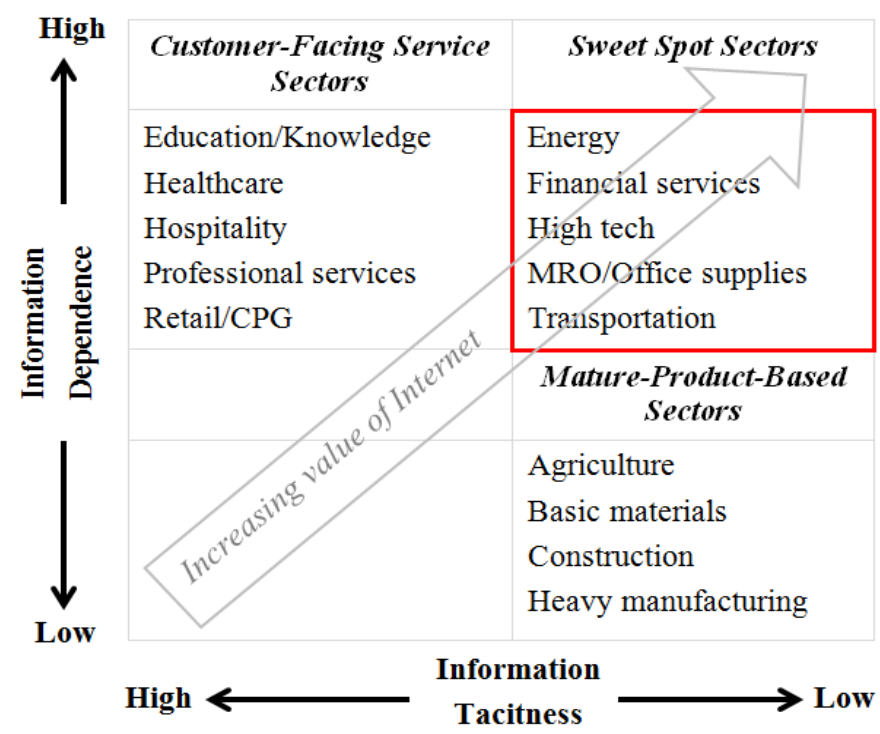

Figure 6.6 The conceptual typology of industries

Sectors in the "sweet spot sectors" category are those featured by the high information dependence and the low information tacitness. Such sectors are found to have the highest probability of success in the adoption of the e-market. Sectors in the "customerfacing service sectors" category are those characterized by the high information 
dependence and the high information tacitness. Sectors in the "mature-product-based sectors" category are those featured by the low information dependence and the low information tacitness. These two categories are less successful in the adoption of the emarket (Rosenzweig et al. 2011).

The correlation patterns between the nature of specific industries and m-commerce adoption rates in Vietnamese SMEs are similar to those of e-market in the study of Rosenzweig et al. (2011). Particularly, the high m-commerce adoption rates in the services industry, finance and insurance industry, and transportation industry can be explained based on the nature of these industries as high information dependence and low information tacitness categorized in the "sweet spot sectors". On the other hand, the low m-commerce adoption rates in the remaining industries are due to the nature of these industries as high information dependence and high information tacitness, or low information dependence, and low information tacitness, which are categorized into "customer-facing service sectors" and "mature-product-based sectors".

The above finding provides useful information to the Vietnamese government departments as well as the m-commerce operators on which industry sectors should be focused on promoting the successful adoption of m-commerce. The effect of the industry on the adoption of m-commerce will be further tested as the role of a control variable in Chapter 7. 


\subsection{Concluding Remarks}

The purpose of this chapter is to identify the emerging patterns for the adoption of $\mathrm{m}$ commerce in Vietnamese SMEs. The findings of this chapter provide an answer to the first research question: What are the current patterns for the adoption of m-commerce in Vietnamese SMEs? This is done by examining the demographic characteristics of the surveyed SMEs and exploring the m-commerce adoption patterns in such SMEs.

The findings show that the m-commerce adoption rate in Vietnamese SMEs, in general, is still quite low. The adoption of m-commerce is not much different between SMEs with a different number of permanent employees. There is, however, a clear gap in the m-commerce adoption between SMEs with different total registered capital. There is also a clear difference in such adoption between SMEs in different industries. Industries with high information dependence and low information tacitness have a higher chance of the adoption of m-commerce. 


\section{Chapter 7}

\section{Critical Determinants for the Adoption of Mobile}

\section{Commerce}

\subsection{Introduction}

Critical determinants are crucial for the success of a decision or an organization (Ulrich 2008). They possess a pivotal degree of control in the accomplishment of a specific task (Deng \& Gupta 2005). Such critical determinants are essential for deciding the overall result of the decision or the organization in a particular situation (Soliman \& Janz 2004). As a result, the identification of the critical determinants is significant for providing better understanding of a specific phenomenon.

M-commerce has been becoming popular due to its tremendous benefits to organizations, especially SMEs including improving productivity, increasing customer satisfaction, and lowering operational costs (Varshney \& Vetter 2002; Chau \& Deng 2018a; Chau et al. 2020). As a result, m-commerce appears to be an attractive option for Vietnamese SMEs to enhance their competitiveness, both locally and internationally (Chau \& Deng 2020). The adoption of m-commerce in Vietnamese SMEs, however, is still disappointing, featured by a relatively low adoption rate (VECITA 2017; Chau \& Deng 2018a; Chau et al. 2020). 
There are specific reasons for such a low adoption of m-commerce in Vietnamese SMEs. One plausible reason for such a low adoption rate is due to various obstacles that SMEs face in the adoption of m-commerce. Particularly, there is lack of the ability to effectively addressing the technological, organizational, environmental, and managerial issues in the adoption of m-commerce (Huy et al. 2012; VCCI 2016; Chau et al. 2020). As a result, better understanding the critical determinants for the adoption of $\mathrm{m}$ commerce is desirable for assisting Vietnamese SMEs in effectively adopting mcommerce for their businesses.

This chapter provides an investigation of the critical determinants for the adoption of $\mathrm{m}$ commerce in Vietnamese SMEs. To effectively achieve this aim, the proposed conceptual framework is tested and validated with the use of SEM on the sample data collected from a survey of the managers of Vietnamese SMEs. This leads to the identification of the critical determinants for the adoption of $\mathrm{m}$-commerce in Vietnamese SMEs. Furthermore, neural network analysis for evaluating the relative importance of these critical determinants for the adoption of $\mathrm{m}$-commerce is conducted. The results from the neural network analysis provide further support for the evaluation of the critical determinants for the adoption of m-commerce in SMEs in Vietnam.

The rest of the chapter is organized into five sections. Section 7.2 presents the steps taken to analyze the structural model. Section 7.3 discusses hypothesis testing using SEM. Section 7.4 presents the results of neural network analysis. Section 7.5 discusses the research findings on the critical determinants for m-commerce adoption in Vietnamese SMEs. Section 7.6 ends the chapter with some concluding remarks. 


\subsection{Structural Model Analysis}

This study adopts a three-stage approach for validating the proposed conceptual framework and testing the hypotheses including (a) reliability and validity assessment, (b) measurement model analysis, and (c) structural model analysis (Hair et al. 2010). The first two stages involve testing the reliability and validity of the construct, as well as the fitness of the full measurement model with the survey data. The results of these two stages are reported in Chapter 5. The third stage involves testing the structural model, including the significance of the structural relationship in the structural model. The results of this stage are presented in the following.

\subsubsection{Structural Model}

A structural model is a conceptual representation of the hypothesized relationship between constructs (Hair et al. 2010). It examines how every single construct is related to another. The path coefficient indicates the strength, the nature, and the significance of each relationship between one construct and another (Schumacker \& Lomax 2004; Hair et al. 2010). The significance of such relationships shows whether the research hypotheses are accepted or rejected (Byrne 2016).

SEM is commonly used to develop and assess the relationship between constructs. It is a multivariate technique combining factor analysis and multiple regression techniques to represent the theory with a set of structural equations in the form of a visual diagram (Hair et al. 2010). SEM employs two acceptable approaches for designing a structural model including (a) fixing the factor loadings and error variances of the structural 
model with the estimates from the measurement model and (b) allowing the factor loadings and error variances of the structural model to be freely estimated (Hair et al. 2010).

The first approach allows the researcher in research projects to estimate the structural model easily. This is because all the parameters of the measurement part of the constructs are fixed. It is, however, possible to change the fitness between the structural model and the measurement model as a result of the problem with the measures rather than the structural theory (Hair et al. 2010).

The second approach provides a convenient basis for comparing the closeness of the fitness between the structural model and the measurement model (Hair et al. 2010; Kline 2015). This can be done by comparing the loading estimates of the structural model with those of the measurement model that is obtained from the CFA model. Such an approach is widely used in practice (Hair et al. 2010; Kline 2015). It is therefore adopted for this study.

The validity and acceptability of the structural model can be evaluated by (a) assessing the structural model fitness through the GOF indices, (b) comparing the factor loadings of the structural model to those of the underlying measurement model, (c) examining the magnitude of variance explained through the $R^{2}$ value, and (d) assessing the size, direction, and significance of the estimated structural parameters. Table 7.1 presents a summary of these tests and the rule of thumb criteria for acceptable values. 
Table 7.1 Tests for structural model validity

\begin{tabular}{|c|c|c|c|}
\hline Tests & Descriptions & Acceptable Values & References \\
\hline Structural model fitness & $\begin{array}{l}\text { Assess the extent of the structural } \\
\text { model fit the survey data using the } \\
\text { GOF indices used for the } \\
\text { measurement model }\end{array}$ & See Table 5.21 & $\begin{array}{l}\text { Hair et al. (2010); } \\
\text { Kline (2015) }\end{array}$ \\
\hline $\begin{array}{l}\text { Comparison of loadings } \\
\text { between the structural } \\
\text { model and the } \\
\text { measurement model }\end{array}$ & $\begin{array}{l}\text { Assess the closeness of the } \\
\text { loadings of the structural model } \\
\text { and measurement model }\end{array}$ & $\begin{array}{l}\text { The difference in } \\
\text { the loading should } \\
\text { be } 0.05 \text { or less }\end{array}$ & Hair et al. (2010) \\
\hline Variance explained $\left(R^{2}\right)$ & $\begin{array}{l}\text { The extent to which the variance is } \\
\text { explained by the estimates of the } \\
\text { model }\end{array}$ & $\begin{array}{l}0.5 \text { and above is } \\
\text { good; } 0.7 \text { and above } \\
\text { is great }\end{array}$ & Chin (1998) \\
\hline $\begin{array}{l}\text { Size and significance of } \\
\text { parameter estimates }\end{array}$ & $\begin{array}{l}\text { Significance of the parameter } \\
\text { estimates based on the } \\
\text { corresponding } p \text {-values }\end{array}$ & $\begin{array}{l}p \leq 0.05 \text { and } / \text { or } t- \\
\text { value above } 2.0\end{array}$ & Hair et al. (2010) \\
\hline
\end{tabular}

Figure 7.1 presents the structural model of this study. Such a model includes twelve independent constructs and one dependent constructs with a total of 41 measurement items. The validity and acceptability of such a model are evaluated based on the four mentioned criteria including the structural model fitness assessment, the factor loading comparison between the structural model and the measurement model, the variance explained examination, and the evaluation of the structural parameters. 


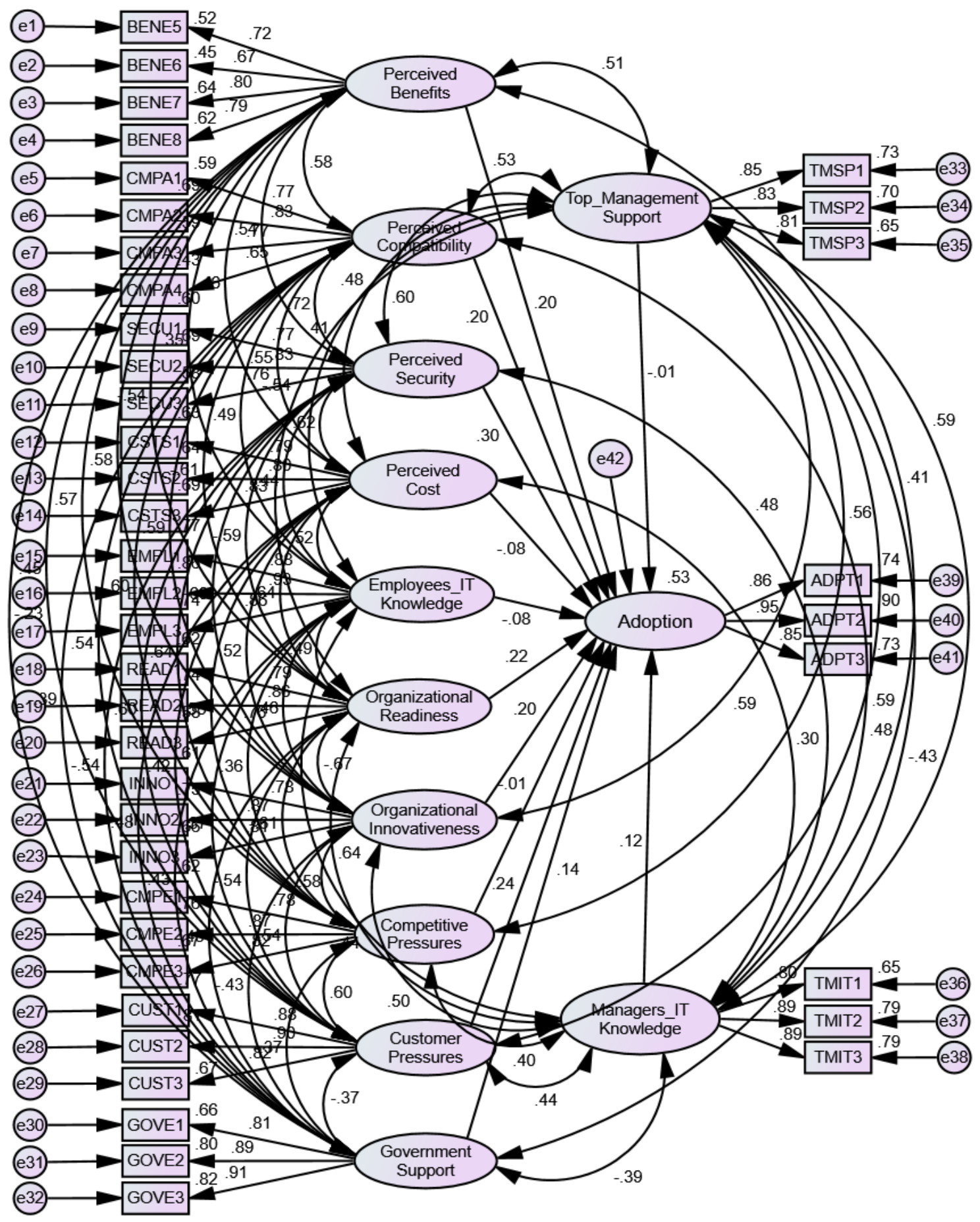

Figure 7.1 A structural model

The GOF indices are used for assessing the fitness of the structural model. The results of such an evaluation are presented in Table 7.2. The thresholds for the model fitness 
indices including the absolute fit indices, the incremental fit indices, and the parsimony fit indices are discussed in Chapter 5. In particular, the normed chi-square value below 5 is acceptable (below 3 is preferred). For the absolute fit indices, the values of RMSEA, RMR, and SRMR below 0.1 are acceptable (below 0.08 are preferred). For the incremental fit indices, the values of IFI, TLI, and CFI above 0.9 are acceptable. The acceptable parsimony fit indices including PNFI and PCFI values are above 0.5. Finally, the PClose value is greater than 0.05 , indicating a good model fit.

Table 7.2 The summary of the model fitness statistics for the structural model

\begin{tabular}{cccccccc}
\hline & Chi-square & \multicolumn{2}{c}{ Absolute Fit Indices } & \multicolumn{2}{c}{ Incremental Fit Indices } & \multicolumn{2}{c}{ Parsimony Fit Indices } \\
\hline$\chi^{2}$ & $1612.405(0.000)$ & RMSEA & 0.050 & IFI & 0.938 & PNFI & 0.766 \\
\hline df & 701 & RMR & 0.024 & TLI & 0.927 & PCFI & 0.802 \\
\hline$\chi^{2 / \mathrm{df}}$ & 2.300 & SRMR & 0.0401 & CFI & 0.938 & PClose & 0.416 \\
\hline
\end{tabular}

The structural model fitness statistics in Table 7.2 show that the normed chi-square value of the structural model is 2.300 that is less than 3 . The absolute fitness indices including RMSEA, RMR, and SRMR are 0.050, 0.024, and 0.0401 respectively, which are below the threshold value of 0.05 . The incremental fitness indices including IFI, TLI, and CFI are $0.938,0.927$, and 0.938 respectively, which are greater than the threshold value of 0.9. The parsimony fitness indices including PNFI and PCFI are 0.766 and 0.802 respectively, which are above 0.5 . The PClose value is 0.416 , which is above 0.05 . These results indicate that the presented structural model is acceptable.

The standardized factor loadings of all measurement items of the structural model are compared against the loadings of these items of the corresponding measurement model. 
The results of such a comparison are presented in Appendix F. These results show that all the loading estimates of the structural model are unchanged from the measurement model. This indicates the existence of parameter stability among these measurement items in such two models, providing further support for the validity of the structural model.

An examination of the magnitude of variance explained through $R^{2}$ value is conducted. The results in Figure 7.1 show that the value of $R^{2}$ is 0.53 . This indicates that all the independent constructs explain $53 \%$ of the variance in the dependent construct, which is very good (Chin 1998). This further supports the validity of the structural model.

An investigation of the size, direction, and significance of the structural parameter estimates is conducted. Table 7.3 presents the structural path estimates. The results show that eight out of twelve structural path estimates are significant at a $95 \%$ confidence level. Additionally, the directions of these paths are in the predicted direction. These results further support the validity of the structural model. 
Table 7.3 An overview of the size, direction, and significance of the structural paths

\begin{tabular}{lclllll}
\hline & & Paths & Est. & SE & CR & Sig. \\
\hline Adoption & $<--$ & Perceived Benefits & 0.266 & 0.075 & 3.541 & $* * *$ \\
\hline Adoption & $<---$ & Perceived Compatibility & 0.232 & 0.081 & 2.844 & 0.004 \\
\hline Adoption & $<---$ & Perceived Security & 0.353 & 0.104 & 3.395 & $* * *$ \\
\hline Adoption & $<--$ & Perceived Cost & -0.084 & 0.068 & -1.238 & 0.216 \\
\hline Adoption & $<---$ & Employees' IT Knowledge & -0.074 & 0.052 & -1.428 & 0.153 \\
\hline Adoption & $<---$ & Organizational Readiness & 0.277 & 0.088 & 3.139 & 0.002 \\
\hline Adoption & $<---$ & Organizational Innovativeness & 0.224 & 0.079 & 2.839 & 0.005 \\
\hline Adoption & $<---$ & Competitive Pressures & -0.006 & 0.062 & -0.092 & 0.927 \\
\hline Adoption & $<---$ & Customer Pressures & 0.265 & 0.061 & 4.368 & $* * *$ \\
\hline Adoption & $<---$ & Government Support & 0.130 & 0.046 & 2.805 & 0.005 \\
\hline Adoption & $<---$ & Top Management Support & -0.008 & 0.074 & -0.107 & 0.915 \\
\hline Adoption & $<---$ & Managers' IT Knowledge & 0.144 & 0.071 & 2.042 & 0.041 \\
\hline
\end{tabular}

Notes: $* * * p<0.001$

\subsubsection{Structural Model with Control Variables}

The structural model with control variables is evaluated for its validity and acceptability. Such a model includes twelve independent constructs, one dependent construct, and three control variables, as shown in Figure 7.2. The validity and acceptability of such a model are evaluated based on the four mentioned criteria including the structural model fitness assessment, the factor loading comparison between the structural model and the measurement model, the variance explained examination, and the evaluation of the structural parameters. 


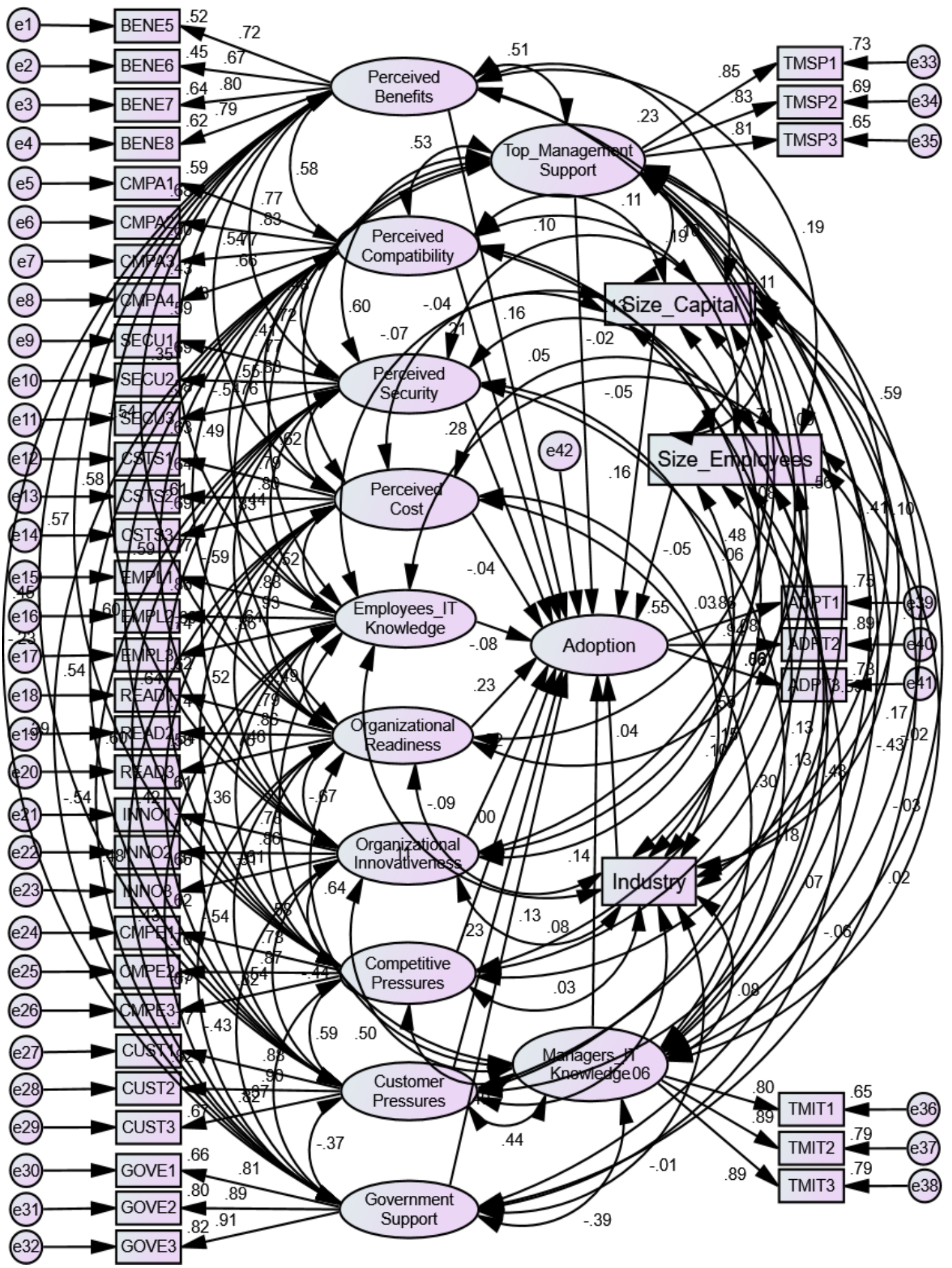

Figure 7.2 Structural equation model with control variables 
The GOF indices are used for assessing the fitness of the structural model. The results of such an evaluation are presented in Table 7.4. The results show that the normed chisquare value of the structural model is 2.182 , which is less than 3 . The absolute fitness indices including RMSEA, RMR, and SRMR are 0.048, 0.024, and 0.0382 respectively, which are below the threshold value of 0.05 . The incremental fitness indices including IFI, TLI, and CFI are $0.939,0.926$, and 0.939 respectively, which are greater than the threshold value of 0.9. The parsimony fitness indices including PNFI and PCFI are 0.742 and 0.779 respectively, which are above 0.5 . The PClose value is 0.849 , which is greater than 0.05 . These results indicate that the presented structural model is acceptable.

Table 7.4 Model fitness statistics for the structural model with control variables

\begin{tabular}{cccccccc}
\hline & Chi-square & \multicolumn{2}{c}{ Absolute Fit Indices } & \multicolumn{2}{c}{ Incremental Fit Indices } & \multicolumn{2}{c}{ Parsimony Fit Indices } \\
\hline$\chi^{2}$ & $1712.575(0.000)$ & RMSEA & 0.048 & IFI & 0.939 & PNFI & 0.742 \\
\hline $\mathrm{df}$ & 785 & RMR & 0.024 & TLI & 0.926 & PCFI & 0.779 \\
\hline$\chi 2 / \mathrm{df}$ & 2.182 & SRMR & 0.0382 & CFI & 0.939 & PClose & 0.849 \\
\hline
\end{tabular}

The standardized factor loadings of all measurement items of the structural model are compared against the loadings of these items of the corresponding measurement model. The results of such a comparison are presented in Appendix F. The results show that most of the loading estimates of the structural model with control variables are mostly unchanged from the measurement model. Twenty-three standardized estimated loadings have changed. However, the absolute maximum change in these standardized loadings is 0.004 , which is not above the 0.05 limit (Hair et al. 2010). This indicates the 
existence of parameter stability among the measurement items in such two models, providing further support for the validity of the structural model with control variables.

An examination of the magnitude of variance explained through $R^{2}$ value is conducted. The results in Figure 7.2 show that the value of $R^{2}$ is 0.55 . This indicates that all the independent constructs and control variables explain $55 \%$ of the variance in the dependent construct, which is very good (Chin 1998). This further supports the validity of the structural model.

An investigation of the size, direction, and significance of the structural parameter estimates is conducted. Table 7.5 presents the structural path estimates. The results show that eight out of twelve structural path estimates are significant at a $95 \%$ confidence level. Additionally, the directions of these paths are in the predicted direction. These results further support the validity of the structural model. 
Table 7.5 An overview of the size, direction, and significance of the structural paths

\begin{tabular}{|c|c|c|c|c|c|c|}
\hline & & Paths & Est. & SE & $\mathbf{C R}$ & Sig. \\
\hline Adoption & $<---$ & Perceived Benefits & 0.208 & 0.076 & 2.733 & 0.006 \\
\hline Adoption & $<---$ & Perceived Compatibility & 0.240 & 0.082 & 2.947 & 0.003 \\
\hline Adoption & $<---$ & Perceived Security & 0.335 & 0.102 & 3.269 & 0.001 \\
\hline Adoption & $<---$ & Perceived Cost & -0.046 & 0.068 & -0.671 & 0.502 \\
\hline Adoption & $<--$ & Employees' IT Knowledge & -0.076 & 0.052 & -1.467 & 0.142 \\
\hline Adoption & $<--$ & Organizational Readiness & 0.289 & 0.088 & 3.297 & $* * *$ \\
\hline Adoption & $<---$ & Organizational Innovativeness & 0.242 & 0.078 & 3.089 & 0.002 \\
\hline Adoption & $<--$ & Competitive Pressures & -0.003 & 0.062 & -0.051 & 0.960 \\
\hline Adoption & $<---$ & Customer Pressures & 0.248 & 0.061 & 4.091 & $* * *$ \\
\hline Adoption & $<---$ & Government Support & 0.126 & 0.046 & 2.745 & 0.006 \\
\hline Adoption & $<--$ & Top Management Support & -0.022 & 0.073 & -0.295 & 0.768 \\
\hline Adoption & $<---$ & Managers' IT Knowledge & 0.166 & 0.070 & 2.352 & 0.019 \\
\hline Adoption & $<---$ & Size_Employees & -0.033 & 0.030 & -1.073 & 0.283 \\
\hline Adoption & $<---$ & Size_Capital & 0.065 & 0.021 & 3.152 & 0.002 \\
\hline Adoption & $<---$ & Industry & 0.015 & 0.012 & 1.211 & 0.226 \\
\hline
\end{tabular}

Notes: $* * * p<0.001$

\subsection{Hypotheses Testing}

The full conceptual framework and hypotheses are illustrated in Figure 3.5. Such a framework consists of twelve independent constructs including perceived benefits, perceived compatibility, perceived security, perceived cost, employees' IT knowledge, organizational readiness, organizational innovativeness, competitive pressures, customer pressures, government support, top management support and managers' IT knowledge, three control variables including the number of permanent employees, the 
total registered capital and industry, and one dependent construct that is m-commerce adoption intention. Table 7.6 presents a summary of the structural paths of the structural model with the estimates and the significance intervals for hypotheses testing.

Table 7.6 Hypotheses testing results

\begin{tabular}{|c|c|c|c|c|}
\hline Constructs & $\begin{array}{l}\text { The Model with } \\
\text { Controls only } \\
\text { ( } \beta)\end{array}$ & $\begin{array}{c}\text { The Model } \\
\text { without } \\
\text { Controls ( } \beta \text { ) }\end{array}$ & $\begin{array}{c}\text { The Model } \\
\text { with all } \\
\text { Variables ( } \beta \text { ) }\end{array}$ & Results \\
\hline Perceived benefits & & $0.204 * *$ & $0.159 * *$ & Supported \\
\hline Perceived compatibility & & $0.199 * *$ & $0.206^{* *}$ & Supported \\
\hline Perceived security & & $0.298 * *$ & $0.282 * *$ & Supported \\
\hline Perceived cost & & -0.082 & -0.045 & Not supported \\
\hline Employees' IT knowledge & & -0.078 & -0.080 & Not supported \\
\hline Organizational readiness & & $0.219 * *$ & $0.227 * *$ & Supported \\
\hline Organizational innovativeness & & $0.200 * *$ & $0.216^{* *}$ & Supported \\
\hline Competitive pressures & & -0.006 & -0.003 & Not supported \\
\hline Customer pressures & & $0.242 * *$ & $0.226 * *$ & Supported \\
\hline Government support & & $0.137 * *$ & $0.132 * *$ & Supported \\
\hline Top management support & & -0.007 & -0.018 & Not supported \\
\hline Managers' IT knowledge & & $0.119 *$ & $0.136 *$ & Supported \\
\hline Adoption intention & $R^{2}=0.06$ & $R^{2}=0.53$ & $R^{2}=0.55$ & \\
\hline Organizational size (employees) & -0.037 & & -0.054 & \\
\hline Organizational size (capital) & $0.253 * *$ & & $0.162 * *$ & \\
\hline Industry & 0.079 & & 0.042 & \\
\hline
\end{tabular}

Notes: $* * p<0.01$ and $* p<0.05$ significance

The path coefficients along with their significance levels ( $p$-value) confirm the statistical significance of eight critical determinants of m-commerce adoption in 
Vietnamese SMEs. Specifically, the results show that perceived benefits (path coefficient $=0.159, p<0.01)$, perceived compatibility $($ path coefficient $=0.206, p<$ 0.01 ), perceived security (path coefficient $=0.282, p<0.01$ ), organizational readiness (path coefficient $=0.227, p<0.01)$, organizational innovativeness $($ path coefficient $=$ $0.216, p<0.01$ ), customer pressures (path coefficient $=0.226, p<0.01$ ), government support (path coefficient $=0.132, p<0.01$ ), and managers' IT knowledge (path coefficient $=0.136, p<0.05)$ are critical for the adoption of m-commerce in Vietnamese SMEs. These provide support for hypotheses H1, H2, H3, H6, H7, H9, H10, and H12. There are, however, insufficient evidences to support hypotheses H4, H5, H8, and H11 as perceived cost (path coefficient $=-0.045, p>0.05$ ), employees' IT knowledge (path coefficient $=-0.080, p>0.05$ ), competitive pressures (path coefficient $=-0.003, p>0.05)$, and top management support (path coefficient $=-0.018, p>0.05$ ) are insignificant for the adoption of m-commerce. Only one control variable of this study (total registered capital) is found to have significant relationship with the adoption intention construct.

All the independent constructs, together with the control variables, explain $55 \%$ of the variance in the dependent construct. This indicates that the proposed conceptual framework possesses adequate predictive power for explaining the adoption of $\mathrm{m}$ commerce in sampled SMEs. This further confirms the robustness of the above hypotheses testing results. 


\subsection{Artificial Neural Network Analysis}

This study employs a multi-analytical approach by combining SEM and neural network analysis to evaluate the critical determinants for m-commerce adoption in Vietnamese SMEs. First, the conceptual framework is validated, and the hypotheses are tested through the use of SEM for identifying the critical determinants for m-commerce adoption in Vietnamese SMEs. Second, the critical determinants from the first stage are evaluated for their relative importance. This can be done with the use of an artificial neural network model. The combination of such techniques is based on the following justifications.

Traditional statistical techniques such as multiple regression analysis and SEM are suitable for theory validation (Chan \& Chong 2012; Tan et al. 2014; Cabanillas et al. 2017). They are, however, only able to detect linear relationships between the research constructs (Hew et al. 2016; Cabanillas et al. 2017). This may lead to the possibility of over-simplification of complex decision-making processes in technology adoption (Chan \& Chong 2012; Tan et al. 2014).

The neural network model is a set of algorithms that are designed in a way to recognize patterns existent in a dataset. It can adapt to changing input; therefore, the network generates the best possible result without needing to redesign the output criteria (Haykin 2001). It is able to detect complex linear and non-linear relationships between the research constructs (Cabanillas et al. 2017). By examining non-linear relationships, the neural network allows exploring the non-compensatory decision processes in technology adoption (Chong 2013a). The neural network is, however, not suitable for 
testing theories and examining causal relationships due to its "black-box" operating nature (Chan \& Chong 2012).

The employment of a two-stage approach of predictive-analytic SEM and neural network analysis in this study can provide a more holistic understanding of the critical determinants for m-commerce adoption in Vietnamese SMEs (Leong et al. 2015). This is because the non-compensatory neural network analysis and the compensatory and linear SEM analysis complement the weakness of each other. Particularly, SEM is able to examine the causal relationship in the conceptual framework. It is, however, only capable of detecting linear relationships between the constructs (Chan \& Chong 2012; Chong 2013b; Leong et al. 2015). On the other hand, the employment of only a neural network will not provide the causal analysis (Chan \& Chong 2012). Furthermore, it is difficult to construct a neural network model when learning from the data. As a result, employing the results from SEM provides a way to develop the neural network model with good prediction performance (Chan \& Chong 2012; Chong 2013b).

The adoption of a multi-analytical approach using SEM and neural networks in this study can improve the validity and confidence of the critical determinants for $\mathrm{m}$ commerce adoption in Vietnamese SMEs (Chong 2013a, 2013b; Ahani, Rahim \& Nilashi 2017). The critical determinants resulting from SEM, for example, are reinforced by the neural network. The neural network is then able to show which of these critical determinants can be used to predict m-commerce adoption. 
The critical determinants for m-commerce adoption in Vietnamese SMEs from the SEM results are presented in Section 7.2. Such critical determinants are used as inputs to the neural network model for evaluating their relative importance. The details of this stage are presented in the following.

\subsubsection{An Overview of the Artificial Neural Networks}

Artificial neural networks are "a massive parallel distributed processor made up of simple processing units, which have a neural propensity for storing experimental knowledge and making it available for use" (Haykin 2001). Such simple processing units are called neurons or nodes. They are analogous to the biological neurons in the human brain as (a) knowledge is acquired by the network through a learning process, and (b) interneuron connection strengths, known as synaptic weights, are used to store knowledge (Cabanillas et al. 2017).

A typical neural network model consists of several hierarchical layers including one input layer, one or more hidden layers, and one output layer (Trenn 2008). The number of hidden layers depends on the complexity of the problem to be solved (Cabanillas et al. 2017). A neural network with one hidden layer can only model continuous activation functions. On the other hand, the network with two or more hidden layers can model not only continuous activation functions but also discontinuous activation functions (Negnevitsky 2011; Cabanillas et al. 2017).

In a neural network, data are received by the input layer through input neurons. The information is then generated in the output layer (Sim et al. 2014). Each input neuron is 
given a specific synaptic weight. These weights are transferred to the hidden layers. These values are added through applied weights and converted into an output value by a non-linear activation function (Haykin 2001). The results are then passed to the neurons in the layer below. Such results provide a feed-forward path to the output layer (Sexton, Johnson \& Hignite 2002). The synaptic weights of the neural connections are adjusted via an iterative training or learning process. The outcome is stored for future predictive usage (Leong et al. 2013). Figure 7.3 presents an example of a typical neural network with one hidden layer.

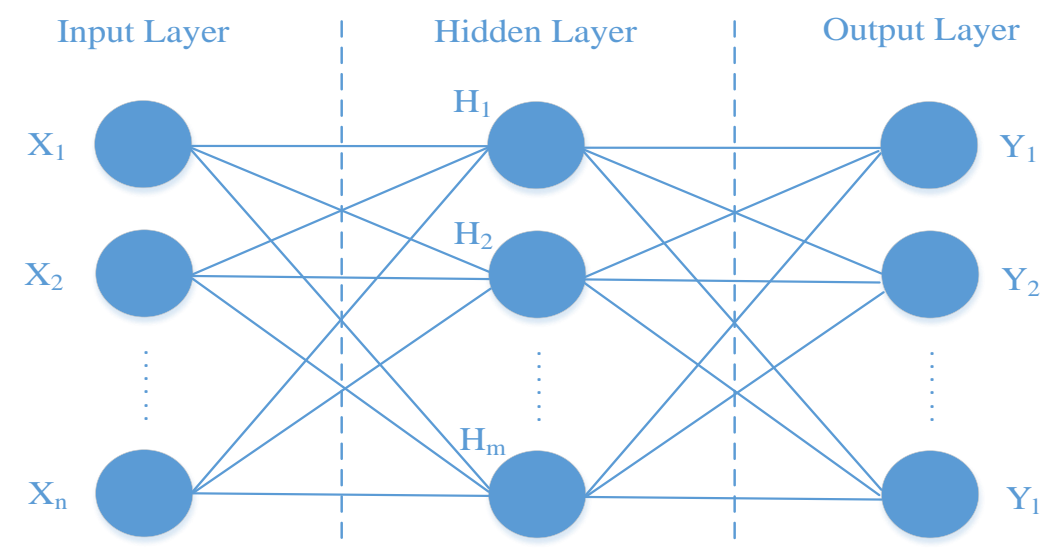

Figure 7.3 A typical three-layer neural network

The number of neurons in the input layer is equal to the number of inputs that are the independent construct. The number of neurons in the output layer is equal to the number of outputs that are the dependent constructs (Cabanillas et al. 2017). There is no heuristic way to determine the number of neurons in the hidden layer. As a result, it is usually determined by using the trial-and-error method (Chong et al. 2015). A higher number of neurons in the hidden layer gives better estimation accuracy. Too many of them, however, can dramatically increase the computational load (Negnevitsky 2011). 
There are several rules for facilitating the determination of the number of hidden neurons in the neural network (Trenn 2008; Fang \& Ma 2009; Shibata \& Ikeda 2009; Panahian 2011). Shibata and Ikeda (2009) and Panahian (2011), for example, suggest that the number of hidden neurons could be calculated as equation (7.1). Trenn (2008) proposes the use of equation (7.2) for determining the number of hidden neurons. Fang and Ma (2009) state that the number of hidden neurons can be calculated using equation (7.3). In such equations, $m$ is the number of hidden neurons, $n$ is the number of input neurons, and $l$ is the number of output neurons.

$$
\begin{aligned}
& \mathrm{m}=\sqrt{n \cdot l} \\
& \mathrm{~m}=\frac{n+l-1}{2} \\
& \mathrm{~m}=\log _{2}(\mathrm{n})
\end{aligned}
$$

Various factors affect the selection of the number of hidden neurons in the neural network. Specifically, such selection depends on the number of hidden layers, the sample size, the neural network architecture, the complexity of the activation function, and the training algorithm (Sheela \& Deepa 2013). For these regards, it is suggested to have the trial-and-error method with all such rules above to determine a suitable number of hidden neurons for specific datasets. The network that performs the best on the testing dataset with the least number of hidden neurons should be selected (Wong, Wong \& Chin 2011; Cabanillas et al. 2017).

There are different types of neural networks available for different applications (Sim et al., 2014). These types can be categorized into four groups including (a) feed-forward 
back neural networks, (b) recurrent neural networks, (c) radial basis function neural networks, and (d) multilayer perceptron (MLP) neural networks (Sharma 2019). Among these groups, MLP neural networks have more advantages with respect to their learning ability, non-linearity, input-output mapping, and robustness. As a result, they have been widely applied to numerous technology adoption studies (Sim et al. 2014; Sharma 2019).

MLP neural networks belong to the class of supervised learning neural networks (Tan et al. 2014; Cabanillas et al. 2017). This means that knowledge is stored in the network by iteratively exposing it to patterns of known inputs and outputs. The error is the difference between the desired (known) output and the actual (predicted) output that is calculated and propagated back in the opposite direction. This helps to adjust the synaptic weights of the neurons to minimize the estimation error (Cabanillas et al. 2017).

In a neural network, an activation function of a node defines the output of that node given an input or set of inputs (Haykin 2001). It is used to propagate the output of a neuron forward. This output is received by the neurons of the next layer to which such a neuron is connected (Hew et al. 2016). Specifically, each hidden unit in an MLP neural network has a non-linear activation function. Each of these hidden units transforms the signals from the former layer to one output signal. All these output signals are then distributed to the next layer. The output of a hidden unit is determined by applying the activation function on the sum of the weighted signals from the former layer and an 
individual bias (Trenn 2008). Overall, the activation function serves to introduce the non-linearity in the modeling capabilities for the whole network (Hew et al. 2016).

There are five common activation functions including linear, sigmoid, tanh, softmax, and ReLU (Haykin 2001). Among them, sigmoid is the most widely-used function in the neural network for studying innovation adoption (Chan \& Chong 2012; Tan et al. 2014; Leong et al. 2015; Hew et al. 2016; Cabanillas et al. 2017). This is because it allows a reduction in extreme or atypical values in a valid dataset without eliminating them. It converts independent variables of almost infinite range into simple probabilities between 0 and 1 . As a result, most of its output will be very close to the extremes of 0 or 1 (Shibata \& Ikeda 2009; Sim et al. 2014).

\subsubsection{Selection and Validation of Neural Networks}

As discussed in earlier sections, the critical determinants identified from SEM are used to develop the neural networks. MLP neural networks with feed-forward backpropagation algorithms are adopted. The sigmoid function is used as an activation function for neurons in both hidden and output layers (Chan \& Chong 2012; Leong et al. 2013). To increase the effectiveness of network training, particularly to provide shorter training time and better performance, all inputs and outputs are normalized to the range of $[0,1]$ (Cabanillas et al. 2017). In this study, the neural network is modeled in SPSS 25 software.

Ten-fold cross-validation is performed to avoid the issue of over-fitting (Wong et al. 2011; Chan \& Chong 2012; Cabanillas et al. 2017). This means that ten different neural 
networks are run for the selection of the best one through comparison. To run these neural networks, $90 \%$ of the data is used for network training, and the remaining $10 \%$ is used for testing (Leong et al. 2013; Sim et al. 2014; Chong et al. 2015). The root mean square error (RMSE) of both training and testing datasets, as well as the averages and standard deviations for these both types of datasets of such networks, are computed for measuring the predictive accuracy of the network (Abubakar et al. 2017; Sharma 2019).

For each neural network, the input layer consists of eight critical determinants including perceived benefits, perceived compatibility, perceived security, organizational readiness, organizational innovativeness, customer pressures, government support, and managers' IT knowledge. The output layer consists of one output variable that is mcommerce adoption. As discussed in Section 7.3.1, three different numbers of hidden neurons based on the equations (7.1), (7.2), and (7.3) are tested. As a result, the preliminary neural networks are examined by including two, three, and four hidden nodes respectively. A summary of the overall predictive accuracy of such neural networks with three different numbers of hidden neurons $(m=2,3,4)$ is presented in Table 7.7. 
Table 7.7 RMSE values for neural networks with three different number of hidden node

\begin{tabular}{ccccccc}
\hline \multirow{2}{*}{$\begin{array}{c}\text { Artificial Neural } \\
\text { networks }\end{array}$} & \multicolumn{2}{c}{$\mathbf{m}=\mathbf{2}$} & \multicolumn{2}{c}{$\mathbf{m}=\mathbf{3}$} & \multicolumn{2}{c}{$\mathbf{4}$} \\
\cline { 2 - 7 } & Training & Testing & Training & Testing & Training & Testing \\
\hline 1 & 0.566 & 0.517 & 0.570 & 0.515 & 0.579 & 0.524 \\
\hline 2 & 0.566 & 0.482 & 0.554 & 0.478 & 0.591 & 0.488 \\
\hline 3 & 0.546 & 0.621 & 0.550 & 0.614 & 0.574 & 0.611 \\
\hline 4 & 0.607 & 0.523 & 0.579 & 0.518 & 0.598 & 0.526 \\
\hline 5 & 0.557 & 0.549 & 0.579 & 0.562 & 0.575 & 0.568 \\
\hline 6 & 0.567 & 0.613 & 0.557 & 0.618 & 0.607 & 0.612 \\
\hline 7 & 0.582 & 0.496 & 0.573 & 0.490 & 0.573 & 0.490 \\
\hline 9 & 0.545 & 0.569 & 0.542 & 0.580 & 0.565 & 0.609 \\
\hline 10 & 0.584 & 0.607 & 0.571 & 0.600 & 0.569 & 0.610 \\
\hline Mean RMSE & 0.567 & 0.554 & 0.562 & 0.555 & 0.580 & 0.564 \\
\hline Standard Deviation & 0.020 & 0.049 & 0.014 & 0.051 & 0.014 & 0.052 \\
\hline
\end{tabular}

The accuracy results in Table 7.7 indicate that networks with three hidden nodes are complex enough to effectively map the dataset without incurring additional errors. The mean RMSE values of 0.562 and 0.555 for the training dataset and the testing dataset respectively are relatively small, with very small standard deviations of 0.014 and 0.051 respectively. This shows the higher accuracy in the results predicted by such neural networks (Yadav et al. 2016; Cabanillas et al. 2017). Figure 7.4 shows such a selected neural network for this study. 


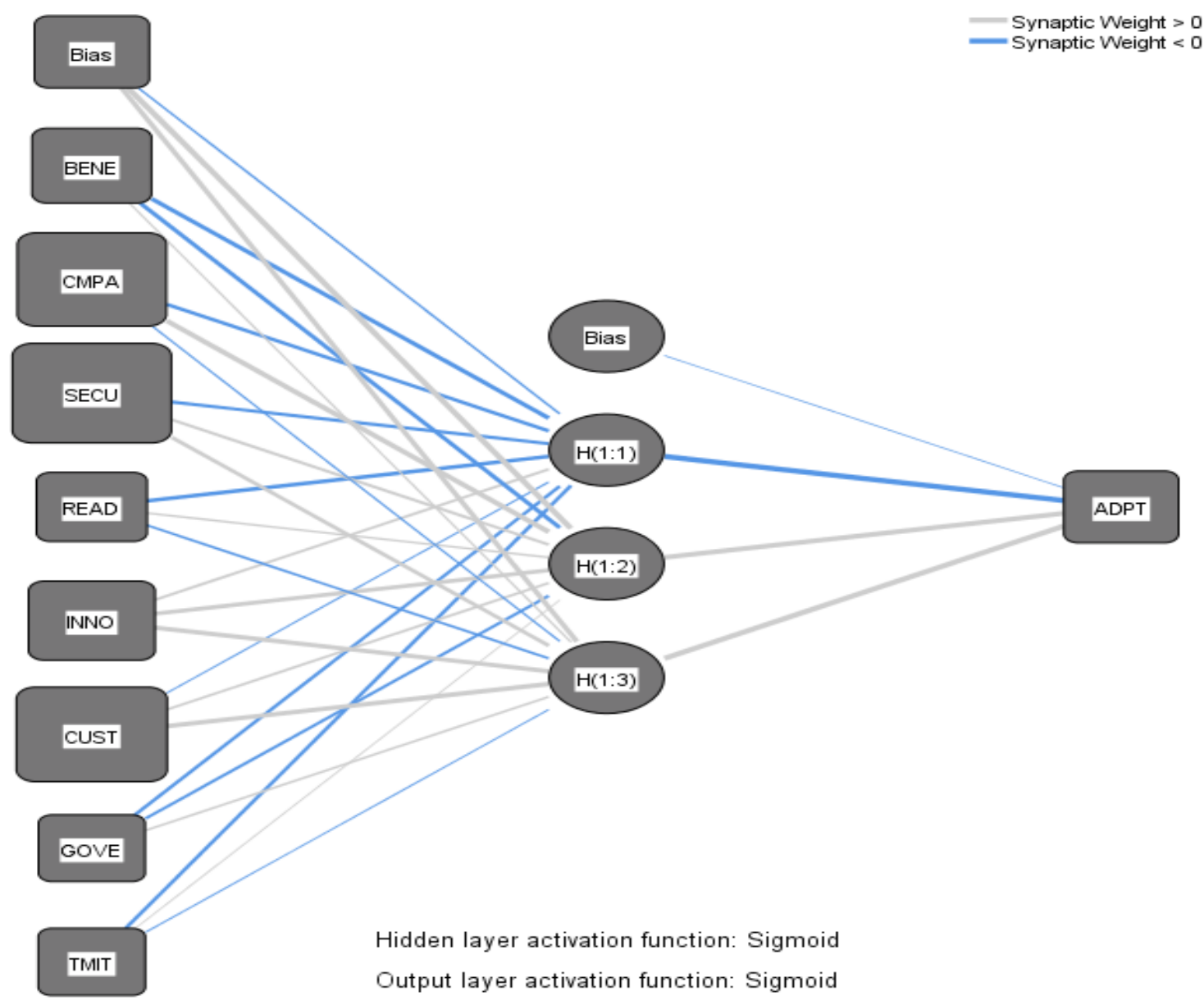

Note $:$ BENE = Perceived Benefits; $C M P A=$ Perceived Compatibility; SECU = Perceived Security; READ = Organizational Readiness; INNO = Organizational Innovativeness; $C U S T=$ Customer Pressures; GOVE = Government Support; TMIT = Managers' IT Knowledge; ADPT = Adoption

Figure 7.4 A neural network model used in this study

\subsubsection{Sensitivity Analysis}

A sensitivity analysis is carried out for evaluating the importance of specific input variables of the neural network. The importance of each input variable is reflected in its (a) relative importance value and (b) normalized importance value (Chong \& Bai 2014; Priyadarshinee et al. 2017). 
The relative importance value of an input variable is a measure of how much the predicted value of the network's model changes for different values of such a predictor variable (Chong et al. 2015). It is performed by averaging the importance values of such an input variable in predicting the output for the ten neural networks above (Chong \& Bai 2014; Chong et al. 2015).

The normalized importance value of an input variable is used for ranking its importance in predicting the output variable of the neural network (Chan \& Chong 2012; Sim et al. 2014). The normalized importance of a specific predictor variable is calculated by dividing its relative importance value by the largest relative importance value of all the predictor variables, expressed as a percentage (Ahani et al. 2017; Sharma 2019). Table 7.8 depicts the results of sensitivity analysis for all the predictor variables in the neural network. 
Table 7.8 Sensitivity analysis: normalized importance

\begin{tabular}{ccccccccc}
\hline $\begin{array}{c}\text { Artificial Neural } \\
\text { Networks }\end{array}$ & BENE & CMPA & SECU & READ & INNO & CUST & GOVE & TMIT \\
\hline 1 & 0.104 & 0.145 & 0.192 & 0.092 & 0.116 & 0.196 & 0.084 & 0.070 \\
\hline 2 & 0.101 & 0.189 & 0.161 & 0.095 & 0.103 & 0.188 & 0.100 & 0.063 \\
\hline 3 & 0.099 & 0.155 & 0.177 & 0.108 & 0.127 & 0.200 & 0.075 & 0.059 \\
\hline 4 & 0.151 & 0.235 & 0.138 & 0.002 & 0.145 & 0.184 & 0.028 & 0.118 \\
\hline 5 & 0.153 & 0.103 & 0.205 & 0.103 & 0.130 & 0.120 & 0.059 & 0.127 \\
\hline 6 & 0.084 & 0.156 & 0.192 & 0.085 & 0.135 & 0.163 & 0.088 & 0.096 \\
\hline 7 & 0.093 & 0.159 & 0.183 & 0.102 & 0.114 & 0.113 & 0.179 & 0.056 \\
\hline 9 & 0.103 & 0.158 & 0.168 & 0.083 & 0.137 & 0.178 & 0.075 & 0.097 \\
\hline 10 & 0.124 & 0.179 & 0.178 & 0.058 & 0.111 & 0.153 & 0.092 & 0.105 \\
\hline Mean importance & 0.112 & 0.159 & 0.178 & 0.085 & 0.122 & 0.167 & 0.088 & 0.089 \\
\hline Normalized & 62.9 & 89.5 & 100.0 & 48.0 & 69.0 & 93.9 & 49.8 & 50.3 \\
\hline importance (\%) & & & & & & & & \\
\hline
\end{tabular}

Table 7.9 presents a comparison of the normalized importance of all predictor variables between SEM and neural network results. As per the sensitivity analysis results, perceived security is stated as the most critical determinant for m-commerce adoption in Vietnamese SMEs. It is followed by customer pressures, perceived compatibility, organizational innovativeness, perceived benefits, managers' IT knowledge, government support, and organizational readiness. 
Table 7.9 Normalized importance comparison between SEM and neural network results

\begin{tabular}{lcccc}
\hline \multirow{2}{*}{ Critical Determinants } & \multicolumn{2}{c}{ Structural Model } & \multicolumn{2}{c}{ Neural Network Models } \\
\cline { 2 - 5 } & Path Coefficients & Ranking & Normalized Importance & Ranking \\
\hline Perceived Benefits & 0.159 & 6 & $62.9 \%$ & 5 \\
\hline Perceived Compatibility & 0.206 & 5 & $89.5 \%$ & 3 \\
\hline Perceived Security & 0.282 & 1 & $100.0 \%$ & 1 \\
\hline Organizational Readiness & 0.227 & 2 & $48.0 \%$ & 8 \\
\hline Organizational Innovativeness & 0.216 & 4 & $69.0 \%$ & 4 \\
\hline Customer Pressures & 0.226 & 3 & $93.9 \%$ & 2 \\
\hline Government Support & 0.132 & 8 & $49.8 \%$ & 7 \\
\hline Managers' IT Knowledge & 0.136 & 7 & $50.3 \%$ & 6 \\
\hline
\end{tabular}

\subsection{Discussion of the Findings}

This study investigates the critical determinants for m-commerce adoption in Vietnamese SMEs. The analytical results show that technological, organizational, environmental, and managerial factors significantly affect the decision to adopt mcommerce in Vietnamese SMEs. The results further confirm the controlling role of the organizational size with respect to the total registered capital for such adoption. These results are discussed in the following.

\subsubsection{Technological Determinants for M-Commerce Adoption}

The analytical results reveal the significant association between three technological determinants including perceived benefits, perceived compatibility, and perceived security and the decision to adopt $\mathrm{m}$-commerce. This indicates that greater perception of 
the benefits and compatibility, as well as the high level of confidence and awareness of $\mathrm{m}$-commerce security increases the intention to adopt $\mathrm{m}$-commerce in Vietnamese SMEs.

The positive influence of perceived benefits on technological innovation adoption in SMEs is confirmed in a wide range of literature such as e-commerce (Wilson, Daniel \& Davies 2008; Sim et al. 2014; Kurnia et al. 2015), e-business (Ifinedo 2011; Trang et al. 2016; Ilin et al. 2017), e-market (Duan et al. 2012), and m-commerce (Picoto et al. 2014b; Njenga et al. 2016; Alfahl et al. 2017). Wilson et al. (2008), for example, find that perceived benefits are positively related to the adoption of e-commerce in SMEs in the UK. Duan et al. (2012) confirm the positive relationship between perceived benefits and the adoption of e-market in Australian SMEs. Trang et al. (2016) find that perceived benefits positively influence e-business adoption in organizations in German. Alfahl et al. (2017) confirm a positive association between perceived benefits and the adoption of m-commerce in Saudi organizations. Such a finding of these studies further confirms that the higher the perceived benefits, the greater the intention to adopt $\mathrm{m}$ commerce in Vietnamese SMEs.

The positive influence of perceived compatibility on the decision to adopt m-commerce in Vietnamese SMEs is consistent with the notion that m-commerce is a complex technological innovation whose successful adoption is closely related to the higher perception of the compatibility (Mallat \& Tuunainen 2008; Alfahl et al. 2017). Mallat and Tuunainen (2008), for example, find that perceived compatibility is associated with the adoption of m-commerce in Finnish organizations. Alfahl et al. (2017) confirm the 
positive relationship between perceived compatibility and the adoption of $\mathrm{m}$-commerce in Saudi organizations. Such a finding implies that Vietnamese SMEs with a greater perception of the compatibility of m-commerce are more likely to adopt m-commerce for their online businesses.

The significant influence of perceived security on the decision to adopt $\mathrm{m}$-commerce in Vietnamese SMEs is in line with the notion that m-commerce is a complex technological innovation whose successful adoption is closely related to the high-level confidence of security (Mashagba et al. 2013; Lu et al. 2015; Njenga et al. 2016; Amegbe et al. 2017; Johnson et al. 2018). Mashagba et al. (2013), for example, find that perceived security has a significant direct effect on the intention to adopt m-commerce in Jordanian telecommunication organizations. Amegbe et al. (2017) confirm the association between security concerns and the adoption of m-commerce in small businesses in Ghana. Johnson et al. (2018) explore the positive influence of perceived security on the intention to adopt m-commerce in organizations in the USA. Such a finding implies that perceived security has an important role in the decision to adopt $\mathrm{m}$ commerce in SMEs.

The analytical results also show the insignificance of the perceived cost for the adoption of m-commerce in Vietnamese SMEs. This is in contrast to the findings of many previous studies confirming perceived cost is significant for $\mathrm{m}$-commerce adoption in SMEs (Mallat \& Tuunainen 2008; Hossain \& Khandanker 2011; Rana et al. 2019). This finding, however, is consistent with the studies of Al-Qirim (2007), Alam et al. (2011), 
and Rahayu and Day (2015), which confirm the insignificance of perceived cost for the adoption of e-commerce in SMEs.

There are several explanations for the insignificant influence of perceived cost on the adoption of m-commerce in Vietnamese SMEs. One possible explanation is that the rapid development of mobile technologies leads to a significant decrease in the acquisition cost of such technologies. As a result, these technologies are not expensive for SMEs. Another plausible reason is that m-commerce adoption brings tremendous benefits to SMEs such as improving productivity, reducing operating cost, and enhancing customer services. Such benefits of m-commerce adoption may outweigh the resource investment required to adopt it as perceived. As a result, adoption cost may not a critical factor for Vietnamese SMEs to adopt m-commerce. Furthermore, SMEs would effectively optimize their limited resources for adopting m-commerce to serve their strategic objectives.

\subsubsection{Organizational Determinants for M-Commerce Adoption}

The analytical results reveal the significant association between two organizational determinants including organizational readiness and organizational innovativeness and the decision to adopt m-commerce. The significance of organizational readiness for technological innovations adoption has been confirmed in various organizational information systems adoption studies such as e-commerce, e-business, and m-commerce (Doolin \& Ali 2008; Jain et al. 2011; Otieno \& Kahonge 2014; Yeh, Lee \& Pai 2015; Lim, Baharudin \& Low 2016; Trang et al. 2016). Doolin and Ali (2008), for example, find that organizational readiness has a positive influence on the adoption of $\mathrm{m}$ - 
commerce in organizations in New Zealand. Yeh et al. (2015) confirm that organizational readiness is a critical determinant for the adoption of e-business in organizations in Taiwan. Lim et al. (2016) find out a positive association between organizational readiness and the adoption of e-commerce in SMEs in Malaysia.

Such a finding implies that a high level of organizational readiness increases the intention to adopt m-commerce by SMEs. This is because SMEs tend to lack resources for m-commerce adoption. Such a lack of financial, technological, and human resources becomes the barrier to their adoption of m-commerce. As a result, increasing their readiness for these resources enhances the intention to adopt $\mathrm{m}$-commerce in Vietnamese SMEs.

The significance of organizational innovativeness for technological innovations adoption in organizations has been confirmed in numerous previous studies (Theodosiou \& Katsikea 2012; Ghobakhloo \& Tang 2013; Martin \& Jimenez 2015; Njenga et al. 2016). Theodosiou and Katsikea (2012), for example, find that organizational innovativeness has a positive influence on the intention to adopt ebusiness in hotel sectors in Greece and Cyprus. Ghobakhloo and Tang (2013) confirm that the greater the level of organizational innovativeness, the more likely e-commerce is adopted in Iranian small businesses. Martin and Jimenez (2015) indicate a positive association between organizational innovativeness and the adoption of $\mathrm{m}$-commerce in organizations in Spain. Njenga et al. (2016) find that organizational innovativeness positively influences the adoption of organizational m-commerce. 
Such a finding implies that innovation-oriented organizations are more likely to adopt $\mathrm{m}$-commerce than non-innovative organizations. This is because the top priority of innovative organizations is to make significant resource commitments to adopting technologies. SMEs tend to be early innovation adopters because of their close attention to emerging technologies and business practices in the external markets (Wang \& Cheung 2004). As a result, the more innovative of Vietnamese SMEs, the more successful adoption of $\mathrm{m}$-commerce for their online businesses.

The results also show the insignificance of employees' IT knowledge for the adoption of m-commerce in Vietnamese SMEs. This is inconsistent with the finding of many previous m-commerce adoption studies (Balocco et al. 2009; Jain et al. 2011; Rana et al. 2019). However, this finding is consistent with the studies of Jeon et al. (2006) and Ilin et al. (2017) that confirm employees' IT knowledge as a non-statistically significant predictor of e-business adoption in SMEs.

Such a finding means that employees' IT knowledge and internal IS expertise are not a challenge for Vietnamese SMEs in adopting m-commerce. One plausible explanation is that m-commerce is an extension of e-commerce. SMEs that have successfully implemented e-commerce in their business will have a good preparation for enough qualified IT staff and expertise. As a result, they find employees' IT knowledge is not an inhibitor when deciding to adopt m-commerce. 


\subsubsection{Environmental Determinants for M-Commerce Adoption}

The analytical results reveal the significant association between two environmental determinants including customer pressures and government support and the decision to adopt $\mathrm{m}$-commerce. The pressures from customers have been found as a significant driver for the adoption of various technological innovations in organizations (Huy et al. 2012; Otieno \& Kahonge 2014; Chatzoglou \& Chatzoudes 2016; Li \& Wang 2018). Huy et al. (2012), for example, find that customer pressures are positively related to the adoption of e-commerce in Vietnamese SMEs. Otieno and Kahonge (2014) confirm the positive association between customer pressures and the adoption of $\mathrm{m}$-commerce in Kenyan SMEs. Chatzoglou and Chatzoudes (2016) indicate that customer pressures positively influence the adoption of e-business in SMEs in Greece. Li and Wang (2018) find that the pressures from customers positively affect the adoption of m-commerce adoption in SMEs in China.

Such a finding implies that the adoption of technological innovations is not only the result of a rational assessment of the business implication of new technologies but also a response to satisfy external pressures, especially the pressures from customers. As customers' sophistication regarding mobile internet usage is increasingly enhanced, organizations must offer them a unique m-commerce experience to meet their expectations and to satisfy their needs at every stage of the buying process (Theodosiou $\&$ Katsikea 2012). As a result, the higher the pressures from customers, the more likely Vietnamese SMEs adopt m-commerce to meet the requirements and expectations of their customers, to maintain the relationship with their customers, and to show their fitness as a business partner. 
This study finds that government support has a significant positive effect on the decision to adopt m-commerce in Vietnamese SMEs. This is consistent with the findings of previous studies in e-commerce adoption (Huy et al. 2012; Al-Somali, Gholami \& Clegg 2015; Miao \& Tran 2018), e-business adoption (Jeon et al. 2006; Chatzoglou \& Chatzoudes 2016; Trang et al. 2016; Ilin et al. 2017), and m-commerce adoption (Alrawabdeh 2014; Lu et al. 2015; Alfahl et al. 2017; Li \& Wang 2018). Huy et al. (2012), for example, find that government support is a driver for the adoption of ecommerce in Vietnamese SMEs. Ilin et al. (2017) confirm that government resource support and government regulatory support positively affect the adoption of e-business in organizations in the Western Balkan Peninsula. Li and Wang (2018) indicate that government support is a critical determinant for $\mathrm{m}$-commerce adoption in Chinese SMEs.

Such a finding means that the support from the government increases the likelihood of SMEs to adopt m-commerce. With support from the government in terms of legal consideration, financial support, as well as training and education programs for $\mathrm{m}$ commerce, SMEs seem to be willing to make the transition to m-commerce. As a result, the higher level of government support, the more likely m-commerce is adopted in Vietnamese SMEs.

This study also shows that competitive pressures are not significant for the adoption of m-commerce in Vietnamese SMEs. This finding is inconsistent with the finding of many previous m-commerce adoption studies (Picoto et al. 2014a, 2014b; Lu et al. 2015; Martin \& Jimenez 2015). However, this finding is in line with the study of 
Swilley (2007) and Martin et al. (2012) that find the pressures from competitors are not significant for the adoption of m-commerce in organizations in the US and Spain respectively.

The insignificant of competitive pressures for the adoption of $\mathrm{m}$-commerce in Vietnamese SMEs can be explained that m-commerce is still in its early stages in Vietnam and not widely adopted by Vietnamese SMEs. As a result, the degree of competitive pressures perceived by SMEs has not significantly affected the adoption of m-commerce. This means that Vietnamese SMEs find other factors than competitive pressures as more important for the adoption of m-commerce.

\subsubsection{Managerial Determinants for M-Commerce Adoption}

The study reveals a significant association between managers' IT knowledge and the decision to adopt m-commerce in Vietnamese SMEs. Such a finding is consistent with the previous finding of technological innovations adoption in organizations studies such as e-commerce (Sam \& Eam 2011; Ghobakhloo \& Tang 2013; Rahayu \& Day 2015), ebusiness (Jeon et al. 2006), and enterprise systems (Ramdani et al. 2009). Jeon et al. (2006), for example, confirm that managers' IT knowledge is a critical determinant for e-business adoption in Korean SMEs. Ramdani et al. (2009) find that managers' IT knowledge and experience significantly affect the adoption of enterprise systems in SMEs in the Northwest of England. Ghobakhloo and Tang (2013) confirm that the greater the level of managers' IS and computer knowledge, the more likely e-commerce is adopted by Iranian small businesses. 
Such a finding implies that an SME which has a more IT/m-commerce knowledgeable managers has a higher probability of successfully adopting m-commerce. For the successful adoption of m-commerce, SMEs need managers who are knowledgeable about IT and m-commerce. As SMEs face significant risks with their adoption of technological innovations regarding their inadequate IT knowledge, greater knowledge of managers reduces the degree of such uncertainties, resulting in a lower risk of adoption (Ghobakhloo \& Tang 2013).

This study shows that top management support is insignificant for the adoption of $\mathrm{m}$ commerce in Vietnamese SMEs. This finding contradicts the findings of many previous m-commerce adoption studies that confirm the role of top management support and its positive relationship with the adoption of m-commerce (Doolin \& Ali 2008; Otieno \& Kahonge 2014; Alfahl et al. 2017; Li \& Wang 2018). This finding, however, is in line with the studies of Seyal et al. (2004) and Salwani et al. (2009) that find top management support is insignificant for the adoption of e-commerce in SMEs in Pakistan and Malaysia respectively.

There are several explanations for the insignificant influence of top management support on the adoption of m-commerce in Vietnamese SMEs. One possible explanation is that the top management of these SMEs has faced other external environmental factors that have contributed to such an adoption indirectly (Seyal et al. 2004). Another plausible explanation is that m-commerce adoption is not a priority in SMEs, but rather meeting the needs of their business partners (Salwani et al. 2009). 


\subsubsection{Ranking of the Critical Determinants for M-Commerce Adoption}

The ranking of the m-commerce adoption determinants is achieved by detecting the normalized variable importance through the neural network analysis. Among the eight significant determinants, the most important determinant is perceived security with the normalized importance of $100 \%$. It is followed by customer pressures (93.9\%), perceived compatibility $(89.5 \%)$, organizational innovativeness $(69.0 \%)$, perceived benefits $(62.9 \%)$, managers' IT knowledge (50.3\%), government support (49.8\%), and organizational readiness $(48.0 \%)$. Table 7.10 presents a summary of these results.

Table 7.10 The ranking of the critical determinants for m-commerce adoption

\begin{tabular}{llc}
\hline \multicolumn{1}{c}{ Critical Determinants } & Normalized Importance & Ranking \\
\hline Perceived Security & $100.0 \%$ & 1 \\
\hline Customer Pressures & $93.9 \%$ & 2 \\
\hline Perceived Compatibility & $89.5 \%$ & 3 \\
\hline Organizational Innovativeness & $69.0 \%$ & 4 \\
\hline Perceived Benefits & $62.9 \%$ & 5 \\
\hline Managers' IT Knowledge & $50.3 \%$ & 6 \\
\hline Government Support & $49.8 \%$ & 7 \\
\hline Organizational Readiness & $48.0 \%$ & 8 \\
\hline
\end{tabular}

The results show that the most critical determinant of m-commerce adoption is the perceived security of m-commerce. This result is estimated as m-commerce transactions are mainly conducted via the internet using mobile devices. The greater perception of security is critical for the successful adoption of m-commerce in Vietnamese SMEs. The study finding on perceived security is consistent with the previous studies which 
find that perceived security is a significant factor for the adoption of $\mathrm{m}$-commerce in organizations (Snowden et al. 2006; Mashagba et al. 2013; Lu et al. 2015; Njenga et al. 2016; Amegbe et al. 2017; Johnson et al. 2018).

The second most important determinant is customer pressures. This finding is consistent with past studies that report that the pressures from customers are a significant factor for the adoption of m-commerce in organizations (Doolin \& Ali 2008; Alrawabdeh 2014; Picoto et al. 2014a, 2014b; Li \& Wang 2018). Moreover, past research indicates that organizations tend to adopt m-commerce to show their fitness as a business partner, as well as to keep the relationships with their customers (Otieno \& Kahonge 2014; Lu et al. 2015; Chau et al. 2020). It could be concluded that perceived security and customer pressures are the leading critical determinants for m-commerce adoption. These determinants should be considered more by SMEs.

\subsection{Concluding Remarks}

The purpose of this chapter is to investigate the critical determinants for m-commerce adoption in Vietnamese SMEs. The findings of this chapter provide an answer to the second research question: What are the critical determinants for the adoption of $m$ commerce in Vietnamese SMEs? This is done by testing and validating the proposed conceptual framework with the use of a two-stage analytical approach of combining SEM and artificial neural networks on the survey data collected from 513 managers of selected Vietnamese SMEs. The GOF statistics of the final measurement model is assessed. The results exemplify a good match between the final measurement model and 
the survey data. The final measurement model is, therefore, suitable to proceed with the hypothesis testing.

The hypotheses testing for this research is performed via structural model analysis. Based on the significance values of the relationships among constructs, the hypotheses are accepted or rejected. The results of the structural model analysis indicate that perceived benefits, perceived compatibility, perceived security, organizational readiness, organizational innovativeness, customer pressures, government support, and managers' IT knowledge are the critical determinants for the adoption of m-commerce in Vietnamese SMEs. The results further confirm the control role of the organizational size in terms of the total registered capital for the adoption of $\mathrm{m}$-commerce in Vietnamese SMEs.

The significant variables from the SEM analysis are used as the inputs for neural network analysis. The networks with three hidden nodes are found as the most effective for this study. The relative importance of each determinant is evaluated using sensitivity analysis. The results of neural network analysis show that perceived security is the most significant determinant for the adoption of $\mathrm{m}$-commerce in Vietnamese SMEs. It is followed by customer pressures, perceived compatibility, organizational innovativeness, perceived benefits, managers' IT knowledge, government support, and organizational readiness.

A discussion on such the above findings is presented. Such findings provide valuable insights for better understanding the critical determinants for m-commerce adoption in 
Vietnamese SMEs. The theoretical and managerial implications of the results, as well as the limitations and implications for future research, will be discussed in Chapter 8 . 


\section{Chapter 8}

\section{Conclusion}

\subsection{Introduction}

The objective of this study is to investigate the critical determinants for m-commerce adoption in Vietnamese SMEs. Specifically, this study aims to achieve two main objectives. The first objective is to identify the emerging pattern of the adoption of $\mathrm{m}$ commerce in Vietnamese SMEs. The second objective is to explore the critical determinants for the adoption of m-commerce in Vietnamese SMEs.

To achieve these objectives, this study formulates the main research question as follows:

What can be done for improving the adoption of m-commerce in Vietnamese SMEs?

To answer the main research question, two secondary research questions are developed as follows:

(1) What are the current patterns of the adoption of m-commerce in Vietnamese SMEs? 
(2) What are the critical determinants for m-commerce adoption in Vietnamese SMEs?

To adequately answer the research question above, a quantitative research methodology is adopted in this study. This leads to the development of a conceptual framework for better understanding the adoption of m-commerce in Vietnamese SMEs. Such a framework is then tested and validated with the use of SEM on the survey data collected from the managers of SMEs in Vietnam. This leads to the identification of the critical determinants for m-commerce adoption in Vietnamese SMEs. Such critical determinants are then evaluated for identifying their relative importance for $\mathrm{m}$ commerce adoption in Vietnamese SMEs with the employment of the neural network analysis.

This chapter summarizes the research findings of the study as well as their contributions and implications to organizational m-commerce adoption research and practices. It discusses the limitation of the study and elaborates on several future research directions in this area.

In what follows, Section 8.2 presents a summary of the research findings of this study. Section 8.3 states the contribution of this study to the field of the m-commerce literature. Section 8.4 discusses the implications of the findings. Section 8.5 discusses the limitation of this study and suggests possible future research directions in related areas. 


\subsection{Summary of the Research Findings}

M-commerce is becoming a cost-effective way for Vietnamese businesses, especially SMEs to improve their competitiveness in the marketplace (Mallat \& Tuunainen 2008; Ullah \& Khan 2012; Njenga et al. 2016; Alfahl et al. 2017). It is, however, not widely adopted in Vietnamese SMEs, featured by a relatively low adoption rate (VECITA 2017; Chau \& Deng 2018a; Chau et al. 2020). Several studies investigating the adoption of internet-based commerce adoption, such as e-commerce adoption in Vietnamese SMEs support this observation (Huy \& Filiatrault 2006; Pham et al. 2011; Huy et al. 2012).

This study further reinforces such an observation on the unsatisfactory adoption of mcommerce in Vietnamese SMEs by surveying the managers of SMEs in Vietnam. The study shows that only $30.6 \%$ of the surveyed SMEs have adopted m-commerce. Furthermore, $54.2 \%$ of these $\mathrm{m}$-commerce non-adopters do not have a plan to adopt $\mathrm{m}$ commerce in the near future. Such results demonstrate that the potential benefits of mcommerce have not fully utilized by Vietnamese SMEs.

This study provides a comprehensive understanding of the organizational m-commerce adoption in Vietnamese SMEs for their successful adoption of m-commerce. Such an understanding includes (a) the emerging patterns for the adoption of m-commerce in Vietnamese SMEs and (b) the critical determinants for the adoption of m-commerce in Vietnamese SMEs. These research findings are summarized in the following. 


\subsubsection{Emerging Patterns for M-Commerce Adoption}

This study has examined the emerging pattern of m-commerce adoption in Vietnamese SMEs from three perspectives including (a) the overall adoption, (b) the size-based adoption, and (c) the industry-based adoption.

The overall m-commerce adoption pattern in Vietnamese SMEs reveals that the $\mathrm{m}$ commerce adoption rate in Vietnamese SMEs is still quite low. The study shows that less than half of the surveyed SMEs (48.9\%) have built a website for their business. Furthermore, the majority of these SMEs only use the website for displaying company information and for promoting their products and services, which accounted for $73.3 \%$ and $84.9 \%$ respectively. Only $39.4 \%$ of these SMEs use websites for conducting online transactions. The study further reveals that only $30.6 \%$ of the surveyed SMEs have been conducting their selling activities with the use of m-commerce. $69.4 \%$ of them have not adopted m-commerce. Overall, m-commerce is not widely adopted in Vietnamese SMEs.

The size-based m-commerce adoption with respect to the number of permanent employees has been investigated in this study. The study shows that the adoption of mcommerce in Vietnamese SMEs does not differ much in terms of the number of permanent employees. SMEs with 101 to 200 employees have the highest m-commerce adoption rate that is $43.33 \%$. They are followed by SMEs with 51 to 100 employees that have an adoption rate of $40.35 \%$. SMEs with 201 to 300 employees have an adoption rate of $31.25 \%$. Such an adoption rate is at $30.35 \%$ for SMEs with 10 to 50 employees. SMEs with less than 10 employees have the lowest adoption rate at $25.91 \%$. 
The size-based m-commerce adoption with respect to the total registered capital has been explored in this study. The study reveals that there is a clear gap in the adoption of $\mathrm{m}$-commerce in Vietnamese SMEs in terms of the total registered capital, expressed in VND billion. The highest adoption rate is at $58.82 \%$ in SMEs with total registered capital from 20 to 50 billion VND. It is followed by a rate of $39.51 \%$ in SMEs with total registered capital from 50 to 100 billion VND and 33.54\% in SMEs with total registered capital from 10 to 20 billion VND. The lowest adoption rate is at $21.37 \%$ in SMEs with total registered capital less than 10 billion VND.

Industry-based m-commerce adoption has been examined in this study. The study indicates that there is a clear gap in the adoption of m-commerce across different industries of Vietnamese SMEs. Industries with high information dependence and low information tacitness have the highest probability of success in the adoption of $\mathrm{m}$ commerce for their business. These industries include the service industry, the finance and insurance industry, and the transportation industry. The promotion of m-commerce adoption in such industries by Vietnamese government departments or m-commerce operators is more likely to be successful. This is because such industries receive more benefits from adopting m-commerce than other industries (Rosenzweig et al. 2011).

The study shows that industries with high information dependence and high information tacitness are less likely to adopt m-commerce. These industries include the trading industry, the healthcare industry, the construction industry, and the ICT industry. The value-added activities in such industries are based on non-standardized information, 
such as verbal negotiation with their trading partners. As a result, m-commerce is less effective in transferring such information (Rosenzweig et al. 2011).

The study also reveals that industries with low information dependence and low information tacitness are less likely to adopt m-commerce. These industries include the manufacturing industry. The value-added activities in this industry are material based. As a result, it is not easy to conduct the exchange of such activities with the use of mcommerce. M-commerce is, therefore, less effective in assisting businesses in such an industry (Rosenzweig et al. 2011).

\subsubsection{Critical Determinants for M-Commerce Adoption}

This study has developed an integrated conceptual framework based on an intensive review of the related literature for investigating the critical determinants for $\mathrm{m}$ commerce adoption in Vietnamese SMEs. Such a framework is conceptualized from the combination of the DOI theory and the TOE framework. The perceived security and the perceived cost are added for extending DOI. The managerial context is included for extending TOE. Such a framework is then tested and validated using a two-stage analytical approach by combining SEM and artificial neural networks on the survey data collected from the managers of SMEs in Vietnam.

The study reveals positive relationships between perceived benefits, perceived compatibility, perceived security, organizational readiness, organizational innovativeness, customer pressures, government support, and managers' IT knowledge and the decision to adopt m-commerce in Vietnamese SMEs. Perceived cost, 
employees' IT knowledge, competitive pressures, and top management support, however, are found to be insignificant in relation to the adoption of $\mathrm{m}$-commerce in Vietnamese SMEs. Furthermore, the organizational size in terms of the total registered capital is found to be a significant control variable for the adoption of $\mathrm{m}$-commerce in Vietnamese SMEs.

The significance of perceived benefits to the adoption of $\mathrm{m}$-commerce indicates that $\mathrm{m}$ commerce is considered as a means for gaining benefits such as creating marketing channels, improving the organizational image, improving the organizational competitiveness, and enhancing customer services. When m-commerce is perceived beneficial to SMEs, its adoption is more likely (Alam et al. 2011). Such a finding suggests that promoting the benefits of m-commerce to Vietnamese SMEs leads to their wide adoption of m-commerce.

The significance of perceived compatibility to the adoption of m-commerce reveals that $\mathrm{m}$-commerce is more likely to be adopted in Vietnamese SMEs when there is a greater perception of m-commerce compatibility. Adopting m-commerce in SMEs require significant organizational and structural changes, as well as changes in existing work practices and organizational culture (Nguyen 2009). As a result, the perception of mcommerce compatibility including the alignment with the current ICT infrastructure, the integration with current business processes, the adaptability of existing distribution channels, and the consistency with the organizational culture significantly affect the adoption of m-commerce in SMEs. Such a finding suggests that managers of 
Vietnamese SMEs decide on the adoption of m-commerce, particularly when they perceive it compatible with their businesses.

The significance of perceived security to the adoption of m-commerce highlights the importance of the awareness of Vietnamese SMEs about the security concerns for ensuring the successful adoption of m-commerce. The security concerns of $\mathrm{m}$ commerce include the awareness of the security of m-commerce, the availability of industry standards for the security of m-commerce, and the availability of laws and regulations for m-commerce. Such a finding suggests that the more secure and trustworthy of the m-commerce environment perceived by the managers of Vietnamese SMEs, the more successful of $\mathrm{m}$-commerce adoption for their businesses.

The significance of organizational readiness to the adoption of m-commerce reveals that $\mathrm{m}$-commerce is more likely to be adopted in Vietnamese SMEs when they possess adequate financial, technological, and human resources. SMEs usually suffer from resource insufficiency. They have to primarily rely on internal financial, technological, and human capital to maintain business operations as well as to adopt technologies for their businesses (Wang \& Ahmed 2009). Such a finding, therefore, suggests that the higher level of organizational readiness is associated with the increased intention to adopt m-commerce by SMEs in Vietnam.

The significance of organizational innovativeness to the adoption of m-commerce indicates that Vietnamese SMEs with the innovativeness ability, the ability to adopt new management approach, and the ability to continuously improve business processes are 
more likely to adopt m-commerce for their businesses. M-commerce adoption in SMEs in developing countries is expected to be riskier compared to developed countries. This is due to the lack of cyber law and regulations and limited ICT support (Molla \& Licker 2005b; Tan et al. 2009). As a result, innovative SMEs would be expected to apply such a risky solution (Ghobakhloo \& Tang 2013). They would be, therefore, more willing to adopt $\mathrm{m}$-commerce for their businesses.

The significance of customer pressures to the adoption of m-commerce reveals that Vietnamese SMEs are more prone to adopt m-commerce to meet the requirement and expectations of their customers, as well as to maintain the relationship with their customers. SMEs tend to innovate when they come under pressures from customers to show their fitness as business partners (Al-Bakri \& Katsioloudes 2015; Chatzoglou \& Chatzoudes 2016). Such a finding suggests that increased external pressures from customers stimulate the adoption of m-commerce in Vietnamese SMEs.

The significance of government support to the adoption of m-commerce highlights that the higher level of the support from the government, the more likely the adoption of mcommerce in Vietnamese SMEs. SMEs encounter the scarcity of resources, especially in financial resources and knowledge. As a result, the incentives from the government such as training workshops, cyber laws, and financial aids, will promote the adoption of m-commerce in SMEs (Lim et al. 2016). Such a finding suggests that the greater the government incentives are as perceived by the managers of Vietnamese SMEs, the higher the likelihood of $\mathrm{m}$-commerce adoption for their businesses. 
The significance of managers' IT knowledge to the adoption of m-commerce reveals that the IT skill and knowledge of the managers can facilitate the adoption of $\mathrm{m}$ commerce in Vietnamese SMEs. SMEs face problems with their computerization as a result of inadequate IT knowledge (Ghobakhloo \& Tang 2013). As a result, SMEs with greater IT knowledge managers can reduce the uncertainty of m-commerce adoption. They are, therefore, more willing to adopt m-commerce for their businesses.

\subsection{Research Contributions}

The major contribution of this study is the extension of existing IS adoption literature to the context of organizational m-commerce. Such an extension enhances the understanding of m-commerce adoption in SMEs, particularly SMEs in developing countries. The study evaluates the influence of the critical determinants on the adoption of m-commerce in SMEs.

This study extends the DOI theory and the TOE framework for investigating the adoption of m-commerce in SMEs in developing countries. It confirms the appropriateness of combining the DOI theory and the TOE framework for investigating the adoption of technological innovations in organizations. This provides a more holistic view of the organizational perspective on m-commerce adoption. Integrating the constructs of DOI and TOE into a single framework offers a richer theoretical basis for explaining the organizational $\mathrm{m}$-commerce adoption. The findings empirically support the DOI theory by suggesting perceived benefits and perceived compatibility of $\mathrm{m}$ commerce as the critical determinants of the adoption. In addition, the DOI theory is 
expanded to include perceived security and perceived cost which is tested and proven to be valid and reliable

This study further considers the managerial factors as an additional dimension of the TOE framework for examining the adoption of $\mathrm{m}$-commerce in SMEs. This is an important contribution to the existing literature in organizational m-commerce adoption. This is because managerial factors have often been ignored in prior research on organizational m-commerce adoption. It is confirmed that the adoption of m-commerce in SMEs is not primarily influenced by the perceived characteristics of mobile technologies, but also affected by other determinants related to the internal organization and the external business environments and the characteristics of SMEs' managers. As a result, this study contributes to the existing knowledge by filling the current literature gap on the important role of managerial factors in the adoption of m-commerce in SMEs in developing countries.

The employment of a multiple-analytic approach using SEM and neural networks in this study provides a significant methodological contribution to the area of technology adoption in organizations. The non-compensatory neural network analysis can balance the flaws of the compensatory SEM analysis (Priyadarshinee et al. 2017). This provides a new perspective on examining organizational m-commerce adoption with a multimethod technique. Such a technique facilitates the addressing of the aforementioned gap in IS literature in general and in organizational technology adoption literature in particular. 


\subsection{Research Implications}

This study presents an attempt to examine an integrated framework of m-commerce adoption in Vietnamese SMEs that is theoretically grounded from the combination of DOI and TOE. Such a framework is empirically tested against the data collected from 513 SMEs in Vietnam using SEM and artificial neural networks. The significant findings of this study have a number of important implications that might assist SMEs' managers, government departments, policy-makers, and technology vendors in facilitating the adoption of m-commerce in SMEs in Vietnam.

\subsubsection{Implications for SMEs' Owners and Managers}

This study attempts to help the owners and managers of SMEs recognize that adopting $\mathrm{m}$-commerce is more of an adaptive than a technical challenge. Its findings can enhance the understanding of the importance of the critical determinants for the adoption of mcommerce.

The findings imply that the owners and managers of SMEs need to understand the potential benefits of $\mathrm{m}$-commerce by learning from the experience of other adopting SMEs and access better education programs provided by industry associations and government. In addition, it is important for SMEs to perceive security issues, not as barriers to the adoption of m-commerce.

The findings further imply that SMEs that intend to adopt m-commerce need to have adequate financial, technological, and human resources. As a result, it is important for 
SMEs' owners and managers to develop strategies for evaluating the availability of existing and required resources for m-commerce adoption. Moreover, an innovative culture within organizations needs to be developed for fostering m-commerce adoption.

The findings also suggest that increasing the external pressures from customers and the support from the government tend to stimulate the adoption of m-commerce. This implies that SMEs should be aware of what their customers want through m-commerce adoption. Finally, the findings suggest that it is important for SMEs' managers to recognize government support for m-commerce adoption.

\subsubsection{Implications for Government and Policy-Makers}

The government is becoming increasingly crucial for the growth of SMEs in the fierce competition of the global business environment. As a result, government support becomes critical in overcoming the challenges associated with the adoption of $\mathrm{m}$ commerce in SMEs.

This study highlights the importance of perceived benefits, perceived compatibility, and perceived security in m-commerce adoption. As a result, government agencies should create better awareness of the benefits of $\mathrm{m}$-commerce to encourage $\mathrm{m}$-commerce adoption. This implies that more seminars and workshops for SMEs' owners and managers should be conducted to show how m-commerce adoption helps with strategic decision making. The government needs to help SMEs build and maintain their internal organizational resources, structures, and governance to fit well with m-commerce technologies. Furthermore, governments should focus their support activities on 
lowering perceived security issues of m-commerce within SMEs by providing more secure and trustworthy e-environments.

The significance of organizational readiness implies that the government should provide SMEs with financial and technological support, as well as other forms of assistance to facilitate the adoption of m-commerce. Furthermore, the study highlights the importance of IT and m-commerce knowledge of SMEs' managers for the adoption of m-commerce. As a result, governmental agencies can play a significant role in promoting the adoption of $\mathrm{m}$-commerce by providing training programs and workshops particularly designed for improving the IT and m-commerce knowledge for owners and managers of SMEs.

\subsubsection{Implications for Technology and M-Commerce Vendors}

Technology and m-commerce vendors are mediating agents in facilitating the adoption of m-commerce in SMEs. As a result, the critical determinants for m-commerce adoption in SMEs must be understood to enable them to design strategies for addressing the technological glitches hindering the adoption of m-commerce. To enhance the adoption of m-commerce, $\mathrm{m}$-commerce vendors are advised to target their products and services at SMEs with innovative business environments having positive attitudes toward the benefits of m-commerce adoption. They are advised to cooperate with SMEs to jointly improve the compatibility of m-commerce by reassuring SMEs that mcommerce could integrate with their existing practices. 


\subsection{Research Limitations and Future Directions}

The findings of this study should be interpreted in light of its limitations. This study only focuses on the adoption of m-commerce in SMEs in Vietnam as the study context. This affects the applicability of the findings across developing countries. As a result, similar research in other developing countries would provide data for comparison.

This study adopts a quantitative methodology for investigating the critical determinants for the adoption of m-commerce in Vietnamese SMEs. The adoption of other methodologies for deeply investigating the findings of this research is needed. Such a need arises because this is the first study investigating the critical determinants in SMEs in Vietnam. Future research could seek to explain why technological factors, organizational factors, environmental factors, and managerial factors influence the adoption of m-commerce with the employment of other research methodologies.

This study examines m-commerce adoption through cross-sectional survey data, which does not permit the interpretation of causal inferences between constructs. As the diffusion of innovations is a socialization process in which attitudes to the desirability of behaviors develop over time, a longitudinal study would be appropriate to see how perceptions change over time.

This study conducts a survey with the collection of single responses from each organization, which are the manager of the surveyed SMEs. As a result, the lack of further respondents from the same organization exists and does not allow evaluating the perspectives of the entire group. This makes the results susceptible to the method bias. 
Future studies could apply multiple informant technique by focusing on both managers and employees of SMEs. This can significantly alleviate the possibility of method bias. Furthermore, assessing the perception of employees would allow for examining the influence of employees-related determinants of m-commerce adoption, which provides more predictive power for the study.

The target population for data collection in this study is SMEs in the Vietnamese market that includes both the adopters and non-adopters. As a result, the differences in their perception of the critical determinants could create a bias for the empirical results. A comparative study on the critical determinants for m-commerce adoption in SMEs between adopters and non-adopters could be conducted in the future to have appropriate suggestions for SMEs' managers and policy-makers in their formulation of specific strategies and policies to facilitate the diffusion of m-commerce in SMEs.

Additional factors may influence m-commerce adoption in developing countries such as culture and industrial support that are not explicitly included. Future studies examining the influence of these factors would, therefore, complement and enrich the findings of this study. 


\section{References}

Abdullah, N. H., Wahab, E. \& Shamsuddin, A. (2013), 'Exploring the common technology adoption enablers among Malaysian SMEs: Qualitative findings', Journal of Management \& Sustainability, vol. 3, no. 4, pp. 78-91.

Abubakar, A. M., Namin, B. H., Harazneh, I., Arasli, H. \& Tunç, T. (2017), 'Does gender moderates the relationship between favoritism/nepotism, supervisor incivility, cynicism and workplace withdrawal: A neural network and SEM approach', Tourism Management Perspectives, vol. 23, no. 2017, pp. 129-139.

Ahani, A., Rahim, N. Z. A. \& Nilashi, M. (2017), 'Forecasting social CRM adoption in SMEs: A combined SEM-neural network method', Computers in Human Behavior, vol. 75, no. 2017, pp. 560-578.

Ahmad, S. Z., Abu Bakar, A. R., Faziharudean, T. M. \& Mohamad Zaki, K. A. (2015), 'An empirical study of factors affecting e-commerce adoption among small and medium-sized enterprises in a developing country: Evidence from Malaysia', Information Technology for Development, vol. 21, no. 4, pp. 555-572.

Ajzen, I. (1991), 'The theory of planned behavior', Organizational Behavior and Human Decision Processes, vol. 50, no. 2, pp. 179-211.

Al-Alawi, A. I. \& Al-Ali, F. M. (2015), 'Factors affecting e-commerce adoption in SMEs in the GCC: An empirical study of Kuwait', Research Journal of Information Technology, vol. 7, no. 1 , pp. 1-21.

Al-Bakri, A. A. \& Katsioloudes, M. I. (2015), 'The factors affecting e-commerce adoption by Jordanian SMEs', Management Research Review, vol. 38, no. 7, pp. 726-749.

Al-Qirim, N. A. Y. (2006), 'Mobile commerce technologies penetration in small to mediumsized enterprises in New Zealand', Proceedings of the International Conference Innovations in Information Technology, Dubai, United Arab Emirates, November 19-21, pp. 1-5. 
Al-Qirim, N. A. Y. (2007), 'The adoption of eCommerce communications and applications technologies in small businesses in New Zealand', Electronic Commerce Research and Applications, vol. 6, no. 4, pp. 462-473.

Al-Somali, S. A., Gholami, R. \& Clegg, B. (2015), 'A stage-oriented model (SOM) for ecommerce adoption: a study of Saudi Arabian organizations', Journal of Manufacturing Technology Management, vol. 26, no. 1, pp. 2-35.

Alam, S. S., Ali, M. Y. \& Jani, M. F. M. (2011), 'An empirical study of factors affecting electronic commerce adoption among SMEs in Malaysia', Journal of Business Economics and Management, vol. 12, no. 2, pp. 375-399.

Alam, S. S., Khatibi, A., Ahmad, M. I. S. \& Ismail, H. B. (2008), 'Factors affecting e-commerce adoption in the electronic manufacturing companies in Malaysia', International Journal of Commerce and Management, vol. 17, no. 1/2, pp. 125-139.

Alam, S. S. \& Noor, M. K. M. (2009), 'ICT adoption in small and medium enterprises: An empirical evidence of service sectors in Malaysia', International Journal of Business and Management, vol. 4, no. 2, pp. 112-125.

Alamro, S. \& Tarawneh, S. A. (2011), 'Factors affecting E-commerce adoption in Jordanian SMEs', European Journal of Scientific Research, vol. 64, no. 4, pp. 497-506.

Alexander, C. (1977), A pattern language: towns, buildings, construction, Oxford University Press, Oxford, United Kingdom.

Alfahl, H., Houghton, L. \& Sanzogni, L. (2017), 'Mobile Commerce Adoption in Saudi Organizations: A Qualitative Study', International Journal of Enterprise Information Systems, vol. 13, no. 4, pp. 31-57.

Alfahl, H., Sanzogni, L. \& Houghton, L. (2012), 'Mobile commerce adoption in organizations: A literature review and future research directions', Journal of Electronic Commerce in Organizations, vol. 10, no. 2, pp. 61-78.

AlHaj Ali, E. (2005), 'Mobile commerce adoption across the supply chain in businesses in New Zealand', Master thesis, Auckland University of Technology, Auckland, New Zealand.

AlKalbani, A., Deng, H. \& Kam, B. 2015, 'Organisational Security Culture and Information Security Compliance for E-Government Development: The Moderating Effect of Social 
Pressure', Proceedings of the 19th Pacific Asia Conference on Information Systems, Marina Bay Sands, Singapore, July 5-9, pp. 65-76.

AlKalbani, A., Deng, H. \& Kam, B. 2019, 'The Influence of Organizational Enforcement on the Attitudes of Employees towards Information Security Compliance', Proceedings of the 10th International Conference on Information and Communication Systems, Irbid, Jordan, June 11-13, pp. 152-159.

Almoawi, A. R. N. A. (2011), 'E-commerce adoption among small and medium enterprises in Saudi Arabia', Doctoral thesis, Universiti Utara, Malaysia.

Almukhlifi, A., Deng, H. \& Kam, B. (2019), 'Critical factors for the adoption of e-government in developing countries: validation of a measurement model', Proceedings of the 12th International Conference on Theory and Practice of Electronic Governance, Melbourne, Australia, April 3-5, pp. 397-407.

Alqatan, S., Noor, N. M. M., Man, M. \& Mohemad, R. (2016), 'An Empirical Study On Success Factors To Enhance Customer Trust For Mobile Commerce In Small And Medium-Sized Tourism Enterprises (SMTEs) In Jordan', Journal of Theoretical and Applied Information Technology, vol. 83, no. 3, pp. 373-398.

Alqatan, S., Noor, N. M. M., Man, M. \& Mohemad, R. (2017), 'A theoretical discussion of factors affecting the acceptance of m-commerce among SMTEs by integrating TTF with TAM', International Journal of Business Information Systems, vol. 26, no. 1, pp. 66-111.

Alrawabdeh, W. (2014), 'Environmental Factors Affecting Mobile Commerce Adoption-An Exploratory Study on the Telecommunication Firms in Jordan', International Journal of Business and Social Science, vol. 5, no. 8, pp. 151-164.

Alrousan, M. K. (2015), 'E-commerce adoption by travel agencies in Jordan', Doctoral thesis, Cardiff Metropolitan University, United Kingdom.

Alrousan, M. K. \& Jones, E. (2016), 'A conceptual model of factors affecting e-commerce adoption by SME owner/managers in Jordan', International Journal of Business Information Systems, vol. 21, no. 3, pp. 269-308.

Alshamaila, Y. Y. (2013), 'An empirical investigation of factors affecting cloud computing adoption among SMEs in the North East of England', Doctoral thesis, Newcastle University, United Kingdom. 
Amegbe, H., Hanu, C. \& Nuwasiima, A. (2017), 'Small-scale individual entrepreneurs and the usage of mobile money and mobile commerce in facilitating business growth in Ghana', Management Science Letters, vol. 7, no. 8, pp. 373-384.

Andreou, A. S., Chrysostomou, C., Leonidou, C., Mavromoustakos, S., Pitsillides, A., Samaras, G. \& Schizas, C. (2002), 'Mobile commerce applications and services: A design and development approach', Proceedings of the First International Conference on Mobile Business, Athens, Greece, July 8-9, pp. 1-9.

Antony, J., Kumar, M. \& Madu, C. N. (2005), 'Six sigma in small-and medium-sized UK manufacturing enterprises: Some empirical observations', International Journal of Quality \& Reliability Management, vol. 22, no. 8, pp. 860-874.

Apulu, I. \& Latham, A. (2011), 'Drivers for information and communication technology adoption: a case study of Nigerian small and medium-sized enterprises', International Journal of Business and Management, vol. 6, no. 5, pp. 51-60.

Armbruster, H., Bikfalvi, A., Kinkel, S. \& Lay, G. (2008), 'Organizational innovation: The challenge of measuring non-technical innovation in large-scale surveys', Technovation, vol. 28 , no. 10 , pp. 644-657.

Ary, D., Jacobs, L. C., Irvine, C. K. S. \& Walker, D. (2018), Introduction to research in education, Cengage Learning, Boston, United States.

Asia-Pacific Economic Cooperation (2018), Small and Medium Enterprises Working Group, viewed 17 August, 2018 <https://www.apec.org/Groups/SOM-Steering-Committee-onEconomic-and-Technical-Cooperation/Working-Groups/Small-and-Medium-Enterprises $>$.

Australia Bureau of Statistics (2018), Counts of Australian Businesses, including Entries and Exits, Jun 2013 to Jun 2017, viewed 17 August, 2018 <http://www.abs.gov.au/ausstats/abs@.nsf/mf/8165.0>.

Awa, H. O., Ukoha, O. \& Emecheta, B. C. (2016), 'Using TOE theoretical framework to study the adoption of ERP solution', Cogent Business \& Management, vol. 3, no. 1, pp. 1-23.

Awiagah, R., Kang, J. \& Lim, J. I. (2016), 'Factors affecting e-commerce adoption among SMEs in Ghana', Information Development, vol. 32, no. 4, pp. 815-836. 
Ayyagari, M., Beck, T. \& Kunt, A. D. (2007), 'Small and medium enterprises across the globe', Small Business Economics, vol. 29, no. 4, pp. 415-434.

Babbie, E. (2010), The Practice of Social Research, 12th edn, Thomson Wadsworth, Australia.

Bajwa, D. \& Lewis, L. F. (2003), 'Does size matter? An investigation of collaborative information technology adoption by US firms', Journal of Information Technology Theory and Application, vol. 5, no. 1, pp. 29-46.

Baker, J. (2012), 'The technology-organization-environment framework', in Information Systems Theory, Springer, New York, United States, pp. 231-245.

Balocco, R., Mogre, R. \& Toletti, G. (2009), 'Mobile internet and SMEs: A focus on the adoption', Industrial Management \& Data Systems, vol. 109, no. 2, pp. 245-261.

Bao, J. \& Sun, X. (2010), 'A conceptual model of factors affecting e-Commerce adoption by SMEs in China', Proceedings of the Fourth International Conference on Management of eCommerce and e-Government, Chengdu, Sichuan, China, October 23-24, pp. 172-175.

Barker, N. (1994), 'The Internet as a reach generator for small business', Master thesis, Business School, University of Durham, United Kingdom.

Barney, J. B. (1986), 'Strategic factor markets: Expectations, luck, and business strategy', Management Science, vol. 32, no. 10, pp. 1231-1241.

Barney, J. B. (1991), 'Firm resources and sustained competitive advantage', Journal of Management, vol. 17, no. 1, pp. 99-120.

Barrett, P. (2007), 'Structural equation modelling: Adjudging model fit', Personality and Individual Differences, vol. 42, no. 5, pp. 815-824.

Barry, H. \& Milner, B. (2002), 'SMEs and electronic commerce: A departure from the traditional prioritization of training', Journal of European Industrial Training, vol. 26, no. 7, pp. 316-326.

Beatty, R. C., Shim, J. P. \& Jones, M. C. (2002), 'Factors influencing corporate web site adoption: A time-based assessment', Information \& Management, vol. 38, no. 6, pp. 337354. 
Beck, M. L., Bryman, A. E. \& Liao, T. F. (2003), The Sage encyclopedia of social science research methods, Sage, Thousand Oaks, California, United States.

Becker, J. \& Niehaves, B. (2007), 'Epistemological perspectives on IS research: a framework for analyzing and systematizing epistemological assumptions', Information Systems Journal, vol. 17, no. 2, pp. 197-214.

Bell, A. R., Brooks, C. \& Prokopczuk, M. (2013), Handbook of research methods and applications in empirical finance, Edward Elgar Publishing, Cheltenham, United Kingdom.

Bernard, H. R. \& Bernard, H. R. (2013), Social research methods: Qualitative and quantitative approaches, 2nd edn, Sage, New York, United States.

Bharati, P., Zhang, C. \& Chaudhury, A. (2014), 'Social media assimilation in firms: Investigating the roles of absorptive capacity and institutional pressures', Information Systems Frontiers, vol. 16, no. 2, pp. 257-272.

Bidgoli, H. (2002), Electronic commerce: principles and practice, Academic Press, MA, United States.

Blaikie, N. (2009), Designing social research, Polity Press, Cambridge, United Kingdom.

Boateng, E. O. Y. \& Essandoh, K. A. (2014), 'Factors influencing the adoption of cloud computing by small and medium enterprises in developing economies', International Journal of Emerging Science and Engineering, vol. 2, no. 4, pp. 13-20.

Borchers, J. O. (2008), 'A pattern approach to interaction design', in Cognition, Communication and Interaction, Springer, Berlin, Germany, pp. 114-131.

Boudreau, M. C., Gefen, D. \& Straub, D. W. (2001), 'Validation in information systems research: A state-of-the-art assessment', MIS Quarterly, vol. 25, no. 1, pp. 1-16.

Bradford, M. \& Florin, J. (2003), 'Examining the role of innovation diffusion factors on the implementation success of enterprise resource planning systems', International Journal of Accounting Information Systems, vol. 4, no. 3, pp. 205-225.

Brown, T. A. \& Moore, M. T. (2012), 'Confirmatory factor analysis', in Handbook of structural equation modeling, Guilford Press, New York, United States, pp. 361-379. 
Bryman, A. (2016), Social research methods, Oxford University Press, Oxford, United Kingdom.

Bryman, A. \& Bell, E. (2015), Business research methods, Oxford University Press, Oxford, United Kingdom.

Bryman, A. \& Cramer, D. (1997), Quantitative Data Analysis with SPSS for Windows, Routledge, London, United Kingdom.

Bunker, D. J. \& MacGregor, R. C. (2002), 'Successful generation of information technology (IT) requirements for small/medium enterprises (SME's)-cases from regional Australia', Proceedings of SMEs in a Global Economy Conference, Wollongong, Australia, July 1213, pp. 72-84.

Burt, R. S. (1987), 'Social contagion and innovation: Cohesion versus structural equivalence', American Journal of Sociology, vol. 92, no. 6, pp. 1287-1335.

Business Insides (2011), The Development of Small and Medium Enterprise in Vietnam, viewed 16 September $2019<$ http://businessinsides.com/development-vietnam-small-mediumenterprises.html>.

Byrne, B. M. (2013), Structural equation modeling with AMOS: basic concepts, applications, and programming, Routledge, New York, United States.

Byrne, B. M. (2016), Structural equation modeling with AMOS: Basic concepts, applications, and programming, Routledge, New York, United States.

Cabanillas, F. L., Marinkovic, V. \& Kalinic, Z. (2017), 'A SEM-neural network approach for predicting antecedents of m-commerce acceptance', International Journal of Information Management, vol. 37, no. 2, pp. 14-24.

Caldeira, M. M. \& Ward, J. M. (2003), 'Using resource-based theory to interpret the successful adoption and use of information systems and technology in manufacturing small and medium-sized enterprises', European Journal of Information Systems, vol. 12, no. 2, pp. 127-141.

Campbell, A. \& Luchs, K. S. (1997), Core competency-based strategy, Cengage Learning Business Press, London, United Kingdom. 
Carlsson, C. \& Walden, P. (2003), 'Mobile commerce-Empirical results on value-added products and services', Proceedings of the Second International Conference on Mobile Business, Vienna, Austria, June 23-24, pp. 61-69.

Carmel, E. \& Nicholson, B. (2005), 'Small firms and offshore software outsourcing: high transaction costs and their mitigation', Journal of Global Information Management, vol. 13, no. 3, pp. 33-54.

Carmines, E. G. \& Zeller, R. A. (1979), Reliability and validity assessment, Sage Publications, New York, United States.

Carroll, G. R. \& Delacroix, J. (1982), 'Organizational mortality in the newspaper industries of Argentina and Ireland: An ecological approach', Administrative Science Quarterly, vol. 27, no. 2, pp. 169-198.

Casalo, L. V., Flavian, C. \& Guinaliu, M. (2011), 'Understanding the intention to follow the advice obtained in an online travel community', Computers in Human Behavior, vol. 27, no. 2, pp. 622-633.

Chan, F. T. S. \& Chong, A. Y. L. (2012), 'A SEM-neural network approach for understanding determinants of interorganizational system standard adoption and performances', Decision Support Systems, vol. 54, no. 1, pp. 621-630.

Chan, S. C. H. \& Ngai, E. W. T. (2007), 'A qualitative study of information technology adoption: how ten organizations adopted Web-based training', Information Systems Journal, vol. 17, no. 3, pp. 289-315.

Chang, D., Li, D. \& Liao, W. (2012), 'The Construction and Simulation of Mobile Commerce Process Based on Grid Management', Proceedings of the 2nd International Conference on Logistics, Informatics and Service Science, Beijing, China, July 12-15, pp. 859-864.

Chang, S. I., Peng, T. C., Hung, Y. C., Chang, I. C. \& Hung, W. H. (2009), 'Critical success factors of mobile commerce adoption: A study based on the system life cycle and diamond model', Proceedings of the 8th International Conference on Mobile Business, Dalian, China, June 27-28, pp. 126-130.

Chatterjee, D., Grewal, R. \& Sambamurthy, V. (2002), 'Shaping up for e-commerce: Institutional enablers of the organizational assimilation of web technologies', MIS Quarterly, vol. 26, no. 2, pp. 65-89. 
Chatzoglou, P. \& Chatzoudes, D. (2016), 'Factors affecting e-business adoption in SMEs: an empirical research', Journal of Enterprise Information Management, vol. 29, no. 3, pp. 327-358.

Chau, N. T. \& Deng, H. (2018a), 'Critical Determinants for Mobile Commerce Adoption in Vietnamese SMEs: A Conceptual Framework', Procedia Computer Science, vol. 138, no. 2018, pp. 433-440.

Chau, N. T. \& Deng, H. (2018b), 'Critical Determinants for Mobile Commerce Adoption in Vietnamese SMEs: A Preliminary Study', Proceedings of the $29^{\text {th }}$ Australasian Conference on Information Systems, Sydney, Australia, December 3-5, pp. 1-11.

Chau, N. T. \& Deng, H. (2020), 'Evaluating the Critical Determinants for Mobile Commerce Adoption in SMEs in Developing Countries: A Case Study of Vietnam', in Handbook of Research on Managing Information Systems in Developing Economies, IGI Global, Hershey, United States, pp. 114-142.

Chau, N. T. \& Deng, H. (2021), 'Conceptualization for Mobile Commerce Adoption in SMEs: A Perspective of Developing Countries', International Journal of Business Information Systems, (Forthcoming).

Chau, N. T., Deng, H. \& Tay, R. (2020), 'Critical determinants for mobile commerce adoption in Vietnamese small and medium-sized enterprises', Journal of Marketing Management, vol. 36, no. 5-6, pp. 456-487.

Chau, N. T., Deng, H. \& Tay, R. (2021), 'A Perception-Based Model for Mobile Commerce Adoption in Vietnamese Small and Medium-Sized Enterprises', Journal of Global Information Management, vol. 29, no. 1, pp. 44-67.

Chau, P. Y. K. \& Tam, K. Y. (1997), 'Factors affecting the adoption of open systems: An exploratory study', MIS Quarterly, vol. 21, no. 1, pp. 1-24.

Chen, W. (2010), 'An Exploratory Research on Adoption of Mobile Commerce Technology in the Supply Chain', Proceedings of the 4th International Conference on Operations and Supply Chain Management, Hongkong \& Guangzhou, China, July 25-31, pp. 90-95.

Chen, W. \& Hirschheim, R. (2004), 'A paradigmatic and methodological examination of information systems research from 1991 to 2001', Information Systems Journal, vol. 14, no. 3, pp. 197-235. 
Chin, W. W. (1998), 'The partial least squares approach to structural equation modeling', Modern Methods for Business Research, vol. 295, no. 2, pp. 295-336.

Chong, A. Y. L. (2013a), 'Predicting m-commerce adoption determinants: A neural network approach', Expert Systems with Applications, vol. 40, no. 2, pp. 523-530.

Chong, A. Y. L. (2013b), 'A two-staged SEM-neural network approach for understanding and predicting the determinants of m-commerce adoption', Expert Systems with Applications, vol. 40, no. 4, pp. 1240-1247.

Chong, A. Y. L. \& Bai, R. (2014), 'Predicting open IOS adoption in SMEs: An integrated SEMneural network approach', Expert Systems with Applications, vol. 41, no. 1, pp. 221-229.

Chong, A. Y. L., Liu, M. J., Luo, J. \& Keng-Boon, O. (2015), 'Predicting RFID adoption in healthcare supply chain from the perspectives of users', International Journal of Production Economics, vol. 159, no. 2015, pp. 66-75.

Chuang, T. T., Nakatani, K., Chen, J. C. H. \& Huang, I. L. (2007), 'Examining the impact of organizational and owner's characteristics on the extent of e-commerce adoption in SMEs', International Journal of Business and Systems Research, vol. 1, no. 1, pp. 61-80.

Churchill, J. G. A. (1979), 'A paradigm for developing better measures of marketing constructs', Journal of Marketing Research, vol. 16, no. 1, pp. 64-73.

Chwelos, P., Benbasat, I. \& Dexter, A. S. (2001), 'Empirical test of an EDI adoption model', Information Systems Research, vol. 12, no. 3, pp. 304-321.

Clarke III, I. (2008), 'Emerging value propositions for m-commerce', Journal of Business Strategies, vol. 25, no. 2, pp. 41-57.

Cohen, J. (2013), Statistical power analysis for the behavioral sciences, Academic Press, MA, United States.

Collis, J. \& Hussey, R. (2013), Business research: A practical guide for undergraduate and postgraduate students, Palgrave Macmillan, London, United Kingdom.

Conner, K. R. (1991), 'A historical comparison of resource-based theory and five schools of thought within industrial organization economics: Do we have a new theory of the firm?', Journal of Management, vol. 17, no. 1, pp. 121-154. 
Coursaris, C. \& Hassanein, K. (2002), 'Understanding m-commerce: a consumer-centric model', Quarterly Journal of Electronic Commerce, vol. 3, no. 2002, pp. 247-272.

Crabbe, M., Standing, C., Standing, S. \& Karjaluoto, H. (2009), 'An adoption model for mobile banking in Ghana', International Journal of Mobile Communications, vol. 7, no. 5, pp. 515543.

Cragg, P. B. \& King, M. (1992), 'Information system sophistication and financial performance of small engineering firms', European Journal of Information Systems, vol. 1, no. 6, pp. 417-426.

Creswell, J. W. (2012), Educational research: Planning, conducting, and evaluating quantitative and qualitative research, 4 th edn, Pearson, Boston, United States.

Creswell, J. W. (2017), Research design: Qualitative, quantitative, and mixed methods approaches, Sage publications, London, United Kingdom.

Creswell, J. W. \& Clark, V. L. P. (2017), Designing and conducting mixed methods research, Sage publications, London, United Kingdom.

Cui, L., Jiang, H., Deng, H. \& Zhang, T. (2019), 'The influence of the diffusion of food safety information through social media on consumers' purchase intentions', Data Technologies and Applications, vol. 53, no. 2, pp. 230-248.

Danhui, F., Jinlong, Z. \& Yuqing, L. (2009), 'Research on the Factors Affecting the Enterprise Business Adoption of Mobile Commerce', Proceedings of the 6th International Conference on Innovation and Management, Sao Paulo, Brazil, December 8-10, pp. 1448-1453.

Davis, D. (2004), Business research for decision making, Wadsworth, Belmont, CA, United States.

Davis, F. D. (1989), 'Perceived usefulness, perceived ease of use, and user acceptance of information technology', MIS Quarterly, vol. 13, no. 3, pp. 319-340.

Deephouse, D. L. (1996), 'Does isomorphism legitimate?', Academy of Management Journal, vol. 39, no. 4, pp. 1024-1039.

Del Canto, J. G. \& Gonzalez, I. S. (1999), 'A resource-based analysis of the factors determining a firm's R\&D activities', Research Policy, vol. 28, no. 8, pp. 891-905. 
Deng, H., Duan, S. X., Jie, D. \& Fu, J. (2019), 'An Efficiency-Based Approach for Selecting Electronic Markets in Sustainable Electronic Business: A SME's Perspective', Sustainability, vol. 11, no. 7, pp. 1858-1870.

Deng, H., Duan, S. X. \& Luo, F. (2019), 'Critical determinants for electronic market adoption: Evidence from Australian small and medium-sized enterprises', Journal of Enterprise Information Management, vol. 33, no. 2, pp. 335-352.

Deng, H. \& Gupta, P. (2005), 'Critical success factors for information systems implementation: An end-user perspective', in Managing Modern Organizations with Information Technology, Idea Group Publishing, United States, pp. 80-82.

Deros, B. M., Yusof, S. M. \& Salleh, A. M. (2006), 'A benchmarking implementation framework for automotive manufacturing SMEs', Benchmarking: An International Journal, vol. 13 , no. 4 , pp. 396-430.

Dicksen, P. R. (1996), 'The static and dynamic mechanics of competitive theory', Journal of Marketing, vol. 60, no. 10, pp. 102-106.

Dillman, D. A. (2011), Mail and Internet surveys: The tailored design method--2007 Update with new Internet, visual, and mixed-mode guide, John Wiley \& Sons, New Jersey, United States.

Dills, C. R. \& Romiszowski, A. J. (1997), Instructional development paradigms, Educational Technology, Portland, OR, United States.

DiMaggio, P. \& Powell, W. W. (1983), 'The iron cage revisited: Collective rationality and institutional isomorphism in organizational fields', American Sociological Review, vol. 48, no. 2, pp. $147-160$.

Ditsa, G. (2004), 'A Research Design and a Methodological Approach to an Explanatory User Behavior Testing: Lessons Learnt', Innovations Through Information Technology, vol. 1, pp. $762-768$.

Donaldson, B., Lee, J. H. \& Wright, G. (2012), 'Strategic and organizational determinants of sophistication in deployed sales force automation systems within three industry sectors in the UK', Journal of Marketing Management, vol. 28, no. 11-12, pp. 1305-1330. 
Dong, Y. \& Peng, C. Y. J. (2013), 'Principled missing data methods for researchers', SpringerPlus, vol. 2, no. 1, pp. 222-238.

Doolin, B. \& Ali, E. A. H. (2008), 'Adoption of mobile technology in the supply chain: An exploratory cross-case analysis', International Journal of E-Business Research, vol. 4, no. 4, pp. 1-15.

Duan, S. X. (2012), 'An integrated solution to the adoption of electronic market in Australian small and medium-sized enterprises', Doctoral thesis, RMIT University, Australia.

Duan, S. X., Deng, H. \& Luo, F. (2019), 'An integrated approach for identifying the efficiencyoriented drivers of electronic markets in electronic business', Journal of Enterprise Information Management, vol. 32, no. 1, pp. 60-74.

Duan, X., Deng, H. \& Corbitt, B. (2012), 'Evaluating the critical determinants for adopting emarket in Australian small and medium-sized enterprises', Management Research Review, vol. 35 , no. 3 , pp. $289-308$.

Duhan, S., Levy, M. \& Powell, P. (2001), 'Information systems strategies in knowledge-based SMEs: The role of core competencies', European Journal of Information Systems, vol. 10, no. 1 , pp. $25-40$.

Dyer, J. H. \& Singh, H. (1998), 'The relational view: Cooperative strategy and sources of interorganizational competitive advantage', Academy of Management Review, vol. 23, no. 4, pp. 660-679.

Edwards, T., Delbridge, R. \& Munday, M. (2005), 'Understanding innovation in small and medium-sized enterprises: a process manifest', Technovation, vol. 25, no. 10, pp. 11191127.

eMarketer (2018), Worldwide Retail and Ecommerce Sales: eMarketer's Updated Forecast and New Mcommerce Estimates for 2016-2021, viewed 7 May, 2019 <https://www.emarketer.com/Report/Worldwide-Retail-Ecommerce-Sales-eMarketersUpdated-Forecast-New-Mcommerce-Estimates-20162021/2002182>.

European Commission (2018), User guide to the SME definition, viewed 17 August, 2018 $<$ http://ec.europa.eu/regional_policy/sources/conferences/stateaid/sme/smedefinitionguide_en.pdf $>$. 
Fabrigar, L. R., Wegener, D. T., MacCallum, R. C. \& Strahan, E. J. (1999), 'Evaluating the use of exploratory factor analysis in psychological research', Psychological Methods, vol. 4, no. 3, pp. 272-299.

Fang, B. \& Ma, S. (2009), 'Application of BP neural network in stock market prediction', Proceedings of the Sixth International Symposium on Neural Networks, Wuhan, China, May 26-29, pp. 1082-1088.

Field, A. P. (2013), Discovering statistics using IBM SPSS statistics, 4th edn, Sage, London, United Kingdom.

Fishbein, M. \& Ajzen, I. (1977), Belief, attitude, intention, and behavior: An introduction to theory and research, Addison-Wesley, MA, United States.

Fornell, C. \& Larcker, D. F. (1981), 'Evaluating structural equation models with unobservable variables and measurement error', Journal of Marketing Research, vol. 18, no. 1, pp. 39-50.

Fowler, J. \& Floyd, J. (2013), Survey research methods, Sage publications, New York, United States.

Galbreath, J. (2005), 'Which resources matter the most to firm success? An exploratory study of resource-based theory', Technovation, vol. 25, no. 9, pp. 979-987.

Gao, K. \& Shao, X. (2018), 'Adoption Research of the M-commerce Application Based on the Perspective of Supply Chain Management in Shipping Industry', Journal of Coastal Research, vol. 83, no. 1, pp. 839-845.

Garg, A. K. \& Choeu, T. (2015), 'The adoption of electronic commerce by small and medium enterprises in Pretoria East', The Electronic Journal of Information Systems in Developing Countries, vol. 68, no. 1, pp. 1-23.

Gefen, D. \& Straub, D. (2007), 'A practical guide to factorial validity using PLS-Graph: Tutorial and annotated example', Communications of the Association for Information Systems, vol. 16, no. 1, pp. 90-109.

General Statistics Office of Vietnam (2017), Small and medium enterprises are getting smaller, viewed 17 August 2018 <http://www.gso.gov.vn>. 
General Statistics Office of Vietnam (2018a), Economic Census 2017, viewed 18 March 2018 <https://www.gso.gov.vn/Default.aspx?tabid=382\&idmid=\&ItemID=18945 >.

General Statistics Office of Vietnam (2018b), The Socio-Economic Situation in 2017, viewed 22 August $2018<$ https://www.gso.gov.vn/default.aspx?tabid=621\&ItemID=18668 $>$.

General Statistics Office of Vietnam (2019), The Socio-Economic Situation in 2018, viewed 29 July 2019 〈https://www.gso.gov.vn/default.aspx?tabid=621\&ItemID=19037>.

George, D. (2011), SPSS for windows step by step: A simple study guide and reference, 17.0 update, 10th edn, Pearson Education, India.

George, D. \& Mallery, P. (2003), SPSS for Windows step by step: A simple guide and reference 11.0 update, 4th edn, Allyn \& Bacon, Boston, United States.

Ghobakhloo, M., Aranda, D. A. \& Amado, J. B. (2011), 'Adoption of e-commerce applications in SMEs', Industrial Management \& Data Systems, vol. 111, no. 8, pp. 1238-1269.

Ghobakhloo, M. \& Tang, S. H. (2013), 'The role of owner/manager in adoption of electronic commerce in small businesses: The case of developing countries', Journal of Small Business and Enterprise Development, vol. 20, no. 4, pp. 754-787.

Gibbs, J. L. \& Kraemer, K. L. (2010), 'A cross-country investigation of the determinants of scope of e-commerce use: An institutional approach', Electronic Markets, vol. 14, no. 2, pp. 124-137.

Goodhue, D. L. \& Thompson, R. L. (1995), 'Task-technology fit and individual performance', MIS Quarterly, vol. 19, no. 2, pp. 213-236.

Grandhi, S. \& Wibowo, S. (2015), 'Predicting organization's preparedness to adopt mobile commerce an empirical study of North American organizations', Proceedings of the 25th International Business Information Management Association Conference, Amsterdam, Netherlands, May 7-8, pp. 2945-2959.

Grandhi, S. \& Wibowo, S. (2016), 'Mobile Commerce Adoption in North American Organizations: An Empirical Study of Organizational Factors', Communications of the IBIMA, vol. 2016, no. 2016, pp. 1-17. 
Grandon, E. E. \& Pearson, J. M. (2004), 'Electronic commerce adoption: An empirical study of small and medium US businesses', Information \& Management, vol. 42, no. 1, pp. 197-216.

Grewal, R. \& Dharwadkar, R. (2002), 'The role of the institutional environment in marketing channels', Journal of Marketing, vol. 66, no. 3, pp. 82-97.

Guba, E. G. \& Lincoln, Y. S. (1994), 'Competing paradigms in qualitative research', in Handbook of qualitative research, Sage, London, United Kingdom, pp. 105-117.

Hair, J. F., Black, W. C., Babin, B. J., Anderson, R. E. \& Tatham, R. L. (2010), Multivariate data analysis, 7th edn, Pearson Prentice Hall, Upper Saddle River, New Jersey, United States.

Hamdan, A. R., Yahaya, J. H., Deraman, A. \& Jusoh, Y. Y. (2016), 'The success factors and barriers of information technology implementation in small and medium enterprises: An empirical study in Malaysia', International Journal of Business Information Systems, vol. 21, no. 4, pp. 477-494.

Hameed, M. A., Counsell, S. \& Swift, S. (2012), 'A conceptual model for the process of IT innovation adoption in organizations', Journal of Engineering and Technology Management, vol. 29, no. 3, pp. 358-390.

Harrigan, P., Ramsey, E. \& Ibbotson, P. (2011), 'Critical factors underpinning the e-CRM activities of SMEs', Journal of Marketing Management, vol. 27, no. 5-6, pp. 503-529.

Harry, B., Vos, H. D. \& Haaker, T. (2008), Mobile service innovation and business models, Springer, Verlag Berlin Heidelberg, German.

Hashim, J. (2007), 'Information and communication technology adoption among SME owner in Malaysia', International Journal of Business and Information, vol. 2, no. 2, pp. 221-240.

Haykin, S. (2001), Neural networks: A comprehensive foundation, Prentice Hall, Englewood Cliffs, New Jersey, United States.

Haynes, S. N., Richard, D. \& Kubany, E. S. (1995), 'Content validity in psychological assessment: A functional approach to concepts and methods', Psychological Assessment, vol. 7, no. 3, p. 238. 
Henseler, J., Ringle, C. M. \& Sinkovics, R. R. (2009), 'The use of partial least squares path modeling in international marketing', Advances in International Marketing, vol. 20, no. 2009, pp. 277-319.

Hew, T. S., Leong, L. Y., Ooi, K. B. \& Chong, A. Y. L. (2016), 'Predicting drivers of mobile entertainment adoption: A two-stage SEM-artificial-neural-network analysis', Journal of Computer Information Systems, vol. 56, no. 4, pp. 352-370.

Hoe, S. L. (2008), 'Issues and procedures in adopting structural equation modeling technique', Journal of Applied Quantitative Methods, vol. 3, no. 1, pp. 76-83.

Hooper, D., Coughlan, J. \& Mullen, M. R. (2008), 'Structural equation modelling: Guidelines for determining model fit', Electronic Journal of Business Research Methods, vol. 6, no. 1, pp. 53-60.

Hopkins, K. D. \& Weeks, D. L. (1990), 'Tests for normality and measures of skewness and kurtosis: Their place in research reporting', Educational and Psychological Measurement, vol. 50, no. 4, pp. 717-729.

Hossain, M. S. \& Khandanker, M. R. A. (2011), 'Implementation challenges of mobile commerce in developing countries - Bangladesh perspective', Proceedings of the 14th International Conference on Computer and Information Technology, Dhaka, Bangladesh, December 22-24, pp. 399-404.

Hsiao, S. J., Li, Y. C., Chen, Y. L. \& Ko, H. C. (2009), 'Critical factors for the adoption of mobile nursing information systems in Taiwan: The nursing department administrators' perspective', Journal of Medical Systems, vol. 33, no. 5, pp. 369-377.

Hsieh, C. T. (2007), 'Mobile commerce: Assessing new business opportunities', Communications of the IIMA, vol. 7, no. 1, pp. 87-100.

Hsu, P. F., Kraemer, K. L. \& Dunkle, D. (2006), 'Determinants of e-business use in US firms', International Journal of Electronic Commerce, vol. 10, no. 4, pp. 9-45.

Hu, Q., Hart, P. \& Cooke, D. (2006), 'The role of external influences on organizational information security practices: An institutional perspective', Proceedings of the 39th Annual Hawaii International Conference on System Science, Kauai, HI, United States, January 4-7, pp. 1-10. 
Hu, S. K., Lu, M. T. \& Tzeng, G. H. (2015), 'Improving mobile commerce adoption using a new hybrid fuzzy MADM model', International Journal of Fuzzy Systems, vol. 17, no. 3, pp. 399-413.

Hung, Y. C., Yang, Y. L., Yang, H. E. \& Chuang, Y. H. (2011), 'Factors affecting the adoption of e-commerce for the tourism industry in Taiwan', Asia Pacific Journal of Tourism Research, vol. 16, no. 1, pp. 105-119.

Huy, L. V. \& Filiatrault, P. (2006), 'The adoption of e-commerce in SMEs in Vietnam: a study of users and prospectors', Proceedings of the 10th Pacific Asia Conference on Information Systems, Kuala Lumpur, Malaysia, July 6-9, pp. 1335-1344.

Huy, L. V., Rowe, F., Truex, D. \& Huynh, M. Q. (2012), 'An empirical study of determinants of e-commerce adoption in SMEs in Vietnam: An economy in transition', Journal of Global Information Management, vol. 20, no. 3, pp. 23-54.

Iacovou, C. L., Benbasat, I. \& Dexter, A. S. (1995), 'Electronic data interchange and small organizations: Adoption and impact of technology', MIS Quarterly, vol. 19, no. 4, pp. 465485 .

Ifinedo, P. (2011), 'Internet/e-business technologies acceptance in Canada's SMEs: An exploratory investigation', Internet Research, vol. 21, no. 3, pp. 255-281.

Ilin, V., Ivetic, J. \& Simic, D. (2017), 'Understanding the determinants of e-business adoption in ERP-enabled firms and non-ERP-enabled firms: A case study of the Western Balkan Peninsula', Technological Forecasting and Social Change, vol. 125, no. 2017, pp. 206-223.

Jain, M., Le, A. N. H., Lin, J. Y. C. \& Cheng, J. M. S. (2011), 'Exploring the factors favoring mcommerce adoption among Indian MSMEs: A TOE perspective', Tunghai Management Review, vol. 13, no. 1, pp. 147-188.

Jarvenpaa, S. L. \& Leidner, D. E. (1998), 'An information company in Mexico: Extending the resource-based view of the firm to a developing country context', Information Systems Research, vol. 9, no. 4, pp. 342-361.

Jeon, B. N., Han, K. S. \& Lee, M. J. (2006), 'Determining factors for the adoption of e-business: The case of SMEs in Korea', Applied Economics, vol. 38, no. 16, pp. 1905-1916. 
Jeyaraj, A., Rottman, J. W. \& Lacity, M. C. (2006), 'A review of the predictors, linkages, and biases in IT innovation adoption research', Journal of Information Technology, vol. 21, no. 1, pp. 1-23.

Johnson, R. B. \& Onwuegbuzie, A. J. (2004), 'Mixed methods research: A research paradigm whose time has come', Educational Researcher, vol. 33, no. 7, pp. 14-26.

Johnson, V. L., Kiser, A., Washington, R. \& Torres, R. (2018), 'Limitations to the rapid adoption of M-payment services: Understanding the impact of privacy risk on M-Payment services', Computers in Human Behavior, vol. 79, no. 2018, pp. 111-122.

Joo, Y. B. \& Kim, Y. G. (2004), 'Determinants of corporate adoption of e-marketplace: An innovation theory perspective', Journal of Purchasing and Supply Management, vol. 10, no. 2, pp. 89-101.

Junglas, I. \& Watson, R. (2003), 'U-commerce: a conceptual extension of e-commerce and mcommerce', Proceedings of the 24th International Conference on Information Systems, Seattle, WA, United States, December 15-17, pp. 667-677.

Kalinic, Z. \& Marinkovic, V. (2016), 'Determinants of users' intention to adopt m-commerce: an empirical analysis', Information Systems and E-Business Management, vol. 14, no. 2, pp. 367-387.

Kamaroddin, J. H., Cheong, D. L. M. \& Ahmad, A. (2008), 'Measuring the perception of Malaysian SME towards e-commerce as an innovation', Social and Management Research Journal, vol. 5, no. 2, pp. 83-95.

Kamthan, P. (2011), 'On the Implications of the Social Web Environment for Pedagogical Patterns', in Investigations of E-Learning Patterns: Context Factors, Problems and Solutions, IGI Global, Hershey, United States, pp. 149-169.

Kaplan, D. (2008), 'Structural equation modeling: Foundations and extensions', in Advanced Quantitative Techniques in the Social Sciences, Sage Publications, London, United Kingdom.

Karahanna, E., Straub, D. W. \& Chervany, N. L. (1999), 'Information technology adoption across time: A cross-sectional comparison of pre-adoption and post-adoption beliefs', MIS Quarterly, vol. 23, no. 2, pp. 183-213. 
Karunasena, K. \& Deng, H. (2012), 'Critical factors for evaluating the public value of egovernment in Sri Lanka', Government Information Quarterly, vol. 29, no. 1, pp. 76-84.

Karunasena, K., Deng, H. \& Singh, M. (2011), 'Measuring the public value of e-government: a case study from Sri Lanka', Transforming Government: People, Process and Policy, vol. 5, no. 1, pp. 81-99.

Keen, P. G., Mackintosh, R. \& Heikkonen, M. F. (2001), The freedom economy: Gaining the mcommerce edge in the era of the wireless Internet, McGraw-Hill Professional, United States.

Khalifa, M., Cheng, S. K. N. \& Shen, K. N. (2012), 'Adoption of mobile commerce: A confidence model', Journal of Computer Information Systems, vol. 53, no. 1, pp. 14-22.

Khaskheli, A., Jun, Y. and Bhuiyan, M.A., 2017. 'M-commerce and mobile apps: opportunities for SMEs in developing countries', Journal of International Business Research and Marketing, vol. 2, no. 2, pp. 20-23.

Khazanchi, D. \& Munkvold, B. E. (2003), 'On the rhetoric and relevance of IS research paradigms: a conceptual framework and some propositions', Proceedings of the 36th Annual Hawaii International Conference on System Sciences, Hawaii, United States, January 6-9, pp. 10-19.

Khosrow-Pour, M. (2006), Encyclopedia of e-commerce, e-government, and mobile commerce, IGI Global, Pennsylvania, United States.

Kline, R. B. (2015), Principles and practice of structural equation modeling, Guilford publications, New York, United States.

Kothari, C. R. (2004), Research methodology: Methods and techniques, New Age International, New Delhi, India.

Kotler, P. \& Armstrong, G. (2010), Principles of Marketing, Pearson Education, London, United Kingdom.

Kunz, W., Schmitt, B. \& Meyer, A. (2011), 'How does perceived firm innovativeness affect the consumer?', Journal of Business Research, vol. 64, no. 8, pp. 816-822. 
Kurnia, S., Karnali, R. J. \& Rahim, M. M. (2015), 'A qualitative study of business-to-business electronic commerce adoption within the Indonesian grocery industry: A multi-theory perspective', Information \& Management, vol. 52, no. 4, pp. 518-536.

Lal, K. (2005), 'Determinants of the adoption of e-business technologies', Telematics and Informatics, vol. 22, no. 3, pp. 181-199.

Lee, C. C., Cheng, H. K. \& Cheng, H. H. (2007), 'An empirical study of mobile commerce in insurance industry: Task-technology fit and individual differences', Decision Support Systems, vol. 43, no. 1, pp. 95-110.

Lee, M. K. O. \& Cheung, C. M. K. (2004), 'Internet retailing adoption by small-to-medium sized enterprises: A multiple-case study', Information Systems Frontiers, vol. 6, no. 4, pp. 385-397.

Leger, P. M., Cassivi, L. \& Wamba, S. F. (2004), 'Determinants of the adoption of customeroriented mobile commerce initiatives', Proceedings of the $13^{\text {th }}$ International Conference on Management of Technology, Washington DC, United States, May 13-15, pp. 1-12.

Leong, L. Y., Hew, T. S., Lee, V. H. \& Ooi, K. B. (2015), 'An SEM-artificial-neural-network analysis of the relationships between SERVPERF, customer satisfaction and loyalty among low-cost and full-service airline', Expert Systems with Applications, vol. 42, no. 19, pp. 6620-6634.

Leong, L. Y., Hew, T. S., Tan, G. W. H. \& Ooi, K. B. (2013), 'Predicting the determinants of the NFC-enabled mobile credit card acceptance: A neural networks approach', Expert Systems with Applications, vol. 40, no. 14, pp. 5604-5620.

Lertwongsatien, C. \& Wongpinunwatana, N. (2003), 'E-commerce adoption in Thailand: An empirical study of Small and Medium Enterprises', Journal of Global Information Technology Management, vol. 6, no. 3, pp. 67-83.

Leung, K. \& Antypas, J. (2001), 'Improving returns on m-commerce investments', The Journal of Business Strategy, vol. 22, no. 5, pp. 12-13.

Levy, M. \& Powell, P. (2003), 'Exploring SME internet adoption: Towards a contingent model', Electronic Markets, vol. 13, no. 2, pp. 173-181. 
Lewis, B. R., Templeton, G. F. \& Byrd, T. A. (2005), 'A methodology for construct development in MIS research', European Journal of Information Systems, vol. 14, no. 4, pp. 388-400.

Li, D. \& Chang, D. (2012), 'Construction and Arena Simulation of Grid M-Commerce Process', Journal of Electronic Commerce in Organizations, vol. 10, no. 4, pp. 1-18.

Li, D., Lai, F. \& Wang, J. (2010), 'E-business assimilation in China's international trade firms: The technology-organization-environment framework', Journal of Global Information Management, vol. 18, no. 1, pp. 39-65.

Li, L. \& Wang, X. (2018), 'M-Commerce Adoption in SMEs of China: The Effect of Institutional Pressures and the Mediating Role of Top Management', Journal of Electronic Commerce in Organizations, vol. 16, no. 2, pp. 48-63.

Li, W. \& McQueen, R. J. (2008), 'Barriers to mobile commerce adoption: An analysis framework for a country-level perspective', International Journal of Mobile Communications, vol. 6, no. 2, pp. 231-257.

Li, Y. H. (2008), 'An empirical investigation on the determinants of e-procurement adoption in Chinese manufacturing enterprises', Proceedings of the $15^{\text {th }}$ International Conference on Management Science and Engineering, Long Beach, CA, United States, September 10-12, pp. 32-37.

Liang, H., Saraf, N., Hu, Q. \& Xue, Y. (2007), 'Assimilation of enterprise systems: The effect of institutional pressures and the mediating role of top management', MIS Quarterly, vol. 31, no. 1 , pp. 59-87.

Liang, T. P., Huang, C. W., Yeh, Y. H. \& Lin, B. (2007), 'Adoption of mobile technology in business: A fit-viability model', Industrial Management \& Data Systems, vol. 107, no. 8, pp. 1154-1169.

Liao, S., Shao, Y. P., Wang, H. \& Chen, A. (1999), 'The adoption of virtual banking: An empirical study', International Journal of Information Management, vol. 19, no. 1, pp. 6374.

Lim, S. C., Baharudin, A. S. \& Low, R. Q. (2016), 'E-commerce adoption in Peninsular Malaysia: Perceived strategic value as moderator in the relationship between perceived 
barriers, organization readiness and competitor pressure', Journal of Theoretical \& Applied Information Technology, vol. 91, no. 2, pp. 228-237.

Lin, C., Huang, Y. A. \& Burn, J. (2007), 'Realising B2B e-commerce benefits: the link with IT maturity, evaluation practices, and B2BEC adoption readiness', European Journal of Information Systems, vol. 16, no. 6, pp. 806-819.

Lin, F. H. \& Wu, J. H. (2004), 'An empirical study of end-user computing acceptance factors in small and medium enterprises in Taiwan: Analyzed by structural equation modeling', Journal of Computer Information Systems, vol. 44, no. 3, pp. 98-108.

Lin, H. F. \& Lin, S. M. (2008), 'Determinants of e-business diffusion: A test of the technology diffusion perspective', Technovation, vol. 28, no. 3, pp. 135-145.

Lincoln, Y. S., Lynham, S. A. \& Guba, E. G. (2011), 'Paradigmatic controversies, contradictions, and emerging confluences, revisited', in The Sage handbook of qualitative research, Sage, London, United Kingdom, pp. 97-128.

Lindner, J. R., Murphy, T. H. \& Briers, G. E. (2001), 'Handling nonresponse in social science research', Journal of Agricultural Education, vol. 42, no. 4, pp. 43-53.

Lippert, S. K. \& Govindarajulu, C. (2006), 'Technological, organizational, and environmental antecedents to web services adoption', Communications of the IIMA, vol. 6, no. 1, pp. 146160.

Lomax, R. G. \& Schumacker, R. E. (2012), A beginner's guide to structural equation modeling, Routledge Academic, New York, United States.

Loukis, E., Arvanitis, S. \& Kyriakou, N. (2017), 'An empirical investigation of the effects of firm characteristics on the propensity to adopt cloud computing', Information Systems and E-Business Management, vol. 15, no. 4, pp. 963-988.

Lu, C. S., Lai, K. H. \& Cheng, T. C. E. (2007), 'Application of structural equation modeling to evaluate the intention of shippers to use Internet services in liner shipping', European Journal of Operational Research, vol. 180, no. 2, pp. 845-867.

Lu, M. T., Hu, S. K., Huang, L. H. \& Tzeng, G. H. (2015), 'Evaluating the implementation of business-to-business m-commerce by SMEs based on a new hybrid MADM model', Management Decision, vol. 53, no. 2, pp. 290-317. 
MacCallum, R. C. \& Tucker, L. R. (1991), 'Representing sources of error in the common-factor model: Implications for theory and practice', Psychological Bulletin, vol. 109, no. 3, pp. $502-511$

MacGregor, R. C., Bunker, D. \& Kartiwi, M. (2010), 'The perception of barriers to e-commerce adoption by SMEs: A comparison of three countries', in Global perspectives on small and medium enterprises and strategic information systems: International approaches, IGI Global, Hershey, Pennsylvania, USA, pp. 145-168.

MacGregor, R. C. \& Vrazalic, L. (2005), 'A basic model of electronic commerce adoption barriers: A study of regional small businesses in Sweden and Australia', Journal of Small Business and Enterprise Development, vol. 12, no. 4, pp. 510-527.

Malhotra, N. K. (2010), Marketing research: An applied orientation, Pearson, Boston, United States.

Mallat, N. \& Tuunainen, V. K. (2008), 'Exploring merchant adoption of mobile payment systems: An empirical study', E-service Journal, vol. 6, no. 2, pp. 24-57.

Martin, S. S., Catalan, B. L. \& Jeronimo, M. A. R. (2012), 'Factors determining firms' perceived performance of mobile commerce', Industrial Management \& Data Systems, vol. 112, no. 6, pp. 946-963.

Martin, S. S. \& Jimenez, N. (2015), 'A Typology of Firms Regarding M-Commerce Adoption', International Journal of Information System Modeling and Design, vol. 6, no. 4, pp. 42-56.

Mashagba, F. F. A., Mashagba, E. F. A. \& Nassar, M. O. (2013), 'Exploring Technological Factors Affecting the Adoption of M-Commerce in Jordan', Australian Journal of Basic and Applied Sciences, vol. 7, no. 6, pp. 395-400.

Masrek, M. N., Karim, N. S. A. \& Hussein, R. (2008), 'The effect of organizational and individual characteristics on corporate intranet utilizations', Information Management \& Computer Security, vol. 16, no. 2, pp. 89-112.

Mata, F. J., Fuerst, W. L. \& Barney, J. B. (1995), 'Information technology and sustained competitive advantage: A resource-based analysis', MIS Quarterly, vol. 19, no. 4, pp. 487505. 
Mbogo, M. (2010), 'The impact of mobile payments on the success and growth of microbusiness: The case of M-Pesa in Kenya', Journal of Language, Technology \& Entrepreneurship in Africa, vol. 2, no. 1, pp. 182-203.

McAdam, R., Keogh, W., Reid, R. S. \& Mitchell, N. (2007), 'Implementing innovation management in manufacturing SMEs: a longitudinal study', Journal of Small Business and Enterprise Development, vol. 14, no. 3, pp. 385-403.

Mehrtens, J., Cragg, P. B. \& Mills, A. M. (2001), 'A model of Internet adoption by SMEs', Information \& Management, vol. 39, no. 3, pp. 165-176.

Miao, J. J. \& Tran, Q. D. (2018), 'Study on E-Commerce Adoption in SMEs Under the Institutional Perspective: The Case of Saudi Arabia', International Journal of E-Adoption, vol. 10 , no. 1 , pp. 53-72.

Michaelidou, N., Siamagka, N. T. \& Christodoulides, G. (2011), 'Usage, barriers and measurement of social media marketing: An exploratory investigation of small and medium B2B brands', Industrial Marketing Management, vol. 40, no. 7, pp. 1153-1159.

Mingers, J. (2003), 'The paucity of multimethod research: A review of the information systems literature', Information Systems Journal, vol. 13, no. 3, pp. 233-249.

Mizruchi, M. S. \& Fein, L. C. (1999), 'The social construction of organizational knowledge: A study of the uses of coercive, mimetic, and normative isomorphism', Administrative Science Quarterly, vol. 44, no. 4, pp. 653-683.

Molla, A. \& Licker, P. S. (2005a), 'eCommerce adoption in developing countries: a model and instrument', Information \& Management, vol. 42, no. 6, pp. 877-899.

Molla, A. \& Licker, P. S. (2005b), 'Perceived e-readiness factors in e-commerce adoption: An empirical investigation in a developing country', International Journal of Electronic Commerce, vol. 10, no. 1, pp. 83-110.

Murphy, A. \& Ledwith, A. (2007), 'Project management tools and techniques in hightechnology SMEs', Management Research News, vol. 30, no. 2, pp. 153-166.

Myers, M. D. (2013), Qualitative research in business and management, Sage, London, United Kingdom. 
Nafea, I. \& Younas, M. (2014), 'Improving the performance and reliability of mobile commerce in developing countries', Proceedings of the International Conference on Mobile Web and Information Systems, Barcelona, Spain, August 27-29, pp. 114-125.

Negnevitsky, M. (2011), Artificial Intelligence: A guide to intelligent systems, 3rd edn, Pearson Education, Essex, England.

Netemeyer, R. G., Bearden, W. O. \& Sharma, S. (2003), Scaling procedures: Issues and applications, Sage Publications, New York, United States.

Neuman, W. L. (2013), Social research methods: Qualitative and quantitative approaches, Pearson Education, Boston, United States.

Nguyen, T. U. H. (2009), 'Information technology adoption in SMEs: an integrated framework', International Journal of Entrepreneurial Behavior \& Research, vol. 15, no. 2, pp. 162-186.

Njenga, A. K., Litondo, K. \& Omwansa, T. (2016), 'A Theoretical Review of Mobile Commerce Success Determinants', Journal of Information Engineering and Applications, vol. 6, no. 5, pp. 13-23.

OECD (2017), Enhancing the contributions of SMEs in a global and digitalized economy, viewed 5 March 2020 <https://www.oecd.org/industry/C-MIN-2017-8-EN.pdf>.

Office of Advocacy (2018), United States Small Business Economic Profile 2018, viewed 5 March 2020 <https://www.sba.gov/sites/default/files/advocacy/2018-Small-BusinessProfiles-US.pdf>.

Oliveira, T. \& Martins, M. F. (2010), 'Understanding e-business adoption across industries in European countries', Industrial Management \& Data Systems, vol. 110, no. 9, pp. 13371354.

Oliveira, T. \& Martins, M. F. (2011), 'Literature review of information technology adoption models at firm level', The Electronic Journal Information Systems Evaluation, vol. 14, no. 1, pp. 110-121.

Oliver, C. (1997), 'Sustainable competitive advantage: Combining institutional and resourcebased views', Strategic Management Journal, vol. 18, no. 9, pp. 697-713. 
Orlikowski, W. J. \& Baroudi, J. J. (1991), 'Studying information technology in organizations: Research approaches and assumptions', Information Systems Research, vol. 2, no. 1, pp. 128.

Otieno, E. O. \& Kahonge, A. M. (2014), 'Adoption of Mobile Payments in Kenyan Businesses: A Case Study of Small and Medium Enterprises in Kenya', International Journal of Computer Applications, vol. 107, no. 7, pp. 5-12.

Paavilainen, J. (2002), Mobile business strategies: understanding the technologies and opportunities, Pearson Education, London, United Kingdom.

Pan, M. J. \& Jang, W. Y. (2008), 'Determinants of the adoption of enterprise resource planning within the technology-organization-environment framework: Taiwan's communications industry', Journal of Computer Information Systems, vol. 48, no. 3, pp. 94-102.

Panahian, H. (2011), 'Stock market index forecasting by neural networks models and nonlinear multiple regression modeling: Study of Iran's capital market', American Journal of Scientific Research, vol. 18, no. 2011, pp. 35-51.

Parker, C. M. \& Castleman, T. (2009), 'Small firm e-business adoption: A critical analysis of theory', Journal of Enterprise Information Management, vol. 22, no. 1/2, pp. 167-182.

Parliament of Australia (2018), Small business sector contribution to the Australian economy, $\begin{array}{llll}\text { viewed } & 5 & \text { March } & 2020\end{array}$ <https://www.aph.gov.au/About Parliament/Parliamentary Departments/Parliamentary Li brary/pubs/rp/rp1819/SmallBusinessSector>.

Peppard, J. \& Ward, J. (2004), 'Beyond strategic information systems: Towards an IS capability', The Journal of Strategic Information Systems, vol. 13, no. 2, pp. 167-194.

Perez, M. P., Sanchez, A. M., Carnicer, P. D. L. \& Jimenez, M. J. V. (2004), 'A technology acceptance model of innovation adoption: The case of teleworking', European Journal of Innovation Management, vol. 7, no. 4, pp. 280-291.

Pham, L., Pham, L. N. \& Nguyen, D. T. (2011), 'Determinants of e-commerce adoption in Vietnamese small and medium-sized enterprises', International Journal of Entrepreneurship, vol. 15, no. 2011, pp. 45-72. 
Picoto, W. N., Belanger, F. \& Palma-dos-Reis, A. (2012), 'Leveraging on Mobile Business to Enhance Firm Performance: An Organizational Level Study', Proceedings of the 20th European Conference on Information Systems, Barcelona, Spain, June 11-13, pp. 113-125.

Picoto, W. N., Belanger, F. \& Palma-dos-Reis, A. (2013), 'M-business organizational benefits and value: A qualitative study', Journal of Organizational Computing and Electronic Commerce, vol. 23, no. 4, pp. 287-324.

Picoto, W. N., Belanger, F. \& Palma-dos-Reis, A. (2014a), 'An organizational perspective on mbusiness: Usage factors and value determination', European Journal of Information Systems, vol. 23, no. 5, pp. 571-592.

Picoto, W. N., Belanger, F. \& Palma-dos-Reis, A. (2014b), 'A technology-organizationenvironment (TOE)-based m-business value instrument', International Journal of Mobile Communications, vol. 12, no. 1, pp. 78-101.

Pipitwanichakarn, T. \& Wongtada, N. (2019), 'Mobile commerce adoption among the bottom of the pyramid: a case of street vendors in Thailand', Journal of Science and Technology Policy Management, vol. 10, no. 1, pp. 193-213.

Podsakoff, P. M., MacKenzie, S. B., Lee, J. Y. \& Podsakoff, N. P. (2003), 'Common method biases in behavioral research: A critical review of the literature and recommended remedies', Journal of Applied Psychology, vol. 88, no. 5, pp. 879-903.

Poon, S. (2002), 'Have SMEs benefited from e-commerce?', Australasian Journal of Information Systems, vol. 10, no. 1, pp. 66-72.

Poon, S. \& Swatman, P. M. (1999), 'An exploratory study of small business Internet commerce issues', Information \& Management, vol. 35, no. 1, pp. 9-18.

Porter, M. E. 1985, Competitive Strategy: Creating and Sustaining Competitive Advantage, Free Press, New York, United States.

Porter, M. E. \& Millar, V. E. (1985), 'How information gives you competitive advantage', Harvard Business Review, vol. 63, no. 4, pp. 149-174.

Prasarry, Y., Astuti, E. S. \& Suyadi, I. (2015), 'Factors affecting the adoption of mobile commerce (a study on SMEs in Malang)', European Journal of Business and Management, vol. 7, no. 2, pp. 30-35. 
Premkumar, G. (2003), 'A meta-analysis of research on information technology implementation in small business', Journal of Organizational Computing and Electronic Commerce, vol. 13, no. 2, pp. 91-121.

Preston, S. H., Patrick, H. \& Michel, G. (2001), 'Demography: measuring and modeling population processes', Population and Development Review, vol. 27, no. 2, pp. 365-379.

Priyadarshinee, P., Raut, R. D., Jha, M. K. \& Gardas, B. B. (2017), 'Understanding and predicting the determinants of cloud computing adoption: A two-staged hybrid SEMNeural networks approach', Computers in Human Behavior, vol. 76, no. 2017, pp. 341-362.

Rahayu, R. \& Day, J. (2015), 'Determinant factors of e-commerce adoption by SMEs in developing country: Evidence from Indonesia', Procedia Social and Behavioral Sciences, vol. 195 , no. 2015 , pp. 142-150.

Rahman, M. M. (2013), 'Barriers to M-commerce adoption in developing countries - A qualitative study among the stakeholders of Bangladesh', The International Technology Management Review, vol. 3, no. 2, pp. 80-91.

Ramdani, B., Kawalek, P. \& Lorenzo, O. (2009), 'Predicting SMEs' adoption of enterprise systems', Journal of Enterprise Information Management, vol. 22, no. 1, pp. 10-24.

Rana, N. P., Barnard, D. J., Baabdullah, A. M., Rees, D. \& Roderick, S. (2019), 'Exploring barriers of m-commerce adoption in SMEs in the UK: Developing a framework using ISM', International Journal of Information Management, vol. 44, no. 2019, pp. 141-153.

Rao, S. S., Metts, G. \& Mora Monge, C. A. (2003), 'Electronic commerce development in small and medium-sized enterprises: A stage model and its implications', Business Process Management Journal, vol. 9, no. 1, pp. 11-32.

Ray, A. W. \& Ray, J. J. (2006), 'Strategic benefits to SMEs from third-party web services: An action research analysis', The Journal of Strategic Information Systems, vol. 15, no. 4, pp. 273-291.

Richardson, H. A., Simmering, M. J. \& Sturman, M. C. (2009), 'A tale of three perspectives: Examining post hoc statistical techniques for detection and correction of common method variance', Organizational Research Methods, vol. 12, no. 4, pp. 762-800. 
Ritchie, J., Lewis, J., Nicholls, C. M. \& Ormston, R. (2013), Qualitative research practice: A guide for social science students and researchers, Sage, London, United Kingdom.

Rodriguez, J. (2005), 'Intemationalisation of the SME: The Aware Manager', Doctoral thesis, University of Sheffield, United Kingdom.

Rogers, E. M. (1995), Diffusion of Innovations, 4th edn, Free Press, New York, United States.

Rogers, E. M. (2003), Diffusion of Innovations, 5th edn, Free Press, New York, United States.

Rogers, E. M. (2010), Diffusion of innovations, Simon and Schuster, New York, United States.

Roscoe, J. T. (1975), Fundamental research statistics for the behavioral sciences, Holt, Rinehart and Winston, New York, United States.

Rosenzweig, E. D., Laseter, T. M. \& Roth, A. V. (2011), 'Through the service operations strategy looking glass: Influence of industrial sector, ownership, and service offerings on B2B e-marketplace failures', Journal of Operations Management, vol. 29, no. 1-2, pp. 3348.

Rowland, D. T. (2003), Demographic methods and concepts, Oxford University Press, Oxford, United Kingdom.

Rudestam, K. E. \& Newton, R. R. (2014), Surviving your dissertation: A comprehensive guide to content and process, Sage Publications, New York, United States.

Sadeh, N. (2003), M-commerce: Technologies, services, and business models, John Wiley \& Sons, Australia.

Salah, K. (2013), 'E-commerce and small and medium enterprises in least developed countries: The case of Tanzania', Doctoral thesis, University of Cape Town, South Africa.

Salimon, M., Bamgbade, J., Nathaniel, A. \& Adekunle, T. (2017), 'Integrating technology acceptance model and organizational innovativeness in the adoption of mobile commerce', Management Science Letters, vol. 7, no. 10, pp. 497-512.

Salwani, I. M., Marthandan, G., Norzaidi, M. D. \& Chong, S. C. (2009), 'E-commerce usage and business performance in the Malaysian tourism sector: Empirical analysis', Information Management \& Computer Security, vol. 17, no. 2, pp. 166-185. 
Sam, T. L. \& Eam, L. H. (2011), 'Estimating the determinants of B2B e-commerce adoption among small \& medium enterprises', International Journal of Business and Society, vol. 12, no. 1, pp. 15-30.

Saprikis, V. \& Vlachopoulou, M. (2012), 'Determinants of suppliers' level of use of B2B emarketplaces', Industrial Management \& Data Systems, vol. 112, no. 4, pp. 619-643.

Saunders, M., Lewis, P. \& Thornhill, A. (2012), Research methods for business students, Pearson Education, Harlow, United Kingdom.

Saunders, M. N. K. (2011), Research methods for business students, 5 edn, Pearson Education, India.

Schumacker, R. E. \& Lomax, R. G. (2004), A beginner's guide to structural equation modeling, Psychology Press, New York, United States.

Scott, W. R. (2004), 'Institutional theory', in Encyclopedia of social theory, Sage, Thousand Oaks, CA, United States, pp. 408-414.

Scupola, A. (2003), 'The adoption of Internet commerce by SMEs in the south of Italy: An environmental, technological and organizational perspective', Journal of Global Information Technology Management, vol. 6, no. 1, pp. 52-71.

Scupola, A. (2009), 'SMEs' e-commerce adoption: perspectives from Denmark and Australia', Journal of Enterprise Information Management, vol. 22, no. 1, pp. 152-166.

Sekaran, U. \& Bougie, R. (2016), Research methods for business: A skill building approach, John Wiley \& Sons, United States.

Selznick, P. (1948), 'Foundations of the theory of organization', American Sociological Review, vol. 13 , no. 1, pp. 25-35.

Senarathna, I., Warren, M., Yeoh, W. \& Salzman, S. (2013), 'An empirical study of the influence of different organisation cultures on e-commerce adoption maturity', Proceedings of the 24th Australasian Conference on Information Systems, Melbourne, Australia, December 4-6, pp. 1-11.

Sexton, R. S., Johnson, R. A. \& Hignite, M. A. (2002), 'Predicting Internet/e-commerce use', Internet Research, vol. 12, no. 5, pp. 402-410. 
Seyal, A. H., Awais, M. M., Shamail, S. \& Abbas, A. (2004), 'Determinants of electronic commerce in Pakistan: Preliminary evidence from small and medium enterprises', Electronic Markets, vol. 14, no. 4, pp. 372-387.

Seyal, A. H. \& Rahim, M. M. (2006), 'A Preliminary investigation of electronic data interchange adoption in Bruneian small business organizations', The Electronic Journal of Information Systems in Developing Countries, vol. 24, no. 4, pp. 1-21.

Seyal, A. H. \& Rahman, M. N. A. (2003), 'A preliminary investigation of e-commerce adoption in small \& medium enterprises in Brunei', Journal of Global Information Technology Management, vol. 6, no. 2, pp. 6-26.

Seyal, A. H., Rahman, M. N. A. \& Mohammad, H. A. Y. (2007), 'A quantitative analysis of factors contributing electronic data interchange adoption among Bruneian SMEs: A pilot study', Business Process Management Journal, vol. 13, no. 5, pp. 728-746.

Shaharudin, M. R., Omar, M. W., Elias, S. J., Ismail, M., Ali, S. M. \& Fadzil, M. I. (2012), 'Determinants of electronic commerce adoption in Malaysian SMEs' furniture industry', African Journal of Business Management, vol. 6, no. 10, pp. 3648-3661.

Sharma, S. K. (2019), 'Integrating cognitive antecedents into TAM to explain mobile banking behavioral intention: A SEM-neural network modeling', Information Systems Frontiers, vol. 21 , no. 4 , pp. $815-827$.

Sheela, K. G. \& Deepa, S. N. (2013), 'Review on methods to fix number of hidden neurons in neural networks', Mathematical Problems in Engineering, vol. 2013, pp. 1-11.

Shibata, K. \& Ikeda, Y. 2009, 'Effect of number of hidden neurons on learning in large-scale layered neural networks', Proceedings of the ICCAS-SICE International Joint Conference, Fukuoka International Congress Center, Japan, August 18-21, pp. 5008-5013.

Shih, Y. Y., Chen, C. Y., Wu, C. H., Huang, T. \& Shiu, S. H. (2010), 'Adopted intention of mobile commerce from TAM perspective: An empirical study of real estate industry', Proceedings of the Portland International Center for Management of Engineering and Technology Conference, Phuket, Thailand, July 18-22, pp. 1-3.

Shih, Y. Y. \& Huang, S. S. (2009), 'Exploring the critical success factors of mobile commerce via qualitative method-in case of insurance industry', Proceedings of the Sixth International 
Conference on Information Technology: New Generations, Las Vegas, Nevada, United States, April 27-29, pp. 958-962.

Siamagka, N. T., Christodoulides, G., Michaelidou, N. \& Valvi, A. (2015), 'Determinants of social media adoption by B2B organizations', Industrial Marketing Management, vol. 51, no. 2015, pp. 89-99.

Siau, K., Lim, E. P. \& Shen, Z. (2003), 'Mobile commerce: Current states and future trends', in Advances in mobile commerce technologies, IGI Global, Hershey, United States, pp. 1-17.

Siau, K., Sheng, H. \& Nah, F. (2003), 'Development of a framework for trust in mobile commerce', Proceedings of the Second Annual Workshop on HCI Research in MIS, Seattle, WA, United States, December 12-13, pp. 85-89.

Sila, I. (2013), 'Factors affecting the adoption of B2B e-commerce technologies', Electronic Commerce Research, vol. 13, no. 2, pp. 199-236.

Sim, J. J., Tan, G. W. H., Wong, J. C. J., Ooi, K. B. \& Hew, T. S. (2014), 'Understanding and predicting the motivators of mobile music acceptance: A multi-stage MRA-artificial neural network approach', Telematics and Informatics, vol. 31, no. 4, pp. 569-584.

Smith, A. D. (2006), 'Exploring m-commerce in terms of viability, growth and challenges', International Journal of Mobile Communications, vol. 4, no. 6, pp. 682-703.

Snowden, S., Spafford, J., Michaelides, R. \& Hopkins, J. (2006), 'Technology acceptance and m-commerce in an operational environment', Journal of Enterprise Information Management, vol. 19, no. 5, pp. 525-539.

Soliman, K. S. \& Janz, B. D. (2004), 'An exploratory study to identify the critical factors affecting the decision to establish Internet-based inter-organizational information systems', Information \& Management, vol. 41, no. 6, pp. 697-706.

Son, J. Y. \& Benbasat, I. (2007), 'Organizational buyers' adoption and use of B2B electronic marketplaces: Efficiency and legitimacy-oriented perspectives', Journal of Management Information Systems, vol. 24, no. 1, pp. 55-99.

Squires, J. E., Estabrooks, C. A., Newburn-Cook, C. V. \& Gierl, M. (2011), 'Validation of the conceptual research utilization scale: an application of the standards for educational and 
psychological testing in healthcare', BMC Health Services Research, vol. 11, no. 1, pp. $107-120$.

Srinivasan, R., Lilien, G. L. \& Rangaswamy, A. (2002), 'Technological opportunism and radical technology adoption: An application to e-business', Journal of Marketing, vol. 66, no. 3, pp. 47-60.

Stanoevska-Slabeva, K. (2003), 'Towards a reference model for m-commerce applications', Proceedings of the 10th European Conference on Information Systems, Gdansk, Poland, June 6-8, pp. 159-173.

Statista (2017a), Number of internet users in Vietnam from 2015 to 2022 (in millions), viewed 11 August 2017 <https://www.statista.com/statistics/369732/internet-users-vietnam/>.

Statista (2017b), Number of smartphone users in Vietnam from 2015 to 2022 (in millions), viewed 11 August 2017 <https://www.statista.com/statistics/467739/forecast-ofsmartphone-users-in-vietnam/>.

Statista (2019a), Number of internet users in Vietnam from 2017 to 2023 (in millions), viewed 25 March 2020 <https://www.statista.com/statistics/369732/internet-users-vietnam/>.

Statista (2019b), Smartphone ownership rate by country 2018, viewed 4 September 2019 <https://www.statista.com/statistics/539395/smartphone-penetration-worldwide-bycountry/>.

Statista (2019c), Smartphone penetration rate as share of the population in Vietnam from 2017 to $2023 *$, viewed 25 March 2020 <https://www.statista.com/statistics/625458/smartphoneuser-penetration-in-vietnam/>.

Statista (2019d), Vietnam - Statistics \& Facts, viewed 25 July 2019 〈https://www.statista.com/topics/4598/vietnam/>.

Statista (2020), Smartphone penetration rate as share of the population in Vietnam from 2017 to 2023*, viewed 11 March $2020<$ https://www.statista.com/statistics/625458/smartphoneuser-penetration-in-vietnam/>.

Stockdale, R. \& Standing, C. (2004), 'Benefits and barriers of electronic marketplace participation: An SME perspective', Journal of Enterprise Information Management, vol. 17, no. 4, pp. 301-311. 
Stoica, M., Miller, D. W. \& Stotlar, D. (2005), 'New technology adoption, business strategy and government involvement: The case of mobile commerce', Journal of Nonprofit \& Public Sector Marketing, vol. 13, no. 1-2, pp. 213-232.

Straub, D., Boudreau, M. C. \& Gefen, D. (2004), 'Validation guidelines for IS positivist research', Communications of the Association for Information Systems, vol. 13, no. 1, pp. $379-427$.

Straub, D. W. (1989), 'Validating instruments in MIS research', MIS Quarterly, vol. 13, no. 2, pp. 147-169.

Street, C. T. \& Meister, D. B. (2004), 'Small business growth and internal transparency: The role of information systems', MIS Quarterly, vol. 28, no. 3, pp. 473-506.

Sun, J. \& Chi, T. (2018), 'Key factors influencing the adoption of apparel mobile commerce: an empirical study of Chinese consumers', The Journal of The Textile Institute, vol. 109, no. 6, pp. 785-797.

Swilley, E. (2007), 'An empirical examination of the intent of firms to adopt mobile commerce as a marketing strategy', Master thesis, The Florida State University, United States.

Tabachnick, B. G. \& Fidell, L. S. (2013), Using multivariate statistics, Allyn and Bacon, Boston, United States.

Tan, G. W. H., Ooi, K. B., Leong, L. Y. \& Lin, B. (2014), 'Predicting the drivers of behavioral intention to use mobile learning: A hybrid SEM-Neural Networks approach', Computers in Human Behavior, vol. 36, no. 2014, pp. 198-213.

Tan, K. S., Chong, S. C., Lin, B. \& Eze, U. C. (2009), 'Internet-based ICT adoption: evidence from Malaysian SMEs', Industrial Management \& Data Systems, vol. 109, no. 2, pp. 224244.

Tan, K. S. \& Eze, U. C. (2008), 'An empirical study of Internet-based ICT adoption among Malaysian SMEs', Communications of the IBIMA, vol. 1, no. 1, pp. 1-12.

Tarhini, A., Alalwan, A. A., Shammout, A. B. \& Al-Badi, A. (2019), 'An analysis of the factors affecting mobile commerce adoption in developing countries', Review of International Business and Strategy, vol. 29, no. 3, pp. 157-179. 
Tarute, A. \& Gatautis, R. (2014), 'ICT impact on SMEs performance', Procedia Social and Behavioral Sciences, vol. 110, no. 2014, pp. 1218-1225.

Taylor, M. \& Murphy, A. (2004), 'SMEs and the take-up of e-business', Urban Geography, vol. 25 , no. 4 , pp. 315-331.

Teddlie, C. \& Yu, F. (2007), 'Mixed methods sampling: A typology with examples', Journal of Mixed Methods Research, vol. 1, no. 1, pp. 77-100.

Teo, H. H., Wei, K. K. \& Benbasat, I. (2003), 'Predicting intention to adopt inter-organizational linkages: An institutional perspective', MIS Quarterly, vol. 27, no. 1, pp. 19-49.

Teo, T. S., Ranganathan, C. \& Dhaliwal, J. (2006), 'Key dimensions of inhibitors for the deployment of web-based business-to-business electronic commerce', IEEE Transactions on Engineering Management, vol. 53, no. 3, pp. 395-411.

Teo, T. S. H., Lin, S. \& Lai, K. H. (2009), 'Adopters and non-adopters of e-procurement in Singapore: An empirical study', Omega, vol. 37, no. 5, pp. 972-987.

Terziyan, V. (2002), 'Ontological modelling of e-services to ensure appropriate mobile transactions', Intelligent Systems in Accounting, Finance \& Management, vol. 11, no. 3, pp. 159-172.

Theodosiou, M. \& Katsikea, E. (2012), 'Antecedents and performance of electronic business adoption in the hotel industry', European Journal of Marketing, vol. 46, no. 1/2, pp. 258283.

Thong, J. Y. (1999), 'An integrated model of information systems adoption in small businesses', Journal of Management Information Systems, vol. 15, no. 4, pp. 187-214.

Thong, J. Y. L. \& Yap, C. S. (1995), 'CEO characteristics, organizational characteristics and information technology adoption in small businesses', Omega, vol. 23, no. 4, pp. 429-442.

Tiwari, R. \& Buse, S. (2007), The mobile commerce prospects: A strategic analysis of opportunities in the banking sector, Hamburg University Press, Germany.

Tjan, A. K. (2001), 'Finally, a way to put your Internet portfolio in order', Harvard Business Review, vol. 79, no. 2, pp. 76-85. 
Tolbert, P. S. (1985), 'Institutional environments and resource dependence: Sources of administrative structure in institutions of higher education', Administrative Science Quarterly, vol. 30, no. 1, pp. 1-13.

Tornatzky, L. G. \& Fleischer, M. (1990), The Processes of Technological Innovation, Lexington Books, Lexington, MA, United States.

Trang, S. T. N., Zander, S., Visser, B. \& Kolbe, L. M. (2016), 'Towards an importanceperformance analysis of factors affecting e-business diffusion in the wood industry', Journal of Cleaner Production, vol. 110, no. 2016, pp. 121-131.

Trenn, S. (2008), 'Multilayer perceptrons: Approximation order and necessary number of hidden units', IEEE Transactions on Neural Networks, vol. 19, no. 5, pp. 836-844.

Tsai, H. S. \& Gururajan, R. (2007), 'Motivations and challenges for M-business transformation: A multiple-case study', Journal of Theoretical and Applied Electronic Commerce Research, vol. 2, no. 2, pp. 19-33.

Ullah, M. \& Khan, S. U. (2012), 'Challenges and success factors in mobile commerce customer relationships management: A systematic literature review protocol', Journal of Computer Engineering, vol. 2, no. 3, pp. 25-34.

Ulrich, A. M. D. (2008), 'A Dyadic Process Model for the Development of Long-Term Business Relationships', Doctoral thesis, Universität Flensburg, German.

US Small Business Administration (2018), Small Business Profile, viewed 17 August 2018 $\langle$ https://www.sba.gov/sites/default/files/advocacy/United_States.pdf $>$.

Usunier, J. C. (1998), International and cross-cultural management research, Sage, London, United Kingdom.

Utami, H. N., Astuti, E. S., Ramadhan, H. M., Trialih, R. \& Aprilian, Y. A. (2019), 'The interests of small-and medium-sized enterprises (SMEs) actor in using mobile commerce in effort to expand business network', Journal of Science and Technology Policy Management, vol. 10, no. 3, pp. 493-508.

Van den Berg, J. \& Van der Lingen, E. (2019), 'An empirical study of the factors affecting the adoption of mobile enterprise applications', South African Journal of Industrial Engineering, vol. 30, no. 1, pp. 124-146. 
Vanderstoep, S. W. \& Johnson, D. D. (2008), Research methods for everyday life: Blending qualitative and quantitative approaches, John Wiley \& Sons, New Jersey, United States.

Varshney, U., Malloy, A., Ahluwalia, P. \& Jain, R. (2004), 'Wireless in the enterprise: Requirements, solutions and research directions', International Journal of Mobile Communications, vol. 2, no. 4, pp. 354-367.

Varshney, U. \& Vetter, R. (2002), 'Mobile commerce: framework, applications and networking support', Mobile Networks and Applications, vol. 7, no. 3, pp. 185-198.

VCCI (2016), Digital technologies: Opportunities for Vietnamese SMEs, viewed 30 August 2017 <http://www.nhandan.com.vn/hangthang/van-hoa/item/29999102-co-hoi-cho-cacdoanh-nghiep-nho-va-vua-viet-nam.html >

VECITA (2017), Only 20\% of small and medium-sized enterprises have been ready for electronic commerce, viewed 24 July $2017<$ https://tintuc.inet.vn/chi-20-doanh-nghiepvua-va-nho-tiep-can-thuong-mai-dien-tu.html>.

VECOM (2019), Vietnam E-Business Index 2019 Report, viewed 11 March 2020 〈http://www.vecom.vn/tai-lieu/bao-cao-chi-thuong-mai-dien-tu-viet-nam-2019>.

Venkatesh, V., Morris, M. G., Davis, G. B. \& Davis, F. D. (2003), 'User acceptance of information technology: Toward a unified view', MIS Quarterly, vol. 27, no. 3, pp. 425478.

Venkatraman, N. (1989), 'Strategic orientation of business enterprises: The construct, dimensionality, and measurement', Management Science, vol. 35, no. 8, pp. 942-962.

Verkijika, S. F. (2018), 'Factors influencing the adoption of mobile commerce applications in Cameroon', Telematics and Informatics, vol. 35, no. 6, pp. 1665-1674.

Vietnam Business (2017), Vietnam Digital Landscape 2017, viewed 19 February 2017 $<$ https://www.vietnambusiness.tv/market-research/marketing-media/628/vietnam-digitallandscape-2017>.

Vietnam eCommerce and Digital Economy Agency (2018), Vietnam Ecommerce White Paper 2018, viewed 7 May 2019 〈http://www.idea.gov.vn/?page=document>. 
Vietnamese Government (2010), Overall Plan for Electronic Commerce Development from 2011 to $2015, \quad$ viewed $\quad 10 \quad$ March 2020 $<$ http://vanban.chinhphu.vn/portal/page/portal/chinhphu/hethongvanban?class_id=1\&_pag

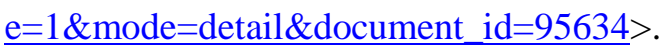

Vietnamese Government (2016), Overall Plan for Electronic Commerce Development from 2016 to 2020, $\quad 10 \quad$ viewed 2020 $<$ http://vanban.chinhphu.vn/portal/page/portal/chinhphu/hethongvanban?class_id=2\&_pag

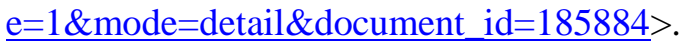

Vittinghoff, E. \& McCulloch, C. E. (2007), 'Relaxing the rule of ten events per variable in logistic and Cox regression', American Journal of Epidemiology, vol. 165, no. 6, pp. 710718.

Wade, M. \& Hulland, J. (2004), 'The resource-based view and information systems research: Review, extension, and suggestions for future research', MIS Quarterly, vol. 28, no. 1, pp. $107-142$.

Waithaka, S. T. \& Mnkandla, E. (2017), 'Challenges Facing the Use of Mobile Applications for E-Commerce in Kenya's Manufacturing Industry', The Electronic Journal of Information Systems in Developing Countries, vol. 83, no. 1, pp. 1-25.

Wamba, S. F. \& Carter, L. (2013), 'Twitter adoption and use by SMEs: An empirical study', Proceedings of the 46th Hawaii International Conference on System Sciences, Hawaii, United States, January 7-10, pp. 2042-2049.

Wang, H. \& Hou, J. (2012), 'Factors Affecting E-commerce Adoption and Implementation in Small and Medium-Sized Enterprises', International Journal of Digital Content Technology and Its Applications, vol. 6, no. 7, pp. 167-182.

Wang, S. \& Cheung, W. (2004), 'E-business adoption by travel agencies: Prime candidates for mobile e-business', International Journal of Electronic Commerce, vol. 8, no. 3, pp. 43-63.

Wang, Y. \& Ahmed, P. K. (2009), 'The moderating effect of the business strategic orientation on eCommerce adoption: Evidence from UK family run SMEs', The Journal of Strategic Information Systems, vol. 18, no. 1, pp. 16-30. 
Wiersema, M. F. \& Bowen, H. P. (2009), 'The use of limited dependent variable techniques in strategy research: Issues and methods', Strategic Management Journal, vol. 30, no. 6, pp. 679-692.

Williams, B., Onsman, A. \& Brown, T. (2010), 'Exploratory factor analysis: A five-step guide for novices', Australasian Journal of Paramedicine, vol. 8, no. 3, pp. 1-13.

Williams, M. D., Dwivedi, Y. K., Lal, B. \& Schwarz, A. (2009), 'Contemporary trends and issues in IT adoption and diffusion research', Journal of Information Technology, vol. 24, no. 1, pp. 1-10.

Wilson, H., Daniel, E. \& Davies, I. A. (2008), 'The diffusion of e-commerce in UK SMEs', Journal of Marketing Management, vol. 24, no. 5-6, pp. 489-516.

Wong, T. C., Wong, S. Y. \& Chin, K. S. (2011), 'A neural network-based approach of quantifying relative importance among various determinants toward organizational innovation', Expert Systems with Applications, vol. 38, no. 10, pp. 13064-13072.

Wrenn, B., Stevens, R. E. \& Loudon, D. L. (2007), Marketing research: Text and cases, Psychology Press, East Sussex, United Kingdom.

Wu, L. \& Chuang, C. H. (2010), 'Examining the diffusion of electronic supply chain management with external antecedents and firm performance: A multi-stage analysis', Decision Support Systems, vol. 50, no. 1, pp. 103-115.

Wymer, S. A. \& Regan, E. A. (2005), 'Factors influencing e-commerce adoption and use by small and medium businesses', Electronic Markets, vol. 15, no. 4, pp. 438-453.

Yadav, R., Sharma, S. K. \& Tarhini, A. (2016), 'A multi-analytical approach to understand and predict the mobile commerce adoption', Journal of Enterprise Information Management, vol. 29, no. 2, pp. 222-237.

Yang, F. (2005), 'Studies on motivation of adoption mobile commerce system in Chinese SMEs', Proceedings of the Conference of System Dynamics and Management Science, Shanghai, China, June 21-22, pp. 410-414.

Yang, K. C. C. (2005), 'Exploring factors affecting the adoption of mobile commerce in Singapore', Telematics and Informatics, vol. 22, no. 3, pp. 257-277. 
Yaseen, S. G. (2010), 'Exploring critical determinants in deploying mobile commerce technology', American Journal of Applied Sciences, vol. 7, no. 1, pp. 35-46.

Yeh, C. H., Lee, G. G. \& Pai, J. C. (2015), 'Using a technology-organization-environment framework to investigate the factors influencing e-business information technology capabilities', Information Development, vol. 31, no. 5, pp. 435-450.

Ygge, B. M. \& Arnetz, J. E. (2004), 'A study of non-response in a questionnaire survey of parents' views of paediatric care', Journal of Nursing Management, vol. 12, no. 1, pp. 5-12.

Yuksel, A., Yuksel, F. \& Bilim, Y. (2010), 'Destination attachment: Effects on customer satisfaction and cognitive, affective and conative loyalty', Tourism Management, vol. 31, no. 2 , pp. 274-284.

Zeeshan, S. A., Cheung, Y. \& Scheepers, H. (2007), 'Developing a collaborative organizational mobile commerce model', Proceedings of the International Conference on Business and Information, Tokyo, Japan, July 11-13, pp. 34-47.

Zhang, J. J., Yuan, Y. \& Archer, N. (2002), 'Driving forces for m-commerce success', Journal of Internet Commerce, vol. 1, no. 3, pp. 81-104.

Zhang, X. J., Li, Z. \& Deng, H. (2017), 'Information security behaviors of smartphone users in China: an empirical analysis', The Electronic Library, vol. 35, no. 6, pp. 1177-1190.

Zhiping, W. (2009), 'Chinese customer's attitude and adopt intention on mobile commerce', Proceedings of the 6th International Conference on Service Systems and Service Management, Xiamen, China, June 8-10, pp. 731-734.

Zhu, K., Dong, S., Xu, S. X. \& Kraemer, K. L. (2006), 'Innovation diffusion in global contexts: Determinants of post-adoption digital transformation of European companies', European Journal of Information Systems, vol. 15, no. 6, pp. 601-616.

Zhu, K., Kraemer, K. \& Xu, S. (2003), 'Electronic business adoption by European firms: A cross-country assessment of the facilitators and inhibitors', European Journal of Information Systems, vol. 12, no. 4, pp. 251-268.

Zhu, K. \& Kraemer, K. L. (2005), 'Post-adoption variations in usage and value of e-business by organizations: Cross-country evidence from the retail industry', Information Systems Research, vol. 16, no. 1, pp. 61-84. 
Zhu, K., Kraemer, K. L. \& Dedrick, J. (2004), 'Information technology payoff in e-business environments: An international perspective on value creation of e-business in the financial services industry', Journal of Management Information Systems, vol. 21, no. 1, pp. 17-54.

Zhu, K., Kraemer, K. L. \& Xu, S. (2006), 'The process of innovation assimilation by firms in different countries: A technology diffusion perspective on e-business', Management Science, vol. 52, no. 10, pp. 1557-1576.

Zikmund, W. G., Carr, J. C. \& Griffin, M. (2013), Business Research Methods, Cengage Learning, Boston, MA, United States. 


\section{Appendix A - Invitation Letter for Participation (English)}

\section{Dear SME's Manager/Owner!}

This questionnaire is a part of my PhD research at RMIT University, Melbourne, Australia. This research entitled "Critical Determinants for Mobile Commerce Adoption in Vietnamese Small and Medium-Sized Enterprises", is attempting to study the adoption of m-commerce in Vietnamese SMEs to have a better explanation of factors affecting decision-makers toward mcommerce adoption.

M-commerce adoption provides organizations with many benefits such as improving productivity, increasing customer satisfaction, and lowering operational costs. Additionally, m-commerce adoption brings SMEs cost-effective ways to promote their products and services and therefore enhancing their national and international competitive advantages. The results of this study would fill the gap by developing a comprehensive model to explain factors affecting the decision to adopt m-commerce in Vietnamese SMEs to facilitate business operations and improve business performance.

Your participation is voluntary. It will only take you no more than 20 minutes to fill out the questionnaire. There is no right or wrong answer; your answer is your opinion. You are not required to identify yourself or your company, and your response will be kept strictly confidential. The data you provide will only be used for research purposes. An executive summary of the major research findings can be sent to the participating enterprises. If you would like to receive a copy of the study summary report, please include the relevant forwarding address at the end of the questionnaire. Your participation in this survey will be accepted as your consent.

Your participation in this research is very important for the successful completion of the research. Your kind cooperation in this research is highly appreciated, and the research team sincerely hopes that you will find the study of interest to you. If you have any questions about the research or how I intend to conduct the study, please contact me.

Thank you very much for your time and cooperation.

\section{Chau Ngoc Tuan}

School of Business IT \& Logistics, College of Business, RMIT University, Australia 


\section{Appendix B - Survey Questionnaire (English)}

Mobile commerce (m-commerce) is about buying and selling goods and services through wireless handheld devices such as cellular phones and personal digital assistants. This survey aims to explore the current patterns and critical determinants for the adoption of m-commerce in Vietnamese SMEs.

\section{DO YOU CONSENT TO TAKE PART IN THIS SURVEY?}

\section{O YES \\ O NO}

By selecting "YES" means that you consent to take part in this survey. The data you provide will only be used for research purposes. The research outcomes and results will be published in the thesis, academic journal, and conference papers. An executive summary of the major research findings can be sent to the participating enterprises. If you would like to receive a copy of the study summary report, please contact the researcher via email: tuan.chau@ rmit.edu.au.

\section{Section 1: Company's background information}

Please respond to these following questions by ticking the choice that best describes your company.

Q1. Where is your company located?
$\bigcirc$ North Vietnam
$\bigcirc$ Central \& Highland Vietnam
$\bigcirc$ South Vietnam

Q2. How long has your company been in operation?
$0<5$ years
5-10 years
○ $11-15$ years
$\bigcirc>15$ years

Q3. Which sector does your company operate?
$\bigcirc$ Construction
$\bigcirc$ Manufacturing
$\bigcirc$ Transportation
$\bigcirc$ Trading
O Healthcare
$\bigcirc$ Finance \& insurance
Services
O ICT
Others: 
Q4. Approximately, how many employees are there in your company?
$\bigcirc<10$
$\bigcirc 51-100$
○ $201-300$
○ $10-50$
○ $101-200$
○> 300

Q5. Approximately, how much is the total capital of your company (VND)?
$\bigcirc<10$ billion
$\bigcirc 20-<50$ billion
$\bigcirc>=100$ billion
$\bigcirc 10-<20$ billion
○ $50-<100$ billion

Q6. Is there an IT department in your company?
$\bigcirc$ Yes
$\mathrm{O}$ No

Q7. How many IT professionals are there in your company?
$\bigcirc 0$
○ $4-6$
$\bigcirc>10$
$\bigcirc 1-3$
○ $7-10$

Q8. Does your company have a website?
$\bigcirc$ Yes
$\mathrm{O}$ No

Q9. Can your company's website be accessible by mobile devices?
$\bigcirc$ Yes
$\bigcirc$ No

Q10. What does your company use the website for? (Please tick as many choices as appropriate)?
$\bigcirc$ Display company information
Promotion of company products/services
$\bigcirc$ Conduct online transaction
$\bigcirc$ Other. Please specify:

Q11. How does your company conduct selling activities (Please tick as many choices as appropriate)?
$\bigcirc$ Using traditional commerce

Q12. How long has your company been conducting m-commerce?
$\bigcirc<1$ years
$\bigcirc 1-<3$ years
$\bigcirc 3-<5$ years
$\bigcirc \geq 5$ years 
Q13. If your company is not adopting m-commerce, does your company have any plan to adopt m-commerce in the next 12 months?
$\bigcirc$ Yes
$\bigcirc$ No

\section{Section 2: Critical determinants for the adoption of mobile commerce}

This part of the questionnaire concerns your company's viewpoints about the variety of factors affecting the decision to adopt mobile commerce. Please indicate the extent you agree or disagree with the following statements by selecting a number from 1 "strongly disagree" to 5 "strongly agree".

Q14. The following statements relate to your company's viewpoints about the influence of the BENEFITS of m-commerce on the adoption of $\mathrm{m}$-commerce. Please indicate to what extent you agree or disagree with these statements by selecting 1 (strongly disagree) to 5 (strongly agree).

\begin{tabular}{|c|c|c|c|c|c|}
\hline & 1 & 2 & 3 & 4 & 5 \\
\hline $\begin{array}{l}\text { The operating costs savings is critical for the adoption of } \mathrm{m} \text { - } \\
\text { commerce. }\end{array}$ & 0 & 0 & 0 & 0 & 0 \\
\hline $\begin{array}{l}\text { The simplification of the operating procedures is critical for the } \\
\text { adoption of m-commerce. }\end{array}$ & 0 & 0 & 0 & 0 & 0 \\
\hline $\begin{array}{l}\text { The increase in market share is critical for the adoption of } \mathrm{m} \text { - } \\
\text { commerce. }\end{array}$ & 0 & 0 & 0 & 0 & $\bigcirc$ \\
\hline $\begin{array}{l}\text { The growth of revenue is critical for the adoption of } \mathrm{m} \text { - } \\
\text { commerce. }\end{array}$ & 0 & 0 & 0 & 0 & 0 \\
\hline $\begin{array}{l}\text { The creation of marketing channels is critical for the adoption of } \\
\text { m-commerce. }\end{array}$ & 0 & 0 & 0 & 0 & 0 \\
\hline $\begin{array}{l}\text { The improvement of the company's image is critical for the } \\
\text { adoption of m-commerce. }\end{array}$ & 0 & 0 & 0 & 0 & 0 \\
\hline $\begin{array}{l}\text { The improvement in competitiveness is critical for the adoption } \\
\text { of m-commerce. }\end{array}$ & 0 & 0 & 0 & 0 & 0 \\
\hline $\begin{array}{l}\text { The enhancement of customer service is critical for the adoption } \\
\text { of m-commerce. }\end{array}$ & 0 & 0 & 0 & 0 & 0 \\
\hline
\end{tabular}


Q15. The following statements relate to your company's viewpoints about the influence of the COMPATIBILITY of m-commerce on the adoption of m-commerce. Please indicate to what extent you agree or disagree with these statements by selecting 1 (strongly disagree) to 5 (strongly agree).

\begin{tabular}{|l|l|l|l|l|l|}
\hline $\begin{array}{l}\text { The alignment with the ICT infrastructure of the company is } \\
\text { critical for the adoption of m-commerce. }\end{array}$ & 0 & 0 & $\bigcirc$ & $\bigcirc$ & $\bigcirc$ \\
\hline $\begin{array}{l}\text { The integration with the current business processes of the } \\
\text { company is critical for the adoption of m-commerce. }\end{array}$ & $\bigcirc$ & $\bigcirc$ & $\bigcirc$ & $\bigcirc$ \\
\hline $\begin{array}{l}\text { The adaptability of existing distribution channels of the company } \\
\text { is critical for the adoption of m-commerce. }\end{array}$ & $\bigcirc$ & $\bigcirc$ & $\bigcirc$ & $\bigcirc$ & $\bigcirc$ \\
\hline $\begin{array}{l}\text { The consistency with the culture of the company is critical for the } \\
\text { adoption of m-commerce. }\end{array}$ & $\bigcirc$ & $\bigcirc$ & $\bigcirc$ & $\bigcirc$ & $\bigcirc$ \\
\hline $\begin{array}{l}\text { The suitability with customers' ways of doing business is critical } \\
\text { for the adoption of m-commerce. }\end{array}$ & $\bigcirc$ & $\bigcirc$ & $\bigcirc$ & $\bigcirc$ & $\bigcirc$ \\
\hline $\begin{array}{l}\text { The richness of the company experience in adopting } \\
\text { technological innovations is critical for the adoption of m- } \\
\text { commerce. }\end{array}$ & $\bigcirc$ & $\bigcirc$ & $\bigcirc$ & $\bigcirc$ & $\bigcirc$ \\
\hline
\end{tabular}

Q16. The following statements relate to your company's viewpoints about the influence of the SECURITY of $\mathrm{m}$-commerce adoption on the adoption of $\mathrm{m}$-commerce. Please indicate to what extent you agree or disagree with these statements by selecting 1 (strongly disagree) to 5 (strongly agree).

\begin{tabular}{|l|l|l|l|l|l|}
\hline & 1 & 2 & 3 & 4 & 5 \\
\hline $\begin{array}{l}\text { The company's awareness of the security of m-commerce is } \\
\text { critical for the adoption of m-commerce. }\end{array}$ & $\bigcirc$ & $\bigcirc$ & $\bigcirc$ & $\bigcirc$ \\
\hline $\begin{array}{l}\text { The availability of industry standards for the security of m- } \\
\text { commerce is critical for the adoption of m-commerce. }\end{array}$ & $\bigcirc$ & $\bigcirc$ & $\bigcirc$ & $\bigcirc$ \\
\hline $\begin{array}{l}\text { The availability of laws and regulations for m-commerce is } \\
\text { critical for the adoption of m-commerce. }\end{array}$ & $\bigcirc$ & $\bigcirc$ & $\bigcirc$ & $\bigcirc$ & $\bigcirc$ \\
\hline
\end{tabular}


Q17. The following statements relate to your company's viewpoints about the influence of the COSTS of m-commerce adoption on the adoption of m-commerce. Please indicate to what extent you agree or disagree with these statements by selecting 1 (strongly disagree) to 5 (strongly agree).

\begin{tabular}{|l|c|c|c|c|c|}
\hline & 1 & 2 & 3 & 4 & 5 \\
\hline $\begin{array}{l}\text { M-commerce infrastructure cost requirements are critical for the } \\
\text { adoption of m-commerce. }\end{array}$ & $\bigcirc$ & $\bigcirc$ & $\bigcirc$ & $\bigcirc$ \\
\hline $\begin{array}{l}\text { Training cost requirements are critical for the adoption of m- } \\
\text { commerce. }\end{array}$ & $\bigcirc$ & $\bigcirc$ & $\bigcirc$ & $\bigcirc$ & $\bigcirc$ \\
\hline $\begin{array}{l}\text { Maintenance cost requirements are critical for the adoption of m- } \\
\text { commerce. }\end{array}$ & $\bigcirc$ & $\bigcirc$ & $\bigcirc$ & $\bigcirc$ & $\bigcirc$ \\
\hline
\end{tabular}

Q18. The following statements relate to your company's viewpoints about the influence of EMPLOYEES' IT KNOWLEDGE on the adoption of m-commerce. Please indicate to what extent you agree or disagree with these statements by selecting 1 (strongly disagree) to 5 (strongly agree).

\begin{tabular}{|l|c|c|c|c|c|}
\hline $\begin{array}{l}\text { The employees' understanding of m-commerce is critical for the } \\
\text { adoption of m-commerce. }\end{array}$ & ○ & $\bigcirc$ & $\bigcirc$ & $\bigcirc$ & $\bigcirc$ \\
\hline $\begin{array}{l}\text { The employees' proficiency in using IT is critical for the } \\
\text { adoption of m-commerce. }\end{array}$ & $\bigcirc$ & $\bigcirc$ & $\bigcirc$ & $\bigcirc$ & $\bigcirc$ \\
\hline $\begin{array}{l}\text { The employees' competence in new technology is critical for the } \\
\text { adoption of m-commerce. }\end{array}$ & $\bigcirc$ & $\bigcirc$ & $\bigcirc$ & $\bigcirc$ & $\bigcirc$ \\
\hline
\end{tabular}

Q19. The following statements relate to your viewpoints about the influence of ORGANIZATIONAL READINESS on the adoption of m-commerce. Please indicate to what extent you agree or disagree with these statements by selecting 1 (strongly disagree) to 5 (strongly agree).

\begin{tabular}{|l|c|c|c|c|c|}
\hline & 1 & 2 & 3 & 4 & 5 \\
\hline $\begin{array}{l}\text { The financial readiness of the company is critical for the adoption } \\
\text { of m-commerce. }\end{array}$ & $\bigcirc$ & $\bigcirc$ & $\bigcirc$ & $\bigcirc$ & $\bigcirc$ \\
\hline $\begin{array}{l}\text { The technological readiness of the company is critical for the } \\
\text { adoption of m-commerce. }\end{array}$ & $\bigcirc$ & $\bigcirc$ & $\bigcirc$ & $\bigcirc$ & $\bigcirc$ \\
\hline $\begin{array}{l}\text { The human resource readiness of the company is critical for the } \\
\text { adoption of m-commerce. }\end{array}$ & $\bigcirc$ & $\bigcirc$ & $\bigcirc$ & $\bigcirc$ & $\bigcirc$ \\
\hline
\end{tabular}


Q20. The following statements relate to your viewpoints about the influence of ORGANIZATIONAL INNOVATIVENESS on the adoption of m-commerce. Please indicate to what extent you agree or disagree with these statements by selecting 1 (strongly disagree) to 5 (strongly agree).

\begin{tabular}{|l|c|c|c|c|c|}
\hline $\begin{array}{l}\text { The innovativeness ability of the company is critical for the } \\
\text { adoption of m-commerce. }\end{array}$ & $\bigcirc$ & 0 & $\bigcirc$ & $\bigcirc$ & $\bigcirc$ \\
\hline $\begin{array}{l}\text { The ability to adopt new management approaches is critical for } \\
\text { the adoption of m-commerce. }\end{array}$ & $\bigcirc$ & $\bigcirc$ & $\bigcirc$ & $\bigcirc$ & $\bigcirc$ \\
\hline $\begin{array}{l}\text { The ability to improve business processes continuously is critical } \\
\text { for the adoption of m-commerce. }\end{array}$ & $\bigcirc$ & $\bigcirc$ & $\bigcirc$ & $\bigcirc$ & $\bigcirc$ \\
\hline
\end{tabular}

Q21. The following statements relate to your viewpoints about the influence of COMPETITORS on the adoption of m-commerce. Please indicate to what extent you agree or disagree with these statements by selecting 1 (strongly disagree) to 5 (strongly agree).

\begin{tabular}{|l|c|c|c|c|c|}
\hline $\begin{array}{l}\text { The availability of similar products/services of competitors is } \\
\text { critical for the adoption of m-commerce. }\end{array}$ & 0 & $\bigcirc$ & $\bigcirc$ & $\bigcirc$ & $\bigcirc$ \\
\hline $\begin{array}{l}\text { The availability of similar products/services of new entrants is } \\
\text { critical for the adoption of m-commerce. }\end{array}$ & $\bigcirc$ & $\bigcirc$ & $\bigcirc$ & $\bigcirc$ & $\bigcirc$ \\
\hline $\begin{array}{l}\text { The availability of substitute products/services is critical for the } \\
\text { adoption of m-commerce. }\end{array}$ & $\bigcirc$ & $\bigcirc$ & $\bigcirc$ & $\bigcirc$ & $\bigcirc$ \\
\hline
\end{tabular}

Q22. The following statements relate to your viewpoints about the influence of CUSTOMERS on the adoption of m-commerce. Please indicate to what extent you agree or disagree with these statements by selecting 1 (strongly disagree) to 5 (strongly agree).

\begin{tabular}{|l|c|c|c|c|c|}
\hline & 1 & 2 & 3 & 4 & 5 \\
\hline $\begin{array}{l}\text { The requirement for adopting m-commerce from customers is } \\
\text { critical for the adoption of m-commerce. }\end{array}$ & $\bigcirc$ & $\bigcirc$ & $\bigcirc$ & $\bigcirc$ & $\bigcirc$ \\
\hline $\begin{array}{l}\text { The expectation for adopting m-commerce from customers is } \\
\text { critical for the adoption of m-commerce. }\end{array}$ & $\bigcirc$ & $\bigcirc$ & $\bigcirc$ & $\bigcirc$ & $\bigcirc$ \\
\hline $\begin{array}{l}\text { The need for maintaining relationships with customers is critical } \\
\text { for the adoption of m-commerce. }\end{array}$ & $\bigcirc$ & $\bigcirc$ & $\bigcirc$ & $\bigcirc$ & $\bigcirc$ \\
\hline
\end{tabular}


Q23. The following statements relate to your viewpoints about the influence of GOVERNMENT SUPPORT on the adoption of m-commerce. Please indicate to what extent you agree or disagree with these statements by selecting 1 (strongly disagree) to 5 (strongly agree).

\begin{tabular}{|l|c|c|c|c|c|}
\hline $\begin{array}{l}\text { Legal considerations for m-commerce are critical for the } \\
\text { adoption of m-commerce. }\end{array}$ & $\bigcirc$ & $\bigcirc$ & $\bigcirc$ & $\bigcirc$ & $\bigcirc$ \\
\hline $\begin{array}{l}\text { Financial support from the government for SMEs to adopt new } \\
\text { technologies is critical for the adoption of m-commerce. }\end{array}$ & $\bigcirc$ & $\bigcirc$ & $\bigcirc$ & $\bigcirc$ & $\bigcirc$ \\
\hline $\begin{array}{l}\text { The availability of training and educational programs from the } \\
\text { government for SMEs to improve the ability to adopt new } \\
\text { technologies is critical for the adoption of m-commerce. }\end{array}$ & $\bigcirc$ & $\bigcirc$ & $\bigcirc$ & $\bigcirc$ & $\bigcirc$ \\
\hline
\end{tabular}

Q24. The following statements relate to your viewpoints about the influence of TOP MANAGEMENT SUPPORT on the adoption of m-commerce. Please indicate to what extent you agree or disagree with these statements by selecting 1 (strongly disagree) to 5 (strongly agree).

\begin{tabular}{|l|c|c|c|c|c|}
\hline & 1 & 2 & 3 & 4 & 5 \\
\hline $\begin{array}{l}\text { The top managers' awareness of m-commerce benefits is critical } \\
\text { for the adoption of m-commerce. }\end{array}$ & $\bigcirc$ & $\bigcirc$ & $\bigcirc$ & $\bigcirc$ & $\bigcirc$ \\
\hline $\begin{array}{l}\text { The allocation of necessary resources for m-commerce adoption } \\
\text { from top management is critical for the adoption of m-commerce. }\end{array}$ & $\bigcirc$ & $\bigcirc$ & $\bigcirc$ & $\bigcirc$ & $\bigcirc$ \\
\hline $\begin{array}{l}\text { The championship of management for m-commerce is critical for } \\
\text { the adoption of m-commerce. }\end{array}$ & $\bigcirc$ & $\bigcirc$ & $\bigcirc$ & $\bigcirc$ & $\bigcirc$ \\
\hline
\end{tabular}

Q25. The following statements relate to your viewpoints about the influence of MANAGERS' IT KNOWLEDGE on the adoption of m-commerce. Please indicate to what extent you agree or disagree with these statements that by selecting 1 (strongly disagree) to 5 (strongly agree).

\begin{tabular}{|l|l|l|l|l|l|}
\hline & 1 & 2 & 3 & 4 & 5 \\
\hline $\begin{array}{l}\text { The top managers' understanding of m-commerce is critical for } \\
\text { the adoption of m-commerce. }\end{array}$ & $\bigcirc$ & $\bigcirc$ & $\bigcirc$ & $\bigcirc$ & $\bigcirc$ \\
\hline $\begin{array}{l}\text { The top managers' proficiency in using IT is critical for the } \\
\text { adoption of m-commerce. }\end{array}$ & $\bigcirc$ & $\bigcirc$ & $\bigcirc$ & $\bigcirc$ & $\bigcirc$ \\
\hline $\begin{array}{l}\text { The top managers' competence in the new technology is critical } \\
\text { for the adoption of m-commerce. }\end{array}$ & $\bigcirc$ & $\bigcirc$ & $\bigcirc$ & $\bigcirc$ & $\bigcirc$ \\
\hline
\end{tabular}


Q26. The following statements relate to your viewpoints about the DECISION TO ADOPT M-COMMERCE in your company. Please indicate to what extent you agree or disagree with these statements by selecting 1 (strongly disagree) to 5 (strongly agree).

\begin{tabular}{|l|c|c|c|c|c|}
\hline & 1 & 2 & 3 & 4 & 5 \\
\hline Our company intends to adopt m-commerce. & $\bigcirc$ & $\bigcirc$ & $\bigcirc$ & $\bigcirc$ & $\bigcirc$ \\
\hline Our company has a certain plan to adopt m-commerce. & $\bigcirc$ & $\bigcirc$ & $\bigcirc$ & $\bigcirc$ & $\bigcirc$ \\
\hline $\begin{array}{l}\text { Our company has a strong commitment to adopting m- } \\
\text { commerce. }\end{array}$ & $\bigcirc$ & $\bigcirc$ & $\bigcirc$ & $\bigcirc$ & $\bigcirc$ \\
\hline
\end{tabular}

\section{Section 3: Respondents' demographic information}

Please respond to these following questions by ticking the choice that best describes you.

Q27. Please indicate your gender
$\bigcirc$ Male
Female

Q28. Please indicate your age range
$\bigcirc 18-25$
○ $26-35$
○ $36-45$
○ $46-55$
$\bigcirc>=55$

Q29. Please indicate your highest qualification
$\bigcirc$ Postgraduate
$\bigcirc$ Diploma
$\bigcirc$ Below high school
$\bigcirc$ Bachelor
$\bigcirc$ High school

Q30. What is your position in the company?
$\bigcirc$ Director
$\bigcirc$ Head of Department
Others:
○ Vice Director
O Deputy Head of Department

Q31. How long have you been in this position?
$0<1$ year
$\bigcirc 1-3$ years
O $3-5$ years
$\bigcirc>=5$ years 


\section{Appendix C - Invitation Letter for Participation (Vietnamese)}

\section{Kính gửi quý anh/chị quản lý doanh nghiệp!}

Bản hỏi này là một phần của đề tài nghiên cứu tiến sĩ của tôi tại Đại học RMIT, Melbourne, Úc. Đề tài "Những yếu tố quyết định cho việc ứng dụng thương mại di động trong các doanh nghiệp nhỏ và vừa tại Việt Nam”, nghiên cứu ý định ứng dụng thương mại di động trong các doanh nghiệp nhỏ và vừa tại Việt Nam nhằm giải thích rõ hơn về các yếu tố ảnh hưởng đến quyết định của doanh nghiệp trong việc ứng dụng thương mại di dộng.

Ứng dụng thương mại di động mang đến cho doanh nghiệp nhiều lợi ích như cải thiện hiệu suất hoạt động, gia tăng sự hài lòng của khách hàng và giảm chi phí hoạt động. Bên cạnh đó, ứng dụng thương mại di động mang đến cho doanh nghiệp cách thức hiệu quả về chi phí trong việc quảng bá sản phẩm và dịch vụ, từ đó nâng cao lợi thế cạnh tranh cho doanh nghiệp ở thị trường nội địa cũng như trên thị trường quốc tế. Kết quả nghiên cứu này dự kiến sẽ khắc phục được những hạn chế của những nghiên cứu tương tự trước đây bằng cách phát triển một mô hình toàn diện nhằm giải thích các yếu tố ảnh hưởng đến quyết định ứng dụng thương mại di động trong các doanh nghiệp nhỏ và vừa nhằm tạo thuận lợi cho hoạt động kinh doanh cũng như nâng cao hiệu quả kinh doanh của doanh nghiệp.

Việc tham gia của anh/chị vào nghiên cứu này là hoàn toàn tự nguyện. Dự kiến việc hoàn thành bản hỏi sẽ mất khoảng 20 phút. Những câu trả lời là ý kiến của cá nhân anh/chị, do vậy không có câu trả lời đúng hay sai. Ngoài ra, thông tin về cá nhân cũng nhưng thông tin của doanh nghiệp nơi anh/chị đang làm việc sẽ được giữ bí mật. Dữ liệu mà anh/chị cung cấp chỉ được sử dụng cho mục đích nghiên cứu. Nếu anh/chị có quan tâm và muốn nhận bản tóm tắt kết quả của nghiên cứu này, vui lòng cung cấp địa chỉ email hoặc thư tay ở cuối bản hỏi. Việc hoàn thành bản hỏi sẽ được xem như sự đồng ý tham gia của anh/chị trong nghiên cứu này.

Chúng tôi, nhóm nghiên cứu rất hoan nghênh và đánh giá cao sự hợp tác của anh/chị trong nghiên cứu này. Ý kiến đánh giá của anh/chị là yếu tố quan trọng cho sự thành công của nghiên cứu. Chúng tôi hy vọng rằng anh/chị sẽ dành nhiều sự quan tâm cho nghiên cứu này. Nếu anh/chị có bất cứ thắc mắc hay góp ý gì cho nghiên cứu, vui lòng liên hệ với chúng tôi theo địa chỉ được cung cấp bên dưới.

Chân thành cảm ơn sự hợp tác của quý anh/chị.

\section{Châu Ngọc Tuấn}

Khoa Kinh doanh CNTT \& Vận tải, Trường Kinh doanh RMIT, Úc 


\section{Appendix D - Survey Questionnaire (Vietnamese)}

Thương mại di động (TMDĐ) bao gồm các hoạt động mua bán hàng hóa và dịch vụ thông qua các thiết bị cầm tay không dây như điện thoại di động và các thiết bị kỹ thuật số cá nhân như ipad... Khảo sát này nhằm mục đích tìm hiểu các mô hình ứng dụng thương mại di động hiện tại và các yếu tố quyết định tác động đến việc ứng dụng thương mại di động trong các doanh nghiệp nhỏ và vừa tại Việt Nam.

Để chọn câu trả lời, xin các anh chị đánh dấu tick $\sqrt{ }$ hoặc dấu $\mathbf{X}$ vào ô chọn.

\section{ANH/CH!̣ CÓ ĐỒNG Ý THAM GIA KHẢO SÁT KHÔNG?}
○ CÓ
O KHÔNG

Lựa chọn “CÓ” nghĩa là anh/chị đồng ý tham gia khảo sát. Dữ liệu anh/chị cung cấp chỉ được sử dụng cho mục đích nghiên cứu. Các kết quả nghiên cứu sẽ được công bố trong luận văn, bài báo, đăng trên các tạp chí chuyên ngành hoặc tại hội thảo khoa học. Bản tóm tắt các kết quả nghiên cứu có thể được gửi đến các doanh nghiệp tham gia khảo sát. Nếu anh/chị muốn nhận báo cáo tóm tắt kết quả nghiên cứu, xin vui lòng liên hệ với tác giả qua email: tuan.chau@rmit.edu.au.

\section{Phần 1: Thông tin doanh nghiệp}

Anh/chị vui lòng trả lời những câu hỏi sau bằng cách chọn MộT ô mô tả đúng nhất về doanh nghiệp nơi anh/chị đang làm việc.

C1. Trụ sở chính của doanh nghiệp anh/chị ở đâu?
Miền Bắc
Miền Trung - Tây nguyên
Miền Nam

C2. Doanh nghiệp của anh/chị đã hoạt động trong thời gian bao lâu?
$\bigcirc<5$ năm
○ - 10 năm
○ $11-15$ năm
○ $>15$ năm

C3. Lĩnh vực hoạt động của doanh nghiệp anh/chị là gì?
Xây dựng
○ Sản xuất
○ Vận tải
○ Thương mại
Y Y tế, dược phẩm
Tài chính \& bảo hiểm
Dịch vụ
CNTT và truyền thông
Lĩnh vực khác: 
C4. Số lượng nhân viên làm việc chính thức tại doanh nghiệp của anh/chị?
$\bigcirc<10$
○ $51-100$
○ $201-300$
$\bigcirc 10-50$
○ $101-200$
$0>300$

C5. Tổng tài sản doanh nghiệp của anh/chị khoảng bao nhiêu (VND)?
$\bigcirc<10$ tỷ
$\bigcirc 20-<50$ tỷ
$\bigcirc>=100$ tỷ
○ $10-<20$ tỷ
○ $50-<100$ tỷ

C6. Doanh nghiệp của anh/chị có bộ phận phụ trách về Công nghệ thông tin không?
○ Có
Không

C7. Có bao nhiêu nhân viên phụ trách Công nghệ thông tin tại doanh nghiệp của anh/chị?
○ 0
○ 4-6
O $>10$
○ 1-3
○ $7-10$

C8. Doanh nghiệp của anh/chị có trang web riêng không?
○ Có
Không

C9. Hiện tại, trang web của doanh nghiệp anh/chị có thể truy cập được bằng thiết bị di động không?
○ Có
Không

C10. Doanh nghiệp anh/chị sử dụng trang web cho mục đích gì? (Anh/chị có thể lựa chọn nhiều hơn 1 mục đích)
Hiển thị thông tin doanh nghiệp
Thực hiện các giao dịch trực tuyến
Quảng bá sản phẩm/dịch vụ
Mục đích khác:

C11. Loại hình kinh doanh thương mại nào doanh nghiệp của anh/chị đang sử dụng cho các hoạt động mua bán hàng hóa/dịch vụ? (Anh/chị có thể lựa chọn nhiều hơn 1 loại hình)
Thương mại truyền
Thương mại điện tử thống
Thương mại di động 
C12. Doanh nghiệp của anh/chị đã ứng dụng thương mại di động được bao lâu?
○ $<1$ năm
○ $1-<3$ năm
○ $3-<5$ năm
$\bigcirc \geq 5$ năm

C13. Nếu chưa ứng dụng thương mại di động, doanh nghiệp của anh/chị có dự định ứng dụng thương mại di động trong vòng 1 năm tới hay không?
○ Có
Không

\section{Phần 2: Các yếu tố quan trọng ảnh hưởng đến quyết định ứng dụng thương mại di động}

Phần này gồm những câu hỏi liên quan đến quan điểm của doanh nghiệp (DN) của anh/chị về các yếu tố quan trọng ảnh hưởng đến quyết định ứng dụng TMDĐ tại DN. And/chị vui lòng cho biết mức độ đồng ý với các phát biểu dưới đây bằng cách lựa chọn từ 1 (HOÀN TOÀN KHÔNG ĐỒNG Ý) đến 5 (HOÀN TOÀN ĐỒNG Ý).

C14. Anh/chị vui lòng cho biết mức độ đồng ý với mỗi phát biểu sau về ảnh hưởng của "LộI ÍCH" của việc ứng dụng TMDĐ đến quyết định ứng dụng TMDĐ tại DN bằng cách chọn từ 1 (hoàn toàn không đồng ý) đến 5 (hoàn toàn đồng ý).

\begin{tabular}{|l|l|l|l|l|l|}
\hline & 1 & 2 & 3 & 4 & 5 \\
\hline $\begin{array}{l}\text { "Tiết kiệm chi phí vận hành DN" là yếu tố quan trọng ảnh hưởng } \\
\text { đến quyết định ứng dụng TMDĐ. }\end{array}$ & $\bigcirc$ & $\bigcirc$ & $\bigcirc$ & $\bigcirc$ \\
\hline $\begin{array}{l}\text { "Đơn giản hóa quy trình vận hành DN" là yếu tố quan trọng ảnh } \\
\text { hưởng đến quyết định ứng dụng TMDĐ. }\end{array}$ & $\bigcirc$ & $\bigcirc$ & $\bigcirc$ & $\bigcirc$ & $\bigcirc$ \\
\hline $\begin{array}{l}\text { "Gia tăng thị phần" là yếu tố quan trọng ảnh hưởng đến quyết } \\
\text { định ứng dụng TMDĐ. }\end{array}$ & $\bigcirc$ & $\bigcirc$ & $\bigcirc$ & $\bigcirc$ & $\bigcirc$ \\
\hline $\begin{array}{l}\text { "Tăng doanh thu" là yếu tố quan trọng ảnh hưởng đến quyết định } \\
\text { ứng dụng TMDĐ. }\end{array}$ & $\bigcirc$ & $\bigcirc$ & $\bigcirc$ & $\bigcirc$ & $\bigcirc$ \\
\hline $\begin{array}{l}\text { "Tạo thêm các kênh tiếp thị" là yếu tố quan trọng ảnh hưởng đến } \\
\text { quyêt định ứng dụng TMDĐ. }\end{array}$ & $\bigcirc$ & $\bigcirc$ & $\bigcirc$ & $\bigcirc$ & $\bigcirc$ \\
\hline $\begin{array}{l}\text { "Cải thiện hình ảnh DN" là yếu tố quan trọng ảnh hưởng đến } \\
\text { quyết định ứng dụng TMDĐ. }\end{array}$ & $\bigcirc$ & $\bigcirc$ & $\bigcirc$ & $\bigcirc$ & $\bigcirc$ \\
\hline $\begin{array}{l}\text { "Thúc đẩy khả năng cạnh tranh" là yếu tố quan trọng ảnh hưởng } \\
\text { đến quyết định ứng dụng TMDĐ. }\end{array}$ & $\bigcirc$ & $\bigcirc$ & $\bigcirc$ & $\bigcirc$ & $\bigcirc$ \\
\hline $\begin{array}{l}\text { "Tăng cường dịch vụ khách hàng" là yếu tố quan trọng ảnh } \\
\text { hưởng đến quyết định ứng dụng TMDĐ. }\end{array}$ & $\bigcirc$ & $\bigcirc$ & $\bigcirc$ & $\bigcirc$ & $\bigcirc$ \\
\hline
\end{tabular}


C15. Anh/chị vui lòng cho biết mức độ đồng ý với mỗi phát biểu sau về ảnh hưởng của "ĐỘ TƯƠNG THÍCH" của TMDĐ đến quyết định ứng dụng TMDĐ tại DN bằng cách chọn từ 1 (hoàn toàn không đồng ý) đến 5 (hoàn toàn đồng ý).

\begin{tabular}{|l|l|l|l|l|l|}
\hline & 1 & 2 & 3 & 4 & 5 \\
\hline $\begin{array}{l}\text { "Mức độ tương thích của TMDĐ với hạ tầng công nghệ của DN" } \\
\text { là yếu tố quan trọng ảnh hưởng đến quyết định ứng dụng TMDĐ. }\end{array}$ & $\bigcirc$ & $\bigcirc$ & $\bigcirc$ & $\bigcirc$ \\
\hline $\begin{array}{l}\text { "Sự đồng bộ của TMDĐ với các quy trình kinh doanh hiện tại } \\
\text { của DN" là yếu tố quan trọng ảnh hưởng đến quyết định ứng } \\
\text { dụng TMDĐ. }\end{array}$ & $\bigcirc$ & $\bigcirc$ & $\bigcirc$ & $\bigcirc$ \\
\hline $\begin{array}{l}\text { "Mức độ thích nghi của TMDĐ với các kênh phân phối hiện tại } \\
\text { của DN" là yếu tố quan trọng ảnh hưởng đến quyết định ứng } \\
\text { dụng TMDĐ. }\end{array}$ & $\bigcirc$ & $\bigcirc$ & $\bigcirc$ & $\bigcirc$ & $\bigcirc$ \\
\hline $\begin{array}{l}\text { "Sự phù hợp của TMDĐ với văn hóa DN" là yếu tố quan trọng } \\
\text { ảnh hưởng đến quyết định ứng dụng TMDĐ. }\end{array}$ & $\bigcirc$ & $\bigcirc$ & $\bigcirc$ & $\bigcirc$ & $\bigcirc$ \\
\hline $\begin{array}{l}\text { "Sự phù hợp của TMDĐ với cách thức/hành vi mua sắm của } \\
\text { khách hàng" là yếu tố quan trọng ảnh hưởng đến quyết định ứng } \\
\text { dụng TMDĐ. }\end{array}$ & $\bigcirc$ & $\bigcirc$ & $\bigcirc$ & $\bigcirc$ & $\bigcirc$ \\
\hline $\begin{array}{l}\text { "Sự phù hợp của TMDĐ với kinh nghiệm của DN trong việc ứng } \\
\text { dụng công nghệ" là yếu tố quan trọng ảnh hưởng đến quyết định } \\
\text { ứng dụng TMDĐ. }\end{array}$ & $\bigcirc$ & $\bigcirc$ & $\bigcirc$ & $\bigcirc$ & $\bigcirc$ \\
\hline
\end{tabular}

C16. Anh/chị vui lòng cho biết mức độ đồng ý với mỗi phát biểu sau về ảnh hưởng của "TíNH BẢO MậT" của TMDĐ đến quyết định ứng dụng TMDĐ tại DN.

\begin{tabular}{|l|l|l|l|l|l|}
\hline & 1 & 2 & 3 & 4 & 5 \\
\hline $\begin{array}{l}\text { "Mức độ hiểu biết của DN về tính bảo mật của TMDĐ” là yếu tố } \\
\text { quan trọng ảnh hưởng đến quyết định ứng dụng TMDĐ. }\end{array}$ & $\bigcirc$ & $\bigcirc$ & $\bigcirc$ & $\bigcirc$ \\
\hline $\begin{array}{l}\text { "Sự sẵn có của các tiêu chuẩn về bảo mật cho TMDĐ” là yếu tố } \\
\text { quan trọng ảnh hưởng đến quyết định ứng dụng TMDĐ. }\end{array}$ & $\bigcirc$ & $\bigcirc$ & $\bigcirc$ & $\bigcirc$ & $\bigcirc$ \\
\hline $\begin{array}{l}\text { "Sự sã̃n có của luật và các qui định cho hoạt động kinh doanh } \\
\text { TMDĐ" là yếu tố quan trọng ảnh hưởng đến quyết định ứng } \\
\text { dụng TMDĐ. }\end{array}$ & $\bigcirc$ & $\bigcirc$ & $\bigcirc$ & $\bigcirc$ & $\bigcirc$ \\
\hline
\end{tabular}


C17. Anh/chị vui lòng cho biết mức độ đồng ý với mỗi phát biểu sau về ảnh hưởng của "CHI PHÍ" cho việc ứng dụng TMDĐ đến quyết định ứng dụng TMDĐ tại DN.

\begin{tabular}{|l|l|l|l|l|l|}
\hline & 1 & 2 & 3 & 4 & 5 \\
\hline $\begin{array}{l}\text { "Chi phí về hạ tầng công nghệ cho TMDĐ” là yếu tố quan trọng } \\
\text { ảnh hưởng đến quyết định ứng dụng TMDĐ. }\end{array}$ & $\bigcirc$ & $\bigcirc$ & $\bigcirc$ & $\bigcirc$ & $\bigcirc$ \\
\hline $\begin{array}{l}\text { "Chi phí đào tạo nhân viên cho việc ứng dụng TMDĐ” là yếu tố } \\
\text { quan trọng ảnh hưởng đến quyết định ứng dụng TMDĐ. }\end{array}$ & $\bigcirc$ & $\bigcirc$ & $\bigcirc$ & $\bigcirc$ & $\bigcirc$ \\
\hline $\begin{array}{l}\text { "Chi phí bảo trì hệ thống TMDĐ” là yếu tố quan trọng ảnh } \\
\text { hưởng đến quyết định ứng dụng TMDĐ. }\end{array}$ & $\bigcirc$ & $\bigcirc$ & $\bigcirc$ & $\bigcirc$ & $\bigcirc$ \\
\hline
\end{tabular}

C18. Anh/chị vui lòng cho biết mức độ đồng ý với mỗi phát biểu sau về ảnh hưởng của “KIẾN THỨC CNTT CỦA NHÂN VIÊN" đến quyết định ứng dụng TMDĐ tại DN.

\begin{tabular}{|l|l|l|l|l|l|}
\hline & 1 & 2 & 3 & 4 & 5 \\
\hline $\begin{array}{l}\text { "Mức độ hiểu biết về TMDĐ của nhân viên" là yếu tố quan trọng } \\
\text { ảnh hưởng đến quyết định ứng dụng TMDĐ. }\end{array}$ & $\bigcirc$ & $\bigcirc$ & $\bigcirc$ & $\bigcirc$ \\
\hline $\begin{array}{l}\text { "Sự thông thạo CNTT của nhân viên" là yếu tố quan trọng ảnh } \\
\text { hưởng đến quyết định ứng dụng TMDĐ. }\end{array}$ & $\bigcirc$ & $\bigcirc$ & $\bigcirc$ & $\bigcirc$ & $\bigcirc$ \\
\hline $\begin{array}{l}\text { "Năng lực tiếp cận và sử dụng công nghệ mới của nhân viên" là } \\
\text { yếu tố quan trọng ảnh hưởng đến quyết định ứng dụng TMDĐ. }\end{array}$ & $\bigcirc$ & $\bigcirc$ & $\bigcirc$ & $\bigcirc$ & $\bigcirc$ \\
\hline
\end{tabular}

C19. Anh/chị vui lòng cho biết mức độ đồng ý với mỗi phát biểu sau về ảnh hưởng của “SỤ” SÃN SÀNG CỦA DOANH NGHIỆP” đến quyết định ứng dụng TMDĐ tại DN.

\begin{tabular}{|l|l|l|l|l|l|}
\hline & 1 & 2 & 3 & 4 & 5 \\
\hline $\begin{array}{l}\text { "Sự sẵn sàng về tài chính của DN" là yếu tố quan trọng ảnh } \\
\text { hưởng đến quyết định ứng dụng TMDĐ. }\end{array}$ & $\bigcirc$ & $\bigcirc$ & $\bigcirc$ & $\bigcirc$ \\
\hline $\begin{array}{l}\text { "Sự sã̃n sàng về công nghệ của DN" là yếu tố quan trọng ảnh } \\
\text { hưởng đến quyết định ứng dụng TMDĐ. }\end{array}$ & $\bigcirc$ & $\bigcirc$ & $\bigcirc$ & $\bigcirc$ & $\bigcirc$ \\
\hline $\begin{array}{l}\text { "Sự sã̃n sàng về nhân lực của DN" là yếu tố quan trọng ảnh } \\
\text { hưởng đến quyết định ứng dụng TMDĐ. }\end{array}$ & $\bigcirc$ & $\bigcirc$ & $\bigcirc$ & $\bigcirc$ & $\bigcirc$ \\
\hline
\end{tabular}


C20. Anh/chị vui lòng cho biết mức độ đồng ý với mỗi phát biểu sau về ảnh hưởng của “TÍNH ĐỔI MỚI CỦA DOANH NGHIỆP” đến quyết định ứng dụng TMDĐ tại DN.

\begin{tabular}{|l|l|l|l|l|l|}
\hline & 1 & 2 & 3 & 4 & 5 \\
\hline $\begin{array}{l}\text { "Khả năng thực hiện đổi mới của DN" là yếu tố quan trọng ảnh } \\
\text { hưởng đến quyết định ứng dụng TMDĐ. }\end{array}$ & $\bigcirc$ & $\bigcirc$ & $\bigcirc$ & $\bigcirc$ \\
\hline $\begin{array}{l}\text { "Năng lực ứng dụng những tiếp cận mới về quản trị của DN" là } \\
\text { yếu tố quan trọng ảnh hưởng đến quyết định ứng dụng TMDĐ. }\end{array}$ & $\bigcirc$ & $\bigcirc$ & $\bigcirc$ & $\bigcirc$ & $\bigcirc$ \\
\hline $\begin{array}{l}\text { "Năng lực cải tiến liên tục các quy trình kinh doanh của DN" là } \\
\text { yếu tố quan trọng ảnh hưởng đến quyết định ứng dụng TMDĐ. }\end{array}$ & $\bigcirc$ & $\bigcirc$ & $\bigcirc$ & $\bigcirc$ & $\bigcirc$ \\
\hline
\end{tabular}

C21. Anh/chị vui lòng cho biết mức độ đồng ý với mỗi phát biểu sau về ảnh hưởng của “ĐỐI THỦ CẠNH TRANH” đến quyết định ứng dụng TMDĐ tại DN.

\begin{tabular}{|l|l|l|l|l|l|}
\hline & 1 & 2 & 3 & 4 & 5 \\
\hline $\begin{array}{l}\text { "Sự hiện diện của các sản phẩm/dịch vụ tương tự của các đối thủ } \\
\text { cạnh tranh" là yếu tố quan trọng ảnh hưởng đến quyết định ứng } \\
\text { dụng TMDĐ. }\end{array}$ & $\bigcirc$ & $\bigcirc$ & $\bigcirc$ & $\bigcirc$ \\
\hline $\begin{array}{l}\text { "Sự hiện diện của các sản phẩm/dịch vụ tương tự của các doanh } \\
\text { nghiệp mới vào ngành" là yếu tố quan trọng ảnh hưởng đến quyết } \\
\text { định ứng dụng TMDĐ. }\end{array}$ & $\bigcirc$ & $\bigcirc$ & $\bigcirc$ & $\bigcirc$ & $\bigcirc$ \\
\hline $\begin{array}{l}\text { "Sự hiện diện của các sản phẩm/dịch vụ thay thế” là yếu tố quan } \\
\text { trọng ảnh hưởng đến quyết định ứng dụng TMDĐ. }\end{array}$ & $\bigcirc$ & $\bigcirc$ & $\bigcirc$ & $\bigcirc$ & $\bigcirc$ \\
\hline
\end{tabular}

C22. Anh/chị vui lòng cho biết mức độ đồng ý với mỗi phát biểu sau về ảnh hưởng của “KHÁCH HÀNG” đến quyết định ứng dụng TMDĐ tại DN.

\begin{tabular}{|l|l|l|l|l|l|}
\hline & 1 & 2 & 3 & 4 & 5 \\
\hline $\begin{array}{l}\text { "Yêu cầu phải ứng dụng TMDĐ từ khách hàng" là yếu tố quan } \\
\text { trọng ảnh hưởng đến quyết định ứng dụng TMDĐ. }\end{array}$ & $\bigcirc$ & $\bigcirc$ & $\bigcirc$ & $\bigcirc$ & $\bigcirc$ \\
\hline $\begin{array}{l}\text { "Mong muốn ứng dụng TMDĐ từ khách hàng" là yếu tố quan } \\
\text { trọng ảnh hưởng đến quyết định ứng dụng TMDĐ. }\end{array}$ & $\bigcirc$ & $\bigcirc$ & $\bigcirc$ & $\bigcirc$ & $\bigcirc$ \\
\hline $\begin{array}{l}\text { "Nhu cầu duy trì các mối quan hệ với khách hàng" là yếu tố quan } \\
\text { trọng ảnh hưởng đến quyết định ứng dụng TMDĐ. }\end{array}$ & $\bigcirc$ & $\bigcirc$ & $\bigcirc$ & $\bigcirc$ & $\bigcirc$ \\
\hline
\end{tabular}


C23. Anh/chị vui lòng cho biết mức độ đồng ý với mỗi phát biểu sau về ảnh hưởng của “SỤ HÕ TRọ CỦA CHÍNH PHỦ” đến quyết định ứng dụng TMDĐ tại DN.

\begin{tabular}{|l|l|l|l|l|l|}
\hline & 1 & 2 & 3 & 4 & 5 \\
\hline $\begin{array}{l}\text { "Hỗ trợ của chính phủ về môi trường pháp lý cho hoạt động kinh } \\
\text { doanh TMDĐ” là yếu tố quan trọng ảnh hưởng đến quyết định } \\
\text { ứng dụng TMDĐ. }\end{array}$ & $\bigcirc$ & $\bigcirc$ & $\bigcirc$ & $\bigcirc$ \\
\hline $\begin{array}{l}\text { "Hỗ trợ của chính phủ về tài chính cho DNVVN nhằm ứng dụng } \\
\text { công nghệ mới” là yếu tố quan trọng ảnh hưởng đến quyết định } \\
\text { ứng dụng TMDĐ. }\end{array}$ & $\bigcirc$ & $\bigcirc$ & $\bigcirc$ & $\bigcirc$ & $\bigcirc$ \\
\hline $\begin{array}{l}\text { "Các chương trình hỗ trợ của chính phủ nhằm nâng cao năng lực } \\
\text { ứng dụng công nghệ mới cho DNVVN" là yếu tố quan trọng ảnh } \\
\text { hưởng đến quyết định ứng dụng TMDĐ. }\end{array}$ & $\bigcirc$ & $\bigcirc$ & $\bigcirc$ & $\bigcirc$ & $\bigcirc$ \\
\hline
\end{tabular}

C24. Anh/chị vui lòng cho biết mức độ đồng ý với mỗi phát biểu sau về ảnh hưởng của “SỰ HỖ TRƠ CỦA BAN LÃNH ĐẠO" doanh nghiệp đến quyết định ứng dụng TMDĐ tại DN.

\begin{tabular}{|l|l|l|l|l|l|}
\hline & 1 & 2 & 3 & 4 & 5 \\
\hline $\begin{array}{l}\text { "Nhận thức của ban lãnh đạo về lợi ích của việc ứng dụng } \\
\text { TMDĐ" là yếu tố quan trọng ảnh hưởng đến quyết định ứng } \\
\text { dụng TMDĐ. }\end{array}$ & $\bigcirc$ & $\bigcirc$ & $\bigcirc$ & $\bigcirc$ \\
\hline $\begin{array}{l}\text { "Sự phân bổ các nguồn lực cần thiết cho việc ứng dụng TMDĐ } \\
\text { từ ban lãnh đạo" là yếu tố quan trọng ảnh hưởng đến quyết định } \\
\text { ứng dụng TMDĐ. }\end{array}$ & $\bigcirc$ & $\bigcirc$ & $\bigcirc$ & $\bigcirc$ & $\bigcirc$ \\
\hline $\begin{array}{l}\text { "Sự quyết tâm của ban lãnh đạo cho việc ứng dụng TMDĐ” là } \\
\text { yếu tố quan trọng ảnh hưởng đến quyết định ứng dụng TMDĐ. }\end{array}$ & $\bigcirc$ & $\bigcirc$ & $\bigcirc$ & $\bigcirc$ & $\bigcirc$ \\
\hline
\end{tabular}

C25. Anh/chị vui lòng cho biết mức độ đồng ý với mỗi phát biểu sau về ảnh hưởng của “KIẾN THỨC CNTT CỦA BAN LÃNH ĐẠO” doanh nghiệp đến quyết định ứng dụng TMDĐ tại DN.

\begin{tabular}{|l|l|l|l|l|l|}
\hline & 1 & 2 & 3 & 4 & 5 \\
\hline $\begin{array}{l}\text { "Mức độ hiểu biết về TMDĐ của ban lãnh đạo" là yếu tố quan } \\
\text { trọng ảnh hưởng đến quyết định ứng dụng TMDĐ. }\end{array}$ & $\bigcirc$ & $\bigcirc$ & $\bigcirc$ & $\bigcirc$ & $\bigcirc$ \\
\hline $\begin{array}{l}\text { "Sự thông thạo CNTT của ban lãnh đạo" là yếu tố quan trọng ảnh } \\
\text { hưởng đến quyết định ứng dụng TMDĐ. }\end{array}$ & $\bigcirc$ & $\bigcirc$ & $\bigcirc$ & $\bigcirc$ & $\bigcirc$ \\
\hline $\begin{array}{l}\text { "Năng lực tiếp cận và sử dụng công nghệ mới của ban lãnh đạo" } \\
\text { là yếu tố quan trọng ảnh hưởng đến quyêt định ứng dụng TMDĐ. }\end{array}$ & $\bigcirc$ & $\bigcirc$ & $\bigcirc$ & $\bigcirc$ & $\bigcirc$ \\
\hline
\end{tabular}


C26. Anh/chị vui lòng cho biết mức độ đồng ý với mỗi phát biểu sau về “QUYẾT ĐỊNH ÚNG DỤNG TMDĐ”" của doanh nghiệp.

\begin{tabular}{|l|l|l|l|l|l|}
\hline & 1 & 2 & 3 & 4 & 5 \\
\hline Doanh nghiệp chúng tôi có dự định sẽ ứng dụng TMDĐ. & $\bigcirc$ & $\bigcirc$ & $\bigcirc$ & $\bigcirc$ & $\bigcirc$ \\
\hline $\begin{array}{l}\text { Doanh nghiệp chúng tôi có kế hoạch chắc chắn cho việc ứng } \\
\text { dụng TMDĐ. }\end{array}$ & $\bigcirc$ & $\bigcirc$ & $\bigcirc$ & $\bigcirc$ & $\bigcirc$ \\
\hline $\begin{array}{l}\text { Doanh nghiệp chúng tôi có cam kết mạnh mẽ cho việc ứng dụng } \\
\text { TMDĐ. }\end{array}$ & $\bigcirc$ & $\bigcirc$ & $\bigcirc$ & $\bigcirc$ & $\bigcirc$ \\
\hline
\end{tabular}

\section{Phần 3: Thông tin người trả lò̀i}

Anh/chị vui lòng trả lời những câu hỏi sau bằng cách lựa chọn mô tả đúng nhất về anh/chị.

C27. Giới tính?
O Nam
Nữ

C28. Độ tuổi?
○ $18-25$
○ $26-35$
○ $36-45$
$\bigcirc 46-55 \quad \bigcirc>=55$

C29. Trình độ học vấn?
O Sau đại học
Trung cấp
Dưới trung học phổ thông
○ Đại học/cao đẳng
Trung học phổ thông

C30. Chức vụ?
○ (Tổng) Giám đốc
$\bigcirc$ Trưởng phòng
O Chức vụ khác:
Phó (tổng) giám đốc
$\bigcirc$ Phó trưởng phòng

C31. Anh/chị hiện giữ chức vụ trên được bao lâu?
$\bigcirc<1$ năm
○ 1 - 3 năm
○ 3-5 năm
○ >=5 năm 


\section{Appendix E - Ethics Approval Letter}

\section{RMIT \\ UNIVERSITY}

Deputy Pro Vice-Chancellor (Research \& Innovation) College of Business

GPO Box 2478

Melbourne VIC 3001 Melbourne
Australia

Notice of Approval

Tel: +61 399255432 Fax: +8139925 5624

Date:

23 February 2018

Project number: 21307

Project title:

Risk classification:

Critical Determinants for Mobile Commerce Adoption in Vietnamese Small and Medium Sized Enterprises: An Empirical Study

Chief Investigator:

Other Investigator:

Student Investigator:

Low Risk

Dr Hepu Deng

A/Prof Richard Tay

Mr Tuan Ngoc Chau

Project Approved:

From: 22 February 2018

To: 26 February 2021

Terms of approval:

Responsibilities of the principal investigator

It is the responsibility of the principal investigator to ensure that all other investigators and staff on a project are aware of the terms of approval and to ensure that the project is conducted as approved by BCHEAN. Approval is only valid while the investigator holds a position at RMIT University.

1. Amendments

Approval must be sought from BCHEAN to amend any aspect of a project including approved documents. To apply for an amendment submit a request for amendment form to the BCHEAN secretary. This form is available on the Human Research Ethics Committee (HREC) website. Amendments must not be implemented without first gaining approval from BCHEAN.

2. Adverse events

You should notify BCHEAN immediately of any serious or unexpected adverse effects on participants or unforeseen events affecting the ethical acceptability of the project.

3. Participant Information and Consent Form (PICF)

The PICF must be distributed to all research participants, where relevant, and the consent form is to be retained and stored by the investigator. The PICF must contain the RMIT University logo and a complaints clause including the above project number.

4. Annual reports

Continued approval of this project is dependent on the submission of an annual report.

5. Final report

A final report must be provided at the conclusion of the project. BCHEAN must be notified if the project is discontinued before the expected date of completion.

6. Monitoring

Projects may be subject to an audit or any other form of monitoring by BCHEAN at any time.

7. Retention and storage of data

The investigator is responsible for the storage and retention of original data pertaining to a project for a minimum period of five years.

Regards,

Associate Professor Penny Weller

Chairperson

RMIT BCHEAN 


\section{Appendix F - Purification Measurement}

\begin{tabular}{|c|c|c|c|}
\hline Constructs & Items & $\begin{array}{l}\text { Corrected Item-Total } \\
\text { Correlation }\end{array}$ & $\begin{array}{c}\text { Cronbach's Alpha If } \\
\text { Item Deleted }\end{array}$ \\
\hline \multirow{8}{*}{ Perceived Benefits } & BENE1 & .639 & .879 \\
\hline & BENE2 & .707 & .872 \\
\hline & BENE3 & .717 & .870 \\
\hline & BENE4 & .675 & .875 \\
\hline & BENE5 & .717 & .871 \\
\hline & BENE6 & .601 & .882 \\
\hline & BENE7 & .634 & .879 \\
\hline & BENE8 & .637 & .879 \\
\hline \multirow{6}{*}{ Perceived Compatibility } & CMPA1 & .670 & .860 \\
\hline & CMPA2 & .736 & .849 \\
\hline & CMPA3 & .698 & .855 \\
\hline & CMPA4 & .639 & .866 \\
\hline & CMPA5 & .673 & .859 \\
\hline & CMPA6 & .695 & .856 \\
\hline \multirow{3}{*}{ Perceived Security } & SECU1 & .653 & .791 \\
\hline & SECU2 & .742 & .701 \\
\hline & SECU3 & .657 & .786 \\
\hline \multirow{3}{*}{ Perceived Cost } & CSTS1 & .706 & .801 \\
\hline & CSTS2 & .720 & .789 \\
\hline & CSTS3 & .729 & .779 \\
\hline \multirow{3}{*}{ Employees' IT Knowledge } & EMPL1 & .824 & .887 \\
\hline & EMPL2 & .863 & .854 \\
\hline & EMPL3 & .810 & .899 \\
\hline Organizational Readiness & READ1 & .698 & .791 \\
\hline
\end{tabular}




\begin{tabular}{|c|c|c|c|}
\hline & READ2 & .759 & .730 \\
\hline & READ3 & .668 & .818 \\
\hline \multirow{3}{*}{ Organizational Innovativeness } & INNO1 & .699 & .831 \\
\hline & INNO2 & .779 & .755 \\
\hline & INNO3 & .720 & .813 \\
\hline \multirow{3}{*}{ Competitive Pressures } & CMPE1 & .696 & .844 \\
\hline & CMPE2 & .795 & .751 \\
\hline & CMPE3 & .727 & .817 \\
\hline \multirow{3}{*}{ Customer Pressures } & CUST1 & .812 & .844 \\
\hline & CUST2 & .832 & .826 \\
\hline & CUST3 & .758 & .890 \\
\hline \multirow{3}{*}{ Government Support } & GOVE1 & .759 & .897 \\
\hline & GOVE2 & .824 & .844 \\
\hline & GOVE3 & .836 & .833 \\
\hline \multirow{3}{*}{ Top Management Support } & TMSP1 & .765 & .803 \\
\hline & TMSP2 & .752 & .816 \\
\hline & TMSP3 & .736 & .830 \\
\hline \multirow{3}{*}{ Managers' IT Knowledge } & TMIT1 & .741 & .889 \\
\hline & TMIT2 & .820 & .822 \\
\hline & TMIT3 & .815 & .825 \\
\hline \multirow{3}{*}{ Adoption } & ADPT1 & .805 & .898 \\
\hline & ADPT2 & .881 & .833 \\
\hline & ADPT3 & .805 & .899 \\
\hline
\end{tabular}




\section{Appendix G - Comparison of Loadings}

\begin{tabular}{|c|c|c|c|c|c|}
\hline \multirow[b]{2}{*}{ Items } & \multicolumn{3}{|c|}{ Standardized Factor Loadings } & \multicolumn{2}{|c|}{ Differences } \\
\hline & $\begin{array}{c}\text { Measurement } \\
\text { Model } \\
\text { (1) }\end{array}$ & $\begin{array}{c}\text { Structural Model } \\
\text { without Controls } \\
\text { (2) }\end{array}$ & $\begin{array}{l}\text { Structural Model } \\
\text { with Controls } \\
\text { (3) }\end{array}$ & $(2)-(1)$ & (3) $-(\mathbf{1})$ \\
\hline BENE5 & 0.718 & 0.718 & 0.72 & 0 & 0.002 \\
\hline BENE6 & 0.674 & 0.674 & 0.673 & 0 & -0.001 \\
\hline BENE7 & 0.799 & 0.799 & 0.797 & 0 & -0.002 \\
\hline BENE8 & 0.786 & 0.786 & 0.787 & 0 & 0.001 \\
\hline CMPA1 & 0.765 & 0.765 & 0.766 & 0 & 0.001 \\
\hline CMPA2 & 0.828 & 0.828 & 0.825 & 0 & -0.003 \\
\hline CMPA3 & 0.771 & 0.771 & 0.771 & 0 & 0 \\
\hline CMPA4 & 0.655 & 0.655 & 0.656 & 0 & 0.001 \\
\hline SECU1 & 0.771 & 0.771 & 0.771 & 0 & 0 \\
\hline SECU2 & 0.829 & 0.829 & 0.829 & 0 & 0 \\
\hline SECU3 & 0.76 & 0.76 & 0.76 & 0 & 0 \\
\hline COST1 & 0.791 & 0.791 & 0.791 & 0 & 0 \\
\hline COST2 & 0.802 & 0.802 & 0.802 & 0 & 0 \\
\hline COST3 & 0.831 & 0.831 & 0.832 & 0 & 0.001 \\
\hline EMPL1 & 0.877 & 0.877 & 0.877 & 0 & 0 \\
\hline EMPL2 & 0.927 & 0.927 & 0.927 & 0 & 0 \\
\hline EMPL3 & 0.859 & 0.859 & 0.859 & 0 & 0 \\
\hline READ1 & 0.789 & 0.789 & 0.79 & 0 & 0.001 \\
\hline READ2 & 0.858 & 0.858 & 0.858 & 0 & 0 \\
\hline READ3 & 0.763 & 0.763 & 0.763 & 0 & 0 \\
\hline INNO1 & 0.783 & 0.783 & 0.784 & 0 & 0.001 \\
\hline INNO2 & 0.866 & 0.866 & 0.865 & 0 & -0.001 \\
\hline
\end{tabular}




\begin{tabular}{lllllc}
\hline INNO3 & 0.811 & 0.811 & 0.811 & 0 & 0 \\
\hline CMPE1 & 0.785 & 0.785 & 0.784 & 0 & -0.001 \\
\hline CMPE2 & 0.873 & 0.873 & 0.873 & 0 & 0 \\
\hline CMPE3 & 0.818 & 0.818 & 0.818 & 0 & 0 \\
\hline CUST1 & 0.877 & 0.877 & 0.876 & 0 & -0.001 \\
\hline CUST2 & 0.902 & 0.902 & 0.904 & 0 & 0.002 \\
\hline CUST3 & 0.819 & 0.819 & 0.818 & 0 & -0.001 \\
\hline GOVE1 & 0.812 & 0.812 & 0.812 & 0 & 0 \\
\hline GOVE2 & 0.892 & 0.892 & 0.892 & 0 & 0 \\
\hline GOVE3 & 0.906 & 0.906 & 0.906 & 0 & 0 \\
\hline TMSP1 & 0.854 & 0.854 & 0.855 & 0 & 0.001 \\
\hline TMSP2 & 0.834 & 0.834 & 0.833 & 0 & -0.001 \\
\hline TMSP3 & 0.806 & 0.806 & 0.805 & 0 & -0.001 \\
\hline TMIT1 & 0.804 & 0.804 & 0.805 & 0 & 0.001 \\
\hline TMIT2 & 0.889 & 0.889 & 0.888 & 0 & -0.001 \\
\hline TMIT3 & 0.888 & 0.888 & 0.888 & 0 & 0 \\
\hline ADPT1 & 0.862 & 0.862 & 0.864 & 0 & 0.002 \\
\hline ADPT2 & 0.948 & 0.948 & 0.944 & 0 & -0.004 \\
\hline ADPT3 & 0.854 & 0.854 & 0.857 & 003 \\
\hline & & 0.85 & 0 & 0 \\
\hline
\end{tabular}




\title{
Appendix H - Ten-Fold Cross-Validation Results for Neural
}

\author{
Networks
}

\section{A Summary of Neural Networks \#1}

\begin{tabular}{|l|l|l|}
\hline \multirow{4}{*}{ Training } & Model Summary \\
\cline { 2 - 3 } & Sum of Squares Error & 5.463 \\
\cline { 2 - 3 } & Relative Error & .555 \\
\cline { 2 - 3 } & Stopping Rule Used & 1 consecutive step(s) with no decrease in error \\
\cline { 2 - 3 } & Training Time & $0: 00: 00.03$ \\
\hline \multirow{3}{*}{ Testing } & Sum of Squares Error & .493 \\
\cline { 2 - 3 } & Relative Error & .460 \\
\hline
\end{tabular}

Dependent Variable: Adoption

a. Error computations are based on the testing sample.

Parameter Estimates

\begin{tabular}{|c|c|c|c|c|c|c|c|}
\hline & \multirow{3}{*}{ Predictor } & \multicolumn{4}{|c|}{ Predicted } & \multirow{2}{*}{\multicolumn{2}{|c|}{ Variable Importance }} \\
\hline & & \multicolumn{3}{|c|}{ Hidden Layer 1} & \multirow{2}{*}{$\begin{array}{c}\text { Output } \\
\text { Layer } \\
\text { Adoption }\end{array}$} & & \\
\hline & & $\mathrm{H}(1: 1)$ & $\mathrm{H}(1: 2)$ & $\mathrm{H}(1: 3)$ & & Importance & $\begin{array}{l}\text { Normalized } \\
\text { Importance }\end{array}$ \\
\hline \multirow{9}{*}{ Input Layer } & (Bias) & .554 & .219 & -.665 & & & \\
\hline & Perceived Benefits & .111 & .214 & 1.049 & & .104 & $53.0 \%$ \\
\hline & Perceived Compatibility & .038 & .505 & .673 & & .145 & $74.1 \%$ \\
\hline & Perceived Security & .847 & -.025 & .445 & & .192 & $98.1 \%$ \\
\hline & Organizational Readiness & .107 & .376 & -1.515 & & .092 & $46.9 \%$ \\
\hline & Organizational Innovativeness & -.177 & .590 & 1.074 & & .116 & $59.3 \%$ \\
\hline & Customer Pressure & .363 & .307 & 1.115 & & .196 & $100.0 \%$ \\
\hline & Government Support & -.233 & .668 & -.602 & & .084 & $43.0 \%$ \\
\hline & Managers' IT Knowledge & .177 & .081 & 1.014 & & .070 & $35.6 \%$ \\
\hline \multirow{4}{*}{ Hidden Layer 1} & (Bias) & & & & -1.282 & & \\
\hline & $\mathrm{H}(1: 1)$ & & & & 1.519 & & \\
\hline & $\mathrm{H}(1: 2)$ & & & & 1.528 & & \\
\hline & $\mathrm{H}(1: 3)$ & & & & .166 & & \\
\hline
\end{tabular}




\section{A Summary of Neural Networks \#2}

\begin{tabular}{|l|l|l|}
\multicolumn{2}{|c}{ Model Summary } \\
\hline \multirow{4}{*}{ Training } & Sum of Squares Error & 5.159 \\
\cline { 2 - 3 } & Relative Error & .541 \\
\cline { 2 - 3 } & Stopping Rule Used & 1 consecutive step(s) with no decrease in error \\
\cline { 2 - 3 } & Training Time & $0: 00: 00.03$ \\
\hline \multirow{3}{*}{ Testing } & Sum of Squares Error & .425 \\
\cline { 2 - 3 } & Relative Error & .306 \\
\hline
\end{tabular}

Dependent Variable: Adoption

a. Error computations are based on the testing sample.

Parameter Estimates

\begin{tabular}{|c|c|c|c|c|c|c|c|}
\hline & \multirow{3}{*}{ Predictor } & \multicolumn{4}{|c|}{ Predicted } & & \\
\hline & & \multicolumn{3}{|c|}{ Hidden Layer 1} & \multirow{2}{*}{$\begin{array}{c}\begin{array}{c}\text { Output } \\
\text { Layer }\end{array} \\
\text { Adoption }\end{array}$} & \multicolumn{2}{|c|}{ Variable Importance } \\
\hline & & $\mathrm{H}(1: 1)$ & $\mathrm{H}(1: 2)$ & $\mathrm{H}(1: 3)$ & & Importance & $\begin{array}{l}\text { Normalized } \\
\text { Importance }\end{array}$ \\
\hline \multirow{9}{*}{ Input Layer } & (Bias) & -1.170 & .581 & -1.573 & & & \\
\hline & Perceived Benefits & 1.440 & -.116 & .659 & & .101 & $53.6 \%$ \\
\hline & Perceived Compatibility & .407 & -.068 & -.675 & & .189 & $100.0 \%$ \\
\hline & Perceived Security & .091 & .581 & -.550 & & .161 & $85.0 \%$ \\
\hline & Organizational Readiness & .270 & -.516 & -.501 & & .095 & $50.2 \%$ \\
\hline & Organizational Innovativeness & .158 & .604 & -.177 & & .103 & $54.3 \%$ \\
\hline & Customer Pressure & -.041 & .822 & -.587 & & .188 & $99.6 \%$ \\
\hline & Government Support & .987 & -.088 & .388 & & .100 & $53.2 \%$ \\
\hline & Managers' IT Knowledge & -.033 & -.330 & -.503 & & .063 & $33.4 \%$ \\
\hline \multirow{4}{*}{ Hidden Layer 1} & (Bias) & & & & .114 & & \\
\hline & $\mathrm{H}(1: 1)$ & & & & 1.523 & & \\
\hline & $\mathrm{H}(1: 2)$ & & & & .586 & & \\
\hline & $\mathrm{H}(1: 3)$ & & & & -1.600 & & \\
\hline
\end{tabular}




\section{A Summary of Neural Networks \#3}

\begin{tabular}{|l|l|l|}
\multicolumn{2}{|c}{ Model Summary } \\
\hline \multirow{4}{*}{ Training } & Sum of Squares Error & 5.082 \\
\cline { 2 - 3 } & Relative Error & .518 \\
\cline { 2 - 3 } & Stopping Rule Used & 1 consecutive step(s) with no decrease in error ${ }^{\mathrm{a}}$ \\
\cline { 2 - 3 } & Training Time & $0: 00: 00.03$ \\
\hline \multirow{2}{*}{ Testing } & Sum of Squares Error & .701 \\
\cline { 2 - 3 } & Relative Error & .632 \\
\hline
\end{tabular}

Dependent Variable: Adoption

a. Error computations are based on the testing sample.

Parameter Estimates

\begin{tabular}{|c|c|c|c|c|c|c|c|}
\hline & \multirow{3}{*}{ Predictor } & \multicolumn{4}{|c|}{ Predicted } & & \\
\hline & & \multicolumn{3}{|c|}{ Hidden Layer 1} & \multirow{2}{*}{$\begin{array}{c}\begin{array}{c}\text { Output } \\
\text { Layer }\end{array} \\
\text { Adoption }\end{array}$} & \multicolumn{2}{|c|}{ Variable Importance } \\
\hline & & $\mathrm{H}(1: 1)$ & $\mathrm{H}(1: 2)$ & $\mathrm{H}(1: 3)$ & & Importance & $\begin{array}{l}\text { Normalized } \\
\text { Importance }\end{array}$ \\
\hline \multirow{9}{*}{ Input Layer } & (Bias) & -.182 & .886 & -.187 & & & \\
\hline & Perceived Benefits & .912 & -.388 & -.239 & & .099 & $49.5 \%$ \\
\hline & Perceived Compatibility & .357 & .169 & -.365 & & .155 & $77.2 \%$ \\
\hline & Perceived Security & -.157 & .790 & -.097 & & .177 & $88.2 \%$ \\
\hline & Organizational Readiness & .106 & .085 & -.435 & & .108 & $53.9 \%$ \\
\hline & Organizational Innovativeness & -.154 & .592 & -.048 & & .127 & $63.5 \%$ \\
\hline & Customer Pressure & .079 & .445 & -.449 & & .200 & $100.0 \%$ \\
\hline & Government Support & -.086 & .082 & -.564 & & .075 & $37.6 \%$ \\
\hline & Managers' IT Knowledge & .641 & -.044 & .260 & & .059 & $29.4 \%$ \\
\hline \multirow{4}{*}{ Hidden Layer 1} & (Bias) & & & & -.694 & & \\
\hline & $\mathrm{H}(1: 1)$ & & & & 1.089 & & \\
\hline & $\mathrm{H}(1: 2)$ & & & & 1.581 & & \\
\hline & $\mathrm{H}(1: 3)$ & & & & -.740 & & \\
\hline
\end{tabular}




\section{A Summary of Neural Networks \#4}

\begin{tabular}{|l|l|l|}
\hline \multirow{4}{*}{ Training } & Model Summary \\
\cline { 2 - 3 } & Sum of Squares Error & 5.980 \\
\cline { 2 - 3 } & Relative Error & .594 \\
\cline { 2 - 3 } & Stopping Rule Used & 1 consecutive step(s) with no decrease in error \\
\cline { 2 - 3 } & Training Time & $0: 00: 00.02$ \\
\hline \multirow{2}{*}{ Testing } & Sum of Squares Error & .497 \\
\cline { 2 - 3 } & Relative Error & .666 \\
\hline
\end{tabular}

Dependent Variable: Adoption

a. Error computations are based on the testing sample.

Parameter Estimates

\begin{tabular}{|c|c|c|c|c|c|c|c|}
\hline & \multirow{3}{*}{ Predictor } & \multicolumn{4}{|c|}{ Predicted } & & \\
\hline & & \multicolumn{3}{|c|}{ Hidden Layer 1} & \multirow{2}{*}{$\begin{array}{c}\begin{array}{c}\text { Output } \\
\text { Layer }\end{array} \\
\text { Adoption }\end{array}$} & \multicolumn{2}{|c|}{ Variable Importance } \\
\hline & & $\mathrm{H}(1: 1)$ & $\mathrm{H}(1: 2)$ & $\mathrm{H}(1: 3)$ & & Importance & $\begin{array}{l}\text { Normalized } \\
\text { Importance }\end{array}$ \\
\hline \multirow{9}{*}{ Input Layer } & (Bias) & .313 & .420 & .219 & & & \\
\hline & Perceived Benefits & .509 & -.062 & .097 & & .151 & $64.5 \%$ \\
\hline & Perceived Compatibility & .735 & -.424 & -.082 & & .235 & $100.0 \%$ \\
\hline & Perceived Security & .297 & -.637 & -.088 & & .138 & $58.6 \%$ \\
\hline & Organizational Readiness & .004 & -.001 & .016 & & .002 & $0.8 \%$ \\
\hline & Organizational Innovativeness & .344 & -.577 & -.024 & & .145 & $61.9 \%$ \\
\hline & Customer Pressure & .681 & -.015 & .003 & & .184 & $78.2 \%$ \\
\hline & Government Support & .044 & -.168 & -.254 & & .028 & $11.9 \%$ \\
\hline & Managers' IT Knowledge & .343 & -.280 & .451 & & .118 & $50.1 \%$ \\
\hline \multirow{4}{*}{ Hidden Layer 1} & (Bias) & & & & .003 & & \\
\hline & $\mathrm{H}(1: 1)$ & & & & 1.478 & & \\
\hline & $\mathrm{H}(1: 2)$ & & & & -.582 & & \\
\hline & $\mathrm{H}(1: 3)$ & & & & .071 & & \\
\hline
\end{tabular}




\section{A Summary of Neural Networks \#5}

\begin{tabular}{|l|l|l|}
\multicolumn{2}{|c}{} & \multicolumn{2}{c|}{ Model Summary } \\
\hline \multirow{4}{*}{ Training } & Sum of Squares Error & 5.633 \\
\cline { 2 - 3 } & Relative Error & .567 \\
\cline { 2 - 3 } & Stopping Rule Used & 1 consecutive step(s) with no decrease in error \\
\cline { 2 - 3 } & Training Time & $0: 00: 00.02$ \\
\hline \multirow{2}{*}{ Testing } & Sum of Squares Error & .585 \\
\cline { 2 - 3 } & Relative Error & .602 \\
\hline
\end{tabular}

Dependent Variable: Adoption

a. Error computations are based on the testing sample.

Parameter Estimates

\begin{tabular}{|c|c|c|c|c|c|c|c|}
\hline & \multirow{3}{*}{ Predictor } & \multicolumn{4}{|c|}{ Predicted } & \multirow{2}{*}{\multicolumn{2}{|c|}{ Variable Importance }} \\
\hline & & \multicolumn{3}{|c|}{ Hidden Layer 1} & \multirow{2}{*}{$\begin{array}{c}\begin{array}{c}\text { Output } \\
\text { Layer }\end{array} \\
\text { Adoption }\end{array}$} & & \\
\hline & & $\mathrm{H}(1: 1)$ & $\mathrm{H}(1: 2)$ & $\mathrm{H}(1: 3)$ & & Importance & $\begin{array}{l}\text { Normalized } \\
\text { Importance }\end{array}$ \\
\hline \multirow{9}{*}{ Input Layer } & (Bias) & -.153 & .379 & -.408 & & & \\
\hline & Perceived Benefits & .326 & .285 & -.533 & & .153 & $74.8 \%$ \\
\hline & Perceived Compatibility & -.111 & .459 & -.375 & & .103 & $50.5 \%$ \\
\hline & Perceived Security & .588 & .642 & -.347 & & .205 & $100.0 \%$ \\
\hline & Organizational Readiness & .414 & .458 & .254 & & .103 & $50.2 \%$ \\
\hline & Organizational Innovativeness & .383 & .354 & -.281 & & .130 & $63.4 \%$ \\
\hline & Customer Pressure & .204 & .557 & .093 & & .120 & $58.7 \%$ \\
\hline & Government Support & .610 & .083 & .228 & & .059 & $29.1 \%$ \\
\hline & Managers' IT Knowledge & .410 & .322 & -.368 & & .127 & $62.1 \%$ \\
\hline \multirow{4}{*}{ Hidden Layer 1} & (Bias) & & & & -.129 & & \\
\hline & $\mathrm{H}(1: 1)$ & & & & .633 & & \\
\hline & $\mathrm{H}(1: 2)$ & & & & 1.076 & & \\
\hline & $\mathrm{H}(1: 3)$ & & & & -.571 & & \\
\hline
\end{tabular}




\section{A Summary of Neural Networks \#6}

\begin{tabular}{|l|l|l|}
\multicolumn{2}{|c}{ Model Summary } \\
\hline \multirow{4}{*}{ Training } & Sum of Squares Error & 5.212 \\
\cline { 2 - 3 } & Relative Error & .519 \\
\cline { 2 - 3 } & Stopping Rule Used & 1 consecutive step(s) with no decrease in error \\
\cline { 2 - 3 } & Training Time & $0: 00: 00.05$ \\
\hline \multirow{3}{*}{ Testing } & Sum of Squares Error & .709 \\
\cline { 2 - 3 } & Relative Error & .816 \\
\hline
\end{tabular}

Dependent Variable: Adoption

a. Error computations are based on the testing sample.

Parameter Estimates

\begin{tabular}{|c|c|c|c|c|c|c|c|}
\hline & \multirow{3}{*}{ Predictor } & \multicolumn{4}{|c|}{ Predicted } & \multirow{2}{*}{\multicolumn{2}{|c|}{ Variable Importance }} \\
\hline & & \multicolumn{3}{|c|}{ Hidden Layer 1} & \multirow{2}{*}{$\begin{array}{c}\begin{array}{c}\text { Output } \\
\text { Layer }\end{array} \\
\text { Adoption }\end{array}$} & & \\
\hline & & $\mathrm{H}(1: 1)$ & $\mathrm{H}(1: 2)$ & $\mathrm{H}(1: 3)$ & & Importance & $\begin{array}{l}\text { Normalized } \\
\text { Importance }\end{array}$ \\
\hline & (Bias) & .462 & -.542 & .562 & & & \\
\hline & Perceived Benefits & .054 & .848 & -.447 & & .084 & $43.8 \%$ \\
\hline & Perceived Compatibility & .686 & -.186 & .514 & & .156 & $81.4 \%$ \\
\hline & Perceived Security & .555 & .339 & .376 & & .192 & $100.0 \%$ \\
\hline Input Layer & Organizational Readiness & .833 & -.077 & -.407 & & .085 & $44.4 \%$ \\
\hline & Organizational Innovativeness & .355 & .297 & .249 & & .135 & $70.7 \%$ \\
\hline & Customer Pressure & .403 & -.007 & .825 & & .163 & $85.2 \%$ \\
\hline & Government Support & .364 & .204 & -.070 & & .088 & $46.0 \%$ \\
\hline & Managers' IT Knowledge & .040 & .494 & .300 & & .096 & $50.1 \%$ \\
\hline & (Bias) & & & & -.940 & & \\
\hline 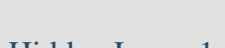 & $\mathrm{H}(1: 1)$ & & & & 1.201 & & \\
\hline & $\mathrm{H}(1: 2)$ & & & & .961 & & \\
\hline & $\mathrm{H}(1: 3)$ & & & & .652 & & \\
\hline
\end{tabular}




\section{A Summary of Neural Networks \#7}

\begin{tabular}{|l|l|l|}
\hline \multicolumn{2}{|c|}{ Model Summary } \\
\hline \multirow{4}{*}{ Training } & Sum of Squares Error & 5.518 \\
\cline { 2 - 3 } & Relative Error & .555 \\
\cline { 2 - 3 } & Stopping Rule Used & 1 consecutive step(s) with no decrease in error \\
\cline { 2 - 3 } & Training Time & $0: 00: 00.03$ \\
\hline \multirow{2}{*}{ Testing } & Sum of Squares Error & .432 \\
\cline { 2 - 3 } & Relative Error & .448 \\
\hline
\end{tabular}

Dependent Variable: Adoption

a. Error computations are based on the testing sample.

Parameter Estimates

\begin{tabular}{|c|c|c|c|c|c|c|c|}
\hline & \multirow{3}{*}{ Predictor } & \multicolumn{4}{|c|}{ Predicted } & & \\
\hline & & \multicolumn{3}{|c|}{ Hidden Layer 1} & \multirow{2}{*}{$\begin{array}{c}\begin{array}{c}\text { Output } \\
\text { Layer }\end{array} \\
\text { Adoption }\end{array}$} & \multicolumn{2}{|c|}{ Variable importance } \\
\hline & & $\mathrm{H}(1: 1)$ & $\mathrm{H}(1: 2)$ & $\mathrm{H}(1: 3)$ & & Importance & $\begin{array}{l}\text { Normalized } \\
\text { Importance }\end{array}$ \\
\hline \multirow{9}{*}{ Input Layer } & (Bias) & -.150 & -.003 & 1.167 & & & \\
\hline & Perceived Benefits & .594 & .208 & -.004 & & .093 & $50.9 \%$ \\
\hline & Perceived Compatibility & .424 & -.255 & .431 & & .159 & $86.9 \%$ \\
\hline & Perceived Security & .452 & .300 & .567 & & .183 & $100.0 \%$ \\
\hline & Organizational Readiness & .060 & -.636 & .477 & & .102 & $55.9 \%$ \\
\hline & Organizational Innovativeness & .195 & -.128 & .416 & & .114 & $62.6 \%$ \\
\hline & Customer Pressure & .529 & .005 & .181 & & .113 & $61.7 \%$ \\
\hline & Government Support & .241 & -.096 & .596 & & .179 & $98.0 \%$ \\
\hline & Managers' IT Knowledge & .320 & -.201 & .047 & & .056 & $30.5 \%$ \\
\hline \multirow{4}{*}{ Hidden Layer 1} & (Bias) & & & & -.995 & & \\
\hline & $\mathrm{H}(1: 1)$ & & & & 1.104 & & \\
\hline & $\mathrm{H}(1: 2)$ & & & & -.044 & & \\
\hline & $\mathrm{H}(1: 3)$ & & & & 1.480 & & \\
\hline
\end{tabular}




\section{A Summary of Neural Networks \#8}

\begin{tabular}{|l|l|l|}
\multicolumn{2}{c}{} & \multicolumn{2}{c}{ Model Summary } \\
\hline \multirow{4}{*}{ Training } & Sum of Squares Error & 4.923 \\
\cline { 2 - 3 } & Relative Error & .503 \\
\cline { 2 - 3 } & Stopping Rule Used & 1 consecutive step(s) with no decrease in error ${ }^{\mathrm{a}}$ \\
\cline { 2 - 3 } & Training Time & $0: 00: 00.04$ \\
\hline \multirow{2}{*}{ Testing } & Sum of Squares Error & .623 \\
\cline { 2 - 3 } & Relative Error & .549 \\
\hline
\end{tabular}

Dependent Variable: Adoption

a. Error computations are based on the testing sample.

Parameter Estimates

\begin{tabular}{|c|c|c|c|c|c|c|c|}
\hline & \multirow{3}{*}{ Predictor } & \multicolumn{4}{|c|}{ Predicted } & & \\
\hline & & \multicolumn{3}{|c|}{ Hidden Layer 1} & \multirow{2}{*}{$\begin{array}{c}\begin{array}{c}\text { Output } \\
\text { Layer }\end{array} \\
\text { Adoption }\end{array}$} & \multicolumn{2}{|c|}{ Variable Importance } \\
\hline & & $\mathrm{H}(1: 1)$ & $\mathrm{H}(1: 2)$ & $\mathrm{H}(1: 3)$ & & Importance & $\begin{array}{l}\text { Normalized } \\
\text { Importance }\end{array}$ \\
\hline \multirow{9}{*}{ Input Layer } & (Bias) & 1.124 & 1.206 & -1.138 & & & \\
\hline & Perceived Benefits & -1.423 & -.946 & -.176 & & .103 & $57.4 \%$ \\
\hline & Perceived Compatibility & -.110 & .223 & -.372 & & .158 & $88.7 \%$ \\
\hline & Perceived Security & .394 & 1.053 & -.018 & & .168 & $94.1 \%$ \\
\hline & Organizational Readiness & -.056 & -.435 & -.841 & & .083 & $46.4 \%$ \\
\hline & Organizational Innovativeness & .264 & .751 & -.033 & & .137 & $76.9 \%$ \\
\hline & Customer Pressure & -.325 & -.065 & -.487 & & .178 & $100.0 \%$ \\
\hline & Government Support & -.045 & .569 & .204 & & .075 & $42.3 \%$ \\
\hline & Managers' IT Knowledge & -.047 & .198 & -.211 & & .097 & $54.5 \%$ \\
\hline \multirow{4}{*}{ Hidden Layer 1} & (Bias) & & & & .716 & & \\
\hline & $\mathrm{H}(1: 1)$ & & & & -1.478 & & \\
\hline & $\mathrm{H}(1: 2)$ & & & & 1.774 & & \\
\hline & $\mathrm{H}(1: 3)$ & & & & -1.507 & & \\
\hline
\end{tabular}




\section{A Summary of Neural Networks \#9}

\begin{tabular}{|l|l|l|}
\multicolumn{2}{c}{ Model Summary } \\
\hline \multirow{4}{*}{ Training } & Sum of Squares Error & 5.466 \\
\cline { 2 - 3 } & Relative Error & .561 \\
\cline { 2 - 3 } & Stopping Rule Used & 1 consecutive step(s) with no decrease in error \\
\cline { 2 - 3 } & Training Time & $0: 00: 00.02$ \\
\hline \multirow{2}{*}{ Testing } & Sum of Squares Error & .671 \\
\cline { 2 - 3 } & Relative Error & .574 \\
\hline
\end{tabular}

Dependent Variable: Adoption

a. Error computations are based on the testing sample.

Parameter Estimates

\begin{tabular}{|c|c|c|c|c|c|c|c|}
\hline & \multirow{3}{*}{ Predictor } & \multicolumn{4}{|c|}{ Predicted } & \multirow{2}{*}{\multicolumn{2}{|c|}{ Variable Importance }} \\
\hline & & \multicolumn{3}{|c|}{ Hidden Layer 1} & \multirow{2}{*}{$\begin{array}{c}\text { Output } \\
\text { Layer }\end{array}$} & & \\
\hline & & $\mathrm{H}(1: 1)$ & $\mathrm{H}(1: 2)$ & $\mathrm{H}(1: 3)$ & & Importance & $\begin{array}{l}\text { Normalized } \\
\text { Importance }\end{array}$ \\
\hline \multirow{9}{*}{ Input Layer } & (Bias) & .178 & -.120 & .113 & & & \\
\hline & Perceived Benefits & -.102 & -.052 & .525 & & .124 & $69.4 \%$ \\
\hline & Perceived Compatibility & -.326 & .494 & .360 & & .179 & $100.0 \%$ \\
\hline & Perceived Security & -.168 & .501 & .484 & & .178 & $99.1 \%$ \\
\hline & Organizational Readiness & .114 & -.006 & .332 & & .058 & $32.5 \%$ \\
\hline & Organizational Innovativeness & .160 & .561 & .313 & & .111 & $61.8 \%$ \\
\hline & Customer Pressure & -.388 & .442 & .211 & & .153 & $85.4 \%$ \\
\hline & Government Support & .140 & .104 & .494 & & .092 & $51.3 \%$ \\
\hline & Managers' IT Knowledge & -.319 & -.200 & .472 & & .105 & $58.6 \%$ \\
\hline \multirow{4}{*}{ Hidden Layer 1} & (Bias) & & & & -.093 & & \\
\hline & $\mathrm{H}(1: 1)$ & & & & -.667 & & \\
\hline & $\mathrm{H}(1: 2)$ & & & & .727 & & \\
\hline & $\mathrm{H}(1: 3)$ & & & & 1.217 & & \\
\hline
\end{tabular}




\section{A Summary of Neural Networks \#10}

Model Summary

\begin{tabular}{|l|l|l|}
\hline \multirow{4}{*}{ Training } & Sum of Squares Error & 4.967 \\
\cline { 2 - 3 } & Relative Error & .520 \\
\cline { 2 - 3 } & Stopping Rule Used & 1 consecutive step(s) with no decrease in error \\
\cline { 2 - 3 } & Training Time & $0: 00: 00.05$ \\
\hline \multirow{2}{*}{ Testing } & Sum of Squares Error & .621 \\
\cline { 2 - 3 } & Relative Error & .457 \\
\hline
\end{tabular}

Dependent Variable: Adoption

a. Error computations are based on the testing sample.

Parameter Estimates

\begin{tabular}{|c|c|c|c|c|c|c|c|}
\hline & \multirow{3}{*}{ Predictor } & \multicolumn{4}{|c|}{ Predicted } & \multirow{2}{*}{\multicolumn{2}{|c|}{ Variable Importance }} \\
\hline & & \multicolumn{3}{|c|}{ Hidden Layer 1} & \multirow{2}{*}{$\begin{array}{c}\begin{array}{c}\text { Output } \\
\text { Layer }\end{array} \\
\text { Adoption }\end{array}$} & & \\
\hline & & $\mathrm{H}(1: 1)$ & $\mathrm{H}(1: 2)$ & $\mathrm{H}(1: 3)$ & & Importance & $\begin{array}{l}\text { Normalized } \\
\text { Importance }\end{array}$ \\
\hline \multirow{9}{*}{ Input Layer } & (Bias) & 1.415 & -1.068 & -.381 & & & \\
\hline & Perceived Benefits & -.563 & 1.240 & -.120 & & .103 & $56.2 \%$ \\
\hline & Perceived Compatibility & -.032 & .655 & -.121 & & .110 & $59.9 \%$ \\
\hline & Perceived Security & .939 & -.107 & -.308 & & .183 & $100.0 \%$ \\
\hline & Organizational Readiness & .144 & .271 & -.329 & & .124 & $67.8 \%$ \\
\hline & Organizational Innovativeness & .733 & .079 & .368 & & .106 & $57.9 \%$ \\
\hline & Customer Pressure & .557 & .042 & -.349 & & .171 & $93.3 \%$ \\
\hline & Government Support & .285 & .909 & .891 & & .101 & $55.1 \%$ \\
\hline & Managers' IT Knowledge & -.436 & .280 & -1.001 & & .102 & $55.4 \%$ \\
\hline \multirow{4}{*}{ Hidden Layer 1} & (Bias) & & & & -.541 & & \\
\hline & $\mathrm{H}(1: 1)$ & & & & 1.464 & & \\
\hline & $\mathrm{H}(1: 2)$ & & & & 1.490 & & \\
\hline & $\mathrm{H}(1: 3)$ & & & & -1.004 & & \\
\hline
\end{tabular}

